\title{
Modulation of protein : protein interactions in inflammatory diseases
}

Citation for published version (APA):

Zarzycka, B. A. (2015). Modulation of protein : protein interactions in inflammatory diseases. [Doctoral Thesis, Maastricht University]. https://doi.org/10.26481/dis.20150702bz

Document status and date:

Published: 01/01/2015

DOI:

10.26481/dis.20150702bz

Document Version:

Publisher's PDF, also known as Version of record

\section{Please check the document version of this publication:}

- A submitted manuscript is the version of the article upon submission and before peer-review. There can be important differences between the submitted version and the official published version of record.

People interested in the research are advised to contact the author for the final version of the publication, or visit the DOI to the publisher's website.

- The final author version and the galley proof are versions of the publication after peer review.

- The final published version features the final layout of the paper including the volume, issue and page numbers.

Link to publication

\footnotetext{
General rights rights.

- You may freely distribute the URL identifying the publication in the public portal. please follow below link for the End User Agreement:

www.umlib.nl/taverne-license

Take down policy

If you believe that this document breaches copyright please contact us at:

repository@maastrichtuniversity.nl

providing details and we will investigate your claim.
}

Copyright and moral rights for the publications made accessible in the public portal are retained by the authors and/or other copyright owners and it is a condition of accessing publications that users recognise and abide by the legal requirements associated with these

- Users may download and print one copy of any publication from the public portal for the purpose of private study or research.

- You may not further distribute the material or use it for any profit-making activity or commercial gain

If the publication is distributed under the terms of Article $25 \mathrm{fa}$ of the Dutch Copyright Act, indicated by the "Taverne" license above, 


\section{Modulation of protein - protein interactions in inflammatory diseases}


(C) Barbara Zarzycka, 2015. For all articles published, the copyright has been transferred to the respective publisher. No part of this publication may be reproduced, stored in a retrieval system or transmitted in any form by any means, without prior written permission from the author, or when appropriate, from the publisher.

ISBN: 978-90-9029108-6

Cover design by: Architect Piotr Zarzycki www.wytworniapp.com

Layout: Tomasz Karawajczyk 


\title{
Modulation of protein - protein interactions in inflammatory diseases
}

\author{
PROEFSCHRIFT
}

ter verkrijging van de graad van doctor aan de Universiteit Maastricht, op gezag van de Rector Magnificus, Prof. Dr. L.L.G. Soete

volgens het besluit van het College van Decanen,

in het openbaar te verdedigen

op donderdag 2 Juli 2015 om 10.00 uur

door

Barbara Anna Zarzycka

Geboren op 12 juni 1985 te Wrocław 
Promotores:

Prof. dr. T. M. Hackeng

Prof. dr. G. Vriend

Copromotores:

Dr. G.A.F. Nicolaes

Dr. S.B. Nabuurs

Beoordelingscommissie:

Prof. dr. Chris Evelo (UM) (voorzitter)

Prof. dr. Erik Biessen (UM)

Dr. Chris de Graaf (VU)

Prof. dr. Jos Kleinjans (UM)

Dr. Maria Miteva (INSERM)

Financial support by the Dutch Heart Foundation for the printing of this thesis is gratefully acknowledged.

Publication of this thesis is further supported by Stichting Hartsvrienden RESCAR.

Additional financial support was granted by Cyttron II and LeadPharma. 




\section{Contents}

Chapter 1

Chapter 2 Targeting the adaptive immune system in atherosclerosis

Chapter 3

Stabilization of protein - protein interaction complexes through small molecules

Chapter 4

Chemical space of small molecule stabilizers of protein - protein interactions

Chapter 5

Discovery of small molecule CD40-TRAF6 inhibitors

Chapter 6

Small-molecule inhibitors of the CD40-TRAF6 interaction as therapy for atherosclerosis

Chapter 7

Blocking CD40-TRAF6 signalling is a novel therapeutic target in obesity-associated insulin resistance

Chapter 8

General Discussion

Appendices

Summary

Samenvatting

Valorisation

Curriculum Vitae

Acknowledgments 


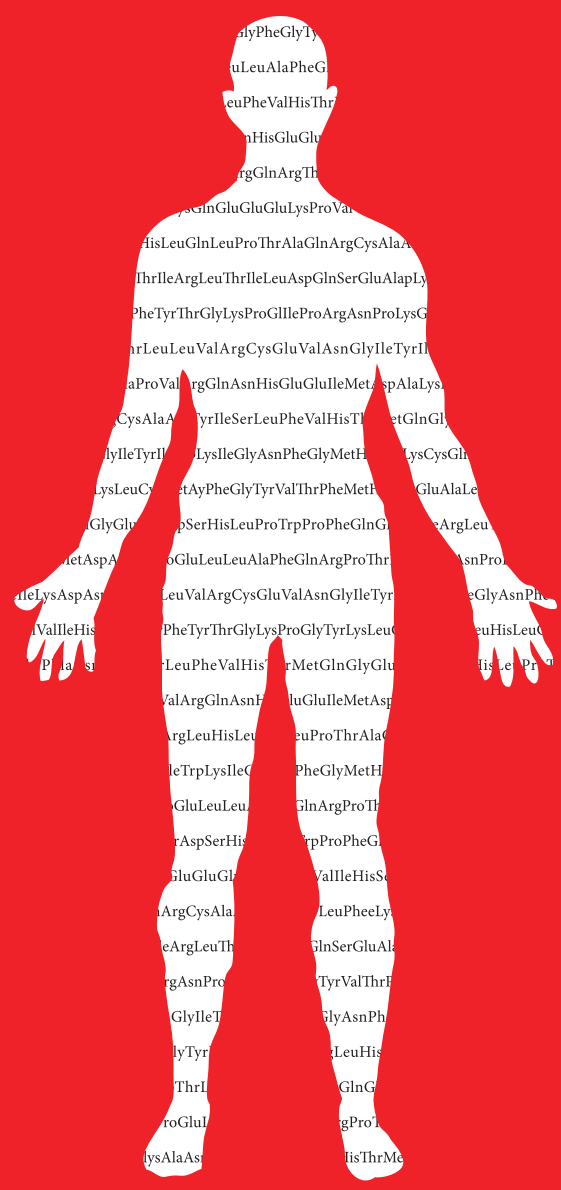




\section{Chapter}

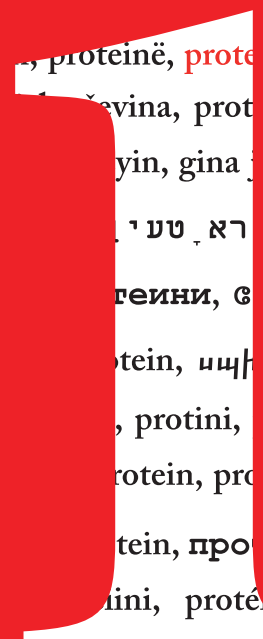

protein, protein, protei

\section{General Introduction}


The first drugs were discovered from natural plant extracts and found mainly thanks to serendipity such as aspirin that was found by ancient Greeks (1). The beginning of the 1900s brought advances in chemical synthesis, which gave rise to the birth of a pharmaceutical industry (2). Current drug design is a time-consuming and costly process. It has been estimated that it takes approximately 12-15 years to develop and market a drug, and recent estimates show that the development of a single drug can cost up to 2.6 billion US\$ $(3,4)$. Here, we present key steps of the drug discovery and development pipeline.

\section{Target identification and validation}

A drug discovery pipeline (figure 1) begins with the identification and validation of a target that plays a pivotal role in the pathogenic mechanism of a given disease. A good target is typically a pivotal protein causally related to disease state and of which the activity can be modulated. Additionally, the target has to be "druggable" which means that it has to be capable of binding modulators, such as small molecules. In the last decade target discovery was documented with omics techniques such as proteomics, transcription profiling, and metabolomics (5). Clinical attrition rates are still relatively high and drug discovery projects are often stopped only at a late stage of development, mostly due to unforeseen side effects. Unsafe drug profile is often caused by a lack of specificity and modulation of more proteins involved in a biological pathways, so called off-targets (6). Thus, recently, a lot of effort has been put into developing methods that will predict off-targets (7-9).

Current therapeutic targets can be divided into the classes: receptors, enzymes, hormones and factors, ion channels, nuclear receptors, and nucleic acids (10). These target classes can be also classified by gene families: G Protein-Coupled Receptors (GPCRs), serine/threonine and tyrosine protein kinases, zinc metallopeptidases, serine proteases, nuclear hormone receptors, and phosphodiesterases (11). In recent years, larger surface and discontinuous protein protein interactions (PPIs) became a new class of therapeutical targets (12).

\section{Lead identification}

Drug discovery process continues with identification of compounds that bind to the target and modulate its activity, so called hits. Compounds used for lead identification are filtered according to ADME/tox properties (adsorption, distribution, metabolism, excretion, and toxicity). These properties are described by the so-called Lipinski rule of five and state that orally available drugs should have a molecular weight below $500 \mathrm{Da}$, a $\log \mathrm{P}$ below 5 , a number of hydrogen bond acceptors below 10, and a number of hydrogen bond donors below 5 (10).

RESEARCH

DEVELOPMENT
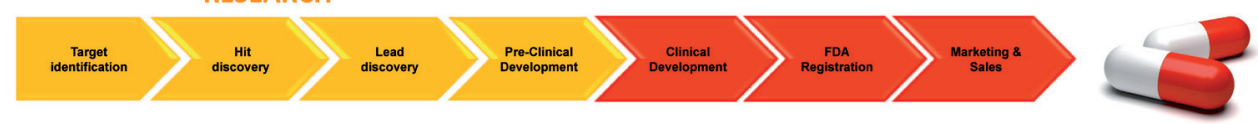

Figure 1. Drug research and development pipeline. 
The most commonly used method for hit identification is high-throughput screening (HTS). In HTS, researchers test the activity of a collection of compounds against a given biomolecular target through in vitro analysis. Additionally, virtual ligand screening (VLS) computational method, aimed at prioritizing large sets of small molecules through in silico screening, is now also widely applied. VLS significantly improve hit ratios, which are estimated between $0.01 \%$ and $0.14 \%$ for HTS, and between $1 \%$ and $40 \%$ for VLS (13).

\section{Lead optimization}

The most potent initial hits usually require further optimization to achieve improved druglike properties such as potency, selectivity, stability, and oral bioavailability. Further, hits are optimized for synthesis routes, metabolic, pharmacodynamic, and pharmacokinetic (DMPK) properties. DMPK studies include solubility, lipophilicity, permeability, and other physicochemical properties (14).

\section{Pre-clinical development}

In the pre-clinical stage, a lead is tested in animal models that can be used to study the targeted disease. In this phase, a new lead is checked not only for in vivo efficacy, but also for safety profile and possible side-effects.

Previously, early stage drug development was mainly performed by the pharmaceutical industry. However, in the recent years, we observe a paradigm shift. This stage of the drug discovery is nowadays also performed in academia, or in joined projects with industry (15). The combined industrial/academic model of early stage drug discovery has proven to be very successful in finding leads (15). Resultantly, a recent hype in early stage drug discovery is the establishment of small knowledge-based companies that collaborate with both academia and big pharmaceutical companies. They focus on the delivery of a validated lead, which can be further licensed or sold to big companies that can afford and facilitate clinical trials. One of the examples are Heptares Therapeutics Ltd, and Griffin Discoveries BV that specializes in drug candidates targeting GPCRs (16-18).

\section{Development stage}

\section{Clinical development, Registration, and Marketing \& Sales}

Clinical development begins with Phase I clinical trials. During this phase, the safety profile of drug candidates is tested in humans. It typically involves approximately 20-80 healthy people and lasts 1-2 years. Only if phase I was sucesful, drug candidate enter Phase II clinical trials in which efficacy and safety is tested in a population of approximately 100-300 patients for 1-2 years. In the final Phase III clinical trials, efficacy and safety is tested in a group of approximately 1000-3000 patients. During clinical development, trial protocols and the recording of clinical findings are carefully administrated under strict regulation and control to provide maximal protection of human volunteers and achieve optimal drug safety. After successful clinical trials, a drug candidate undergoes inspection by the European Medicines 
Agency (EMA) within Europe or by the Food and Drug Administration (FDA) within US. Approved drug candidate is brought to the market (19).

\section{Protein - protein interactions (PPIs), as a new drug target}

Protein - protein interactions (PPIs) are of vital importance to biological processes in all living organisms. The complete protein interaction network has been estimated to contain from 130,000 (20) to 650,000 (21) interactions in all living organisms, and 370,000 PPIs have been predicted in humans (22). Thus, modulation of PPIs might give new opportunities for therapeutical interventions.

A PPI interface typically is very large and generally range from $\sim 1,500$ to $3,000 \AA^{2}$. PPI interfaces are more flat and more hydrophobic than other drug target sites such as active sites in enzymes $(23,24)$. Additionally, many PPIs do not have well-defined druggable cavities (25), but instead appear to possess small pockets located in the surrounding of the interaction interface (26). This characteristic, which is very distinct from the other and well-described classes of drug targets, considered PPIs as "undruggable". However, PPI interfaces have one important feature; they possess hot spots, these are residues that contribute most to the binding energy of the interaction. Thus, by disrupting interactions with hot spots, it is possible to inhibit protein - protein complexes (12). Additionally, recent success stories showed that, even though, PPIs are considered to be challenging targets, they can be modulated $(27,28)$. Inhibitors of protein - protein interactions (iPPIs) are collected in databases such as iPPI-DB (29), 2P2IDB (30), and Timbal (31). The iPPI-DB database contains 1650 compounds for 13 protein families and gave rise to analysis of the chemical space of iPPIs. The analysis of the physico-chemical properties of iPPIs revealed that their average molecular weight (MW) and hydrophobicity are higher than for conventional drugs, $421 \mathrm{Da}$ versus $341 \mathrm{Da}$ and 3.58 versus 2.61, respectively. Additionally, the number of rings, benzene-like rings, and aromatic bonds are also significantly higher in comparison with conventional drugs $(32,33)$. Three dimensional shape of a molecule is another feature that plays an important role in proteinligand interaction. 3D characteristics of iPPIs showed that an ideal iPPIs candidate should be globular, have a high capacity to bind hydrophobic patches, have a low proportion of exposed polar groups, and should have exposed polar groups sequestered at one end of the molecule (34). Modulations of the PPI complexes can be achieved in different ways. These modulation can occur via competitive inhibition, where a small molecule binds to the interface of one protein partner and prevents binding of the "natural" ligand, or via allosteric modulation, where binding of a iPPI alters the binding properties for the "natural" ligand through binding at a site that is distant from the protein - protein interaction surface. Another way of PPIs modulation is by stabilization of the PPIs complex, where a small molecule binds to both protein partners, working as a molecular glue (35) (figure 2). This concept, despite being relatively new, has already been successful in a number of cases (36-38). However, detailed analyses of the chemical space of PPI stabilizers are sparse. 


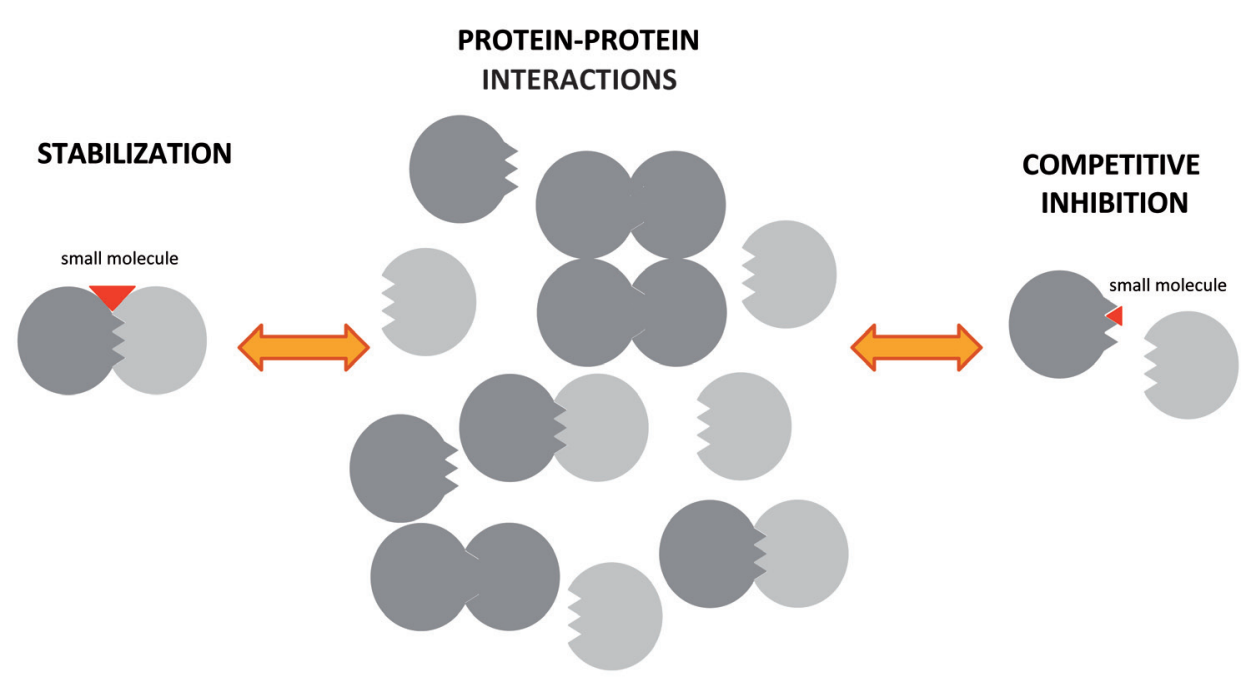

Figure 2. Protein - protein interactions and their modulations.

\section{CD40-TRAFs interactions in inflammatory diseases}

CD40 ligand (CD40L, CD154, gp139) is a 261 amino acid, type II transmembrane protein from the tumour necrosis factor (TNF) family. It is constitutively expressed on T-cells and platelets. Upon activation, it is also expressed on B-cells, monocytes/macrophages, dendritic cells, and on non-hematopoietic cells such as endothelial cells, smooth muscle cells, fibroblasts, epithelial cells (39). CD40L is present in the transmembrane form in T-cells and platelets. CD40L can be cleaved by the proteinases ADAM10 and ADAM17, which results in the formation of extracellular soluble CD40L (sCD40L) that consists of the 215 C-terminal amino acids (40). Native SCD40L is present in a trimeric form (41), thus it was suggested that binding of CD40L to its receptor leads to trimerization of the CD40 receptor (42).

CD40 is a 277 amino acid, transmembrane protein receptor from the tumour necrosis factor receptor (TNFR) family. It is a co-stimulatory protein constitutively expressed on antigen presenting cells (APC) such as B-cells and dendritic cells. Upon activation, it is also expressed on T-cells, monocytes/macrophages, and non-hematopoietic cells such as platelets and smooth muscle cells (42). CD40 lacks intrinsic activity and has to recruit an adaptor protein from the TNF receptor associated factor (TRAF) family that binds to the intracellular domain of CD40 receptor (43).

The TRAF family consists of seven members. However, only TRAF2, 3, 5 and 6 can bind to the intracellular part of CD40. CD40 has two binding sites, one for TRAF6 only, and a second for TRAF2, 3 and 5 (43). TRAF2, 3, 5, and 6 share a high sequence identity in their C-domains. However, they significantly differ in the CD40 peptide binding groove (44). TRAF6 protein recognizes a Pro-X-Glu-X-X (X stands for aromatic or acidic residue) binding motif present on the CD40 receptor (44), whereas TRAF2 recognizes the Ser-X-X-Glu binding motif 
present on the CD40 receptor (45).

Binding of TRAF proteins to the intracellular part of CD40 activates signaling pathways such as NFKB, C-Jun N-terminal kinase (JNK), and p38 mitogen-activated protein (MAP) kinase (43). Activation of individual pathways depends on which TRAF protein is recruited to the CD40 receptor and on the cell-type in which activation takes place. An overview of the CD40L-CD40-TRAF protein interactions is presented in figure 3.

CD40 signaling leads to several immune responses, which may display pro-inflammatory or anti-inflammatory activity. CD40 signaling plays a crucial role in the development of (chronic) inflammatory diseases such as atherosclerosis, obesity, and multiple sclerosis. Interaction of CD40 with TRAF6, but not with TRAF2, 3, and 5 is involved in the development of

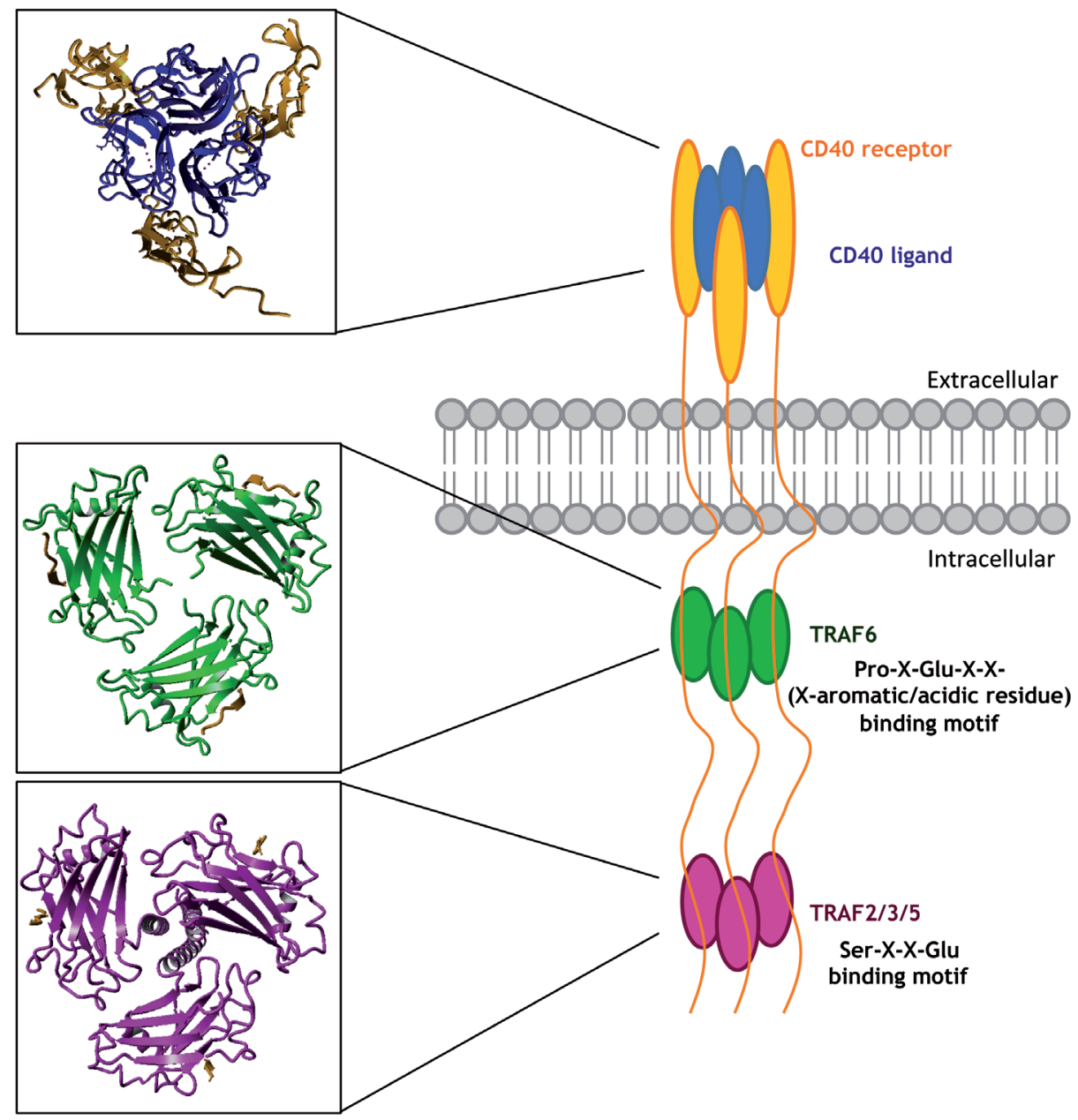

Figure 3. Schematic representation of the CD40 ligand-CD40 receptor-TRAFs interaction. View from the top of the following X-ray structures: CD40 receptor-CD40 ligand complex (PDB ID: 3QD6, trimeric CD40 receptor was modelled), TRAF6-CD40 receptor (PDB ID: 1LB6; trimer modelled based on TRAF2 template), TRAF2-CD40 receptor (PDB ID: 1QSC). 
atherosclerosis (46) and obesity-associated insulin resistance (Chapter 7; (47)). In addition, CD40-TRAF2, 3, and 5 interaction protect against metabolic dysfunction and inflammation associated with obesity (Chapter 7; (47)). Previous modulation of the CD40L-CD40 interaction showed beneficial effects; however it resulted in severe side-effects such as immunosuppression. Since the CD40-TRAFs interaction is located more downstream the CD40 signaling pathway, this protein - protein interaction was deemed to have a high potential as a target for the development of (chronic) anti-inflammatory drugs.

\section{Outline of the thesis}

The aim of this thesis was to investigate the modulation, both inhibition and stabilization, of protein - protein interactions. We specifically addressed the interactions between CD40 and TRAF proteins, which are known to be of relevance for a number of (chronic) inflammatory diseases such as peritonitis, sepsis, atherosclerosis, diet-induced obesity, and multiple sclerosis.

In chapter 2 we describe proteins that play a pivotal role in the adaptive immune system. We access their role as potential targets for the treatment of chronic inflammatory diseases such as atherosclerosis, with a special focus on CD40-TRAF6 interaction.

Modulation of protein - protein interaction can be achieved via either stabilization or inhibition (48). In the first part of the thesis, we focus on stabilizers of PPIs. In chapter 3 we suggest a classification of PPIs based on their mode of binding and architecture of complexes. We present a conceptual decision tree that aims at assisting in the design of stabilizers. Further, in chapter 4 we characterize the chemical space of a set of stabilizers and compared them with inhibitors of PPIs and conventional drugs.

In the second part of the thesis, we focus on inhibitors of PPIs. In chapter $\mathbf{5}$ we present the drug discovery pipeline that resulted in CD40-TRAF6 inhibitors, validated in an in vitro cellbased assay and finally in an in vivo mouse model of acute inflammation including peritonitisand sepsis-models. In chapter 6 we present the application of our CD40-TRAF6 inhibitors in other (chronic) inflammatory disease such as atherosclerosis. In chapter 7 we discuss the therapeutical potential of our inhibitors in diet-induced obesity. Finally, chapter 8 consists of a general discussion that describes the most important results obtained in this thesis and puts them in a future perspective. 


\section{References}

1. Jack DB. One hundred years of aspirin. Lancet. 1997 Aug 9;350(9075):437-9.

2. Drews J. Drug discovery: a historical perspective. Science. 2000 Mar 17;287(5460):1960-4.

3. Morgan S, Grootendorst P, Lexchin J, Cunningham C, Greyson D. The cost of drug development: a systematic review. Health Policy Amst Neth. 2011 Apr;100(1):4-17.

4. Mullard A. New drugs cost US\$2.6 billion to develop. Nat Rev Drug Discov. 2014 Dec;13(12):877-877.

5. Smith C. Drug target validation: Hitting the target. Nature. 2003 Mar 20;422(6929):341-7.

6. Learning lessons from Pfizer's \$800 million failure. Nat Rev Drug Discov. 2011 Mar;10(3):163-4.

7. Yera ER, Cleves AE, Jain AN. Prediction of off-target drug effects through data fusion. Pac Symp Biocomput Pac Symp Biocomput. 2014;160-71.

8. Ritschel T, Schirris TJ, Russel FG. KRIPO - a structure-based pharmacophores approach explains polypharmacological effects. J Cheminformatics. 2014 Mar;6(Suppl 1):O26.

9. Grau J, Boch J, Posch S. TALENoffer: genome-wide TALEN off-target prediction. Bioinformatics. 2013 Nov 15;29(22):2931-2.

10. Bleicher KH, Böhm H-J, Müller K, Alanine AI. Hit and lead generation: beyond high-throughput screening. Nat Rev Drug Discov. 2003 May;2(5):369-78.

11. Hopkins AL, Groom CR. The druggable genome. Nat Rev Drug Discov. 2002 Sep;1(9):727-30.

12. Arkin MR, Tang Y, Wells JA. Small-molecule inhibitors of protein-protein interactions: progressing toward the reality. Chem Biol. 2014 Sep 18;21(9):1102-14.

13. Truchon J-F, Bayly CI. Evaluating virtual screening methods: good and bad metrics for the 'early recognition' problem. J Chem Inf Model. 2007 Apr;47(2):488-508.

14. Hughes J, Rees S, Kalindjian S, Philpott K. Principles of early drug discovery. Br J Pharmacol. 2011 Mar;162(6):1239-49.

15. Tralau-Stewart C, Low CMR, Marlin N. UK academic drug discovery. Nat Rev Drug Discov. 2014 Jan;13(1):156.

16. Congreve M, Dias JM, Marshall FH. Structure-based drug design for G protein-coupled receptors. Prog Med Chem. 2014;53:1-63.

17. Marshall F. Interview with Fiona Marshall. Trends Pharmacol Sci. 2012 Aug;33(8):413-4.

18. Andaloussi M, Lim HD, van der Meer T, Sijm M, Poulie CBM, de Esch IJP, et al. A novel series of histamine H4 receptor antagonists based on the pyrido[3,2-d]pyrimidine scaffold: comparison of hERG binding and target residence time with PF-3893787. Bioorg Med Chem Lett. 2013 May 1;23(9):2663-70.

19. Friedman LM, Furberg CD, DeMets DL. Fundamentals of Clinical Trials. 4th ed. 2010 edition. New York: Springer; 2010. 445 p.

20. Venkatesan K, Rual J-F, Vazquez A, Stelzl U, Lemmens I, Hirozane-Kishikawa T, et al. An empirical framework for binary interactome mapping. Nat Methods. 2009 Jan;6(1):83-90.

21. Stumpf MPH, Thorne T, de Silva E, Stewart R, An HJ, Lappe M, et al. Estimating the size of the human interactome. Proc Natl Acad Sci U S A. 2008 May 13;105(19):6959-64.

22. Zhang QC, Petrey D, Garzón JI, Deng L, Honig B. PrePPI: a structure-informed database of protein-protein interactions. Nucleic Acids Res. 2013 Jan;41(Database issue):D828-33.

23. Jones S, Thornton JM. Principles of protein-protein interactions. Proc Natl Acad Sci U S A. 1996 Jan 9;93(1):1320.

24. Conte LL, Chothia C, Janin J. The atomic structure of protein-protein recognition sites1. J Mol Biol. 1999 Feb 5;285(5):2177-98.

25. Pérot S, Sperandio O, Miteva MA, Camproux A-C, Villoutreix BO. Druggable pockets and binding site centric chemical space: a paradigm shift in drug discovery. Drug Discov Today. 2010 Aug;15(15-16):656-67.

26. Fuller JC, Burgoyne NJ, Jackson RM. Predicting druggable binding sites at the protein-protein interface. Drug Discov Today. 2009 Feb;14(3-4):155-61.

27. Wells JA, McClendon CL. Reaching for high-hanging fruit in drug discovery at protein-protein interfaces. Nature. 2007 Dec 13;450(7172):1001-9.

28. Huang Y, Wolf S, Beck B, Köhler L-M, Khoury K, Popowicz GM, et al. Discovery of highly potent p53-MDM2 antagonists and structural basis for anti-acute myeloid leukemia activities. ACS Chem Biol. 2014 Mar 21;9(3):802-11.

29. Labbé CM, Laconde G, Kuenemann MA, Villoutreix BO, Sperandio O. iPPI-DB: a manually curated and interactive database of small non-peptide inhibitors of protein-protein interactions. Drug Discov Today. 2013 Oct;18(19-20):958-68.

30. Basse MJ, Betzi S, Bourgeas R, Bouzidi S, Chetrit B, Hamon V, et al. 2P2Idb: a structural database dedicated to 
orthosteric modulation of protein-protein interactions. Nucleic Acids Res. 2013 Jan;41(Database issue):D824-7.

31. Higueruelo AP, Jubb H, Blundell TL. TIMBAL v2: update of a database holding small molecules modulating protein-protein interactions. Database J Biol Databases Curation. 2013;2013:bat039.

32. Sperandio O, Reynès CH, Camproux A-C, Villoutreix BO. Rationalizing the chemical space of protein-protein interaction inhibitors. Drug Discov Today. 2010 Mar;15(5-6):220-9.

33. Reynès C, Host H, Camproux A-C, Laconde G, Leroux F, Mazars A, et al. Designing focused chemical libraries enriched in protein-protein interaction inhibitors using machine-learning methods. PLoS Comput Biol. 2010 Mar;6(3):e1000695.

34. Kuenemann MA, Bourbon LML, Labbé CM, Villoutreix BO, Sperandio O. Which Three-Dimensional Characteristics Make Efficient Inhibitors of Protein-Protein Interactions? J Chem Inf Model. 2014;54(11):306779.

35. Thiel P, Kaiser M, Ottmann C. Small-molecule stabilization of protein-protein interactions: an underestimated concept in drug discovery? Angew Chem Int Ed Engl. 2012 Feb 27;51(9):2012-8.

36. Molzan M, Kasper S, Röglin L, Skwarczynska M, Sassa T, Inoue T, et al. Stabilization of physical RAF/14-3-3 interaction by cotylenin A as treatment strategy for RAS mutant cancers. ACS Chem Biol. 2013 Sep 20;8(9):1869-75.

37. Anders C, Higuchi Y, Koschinsky K, Bartel M, Schumacher B, Thiel P, et al. A semisynthetic fusicoccane stabilizes a protein-protein interaction and enhances the expression of $\mathrm{K}+$ channels at the cell surface. Chem Biol. 2013 Apr 18;20(4):583-93.

38. Graves B, Thompson T, Xia M, Janson C, Lukacs C, Deo D, et al. Activation of the p53 pathway by smallmolecule-induced MDM2 and MDMX dimerization. Proc Natl Acad Sci. 2012 Jul 17;109(29):11788-93.

39. Schönbeck U, Libby P. The CD40/CD154 receptor/ligand dyad. Cell Mol Life Sci CMLS. 2001 Jan;58(1):4-43.

40. Yacoub D, Benslimane N, Al-Zoobi L, Hassan G, Nadiri A, Mourad W. CD154 is released from T-cells by a disintegrin and metalloproteinase domain-containing protein 10 (ADAM10) and ADAM17 in a CD40 protein-dependent manner. J Biol Chem. 2013 Dec 13;288(50):36083-93.

41. Pietravalle F, Lecoanet-Henchoz S, Blasey H, Aubry JP, Elson G, Edgerton MD, et al. Human native soluble CD40L is a biologically active trimer, processed inside microsomes. J Biol Chem. 1996 Mar 15;271(11):5965-7.

42. Elgueta R, Benson MJ, de Vries VC, Wasiuk A, Guo Y, Noelle RJ. Molecular mechanism and function of CD40/ CD40L engagement in the immune system. Immunol Rev. 2009 May;229(1):152-72.

43. Zapata JM. TNF-receptor-associated factors as targets for drug development. Expert Opin Ther Targets. 2003 Jun;7(3):411-25.

44. Ye H, Arron JR, Lamothe B, Cirilli M, Kobayashi T, Shevde NK, et al. Distinct molecular mechanism for initiating TRAF6 signalling. Nature. 2002 Jul 25;418(6896):443-7.

45. Park YC, Burkitt V, Villa AR, Tong L, Wu H. Structural basis for self-association and receptor recognition of human TRAF2. Nature. 1999 Apr 8;398(6727):533-8.

46. Lutgens E, Lievens D, Beckers L, Wijnands E, Soehnlein O, Zernecke A, et al. Deficient CD40-TRAF6 signaling in leukocytes prevents atherosclerosis by skewing the immune response toward an antiinflammatory profile. J Exp Med. 2010 Feb 15;207(2):391-404.

47. Chatzigeorgiou A, Seijkens T, Zarzycka B, Engel D, Poggi M, van den Berg S, et al. Blocking CD40-TRAF6 signaling is a therapeutic target in obesity-associated insulin resistance. Proc Natl Acad Sci U S A. 2014 Feb 18;111(7):2686-91.

48. Milroy L-G, Brunsveld L, Ottmann C. Stabilization and inhibition of protein-protein interactions: the 14-3-3 case study. ACS Chem Biol. 2013 Jan 18;8(1):27-35. 







\section{Chapter}

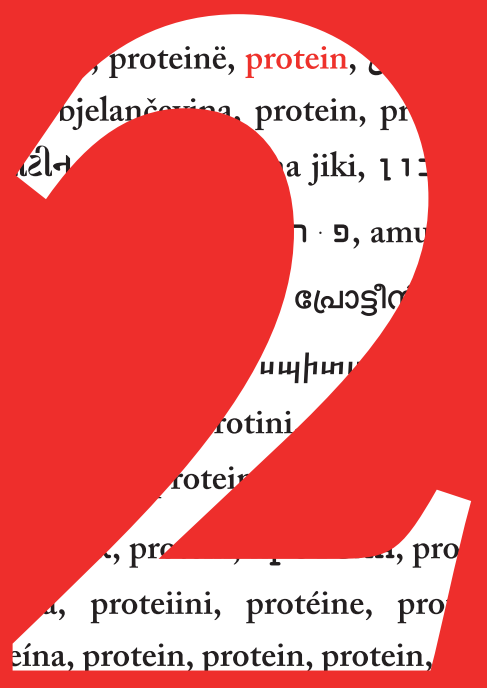

Targeting the adaptive immune system: new strategies in the treatment of atherosclerosis

B. Zarzycka, G.A.F. Nicolaes, E. Lutgens

Expert Review of Clinical Pharmacology, 2015; 4:1-17 


\begin{abstract}
Atherosclerosis is a lipid-driven chronic inflammatory disease of the arterial wall. Current treatment of atherosclerosis is focused on limiting its risk factors such as hyperlipidemia or hypertension. However, treatments that target the inflammatory nature of atherosclerosis are still under development. Discovery of novel targets involved in the inflammation of the arterial wall creates opportunities to design new therapeutics that successfully modulate atherosclerosis. Here, we review drug targets that have proven to play pivotal roles in the adaptive immune system in atherosclerosis, and we discuss their potential as novel therapeutics.
\end{abstract}




\section{Introduction}

Atherosclerosis is a lipid-driven chronic inflammatory disease of the arterial wall. In hypercholesterolemic conditions, low-density lipoproteins (LDL) become oxidized (oxLDL) and accumulate in the arterial intima, causing an inflammatory trigger. Monocytes are recruited to the site of inflammation and upon migration into the intima, differentiate into macrophages and initiate an immune response (1). Macrophages can polarized into classical pro-atherogenic M1 macrophages, and more inflammation and atherosclerosis-regulating M2 macrophages (2). In concord, other immune cells including neutrophils, mast-cells, dendritic cells, T- and B-lymphocytes are also recruited. This results in the formation of atherosclerotic lesions that consist of inflammatory cells, necrotic cores, calcifications and fibrous caps. Rupture of atherosclerotic plaques can result in the formation of (occluding) thrombi that can cause myocardial infarction or ischemic stroke (1).

For a long time, atherosclerosis was considered solely as a lipid-driven disease. Thus, current therapies such as statins were supposed to focus on prevention of risk factors such as hyperlipidemia or hypertension only. Even though the inflammatory nature of atherosclerosis was hypothesized by Rudolf Virchow already in 1856 (3), this hypothesis was not commonly accepted at that time. Only three decades ago, it was acknowledged that the immune system and inflammatory processes play a pivotal role in the development and progression of atherosclerosis (4). Recent advances in the role of immunity in atherosclerosis confirm their inevitable importance (5). Currently, it is known that statins also have anti-inflammatory effects on atherogenesis (6) and contribute to the treatment of cardiovascular diseases (7). However, treatment targeting the inflammatory nature of atherosclerosis is still very limited and deserves further attention to fight atherosclerosis successfully (8). Interestingly, the first clinical trial, that utilizes an anti-IL-1 $\beta$ antibody to treat atherosclerosis, is ongoing (9).

In the last years, a growing the number of new targets, derived from players in innate and adaptive immune reactions, have been discovered and validated for their capacity to modulate atherogenesis. In this review, we will discuss novel targets that have emerged to play a central role in modulating atherosclerosis via the adaptive immune system, and their potential to evolve into therapeutics. Although we consider the innate immune system and its immune cell subtypes very important in the pathogenesis of atherosclerosis, this review will only focus on the adaptive immune cell-types.

The knowledge that was used to compose this review is mostly derived from experimental atherosclerosis studies that have been performed in mouse models such as the apolipoprotein E deficient mouse $\left(A p o E^{-/}\right)$and the low-density lipoprotein receptor deficient $\left(L D L r^{\prime-}\right)$ mouse. Needless to say, mice are not humans, and are especially different with regards to lipid profile, stage of the atherosclerotic disease, and incidence of plaque rupture, which is virtually absent in mice. Although mouse models do not spontaneously have plaque rupture, they do develop thin fibrous cap atheroma, which, upon intervention can transform into a more stable "thick" 
fibrous cap atheroma. This reflects the human disease stage of vulnerable, rupture prone plaques, can be converted into stable plaques upon therapy. After haven taken these potential caveats into consideration, the atherosclerotic mouse is a good model to study the pathogenesis of atherosclerosis, and is ideal to unravel the effect of the various players of the adaptive immune system in atherosclerosis, and test potential therapeutics (table 1).

\section{The adaptive immune system in atherosclerosis}

The adaptive immune system consists of specialized cells, and is called into play after the innate immune system has been activated by pathogens. The adaptive immune system can act in two different ways: by antibody responses or cell-mediated immune responses. In antibody responses, activated B-cells secrete antibodies (immunoglobulins) that bind specifically to an antigen, thus block their interaction with their receptor on the host cell. In the cell-mediated immune responses, activated T-cells respond directly to antigens presented on the antigen presenting cells (APC). Activated T-cells secrete signal molecules that activate neutrophils and macrophages for the fight with pathogens. After exposure to a specific pathogen, the adaptive immune system generates highly specific immune memory that can provide longterm protection. Atherosclerotic lesions consist of self-antigens, which are binding the epitopes of the components of (oxidized) LDL ((ox)LDL). This response of the immune system considers atherosclerosis as an autoimmune disease (10). Thus, such a process constitutes the basis of vaccination (11). The key components of adaptive immune system are T-cells, B-cells, and the antigen presenting dendritic cells (figure 1).

The newest advances in experimental studies of adaptive immune system and their effect on atherogenesis give an opportunity for new therapies (12). The extrapolation of these experimental data to clinical applicability is still a long way to go (13). However, a correlation between activation of the adaptive immune system has already been observed in several clinical studies (14-17). The immune-based treatment might compromise entire host defense system, which is essential for survival. Therefore, it is suggested that this treatment should be either applied to selected group of patients, or modified to target atherosclerosis-associated immune reactions more selectively. For treatments affecting the function of the adaptive immune system, people with impaired tumor surveillance and increased susceptibility to infections are needed to be excluded. The challenge in the targeting inflammatory nature of atherosclerosis is to find a target that will modulate it without suppressing entire host defense system. Treatment with such a modulator would not demand preselection of patients (16).

\section{Dendritic cells}

Dendritic cells (DCs) are located at the interface of innate and adaptive immune response. In the innate response, immature DCs are located in the intima of the normal arterial walls in the regions subjected to the development of atherosclerosis and in atherosclerotic lesions. In the presence of oxLDL, DCs can internalize them and become foam cells (17). The innate 


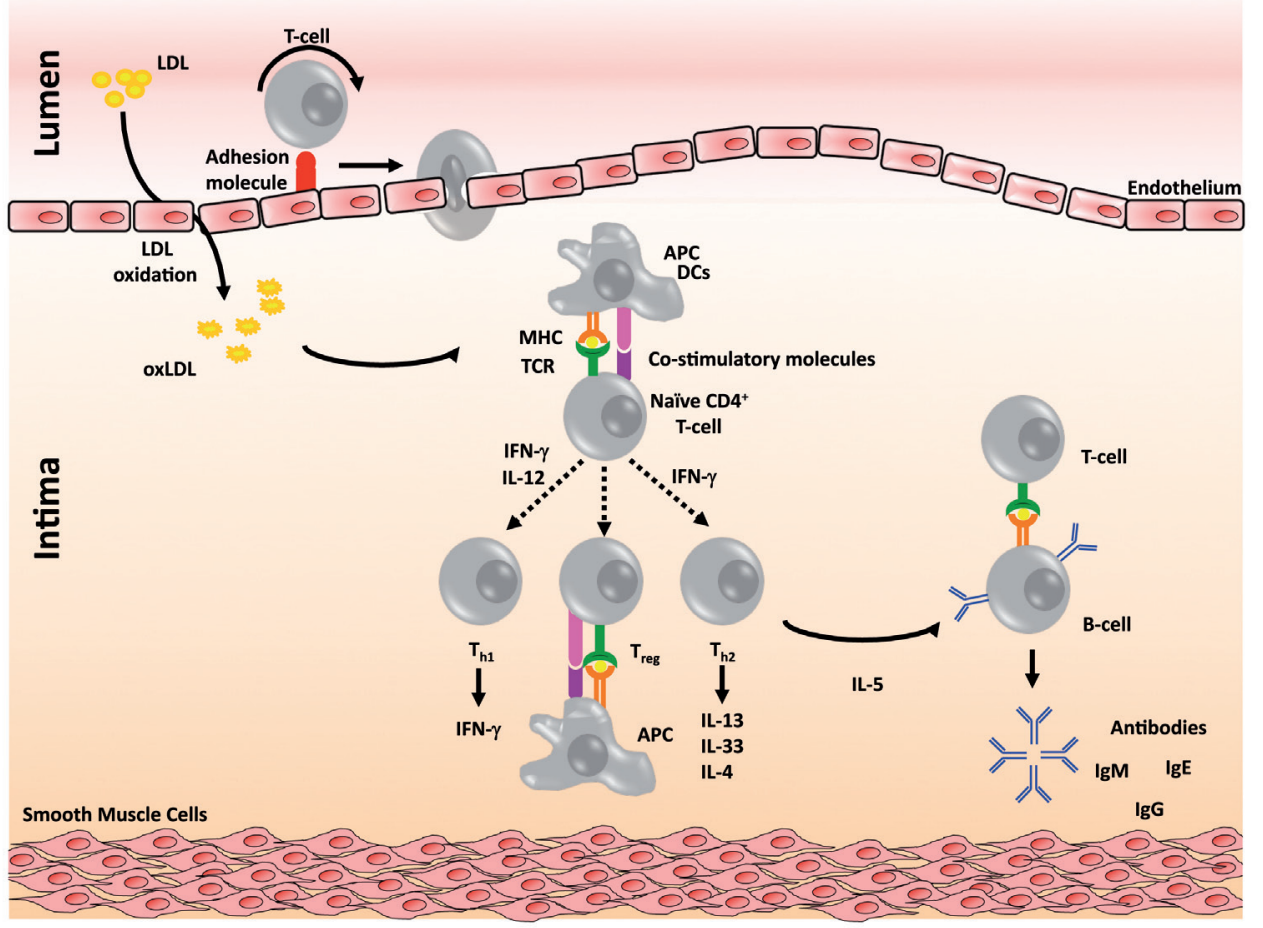

Figure 1. Role of T-cells, B-cells, DCs, and their mediators in atherosclerosis. APC: antigen-presenting cells; DC: dendritic cells; LDL: low-density lipoproteins; MHC: major histocompatibility complex; oxLDL: oxidized low-density lipoproteins.

immune response DCs translate innate into adaptive immune response. However, in this review we will focus on the role of DCs in the adaptive immune system.

In the adaptive response, mature DCs work as professional antigen-presenting cells. They activate the immune response by presenting antigen on their surface to other cells, e.g. naive T-cells. Thus, DCs contribute to ongoing inflammation (18) and are present in both murine (19), and human atherosclerotic lesions (20). Accumulation of DCs was detected in an $\mathrm{ApoE}^{-/-}$mouse model in the intima and adventitia of atherosclerotic arteries (19). In humans, DCs were identified in the intima and adventitia of both healthy and atherosclerotic arteries (20). DCs can be divided into two subtypes: conventional DCs (cDCs) and plasmacytoid DCs (pDCs). It was suggested that $\mathrm{cDCs}$ play a pro-atherogenic role, whereas pDCs play an antiatherogenic role. Thus, inhibition of cDCs would lead to inhibition of atherosclerosis (21). However, recent studies showed pro-atherogenic role of pDCs in the mouse model of atherosclerosis, suggesting that pDCs might be also a target in the treatment of atherosclerosis (22).

\section{T-cells}

T-cells play a pivotal role in immune responses, and are found in atherosclerotic lesions (23). T-cells have an ability to differentiate into different subtypes of helper T-cells such as $T_{h 1}, T_{h 2}$, 
$\mathrm{T}_{\mathrm{h} 17}$, and $\mathrm{T}_{\text {reg }}(24) . \mathrm{T}_{\mathrm{h} 1}$ cells are clearly pro-atherogenic, whereas $\mathrm{T}_{\text {reg }}$ cells are athero-protective. The role of $\mathrm{T}_{\mathrm{h} 2}$ and $\mathrm{T}_{\mathrm{h} 17}$ cells in atherosclerosis is still not clear. Besides helper-T-cells, CD8+ cytotoxic T-cells are also present in both murine and human atherosclerotic lesions, and these are considered disease-promoting (25). In the murine models, CD4+ T-cells are the most abundant type of T-cells present in atherosclerotic plaque (26). However, in in human plaque, CD8+ T-cells, but not CD4+ T-cells are predominant and clinical evidences show correlation of CD8+ T-cells with increased risk of myocardial infarction (27). The gd T-cells are another subgroup of T-cells present in human arterial lesions (28), and have been shown to promote plaque progression during the early development stage in $A p o E^{-/-}$mice (29). However, their role in human atherosclerosis needs to be evaluated.

\section{B-cells}

Initially, the presence and role of B-cells in atherosclerosis was neglected. However, although, in small amounts, B-cells are present and can appear individually or as aggregates in atherosclerotic plaques $(30,31)$. B-cells are divided into two subsets: the B1 cells, that produce natural polyspecific antibodies, predominantly of the IgM subtype, and that are protective against atherosclerosis (32); and B2 cells that predominantly produce highly specific IgG antibodies and promote atherosclerosis (33). B1 cells have three different subtypes: B1a, B1b, and Innate Response Activator (IRA). B1a cells produce natural specific antibodies, predominantly of the IgM subtype, which are atheroprotective (34). The role of the B1b cells in atherosclerosis remains unknown (35). Whereas, it was recently discovered that IRA subtype play a pro-atherogenic role by promoting DCs and polarization of $\mathrm{T}_{h 1}$ (36). B2 cells have two subtypes: B2 conventional and regulatory B-cells (Bregs). B2 conventional play a proatherogenic role by taking part in CD4 T-cells activation and effector T-cell proliferation (37). Bregs secrete IL-10 (38), thus it is suggested that they might play an atheroprotective role. However, their direct role in the atherosclerosis have not been unraveled yet (35). B-cells have therapeutic potential via inhibition of pro-atherogenic or boost of anti-atherogenic responses, and may be used via B2-cells in vaccination strategies against atherosclerosis (figure 2).

In patients reduced levels of anti-oxLDL IgM antibodies are associated with an increase in CVD (39), whereas there is no clinically significant correlation between anti-oxLDL IgG antibodies and risk factors of both coronary artery disease and CVD. However, the predictive association of the oxLDL IgG and CVD endpoints requires further investigation (40). Clinical evidences show that CD19+CD86+ B-cell subset correlate with higher risk for development of a stroke, whereas CD19+CD40+ subset does not. It suggests that different B-cells subsets might have a different effect on CVD, thus needs further investigation (41).

\section{Co-stimulation}

T-cells play a pivotal role in the progression of atherosclerosis. To initiate inflammatory responses, T-cells have to be activated. Activation of the T-cells is done in a two-step process. 


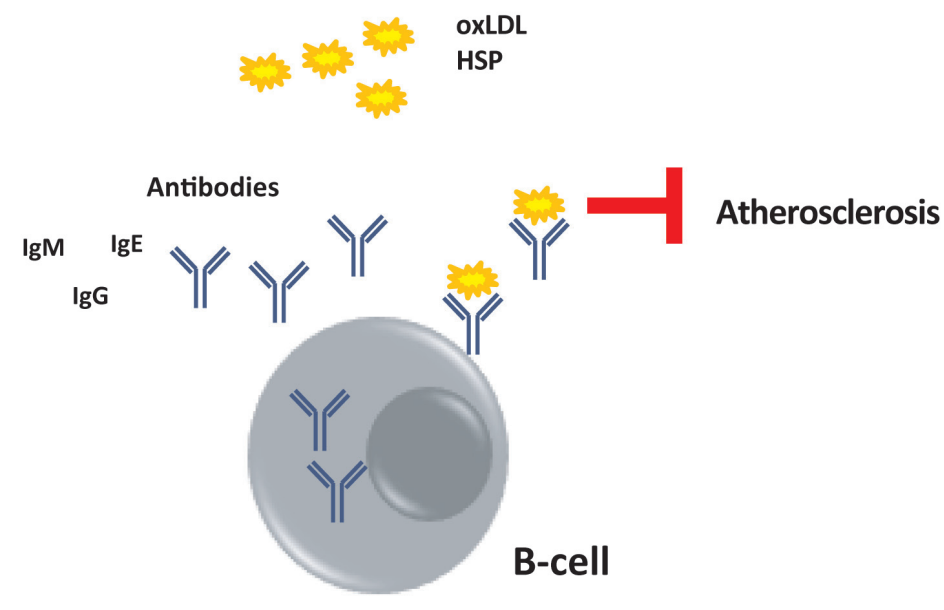

Figure 2. The schematic depicts production of the athero-protective antibodies as a response of autoimmune antigens. It shows a potential approach to development of vaccines against atherosclerosis.

In the first step, known as antigen-specific step, a signal from the T-cell receptor interacts with the major histocompatibility complex (MHC) expressed on antigen presenting cells (APC). In the second step, known as antigen nonspecific step, a co-stimulatory signal, from costimulatory molecules that are expressed on the APC, interacts with its corresponding receptor present on T-cells (42) (figure 3a), resulting in T-cell proliferation and prevention of T-cell anergy. Co-stimulatory molecules predominantly modulate the immune responses by activating T- and B-cell functions, but also affect dendritic cell and macrophage functions and play a crucial role in the progression of atherosclerosis. Thus, blocking this interaction seems to have therapeutic potential in the treatment of atherosclerosis (figure $3 b$ ).

\section{Targets of the adaptive immune system with great potential}

In this section of the review, we summarize several therapeutic targets of the adaptive immune system with the largest potential to result in treatment for atherosclerosis. Unfortunately, we are not able to cover all the components/cell types of the adaptive immune system relevant for atherosclerosis. T helper cells play an important role in the atherogenesis and were shown to be susceptible to modulation of atherosclerosis. Here, we describe the most important mediators of $\mathrm{T}_{\mathrm{h} 1}$ cells such as IFN- $\gamma$ and IL-12, as well as of $\mathrm{T}_{\mathrm{h} 2}$ such as IL-4, IL-5, and IL-13, which constitute promising targets for development of the treatment of atherosclerosis.

$\mathrm{T}_{\mathrm{h} 1}$ cytokines

IFN- $\gamma$

IFN- $\gamma$ is a prototypic cytokine that is secreted by $\mathrm{T}_{\mathrm{h} 1}$ cells (figure 1 ) and is present in atherosclerotic lesions upon activation by low-density lipoprotein (LDL) or oxidized LDL (oxLDL) (43). Depletion of IFN- $\gamma$ in either hyperlipidemic ApoE $E^{-/}$or $L D L r^{--}$mice showed a significant reduction of atherosclerosis $(44,45)$. In the $A p o E^{-/-}$mouse model, but not in the 


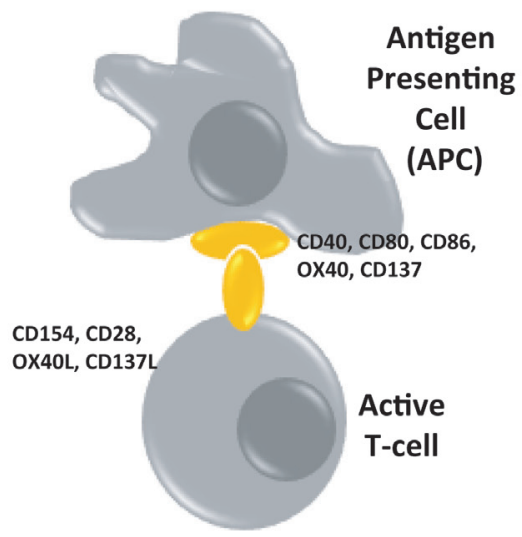

b

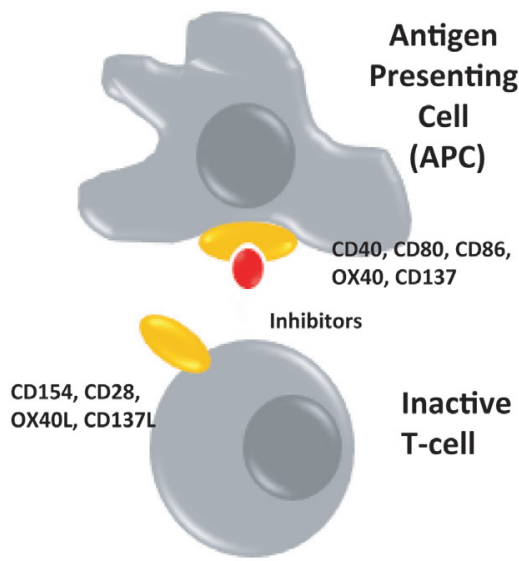

Figure 3. Co-stimulatory molecules in atherosclerosis. (a) APC (grey) derived signal promotes T-cell (grey) activation when carried by co-stimulatory molecules (orange) such as CD154-CD40, CD80/CD86-CD28, OX40L-OX40, CD137-CD137L. (b) T-cell (grey) activation can be inhibited by inhibitors (red) of co-stimulatory molecules (orange).

LDLr-/- model, IFN- $\gamma$ deficiency resulted in a more stable plaque phenotype $(44,46)$. Concordantly, intraperitoneal injections with IFN- $\gamma$ into the $A p o E^{-/-}$mice resulted in a twofold increase in lesion size. Thus, this suggests that IFN- $\gamma$ plays a pro-atherogenic role (47). Treatment targeted at IFN- $\gamma$ with sIFNgR gene transfer in $\mathrm{ApoE}^{-/-}$mice resulted in significant $60 \%$ reduction of atherosclerosis (48). INF- $\gamma$ is, therefore, considered a good target for the treatment of atherosclerosis. IFN- $\gamma$ and IL-6 have a common receptor, sortilin. Recently, it was shown that sortilin plays a role in the atherogenesis. The ApoE $E^{-/-}$mice model with sortilin deficiency decreased level of IFN- $\gamma$ and IL-6, and resulted in a reduction of the size of atherosclerotic lesion (49). Thus, blocking sortilin is suggested to be a promising strategy to modulate pro-inflammatory cytokines and treat atherosclerosis.

IFN- $\gamma$ is relatively small protein (146 aa) with a known 3D structure. The availability of the 3D structure makes it a potentially attractive target for structure-based drug design so as $\mathrm{t} o$ obtain orally available small molecules that can interfere with its function. However, until now there are no small molecules directly targeting IFN- $\gamma$ available. The only therapeutics available are antibodies. Fontolizumab (also known as future trade name HuZAF) is a humanized murine anti-IFN- $\gamma$ antibody (50). The X-ray structure revealed its 3D structure (figure 4) (51). Fontolizumab was tested in Phase II clinical trials for the treatment of rheumatoid arthritis. However, its development was stopped because the Phase I clinical trials did not meet the endpoint (52). Fontolizumab was also tested for treatment of psoriasis but did not show a significant effect (53). Considering the availability of the 3D structure of IFN- $\gamma$, it is conceivable that new antibodies, as well as small molecules, will be developed in the coming years. 


\section{IL-12}

IL-12 plays a central role in the differentiation of the T-cells into $\mathrm{T}_{\mathrm{h} 1}$ cells (figure 1), triggers the expression of IFN- $\gamma$ and TNF- $\alpha$ by T-cells (54). IL-12 is abundantly expressed by macrophages and DCs present in human and murine atherosclerotic lesions (55). IL-12 deficiency in $A p o E^{-/-}$mice was able to reduce atherosclerosis by $52 \%$ in the aortic root (56). Administration of IL-12 significantly increased the size of atheroscleroticlesions, corroborating with the aforementioned results (57). These data suggest that IL-12 is involved in the development of atherosclerosis. $L D L r^{/-}$mice vaccinated against IL-12 by the IL-12-PADRE complex induced an anti-IL-12 antibody that blocked IL-12 function and resulted in a significant $68.5 \%$ reduction of atherosclerotic lesion size. Moreover, the IL-12 antibody induced a stable plaque phenotype by an increase in the content of both smooth muscle cells and collagen (58).

In humans, the increased level of CCL19 and CCL21 is correlated with atherosclerotic carotid plaques (59). Recent studies showed that modulation of CCL19 and CCL21 chemokines in $L D L r^{-/}$mice model reduced the level of pro-inflammatory cytokines such as IL-12 and IFN- $\gamma$ which resulted in atherosclerotic plaque stabilization, but not the size of atherosclerotic lesion (60).

Ustekinumab (CNTO-1275) is a new antibody against the p40 subunit of IL-12 and IL-23. It is approved by the FDA as a drug for the treatment of Psoriatic arthritis (PsA) and moderateto-severe plaque psoriasis (61). The X-ray structure of the IL-12 in complex with Ustekinumab showed the epitope responsible for binding the antibody (figure 5) (62). Ustekinumab was also tested in Phase II clinical trials for other inflammatory diseases such as multiple sclerosis (63) and sarcoidosis (64). Briakinumab (ABT-874) is another human monoclonal antibody targeting both IL-12 and IL-23 for treatment of autoimmune diseases (65). It was tested for the treatment of moderate to severe psoriasis, but in 2011, it was withdrawn from Phase I clinical trials (66). The aforementioned animal models suggest that IL-12 is a good target for the

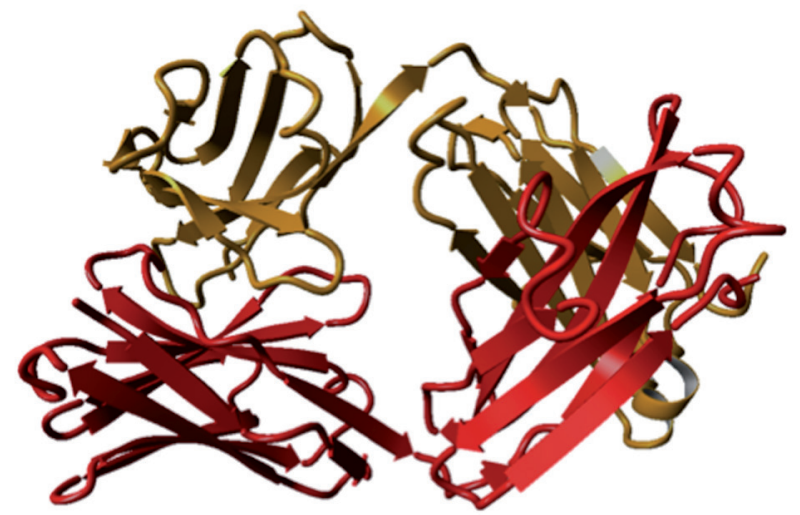

Figure 4. X-ray structure of apo-structure of Fontolizumab, light chain (orange), heavy chain (red). (PDB ID: 1T3F). 


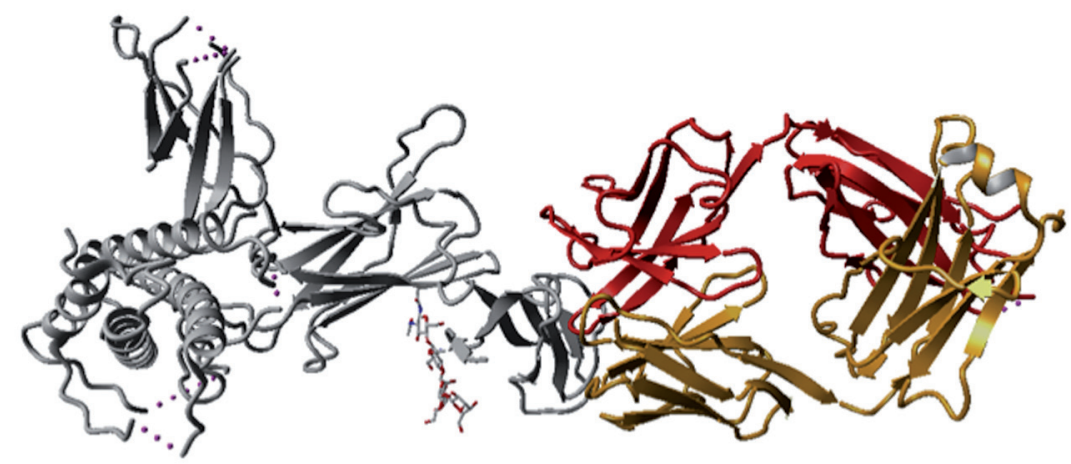

Figure 5. X-ray structure of IL-12 (grey) in complex with Ustekinumab Fab light chain (orange) and heavy chain (red) (PDB ID: 3HMX).

treatment of atherosclerosis. The progress of antibody development for treatment of inflammatory diseases provides the opportunity for anti-IL12 antibodies to be tested for the treatment of atherosclerosis.

$\mathrm{T}_{\mathrm{h} 2}$ cytokines

$\mathrm{T}_{\mathrm{h} 2}$ cells present in atherosclerotic lesion play both athero-protective and athero-promoting roles (figure 1). Thus, their importance as a target for the treatment of atherosclerosis remains controversial (67). Cytokines such as IL-13, IL-5, IL-4, and IL-10 (67) play a central role in differentiation of $\mathrm{T}_{\mathrm{h} 2}$ cells. IL-13 is a major $\mathrm{T}_{\mathrm{h} 2}$ cytokine expressed by activated T-cells (68). IL-13 deficiency in $L D L r^{-1}$ mice resulted in an increase in atherosclerosis whereas administration of IL-13 into $L D L r^{-}$mice reduced atherosclerotic lesion size and induced a stable plaque phenotype, indicating its athero-protective role (69). Similarly, IL-5 deficiency in $A p o E^{-/}$mice increased atherosclerosis by prevention of the production of anti-oxLDL antibodies. Thus, IL-5 plays an athero-protective role (70). IL-4 is another $\mathrm{T}_{\mathrm{h} 2}$ cytokine expressed in atherosclerotic lesions in both mice (71) and humans (72). The results from the deficiency of IL-4 in ApoE $E^{-/-}$and $L D L r^{/-}$, and exogenous administration of IL-4 in ApoE $E^{-/}$mice are contradictory $(56,73,74)$. The role of the IL-4 in atherogenesis remains controversial. Thus, its therapeutical potential requires further investigation. Currently, there are several neutralizing antibodies that block the activity of IL-4 and IL-13, and are tested in the clinical trials for the allergic airway inflammation (asthma) (75). However, in atherosclerosis, IL-5 and IL-13 play an athero-protective role thus their activity has to be boosted for the potential therapy of atherosclerosis. IL-33 is a cytokine that induces shift of $\mathrm{T}_{\mathrm{h} 1}$ into $\mathrm{T}_{\mathrm{h} 2}$. ApoE - $^{-/}$mice treated with recombinant IL-33 showed an increase in IL-4, IL-5, and IL-13 which resulted in a reduction of atherosclerotic lesion (76). In humans, a reduced level of IL-33 was associated with an increased risk of atherosclerosis. However, this small observational study requires further investigation (77).

The availability of X-ray structures of the apo IL-4 (78), IL-5 (79) and IL-13 in complex with 
their antibodies $(78,80)$, and NMR structure of the IL-33 in complex with its receptor (81) provides an opportunity for rational structure-based design of their modulators.

\section{B-cells in therapy for atherosclerosis}

One of the strategies to modulate B-cells and thus reduce atherosclerosis is depletion of B2 cells. Here, we describe two ways of their modulation, via depletion of CD20 antigen and via depletion of B-cells activating factor receptor (BAFF-R).

\section{CD20}

CD20 is an antigen expressed on mature B-cells and pre-B-cells, but is absent on plasma cells and hematopoietic stem B-cells (82). Currently, B-cell depletion therapy via anti-CD20 is in use for the treatment of auto-immune diseases such as rheumatoid arthritis (83). In human atherosclerotic plaques, CD20 was expressed on B-cells. Mature B-cell depletion via CD20specific monoclonal antibody therapy reduces atherosclerosis in both $L D L r^{-/}$and $A p o E^{-1-}$ mice. B-cell depletion resulted in a reduction of the pro-atherogenic $\mathrm{T}_{\mathrm{h} 1}$ immune response and reduced the production of IL-17. Anti-CD20 treatment did not affect the production of anti-atherogenic anti-oxLDL IgM autoantibodies (33). Therefore, CD20 is considered as a good target for treatment of atherosclerosis (84).

Currently, the only CD20 targeted drug approved by FDA is rituximab (RTX). RTX is a chimeric human-mouse IgG1 antibody directed against the CD20 antigen used for treatment of rheumatoid arthritis (RA) (85). The X-ray structure of the CD20-RTX complex unraveled the molecular details of the recognition of CD20 by the antibody (figure 6) (86). RTX is also tested for other inflammatory diseases. For now, small observational studies showed that RTX treatment of RA patients with atherosclerosis have reduced progression of atherosclerotic plaques (87). However, studies with a larger population of patients are needed.

\section{BAFF-R (B-cell activating factor receptor)}

$\mathrm{B}$-cell activating factor receptor (BAFF-R) is a pivotal survival factor for peripheral B-cells. It is expressed on mature B-cells and binds B-cell activating factor (BAFF) that is crucial for maturation and survival of B2 cells (88). Upon BAFF binding, BAFF-R activates B-cell development and survival (89). Depletion of BAFF-R in the $A p o E^{-/}$mice leads to a significant reduction in mature B2 cells, but not in B1a cells (90). As B2 cells are known to play proatherogenic roles, whereas B1a cells anti-atherogenic role, BAFF-R was hypothesized to be a good target for selective depletion of B-cells thus for treatment of atherosclerosis. The BAFF-R knockout in both $A p o E^{-/}$and $L D L r^{-/}$mice significantly reduced atherosclerotic lesion size and its inflammatory cells $(90,91)$. Anti-BAFF-R monoclonal antibody treatment in $A p o E^{-/}$mice showed a reduction of atherosclerotic lesions in both development and progression of inflammation (92). Aforementioned data corroborate with the previous findings and suggest that BAFF-R is a good target for treatment of atherosclerosis.

Tabalumab, a human IgG4 monoclonal antibody for BAFF, was used in Phase II clinical trials 


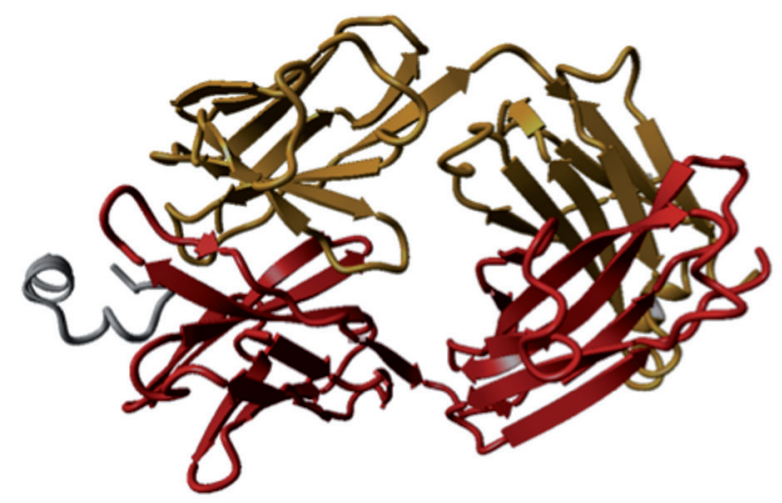

Figure 6. X-ray structure of rituximab Fab light chain (orange) and heavy chain (red) in complex with the epitope of B-cell antigen CD20 (grey), (PDB ID: 2OSL).

for patients with moderate to severe rheumatoid arthritis (RA) (93). However, it failed in Phase III of FLEX-V study, due to lack of efficacy (94). Currently, Tabalumab is in Phase III clinical trials for the treatment of systemic lupus erythematosus (SLE). The final results are expected to be announced in July 2015 (95). There is no information about the influence of the Tabalumab on atherosclerosis in patients with RA or SLE. However, the results of an ongoing SLE clinical trial (NCT01205438) might bring new insights. The anti-BAFF antibody therapy seems to have an advantage over the anti-CD20 antibody therapy, by targeting only pro-atherogenic B2 cells, while leaving anti-atherogenic B1a cells intact. As B-cell-mediated immune responses are involved in both SLE and atherosclerosis, we hypothesize that an antiBAFF antibody might also be effective in the treatment of atherosclerosis. Moreover, the $\mathrm{X}$-ray structure of the BAFF/BAFF-R complex is known (96), which gives a further opportunity for the future structure-based design of their modulators for instance by development of small molecule or peptidic inhibitors.

\section{CCL17}

The mature subset of cDCs exclusively expresses chemokine (C-C motif) ligand 17 (CCL17) (97). CCL17 chemokines play a pivotal role in the development of atherosclerosis. Deficiency in CCL17 in ApoE $E^{-/}$mice model resulted in a reduction of atherosclerotic plaque formation. Moreover, atherosclerotic plaques showed a lower accumulation of both macrophages and T-cells. In addition, it was demonstrated that CCL17 promotes atherosclerosis via regulation of $\mathrm{T}_{\text {reg }}$ homeostasis (98), an important $\mathrm{T}$-cell subset which strongly modulates immune cell activation and atherosclerosis. The anti-CCL17 specific antibody treatment of $A p o E^{-/-}$mice resulted in significant inhibition of atherosclerotic plaques (98). Thus, it demonstrated that CCL17 chemokine is a new potential target for treatment of atherosclerosis. Targeting of CCL17 in a selective manner seems to be a good approach for immune homeostasis 
modulation in atherosclerosis.

Till now there is no information about a small molecule or another modulator that is directly targeted at CCL17. However, in silico virtual ligand screening against the CCR4 - receptor of CCL17 and CCL22 resulted in in vitro validated small molecule inhibitors of the CCL17CCR4 interaction (99), suggesting that validation of CCL17 as a target to inhibit atherogenesis is feasible. Furthermore, availability of the X-ray structure of CCL17 may, in the future, facilitate CCL17-targeting therapy for atherosclerosis.

\section{Intervening in immune cell interactions: co-stimulatory dyads}

\section{CD154-CD40}

CD154 (CD40L) is expressed on T-cells and platelets, whereas CD40 can be predominantly observed in B-cells, DCs and macrophages $(100,101)$. The pivotal role of the CD154-CD40 interaction in atherosclerosis was established in both the $\mathrm{LDLr}^{-/}$and $\mathrm{ApoE^{-/ }}$ mouse models $(102,103)$. CD154 deficiency in $\mathrm{ApoE}^{-/-}$mice resulted in a 5.5 fold reduction of advanced atherosclerosis and induced a more stable plaque phenotype (103). Anti-CD154 antibody treatment in $\mathrm{LDLr}^{-/-}$mice significantly reduced initial atherosclerotic plaque size (102). AntiCD154 antibody treatment, of primary and advanced atherosclerotic lesion in $A p o E^{-/}$mice, reduced the content of inflammatory cells in both early and advanced plaques, inducing a more stable plaque phenotype (104). The anti-CD154 antibody treatment was also used in monkeys for renal transplantation. It showed long-term acceptance of renal allografts $(105,106)$. However, it also resulted in side-effects such as thrombo-embolic events (107). To unravel binding epitopes and provide a detailed structural rationale for inhibitor binding, CD154 was co-crystalized with one of its antibodies - 5c8 (figure 7a). CD154-CD40 interaction can be also modulated by small molecules. Analysis of an crystal structure of the complex between CD154 and a small molecule inhibitor showed that binding of a small molecule to a CD154 trimer changes the 3-fold symmetry and inhibits the interaction with CD40 (figure 7b). This inhibitor had significant effects in an in vitro assay. However, there is no information about an eventual follow-up in inflammatory in vivo models (108).

The alternative to anti-CD154 treatment could be CD40-targeted inhibition. We showed that deficiency of CD40 in ApoE $E^{-/-}$mice reduced atherosclerotic plaque size and induced a stable plaque phenotype (109). CD40 has no intrinsic signalling properties and requires recruitment of adaptor proteins from the TNF receptor-associated factor (TRAF) family to signal. We showed that $A p o E^{-/-}$mice in which the CD40-TRAF6 binding domain was mutated via sitedirected mutagenesis were protected against atherosclerosis. Thus by blocking CD40-TRAF6, the more downstream interaction of CD40 signaling, it is possible to overcome previously seen side-effects (109). We have developed a small molecule inhibitor of CD40-TRAF6 interaction that improved insulin sensitivity and reduced hepatosteatosis in diet-induced obesity mice (110). This implies that modulation of CD40-TRAF6 interactions via small 
a

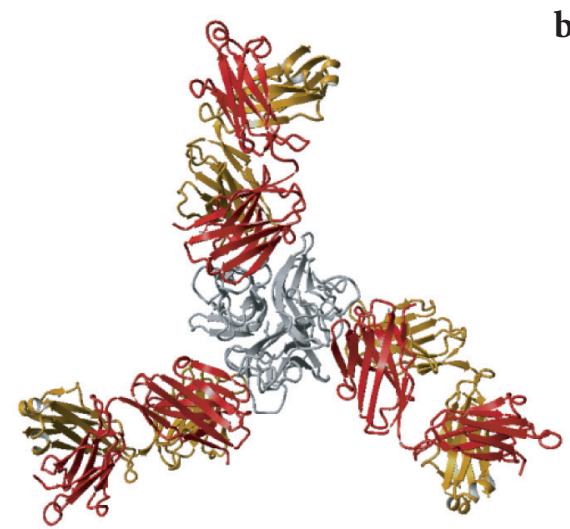

b

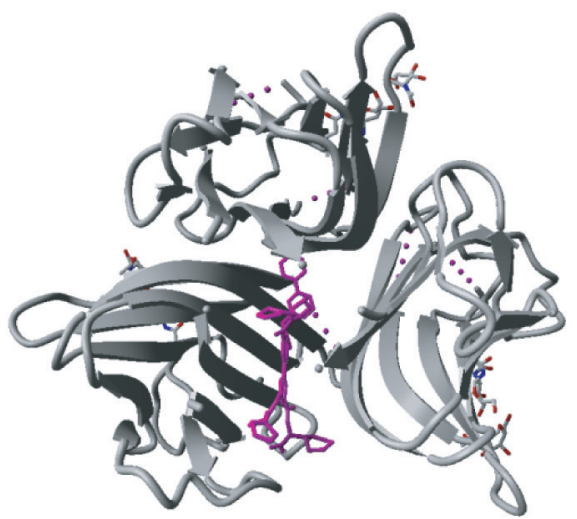

Figure 7. X-ray structures of CD154. (a) CD154 (grey) in complex with Fab fragment of humanized $5 c 8$ monoclonal antibody, light chain (orange), heavy chain (red), PDB ID: 1I9R. (b) CD154 (grey) in complex with small molecule inhibitor (magenta), (PDB ID: 3LKJ).

molecule inhibitor might reduce atherosclerosis and is suggested to be a promising approach for the treatment of atherosclerosis.

\section{OX40L-OX40}

OX40 is present on the surface of T-cells, and OX40L on APCs. Disruption of OX40L in $\mathrm{C} 57 \mathrm{Bl} / 6$ mice significantly reduced the size of atherosclerotic lesions, whereas overexpression of OX40L resulted in increased development of atherosclerotic plaques in C57Bl/6 mice (111). A polymorphism in human genes encoded for OX40 or OX40L is correlated with risk of myocardial infarction (111-113). To assess the role of the OX40L-OX40 pathway on development of atherosclerotic lesions, the anti-OX40L antibody (RM134) was used in the $L D L r^{-}$mouse model. Antibody treatment reduced progression of atherosclerotic lesions by inhibition of IL-4 mediated $\mathrm{T}_{\mathrm{h} 2}$ isotope switching and reduction of anti-oxLDL IgM (113). The anti-OX40L antibody treatment (RM134L) in $\mathrm{LDLr}^{-1-}$ mice also reduced advanced atherosclerotic lesions. However, regression of atherosclerotic lesions was obtained only with a combination of anti-lipid and anti-inflammatory treatment (114). Since OX40 is only expressed on T-cells present at the site of inflammation, it suggests that inhibition of the OX40L-OX40 interaction will not suppress the peripheral T-cells (115). Therefore, OX40LOX40 seems to be a clinically relevant target for treatment of atherosclerosis.

\section{CD137L-CD137}

CD137 is constitutively expressed on T-cells, whereas its ligand, CD137L is constitutively expressed on APCs such as B-cells, DCs, and monocytes/macrophages (116). However, CD137 is also expressed on endothelial cells present in human atherosclerotic plaques (117). It was shown that treatment of $A p o E^{-1-}$ mice model with a CD137 agonist - 2A significantly increased inflammation (117). It suggested that CD137 may play an important role in the inflammation of the arterial wall. Further, CD137 deficiency in both $A p o E^{-/-}$and $L D L r^{-/}$mice 
significantly reduced atherosclerosis by inhibition of monocyte/macrophage infiltration into the atherosclerotic lesion (118). These data were confirmed in another research that established a correlation between the CyPa protein and CD137L-CD137 in atherogenesis (119). These results suggest that the CD137L-CD137 interaction plays an important role in atherogenesis. Clinical data imply that the results from in vivo models can be relevant to the human situation. Increased presence of CD137 in patients with acute coronary syndrome (ACS) suggests a correlation between the CD137L-CD137 interaction and atherogenesis in human (120, 121). These data imply that CD137L-CD137 is a good target for treatment of atherosclerosis. Currently, there is no X-ray structure that could support a structure-based drug design for interruption of the CD137L-CD137 interaction; however, progress in this technique might bring solutions in the coming years.

\section{CD80/CD86-CD28-CTLA4}

CD80 and CD86 (B7-1 and B7-2, respectively) are expressed on the surface of APCs and both bind to the corresponding receptor CD28 expressed on T-cells, leading to T-cell activation and proliferation (122). Depletion of CD80 and CD86 showed contradictory results in different in vivo atherosclerosis models. The presence of the CD80 and CD86 receptors in atherosclerotic plaques of $A p o E^{-/-}$mice however suggested their regulatory role in atherogenesis (123). Deficiency of CD80 and CD86 in $\mathrm{LDLr}^{-/}$mice significantly reduced atherosclerosis. It suggested that the CD28-CD80/CD86 pathway is a potential target for treatment of atherosclerosis (124). However, Ait-Oufella et al. showed that LDLr-1-CD80-/-CD86-1- mice have two-fold increase of atherosclerotic lesion, most likely due to the decreased level of $\mathrm{T}_{\text {reg }}$ (125). Thus, the role of CD80/CD86-CD28 molecules remains controversial.

Cytotoxic T-Lymphocyte Antigen 4 (CTLA-4, CD152) is a co-inhibitory receptor for CD80 and CD86 expressed on activated T-cells and is essential for their function (126). CTLA-4 negatively regulates T-cell CD80/86-CD28 pathway, which plays an important role in the post-intervention accelerated atherosclerosis (127). Thus, blocking CD80/CD86-CD28 costimulatory molecules by its negative regulator seems to have beneficial effects in the inflammatory diseases.

\section{Pharmaceutics targeting co-stimulatory pathways}

Currently, several modulators, that target co-stimulatory pathways, are being used in the clinics. Abatacept is a fusion protein of the extracellular domain of CTLA-4 and Fc fragment of human IgG1 immunoglobulin (CTLA-4-Ig) that inhibits CD80/CD86-CD28 interaction (128). It is an FDA-approved drug for the treatment of rheumatoid arthritis (129). Abatacept reduced development of atherosclerotic plaques in an in vivo model of post-intervention atherosclerosis (127). Another biological, that disrupts CD80/CD86-CD28 interactions, is Belatacept (trade name Nulojix). It is also an FDA-approved anti-CD80 and anti-CD86 fusion protein used as an immune suppressant after kidney transplantation (130, 131). Besides 
biologicals, there is also a small molecule inhibitor that specifically targets CD80 (RhuDex ). It completed Phase II clinical trial for the treatment of rheumatoid arthritis (132). RhuDex was also tested in an ex vivo model of inflammation in human atherosclerotic lesion (133). Thus, this interaction can be considered as a promising target for the therapy of atherosclerosis. Additionally, the known X-ray structure of CD86 provides an opportunity for future structurebased development of new orally available therapeutics $(134,135)$.

The anti-OX40L antibodies or OX40 immunoglobulin fusion proteins block the OX40LOX40 interaction in several inflammatory diseases such as inflammatory bowel disease, graftversus-host disease, and rheumatoid arthritis (136). Currently, there is no structural information about the antibody binding to the OX40L. However, a number of X-ray structures of the OX40L-OX40 complex are available (137), which gives an opportunity for future structure-based design of their modulators. Positive results obtained in inflammatory diseases, suggest that anti-OX40L antibody treatment might be successful in the treatment of atherosclerosis.

The anti-CD154 antibodies were tested in the inflammatory diseases. Ruplizumab (hu5c8) is an anti-CD154 monoclonal antibody tested for treatment of systemic lupus erythematosus (SLE) and inflammatory bowel disease (IBD). However, it showed severe side-effects such as pro-thrombotic activity and thrombocytopenia (138, 139). Another anti-CD154 mAb, ABI793 was tested for treatment of renal transplantation model in monkeys. However, its development was halted due to the thromboembolic complications (140). Currently, there are a few agonistic and antagonistic anti-CD40 antibodies tested in the clinical trials mainly for the treatment of cancer. Ch5D12 is antagonistic mAb that was tested in Phase I/II clinical trials for the treatment moderate to severe Crohn's disease (141). However, there is no information about the further development of this antibody. CP-870,893 is a fully human $\mathrm{CD} 40$ agonistic $\mathrm{mAb}$, which was tested in Phase I clinical trials for the treatment of pancreatic ductal adenocarcinoma (PDA) and induced anti-tumor activity (142). Currently, it is investigated in combination with other drugs in Phase I clinical trials for the treatment of metastatic melanoma (143). CP-870,893 was a precursor for the development of Dacetuzumab (SGN-40), a partial agonistic, humanized IgG1, and anti-CD40 mAb. It was tested in Phase II clinical trials for the treatment of diffuse large B-cell lymphoma (DLBCL) and showed modest activity (144). Currently, it is in combination with anti-CTLA-4 antibody, in the Phase I clinical trials for the treatment of metastatic myeloma (145). Lucatumumab (HDC122, CHIR-12.12) is a fully human, antagonistic, recombinant mAb. It was also tested in the Phase I for the treatment of chronic lymphocytic leukemia (CLL) (146) and multiple myeloma (MM) (147). In the treatment for CCL, it showed only minimal activity (146), whereas in MM moderate activity (147). Lucatumumab was also investigated in Phase IA/II clinical trials for the treatment of cancers such as non-Hodgkin lymphoma (NHL) and Hodgkin lymphoma (HL). It showed modest activity in patients with advanced lymphoma (148). ChiLob 7/4 is an 
agonistic, IgG1 chimeric mAb. Currently, it is tested in Phase I clinical trials for anti-cancer treatment (149). Treatment of the anti-CD154 antibodies in the inflammatory disease showed side effects, however, anti-CD40 antibodies, both agonistic and antagonistic, are under the development for inflammatory and cancer therapies. Their preliminary results imply further exploration, especially in combination with other drugs.

Co-stimulatory molecules play a crucial role in the immune system. Some of the aforementioned modulators are used in the treatment of inflammatory diseases without comprise of the immune system. Thus, it is suggested that inhibition of co-stimulatory pathway is a very promising strategy for treatment of atherosclerosis.

\section{Athero-protective immunization}

Immunomodulatory therapies, such as immunization activates responses of the adaptive immune system. As atherosclerosis is an inflammatory disease in which adaptive immune system plays a major role, it is believed that immunization can become a new therapy.

\section{Passive immunization}

Passive immunization is characterized by direct administration of pre-formed antibodies. This method is commonly used in the treatment of infectious diseases (150). Nevertheless, it is also used in the treatment of non-infectious inflammatory diseases like rheumatoid arthritis (151).

Intravenous immunoglobulin (IVIg) is a pooled polyvalent IgG antibody that was extracted from plasma of approximately thousand different human blood donors. It is used as plasma protein replacement therapy (IgG) for patients with immune deficiency, especially autoimmune and systemic inflammatory diseases (152). As atherosclerosis is associated with immune responses, it was hypothesized that IVIg could be used for its treatment. ApoE $E^{-/-}$mice treated with IVIg, showed a reduced atherosclerotic lesion by $50 \%$, suggesting that immunoglobulins might be a new therapy for atherosclerosis (153).

\section{ApoB-100}

Apolipoprotein B (ApoB) is a protein component of LDL that is one of the main classes of antigens present on oxLDL. Human IgG1 antibodies against two malondialdehyde (MDA)modified ApoB-100 peptide sequences injected in $A p o E^{-/-}$mice resulted in a reduction of the size and inflammatory content of atherosclerotic lesion (154). To induce regression of atherosclerotic lesion, $L D L^{-/}$mice were treated with either of two recombinant human IgG1 antibodies against a malondialdehyde-modified apoB-100 peptide sequence (IEI-E3 or 2D03). Treatment resulted in significant regression of atherosclerotic lesion (155). Thus, ApoB-100 antibodies can reduce both progression and regression of atherosclerotic plaque in the animal model.

BI-204 is a monoclonal antibody targeting oxLDL which was subjected to the GLACIER clinical study aiming at exploration of the anti-inflammatory effect on stable atherosclerotic 
cardiovascular disease. In July 2012 BI-204 failed in Phase II of clinical trials due to a lack of statistically significant reduction of inflammation in the group of patients with atherosclerotic disease in comparison with the control group (156).

\section{Active immunization}

Active immunization is characterized by delivery of antigens, in the majority as vaccines, to stimulate a proactive response of the immune system. Vaccines are commonly used in the treatment of infectious diseases; nevertheless, recently, there are also attempts for treatment of non-infectious diseases like Alzheimer or rheumatoid arthritis (151). Atherosclerosis, known as an autoimmune disease, has self-antigens that contribute to their initiation and progression. Here, we describe antigens of oxLDL and heat shock proteins (HSPs) that upon activation can boost the production of athero-protective antibodies and give a rise for the development of novel vaccines against atherosclerosis.

\section{ApoB-100}

Immunization with ApoB100-pulsed DCs, in $L D L r^{-}$mice with human ApoB-100, resulted in $70 \%$ reduction of atherosclerotic lesion size (157). T-cells which recognize LDL/ApoB100, express T-cells receptor with TRBV31-type $\beta$ chains, thus immunization with TRBV31 peptides induced T-cells response blocking antibodies and resulted in $65 \%$ reduction of atherosclerotic lesion size (158).

The study done in the Nilsson group, regarding immunization with ApoB-100 peptide sequences showed reduced atherosclerosis in $A p o E^{-/-}$mice (159). Based on these results, CardioVax has developed a lead candidate vaccine against ApoB-100 - CVX-210-H. It consists of a fragment of human ApoB-100 (3136-3155 amino acids) that is conjugated to recombinant human serum albumin. Administration of CVX-210-H resulted in $60 \%$ reduction of atherosclerotic lesion (160). CVX-210-H completed pre-clinical phase for treatment of patients with atherosclerotic cardiovascular diseases (161). Unfortunately, information about the progress of CVX-210-H is not yet available.

Aforementioned data suggest that ApoB-100 vaccination is a promising strategy for treatment of atherosclerosis, and it is expected to have few side-effects, since the immune system will not be compromised upon vaccination. However, translating the in vivo result into clinical setting remains a challenge and pharmacological issues, such as those regarding dosing, or issues as patient selection, are likely of influence.

\section{Phosphatidylcholine (PC)}

Phosphatidylcholine (PC) is a major phospholipid present on oxLDL, which is compatible with PC epitopes of pathogens such as Streptococcus pneumoniae (162). Pneumococcal vaccination of $\mathrm{LDLr}^{-1}$ mice induces an athero-protective response by an increase of antioxLDL IgM antibodies, which resulted in a reduction of atherosclerotic lesions by $32 \%$ (162). However, patients vaccinated with Pneumovax ${ }^{\circledR}$, a pneumococcal polysaccharide vaccine, did 
not increase the level of anti-oxLDL IgM antibodies (163). This suggests that the translation of pneumococcal vaccination from an in vivo mouse model to humans will be very challenging. However, more recent studies showed an association between pneumococcal vaccination and a protective effect on cardiovascular disease in humans (164). The abovementioned contradictory results underscore the need for a more extensive investigation of pneumococcal vaccination as a therapeutic approach in the treatment of atherosclerosis.

\section{Heat shock proteins}

The heat shock proteins (HSPs) form a highly conserved family of proteins expressed on the endothelial cell surface and are found in atheroscleroticlesions (165). The HSP-60/65 are a major autoantigen present in atherosclerotic plaques that can stimulate both anti- and proatherogenic effects (166). Therefore, much effort was invested to identify anti-atherogenic T-cell and B-cell HSP-60 epitopes that could induce athero-protective effects. Nasal administration of mycobacterial HSP-65 into $L D L r^{-1}$ mice model reduced atherosclerotic plaque size by $50 \%$ (167), and in wild-type rabbits by $80 \%$ (168). Subcutaneous immunization of mycobacterial HSP-65 in ApoE $E^{-/-}$mice had a different effect on different phases of the progression of atherosclerosis (169). Aforementioned results imply that HSP might be a good target for treatment of atherosclerosis. However, further investigation is needed to access the possibility of translating these findings into clinical setting.

\section{Expert commentary \& five-year view}

Discovery of the inflammatory nature of atherosclerosis gave rise to new targets that can modulate atherosclerosis via the adaptive immune system. Several in vivo studies validated targets that play a crucial role in atherogenesis. Co-stimulatory molecules are one of the most promising targets. Blocking their interactions in inflammatory diseases other than atherosclerosis such as rheumatoid arthritis resulted in biologics approved by FDA $(129,131)$. It is suggested that these inhibitors have a very high potential in the treatment of atherosclerosis. However, further work is needed to assess their efficacy in inflammation of the arterial wall. Biologics tend to be expensive, usually require injection for their administration, and can have complex pharmacodynamics and pharmacokinetic properties. This bottleneck has been overcome by the use of small molecule inhibitors. The successful blockade of the CD40TRAF6 and CD80/CD86-CD26 interactions by small molecules in an in vivo model of dietinduced obesity and rheumatoid arthritis provided a proof of the principle $(110,133)$. It showed that these co-stimulatory molecules can be used for structure-based drug design and that they show potential to serve as new oral drugs in the treatment of atherosclerosis.

Another promising strategy for treatment of atherosclerosis is vaccination. The main targets for vaccination in atherosclerosis are (ox)LDL (apoB100) and HSP. There are successful examples of vaccines against these targets in other inflammatory diseases such as rheumatoid arthritis (151). It shows its potential as a new therapy for the treatment of atherosclerosis. 
However, atherosclerosis has a more systemic character than other inflammatory diseases, thus, finding specific antibodies that will not compromise systemic immunity may be the next step in the development of vaccines against atherosclerosis (173). Importantly, atherosclerosis is a chronic disease that develops at an early age, but is mostly diagnosed only at a later age. Current research on development of vaccines focuses on their use in the early stage of atherosclerosis whereas treatment in the advanced stage is clinically more relevant. Therefore, future vaccine research should be focused on the regression of existing atherosclerosis.

The challenge for therapy-development for atherosclerosis is the need for an extra-ordinary

Table 1. Summary of modulators of atherosclerosis.

\begin{tabular}{|c|c|c|c|c|c|}
\hline Target & Treatment & Model & Effect on atherosclerosis & Other disease & Ref \\
\hline \multirow[t]{2}{*}{ IFN- $\gamma$} & exogenous IFN- $\gamma$ & $A p o E^{-/-}$ & Two fold $\uparrow$ plaque size & & $(47)$ \\
\hline & sIFNgR gene transfer & $A p o E^{-/}$ & $60 \% \downarrow$ plaque size & & $(48)$ \\
\hline IL-12 & IL-12 antibody & $L D L r^{/-}$ & $\begin{array}{l}68.5 \% \downarrow \text { plaque size } \\
\text { SMC, collagen } \uparrow\end{array}$ & & $(58)$ \\
\hline \multirow[t]{4}{*}{$\mathrm{CD} 20$} & Anti-CD20 mAb & $A p o E^{-/-}$ & $\begin{array}{l}\text { significant } \downarrow \\
\text { plaque size }\end{array}$ & & (33) \\
\hline & Anti-CD20 mAb & $L D L r^{-}$ & $\begin{array}{l}\text { significant } \downarrow \\
\text { plaque size }\end{array}$ & & (33) \\
\hline & $\begin{array}{l}\text { chimeric human-mouse } \\
\text { IgG1 antibody - } \\
\text { rituximab (RTX) }\end{array}$ & & & RA & $(85)$ \\
\hline & $\begin{array}{l}\text { chimeric human-mouse } \\
\text { IgG1 antibody - } \\
\text { rituximab (RTX) }\end{array}$ & $\begin{array}{l}\text { Patients with } \\
\text { RA }\end{array}$ & $\downarrow$ plaque size & & (87) \\
\hline \multirow[t]{4}{*}{ BAFF-R } & anti-BAFF mAb & $\begin{array}{l}A p o E^{-/-} \\
\text {prevention } \\
\text { model }\end{array}$ & $\begin{array}{l}25 \% \downarrow \text { plaque size } \\
36 \% \downarrow \text { lipid } \\
46 \% \downarrow \text { macrophage } \\
60 \% \downarrow \text { IL- } 1 \beta\end{array}$ & & $(92)$ \\
\hline & anti-BAFF mAb & $\begin{array}{l}A p o E^{-/-} \\
\text {progression } \\
\text { model }\end{array}$ & $\begin{array}{l}30 \% \downarrow \text { plaque size } \\
33 \% \downarrow \text { lipid } \\
35 \% \downarrow \text { macrophage }\end{array}$ & & $(92)$ \\
\hline & $\begin{array}{l}\text { human IgG4 mAb - } \\
\text { Tabalumab }\end{array}$ & & & SLE & (95) \\
\hline & Ustekinumab & & & $\begin{array}{l}\text { Psoriasis, } \\
\text { Psoriatic arthritis }\end{array}$ & (61) \\
\hline CCL17 & $\mathrm{Ab}$ & $A p o E^{-/-}$ & $\begin{array}{l}\text { significant } \downarrow \\
\text { plaque size }\end{array}$ & & (98) \\
\hline CD154-CD40 & anti-CD154 antibody & $A p o E^{-/-}$ & $\begin{array}{l}\downarrow \text { T-cells } \\
\uparrow \text { collagen, SMC, } \\
\text { myofibroblasts, fibrous } \\
\text { cap }\end{array}$ & & (104) \\
\hline
\end{tabular}




\begin{tabular}{|c|c|c|c|c|c|}
\hline Target & Treatment & Model & Effect on Atherosclerosis & Other disease & Ref \\
\hline \multirow{3}{*}{ OX40-OX40L } & Small molecule inhibitor & & & $\begin{array}{l}\text { Diet-induced } \\
\text { obesity }\end{array}$ & $(110)$ \\
\hline & $\begin{array}{l}\text { anti-OX40L Ab } \\
\text { (RM134L) }\end{array}$ & $L D L r^{-}$ & $\downarrow 29 \%$ plaque size & & (114) \\
\hline & OX40 immunoglobulin & & & $\begin{array}{l}\text { inflammatory } \\
\text { bowel diseases, } \\
\text { graft-versus-host } \\
\text { disease, RA }\end{array}$ & (136) \\
\hline CD137-CD137L & agonist of CD137 - 2A & $A p o E^{-/-}$ & $\begin{array}{l}\text { significant } \uparrow \text { plaque size } \\
\uparrow \mathrm{T} \text {-cells }\end{array}$ & & (117) \\
\hline \multirow[t]{5}{*}{$\begin{array}{l}\text { CD28-CD80/ } \\
\text { CD86 }\end{array}$} & $\begin{array}{l}\text { RhuDex }{ }^{\oplus} \text { small molecule } \\
\text { CD80 inhibitor }\end{array}$ & $\begin{array}{l}\text { ex vivo } \\
\text { human plaque }\end{array}$ & $\downarrow$ TNF- $\alpha$, IFN- $\gamma$, CCL 2 & & (133) \\
\hline & RhuDex & & & RA & (170) \\
\hline & $\begin{array}{l}\text { anti-CD80 mAb- } \\
\text { Galiximab }\end{array}$ & & & cancer & $(171)$ \\
\hline & Belatacept & & & $\begin{array}{l}\text { Kidney } \\
\text { transplant }\end{array}$ & (131) \\
\hline & Abatacept & & & RA & (129) \\
\hline \multirow[t]{2}{*}{ B-cells } & IVIg & ApoE-/ & $50 \% \downarrow$ plaque size & & (153) \\
\hline & $2 \mathrm{D} 03 \mathrm{Ab}$ & $L D L r^{\prime}$ & $>90 \% \downarrow$ plaque size & & $(172)$ \\
\hline oxLDL & $\begin{array}{l}\text { Streptococcus pneumoniae } \\
\text { vaccination }\end{array}$ & $L D L r^{-}$ & $32 \% \downarrow$ plaque size & & $(162)$ \\
\hline \multirow[t]{4}{*}{ ApoB-100 } & $\begin{array}{l}\text { ApoB- } 100 \text { peptides } \\
\text { immunization }\end{array}$ & $A p o E^{-/}$ & $60 \% \downarrow$ plaque size & & (159) \\
\hline & ApoB100-pulsed DCs & $L D L r^{/-}$ & $70 \% \downarrow$ plaque size & & (157) \\
\hline & TRBV31 peptides & $L D L r^{-}$ & $65 \% \downarrow$ plaque size & & (158) \\
\hline & CVX-210-H vaccine & & $60 \% \downarrow$ plaque size & & $\begin{array}{l}(160) \\
(161)\end{array}$ \\
\hline \multirow[t]{3}{*}{$\begin{array}{l}\text { Heat shock } \\
\text { proteins }\end{array}$} & $\begin{array}{l}\text { Mycobacterial HSP-65 } \\
\text { immunization }\end{array}$ & $L D L r^{-}$ & $\begin{array}{l}50 \% \downarrow \text { plaque size } \\
36 \% \downarrow \text { macrophages } \\
36 \% \downarrow \text { T-cells }\end{array}$ & & (167) \\
\hline & $\begin{array}{l}\text { Mycobacterial HSP- } 65 \\
\text { immunization }\end{array}$ & Rabbit model & $80 \% \downarrow$ plaque size & & $(168)$ \\
\hline & $\begin{array}{l}\text { Mycobacterial HSP-65 } \\
\text { immunization }\end{array}$ & $A p o E^{--}$ & $34 \% \downarrow$ plaque size & & $(169)$ \\
\hline
\end{tabular}


safety profile. Since atherosclerosis is a chronic inflammatory disease, its treatment will demand chronic administration. The long-term treatment is additionally exposed to sideeffects. Otherwise patients might be exposed to the infections arising from constant interference with the immune system as it was seen in the case of treatment of other inflammatory diseases. Thus, the development of therapy that will be highly specific can be the only solution. Possible solution to prevent systemic side effects could be cell-specific delivery of new inhibitors into the atherosclerotic plaque, such as nanoparticles (174).

Since atherosclerosis for a long time has been known to be only lipid-driven disease, current therapy is limited to the treatment of it risk factors such as hyperlipidemia and hypertension. The most known drugs are cholesterol lowering statins (175). Even though statins show antiinflammatory mechanism of action, there are not directly targeting inflammatory nature of atherosclerosis and cannot reduce the high contribution of inflammation (176). The antiinflammatory drugs tested presently in clinical trials for the cardiovascular complications are not yet checked for their impact on the lipids (177). However, it is suggested that a combination of anti-lipid and anti-inflammatory treatments might be the most successful strategy towards future therapies. Thus, possible synergistic effect of this therapy might show the future direction for the new treatment. 


\section{References}

1. Hansson GK, Hermansson A. The immune system in atherosclerosis. Nat Immunol. 2011 Mar;12(3):204-12.

2. Stöger JL, Goossens P, de Winther MPJ. Macrophage heterogeneity: relevance and functional implications in atherosclerosis. Curr Vasc Pharmacol. 2010 Mar;8(2):233-48.

3. Virchow R. Cellular Pathology. London, United Kingdom: John Churchill; 1860.

4. Hansson GK. Immune and inflammatory mechanisms in the development of atherosclerosis. Br Heart J. 1993 Jan;69(1 Suppl):S38-41.

5. Fredman G, Spite M. Recent advances in the role of immunity in atherosclerosis. Circ Res. 2013 Dec 6;113(12):e111-4.

6. Antonopoulos AS, Margaritis M, Lee R, Channon K, Antoniades C. Statins as anti-inflammatory agents in atherogenesis: molecular mechanisms and lessons from the recent clinical trials. Curr Pharm Des. 2012;18(11):1519-30.

7. Mihos CG, Pineda AM, Santana O. Cardiovascular effects of statins, beyond lipid-lowering properties. Pharmacol Res. 2014 Oct;88:12-9.

8. Weber C, Noels H. Atherosclerosis: current pathogenesis and therapeutic options. Nat Med. 2011;17(11):141022.

9. Ridker PM, Thuren T, Zalewski A, Libby P. Interleukin-1 $\beta$ inhibition and the prevention of recurrent cardiovascular events: rationale and design of the Canakinumab Anti-inflammatory Thrombosis Outcomes Study (CANTOS). Am Heart J. 2011 Oct;162(4):597-605.

10. Nilsson J, Hansson GK. Autoimmunity in atherosclerosis: a protective response losing control? J Intern Med. 2008 May;263(5):464-78.

11. Hansson GK, Libby P, Schönbeck U, Yan Z-Q. Innate and adaptive immunity in the pathogenesis of atherosclerosis. Circ Res. 2002 Aug 23;91(4):281-91.

12. Lichtman AH, Binder CJ, Tsimikas S, Witztum JL. Adaptive immunity in atherogenesis: new insights and therapeutic approaches. J Clin Invest. 2013 Jan 2;123(1):27-36.

13. Libby P, Ridker PM, Hansson GK. Progress and challenges in translating the biology of atherosclerosis. Nature. 2011 May 19;473(7347):317-25.

14. Tsimikas S, Willeit P, Willeit J, Santer P, Mayr M, Xu Q, et al. Oxidation-specific biomarkers, prospective 15-year cardiovascular and stroke outcomes, and net reclassification of cardiovascular events. J Am Coll Cardiol. 2012 Nov 20;60(21):2218-29.

15. Ramos-Arellano LE, Muñoz-Valle JF, De la Cruz-Mosso U, Salgado-Bernabé AB, Castro-Alarcón N, ParraRojas I. Circulating CD36 and oxLDL levels are associated with cardiovascular risk factors in young subjects. BMC Cardiovasc Disord. 2014;14:54.

16. Libby P, Lichtman AH, Hansson GK. Immune effector mechanisms implicated in atherosclerosis: from mice to humans. Immunity. 2013 Jun 27;38(6):1092-104.

17. Millonig G, Niederegger H, Rabl W, Hochleitner BW, Hoefer D, Romani N, et al. Network of vascular-associated dendritic cells in intima of healthy young individuals. Arterioscler Thromb Vasc Biol. 2001 Apr;21(4):503-8.

18. Bobryshev YV. Dendritic cells and their involvement in atherosclerosis. Curr Opin Lipidol. 2000 Oct;11(5):5117.

19. Bobryshev YV, Taksir T, Lord RS, Freeman MW. Evidence that dendritic cells infiltrate atherosclerotic lesions in apolipoprotein E-deficient mice. Histol Histopathol. $2001 \mathrm{Jul}$;6(3):801-8.

20. Bobryshev YV, Lord RS. Ultrastructural recognition of cells with dendritic cell morphology in human aortic intima. Contacting interactions of Vascular Dendritic Cells in athero-resistant and athero-prone areas of the normal aorta. Arch Histol Cytol. 1995 Aug;58(3):307-22.

21. Bobryshev YV. Dendritic cells and their role in atherogenesis. Lab Invest. 2010 Jul;90(7):970-84.

22. Sage AP, Murphy D, Maffia P, Masters LM, Sabir SR, Baker LL, et al. MHC Class II-restricted antigen presentation by plasmacytoid dendritic cells drives proatherogenic T cell immunity. Circulation. 2014 Oct 14;130(16):1363-73.

23. Hansson GK, Holm J, Jonasson L. Detection of activated T lymphocytes in the human atherosclerotic plaque. Am J Pathol. 1989 Jul;135(1):169-75.

24. Dong C. Diversification of T-helper-cell lineages: finding the family root of IL-17-producing cells. Nat Rev Immunol. 2006 Apr;6(4):329-33.

25. Andersson J, Libby P, Hansson GK. Adaptive immunity and atherosclerosis. Clin Immunol. 2010 Jan;134(1):3346.

26. Zhou X, Stemme S, Hansson GK. Evidence for a local immune response in atherosclerosis. CD4+ T cells infiltrate lesions of apolipoprotein-E-deficient mice. Am J Pathol. 1996 Aug;149(2):359-66. 
27. Kolbus D, Ljungcrantz I, Andersson L, Hedblad B, Fredrikson GN, Björkbacka H, et al. Association between CD8+ T-cell subsets and cardiovascular disease. J Intern Med. 2013 Jul;274(1):41-51.

28. Kleindienst R, Xu Q, Willeit J, Waldenberger FR, Weimann S, Wick G. Immunology of atherosclerosis. Demonstration of heat shock protein 60 expression and $\mathrm{T}$ lymphocytes bearing alpha/beta or gamma/delta receptor in human atherosclerotic lesions. Am J Pathol. 1993 Jun;142(6):1927-37.

29. Vu DM, Tai A, Tatro JB, Karas RH, Huber BT, Beasley D. $\gamma \delta$ T cells are prevalent in the proximal aorta and drive nascent atherosclerotic lesion progression and neutrophilia in hypercholesterolemic mice. PloS One. 2014;9(10):e109416.

30. Houtkamp MA, de Boer OJ, van der Loos CM, van der Wal AC, Becker AE. Adventitial infiltrates associated with advanced atherosclerotic plaques: structural organization suggests generation of local humoral immune responses. J Pathol. 2001 Feb;193(2):263-9.

31. Ylä-Herttuala S, Palinski W, Butler SW, Picard S, Steinberg D, Witztum JL. Rabbit and human atherosclerotic lesions contain IgG that recognizes epitopes of oxidized LDL. Arterioscler Thromb. 1994 Jan;14(1):32-40.

32. Binder CJ. Natural IgM Antibodies Against Oxidation-Specific Epitopes. J Clin Immunol. 2010 May 1;30(1):5660 .

33. Ait-Oufella H, Herbin O, Bouaziz J-D, Binder CJ, Uyttenhove C, Laurans L, et al. B cell depletion reduces the development of atherosclerosis in mice. J Exp Med. 2010 Aug 2;207(8):1579-87.

34. Kyaw T, Tay C, Krishnamurthi S, Kanellakis P, Agrotis A, Tipping P, et al. B1a B lymphocytes are atheroprotective by secreting natural IgM that increases IgM deposits and reduces necrotic cores in atherosclerotic lesions. Circ Res. 2011 Sep 30;109(8):830-40.

35. Perry HM, Bender TP, McNamara CA. B Cell Subsets in Atherosclerosis. Front Immunol. 2012 Dec 11;3:373.

36. Hilgendorf I, Theurl I, Gerhardt LMS, Robbins CS, Weber GF, Gonen A, et al. Innate response activator B cells aggravate atherosclerosis by stimulating T helper-1 adaptive immunity. Circulation. 2014 Apr 22;129(16):167787.

37. Kyaw T, Tay C, Khan A, Dumouchel V, Cao A, To K, et al. Conventional B2 B cell depletion ameliorates whereas its adoptive transfer aggravates atherosclerosis. J Immunol. 2010 Oct 1;185(7):4410-9.

38. Mauri C, Williams RO, Walmsley M, Feldmann M. Relationship between Th1/Th2 cytokine patterns and the arthritogenic response in collagen-induced arthritis. Eur J Immunol. 1996 Jul;26(7):1511-8.

39. Karvonen J, Päivänsalo M, Kesäniemi YA, Hörkkö S. Immunoglobulin M Type of Autoantibodies to Oxidized Low-Density Lipoprotein Has an Inverse Relation to Carotid Artery Atherosclerosis. Circulation. 2003 Oct 28;108(17):2107-12.

40. Moohebati M, Kabirirad V, Ghayour-Mobarhan M, Esmaily H, Tavallaie S, Akhavan Rezayat A, et al. Investigation of serum oxidized low-density lipoprotein IgG levels in patients with angiographically defined coronary artery disease. Int J Vasc Med. 2014;2014:845960.

41. Mantani PT, Ljungcrantz I, Andersson L, Alm R, Hedblad B, Björkbacka H, et al. Circulating CD40+ and CD86+ B cell subsets demonstrate opposing associations with risk of stroke. Arterioscler Thromb Vasc Biol. 2014 Jan;34(1):211-8.

42. Gerdes N, Zirlik A. Co-stimulatory molecules in and beyond co-stimulation - tipping the balance in atherosclerosis? Thromb Haemost. 2011 Nov;106(5):804-13.

43. Stemme S, Faber B, Holm J, Wiklund O, Witztum JL, Hansson GK. T lymphocytes from human atherosclerotic plaques recognize oxidized low density lipoprotein. Proc Natl Acad Sci U S A. 1995 Apr 25;92(9):3893-7.

44. Gupta S, Pablo AM, Jiang X c, Wang N, Tall AR, Schindler C. IFN-gamma potentiates atherosclerosis in ApoE knock-out mice. J Clin Invest. 1997 Jun 1;99(11):2752-61.

45. Buono C, Come CE, Stavrakis G, Maguire GF, Connelly PW, Lichtman AH. Influence of interferon-gamma on the extent and phenotype of diet-induced atherosclerosis in the LDLR-deficient mouse. Arterioscler Thromb Vasc Biol. 2003 Mar 1;23(3):454-60.

46. Gotsman I, Lichtman AH. Targeting interferon-gamma to treat atherosclerosis. Circ Res. 2007 Aug 17;101(4):333-4.

47. Whitman SC, Ravisankar P, Elam H, Daugherty A. Exogenous interferon-gamma enhances atherosclerosis in apolipoprotein E-/- mice. Am J Pathol. 2000 Dec;157(6):1819-24.

48. Koga M, Kai H, Yasukawa H, Yamamoto T, Kawai Y, Kato S, et al. Inhibition of progression and stabilization of plaques by postnatal interferon-gamma function blocking in ApoE-knockout mice. Circ Res. 2007 Aug 17;101(4):348-56.

49. Mortensen MB, Kjolby M, Gunnersen S, Larsen JV, Palmfeldt J, Falk E, et al. Targeting sortilin in immune cells reduces proinflammatory cytokines and atherosclerosis. J Clin Invest. 2014 Dec 1;124(12):5317-22.

50. Dumont FJ. Fontolizumab Protein Design Labs. Curr Opin Investig Drugs. 2005 May;6(5):537-44. 
51. Bourne PC, Terzyan SS, Cloud G, Landolfi NF, Vásquez M, Edmundson AB. Three-dimensional structures of a humanized anti-IFN-gamma Fab (HuZAF) in two crystal forms. Acta Crystallogr D Biol Crystallogr. 2004 Oct;60(Pt 10):1761-9.

52. https://clinicaltrials.gov/ct2/show/NCT00281294?term=Fontolizumab\&rank=1.

53. Harden JL, Johnson-Huang LM, Chamian MF, Lee E, Pearce T, Leonardi CL, et al. Humanized anti-IFN- $\gamma$ (HuZAF) in the treatment of psoriasis. J Allergy Clin Immunol 2015 Feb;135(2):553-6.

54. Gately MK, Desai BB, Wolitzky AG, Quinn PM, Dwyer CM, Podlaski FJ, et al. Regulation of human lymphocyte proliferation by a heterodimeric cytokine, IL-12 (cytotoxic lymphocyte maturation factor). J Immunol Baltim Md 1950. 1991 Aug 1;147(3):874-82.

55. Uyemura K, Demer LL, Castle SC, Jullien D, Berliner JA, Gately MK, et al. Cross-regulatory roles of interleukin (IL)-12 and IL-10 in atherosclerosis. J Clin Invest. 1996 May 1;97(9):2130-8.

56. Davenport P, Tipping PG. The Role of Interleukin-4 and Interleukin-12 in the Progression of Atherosclerosis in Apolipoprotein E-Deficient Mice. Am J Pathol. 2003 Sep;163(3):1117-25.

57. Lee TS, Yen HC, Pan CC, Chau LY. The role of interleukin 12 in the development of atherosclerosis in ApoEdeficient mice. Arterioscler Thromb Vasc Biol. 1999 Mar;19(3):734-42.

58. Hauer AD, Uyttenhove C, de Vos P, Stroobant V, Renauld JC, van Berkel TJC, et al. Blockade of interleukin-12 function by protein vaccination attenuates atherosclerosis. Circulation. 2005 Aug 16;112(7):1054-62.

59. Damås JK, Smith C, Øie E, Fevang B, Halvorsen B, Waehre T, et al. Enhanced expression of the homeostatic chemokines CCL19 and CCL21 in clinical and experimental atherosclerosis: possible pathogenic role in plaque destabilization. Arterioscler Thromb Vasc Biol. 2007 Mar;27(3):614-20.

60. Akhavanpoor M, Gleissner CA, Gorbatsch S, Doesch AO, Akhavanpoor H, Wangler S, et al. CCL19 and CCL21 modulate the inflammatory milieu in atherosclerotic lesions. Drug Des Devel Ther. 2014;8:2359-71.

61. Davari P, Leo MS, Kamangar F, Fazel N. Ustekinumab for the treatment of psoriatic arthritis: an update. Clin Cosmet Investig Dermatol. 2014;7:243-9.

62. Luo J, Wu S-J, Lacy ER, Orlovsky Y, Baker A, Teplyakov A, et al. Structural basis for the dual recognition of IL12 and IL-23 by ustekinumab. J Mol Biol. 2010 Oct 8;402(5):797-812.

63. https://clinicaltrials.gov/ct2/show/NCT00207727?term=Ustekinumab+multiple+sclerosis\&rank=1.

64. https://clinicaltrials.gov/ct2/show/study/NCT00955279?term=Ustekinumab+Sarcoidosis\&rank=1.

65. Lima XT, Abuabara K, Kimball AB, Lima HC. Briakinumab. Expert Opin Biol Ther. 2009 Jul 2;9(8):1107-13.

66. https://clinicaltrials.gov/ct2/show/NCT01260844?term=Briakinumab\&rank=1.

67. Taleb S, Tedgui A, Mallat Z. Adaptive T cell immune responses and atherogenesis. Curr Opin Pharmacol. 2010 Apr;10(2):197-202.

68. Minty A, Chalon P, Derocq J-M, Dumont X, Guillemot J-C, Kaghad M, et al. Interleukin-13 is a new human lymphokine regulating inflammatory and immune responses. Nature. 1993 Mar 18;362(6417):248-50.

69. Cardilo-Reis L, Gruber S, Schreier SM, Drechsler M, Papac-Milicevic N, Weber C, et al. Interleukin-13 protects from atherosclerosis and modulates plaque composition by skewing the macrophage phenotype. EMBO Mol Med. 2012 Oct;4(10):1072-86.

70. Binder CJ, Hartvigsen K, Chang M-K, Miller M, Broide D, Palinski W, et al. IL-5 links adaptive and natural immunity specific for epitopes of oxidized LDL and protects from atherosclerosis. J Clin Invest. 2004 Aug;114(3):427-37.

71. Davenport P, Tipping PG. The Role of Interleukin-4 and Interleukin-12 in the Progression of Atherosclerosis in Apolipoprotein E-Deficient Mice. Am J Pathol. 2003 Sep;163(3):1117-25.

72. Sasaguri T, Arima N, Tanimoto A, Shimajiri S, Hamada T, Sasaguri Y. A role for interleukin 4 in production of matrix metalloproteinase 1 by human aortic smooth muscle cells. Atherosclerosis. 1998 Jun;138(2):247-53.

73. King VL, Szilvassy SJ, Daugherty A. Interleukin-4 deficiency decreases atherosclerotic lesion formation in a site-specific manner in female LDL receptor-/- mice. Arterioscler Thromb Vasc Biol. 2002 Mar 1;22(3):45661.

74. King VL, Cassis LA, Daugherty A. Interleukin-4 does not influence development of hypercholesterolemia or angiotensin II-induced atherosclerotic lesions in mice. Am J Pathol. 2007 Dec;171(6):2040-7.

75. Maes T, Joos GF, Brusselle GG. Targeting interleukin-4 in asthma: lost in translation? Am J Respir Cell Mol Biol. 2012 Sep;47(3):261-70.

76. Miller AM, Xu D, Asquith DL, Denby L, Li Y, Sattar N, et al. IL-33 reduces the development of atherosclerosis. J Exp Med. 2008 Feb 18;205(2):339-46.

77. Hasan A, Al-Ghimlas F, Warsame S, Al-Hubail A, Ahmad R, Bennakhi A, et al. IL-33 is negatively associated with the BMI and confers a protective lipid/metabolic profile in non-diabetic but not diabetic subjects. BMC Immunol. 2014;15:19. 
78. Kraich M, Klein M, Patiño E, Harrer H, Nickel J, Sebald W, et al. A modular interface of IL-4 allows for scalable affinity without affecting specificity for the IL-4 receptor. BMC Biol. 2006;4:13.

79. Kusano S, Kukimoto-Niino M, Hino N, Ohsawa N, Ikutani M, Takaki S, et al. Structural basis of interleukin-5 dimer recognition by its a receptor. Protein Sci. 2012 Jun;21(6):850-64.

80. Teplyakov A, Obmolova G, Wu S-J, Luo J, Kang J, O’Neil K, et al. Epitope mapping of anti-interleukin-13 neutralizing antibody CNTO607. J Mol Biol. 2009 May 29;389(1):115-23.

81. Lingel A, Weiss TM, Niebuhr M, Pan B, Appleton BA, Wiesmann C, et al. Structure of IL-33 and its interaction with the ST2 and IL-1RAcP receptors--insight into heterotrimeric IL-1 signaling complexes. Structure. 2009 Oct 14;17(10):1398-410.

82. Ahmadzadeh V, Farajnia S, Hosseinpour Feizi MA, Khavarinejad RA. Design, expression and characterization of a single chain anti-CD20 antibody; a germline humanized antibody derived from Rituximab. Protein Expr Purif. 2014 Oct;102:45-51.

83. Dörner T, Radbruch A, Burmester GR. B-cell-directed therapies for autoimmune disease. Nat Rev Rheumatol. 2009 Aug;5(8):433-41.

84. Hamze M, Desmetz C, Berthe ML, Roger P, Boulle N, Brancherau P, et al. Characterization of resident B cells of vascular walls in human atherosclerotic patients. J Immunol Baltim Md 1950. 2013 Sep 15;191(6):3006-16.

85. Edwards JCW, Leandro MJ, Cambridge G. B lymphocyte depletion therapy with rituximab in rheumatoid arthritis. Rheum Dis Clin North Am. 2004 May;30(2):393-403, viii.

86. Du J, Wang H, Zhong C, Peng B, Zhang M, Li B, et al. Structural basis for recognition of CD20 by therapeutic antibody Rituximab. JBiolChem. 2007 Feb 6;282:15073-80.

87. Benucci M, Saviola G, Manfredi M, Sarzi-Puttini P, Atzeni F. Factors correlated with improvement of endothelial dysfunction during rituximab therapy in patients with rheumatoid arthritis. Biol Targets Ther. 2013;7:69-75.

88. Mackay F, Schneider P. Cracking the BAFF code. Nat Rev Immunol. 2009 Jul;9(7):491-502.

89. Thompson JS, Bixler SA, Qian F, Vora K, Scott ML, Cachero TG, et al. BAFF-R, a newly identified TNF receptor that specifically interacts with BAFF. Science. 2001 Sep 14;293(5537):2108-11.

90. Kyaw T, Tay C, Hosseini H, Kanellakis P, Gadowski T, MacKay F, et al. Depletion of B2 but Not B1a B Cells in BAFF Receptor-Deficient ApoE-/- Mice Attenuates Atherosclerosis by Potently Ameliorating Arterial Inflammation. PLoS ONE. 2012 Jan 4;7(1):e29371.

91. Sage AP, Tsiantoulas D, Baker L, Harrison J, Masters L, Murphy D, et al. BAFF receptor deficiency reduces the development of atherosclerosis in mice--brief report. Arterioscler Thromb Vasc Biol. 2012 Jul;32(7):1573-6.

92. Kyaw T, Cui P, Tay C, Kanellakis P, Hosseini H, Liu E, et al. BAFF receptor mAb treatment ameliorates development and progression of atherosclerosis in hyperlipidemic ApoE(-/-) mice. PloS One. 2013;8(4):e60430.

93. Genovese MC, Fleischmann RM, Greenwald M, Satterwhite J, Veenhuizen M, Xie L, et al. Tabalumab, an antiBAFF monoclonal antibody, in patients with active rheumatoid arthritis with an inadequate response to TNF inhibitors. Ann Rheum Dis. 2013 Sep 1;72(9):1461-8.

94. https://clinicaltrials.gov/ct2/show/NCT01202773?term=Tabalumab+FLEX-V\&rank=1.

95. https://clinicaltrials.gov/ct2/show/NCT01205438?term=systemic+lupus+erythematosus+tabalumab\&rank=1 .

96. Kim HM, Yu KS, Lee ME, Shin DR, Kim YS, Paik S-G, et al. Crystal structure of the BAFF-BAFF-R complex and its implications for receptor activation. Nat Struct Biol. 2003 May;10(5):342-8.

97. Alferink J, Lieberam I, Reindl W, Behrens A, Weiss S, Hüser N, et al. Compartmentalized production of CCL17 in vivo: strong inducibility in peripheral dendritic cells contrasts selective absence from the spleen. J Exp Med. 2003 Mar 3;197(5):585-99.

98. Weber C, Meiler S, Döring Y, Koch M, Drechsler M, Megens RTA, et al. CCL17-expressing dendritic cells drive atherosclerosis by restraining regulatory T cell homeostasis in mice. J Clin Invest. 2011 Jul;121(7):2898-910.

99. Bayry J, Tchilian EZ, Davies MN, Forbes EK, Draper SJ, Kaveri SV, et al. In silico identified CCR4 antagonists target regulatory $\mathrm{T}$ cells and exert adjuvant activity in vaccination. Proc Natl Acad Sci U S A. 2008 Jul 22;105(29):10221-6.

100. Engel D, Seijkens T, Poggi M, Sanati M, Thevissen L, Beckers L, et al. The immunobiology of CD154-CD40TRAF interactions in atherosclerosis. Semin Immunol. 2009 Oct;21(5):308-12.

101. Seijkens T, Engel D, Tjwa M, Lutgens E. The role of CD154 in haematopoietic development. Thromb Haemost. 2010 Oct;104(4):693-701.

102. Mach F, Schönbeck U, Sukhova GK, Atkinson E, Libby P. Reduction of atherosclerosis in mice by inhibition of CD40 signalling. Nature. 1998 Jul 9;394(6689):200-3.

103. Lutgens E, Gorelik L, Daemen MJ, de Muinck ED, Grewal IS, Koteliansky VE, et al. Requirement for CD154 in the progression of atherosclerosis. Nat Med. 1999 Nov;5(11):1313-6.

104. Lutgens E, Cleutjens KB, Heeneman S, Koteliansky VE, Burkly LC, Daemen MJ. Both early and delayed antiCD40L antibody treatment induces a stable plaque phenotype. Proc Natl Acad Sci U S A. 2000 Jun 
20;97(13):7464-9.

105. Kirk AD, Burkly LC, Batty DS, Baumgartner RE, Berning JD, Buchanan K, et al. Treatment with humanized monoclonal antibody against CD154 prevents acute renal allograft rejection in nonhuman primates. Nat Med. 1999 Jun;5(6):686-93.

106. Kenyon NS, Chatzipetrou M, Masetti M, Ranuncoli A, Oliveira M, Wagner JL, et al. Long-term survival and function of intrahepatic islet allografts in rhesus monkeys treated with humanized anti-CD154. Proc Natl Acad Sci U S A. 1999 Jul 6;96(14):8132-7.

107. Kawai T, Andrews D, Colvin RB, Sachs DH, Cosimi AB. Thromboembolic complications after treatment with monoclonal antibody against CD40 ligand. Nat Med. 2000 Feb;6(2):114.

108. Silvian LF, Friedman JE, Strauch K, Cachero TG, Day ES, Qian F, et al. Small molecule inhibition of the TNF family cytokine CD40 ligand through a subunit fracture mechanism. ACS Chem Biol. 2011 Jun 17;6(6):636-47.

109. Lutgens E, Lievens D, Beckers L, Wijnands E, Soehnlein O, Zernecke A, et al. Deficient CD40-TRAF6 signaling in leukocytes prevents atherosclerosis by skewing the immune response toward an antiinflammatory profile. J Exp Med. 2010 Feb 15;207(2):391-404.

110. Chatzigeorgiou A, Seijkens T, Zarzycka B, Engel D, Poggi M, van den Berg S, et al. Blocking CD40-TRAF6 signaling is a therapeutic target in obesity-associated insulin resistance. Proc Natl Acad Sci U S A. 2014 Feb 18;111(7):2686-91.

111. Wang X, Ria M, Kelmenson PM, Eriksson P, Higgins DC, Samnegård A, et al. Positional identification of TNFSF4, encoding OX40 ligand, as a gene that influences atherosclerosis susceptibility. Nat Genet. 2005 Apr;37(4):365-72.

112. Olofsson PS, Söderström LA, Jern C, Sirsjö A, Ria M, Sundler E, et al. Genetic variants of TNFSF4 and risk for carotid artery disease and stroke. J Mol Med. 2009 Apr;87(4):337-46.

113. Van Wanrooij EJA, van Puijvelde GHM, de Vos P, Yagita H, van Berkel TJC, Kuiper J. Interruption of the Tnfrsf4/Tnfsf4 (OX40/OX40L) pathway attenuates atherogenesis in low-density lipoprotein receptor-deficient mice. Arterioscler Thromb Vasc Biol. 2007 Jan;27(1):204-10.

114. Foks AC, van Puijvelde GHM, Bot I, ter Borg MND, Habets KLL, Johnson JL, et al. Interruption of the OX40OX40 ligand pathway in LDL receptor-deficient mice causes regression of atherosclerosis. J Immunol Baltim Md 1950. 2013 Nov 1;191(9):4573-80.

115. Weinberg AD. OX40: targeted immunotherapy--implications for tempering autoimmunity and enhancing vaccines. Trends Immunol. 2002 Feb;23(2):102-9.

116. Kwon B. CD137-CD137 Ligand Interactions in Inflammation. Immune Netw. 2009 Jun;9(3):84-9.

117. Olofsson PS, Söderström LÅ, Wågsäter D, Sheikine Y, Ocaya P, Lang F, et al. CD137 Is Expressed in Human Atherosclerosis and Promotes Development of Plaque Inflammation in Hypercholesterolemic Mice. Circulation. 2008 Nov 3;117(10):1292-301.

118. Jeon HJ, Choi J-H, Jung I-H, Park J-G, Lee M-R, Lee M-N, et al. CD137 (4-1BB) deficiency reduces atherosclerosis in hyperlipidemic mice. Circulation. 2010 Mar 9;121(9):1124-33.

119. Li Y, Yan J, Wu C, Wang Z, Yuan W, Wang D. CD137-CD137L Interaction Regulates Atherosclerosis via Cyclophilin A in Apolipoprotein E-Deficient Mice. PLoS ONE. 2014 Feb 10;9(2):e88563.

120. Dongming L, Zuxun L, Liangjie X, Biao W, Ping Y. Enhanced levels of soluble and membrane-bound CD137 levels in patients with acute coronary syndromes. Clin Chim Acta. 2010 Mar;411(5-6):406-10.

121. Yan J, Wang C, Chen R, Yang H. Clinical implications of elevated serum soluble CD137 levels in patients with acute coronary syndrome. Clinics. 2013;68(2):193-8.

122. Sharpe AH, Freeman GJ. The B7-CD28 superfamily. Nat Rev Immunol. 2002 Feb;2(2):116-26.

123. Afek A, Harats D, Roth A, Keren G, George J. Evidence for the involvement of T cell costimulation through the B-7/CD28 pathway in atherosclerotic plaques from apolipoprotein E knockout mice. Exp Mol Pathol. 2004 Jun;76(3):219-23.

124. Buono C, Pang H, Uchida Y, Libby P, Sharpe AH, Lichtman AH. B7-1/B7-2 costimulation regulates plaque antigen-specific T-cell responses and atherogenesis in low-density lipoprotein receptor-deficient mice. Circulation. 2004 Apr 27;109(16):2009-15.

125. Ait-Oufella H, Salomon BL, Potteaux S, Robertson A-KL, Gourdy P, Zoll J, et al. Natural regulatory T cells control the development of atherosclerosis in mice. Nat Med. 2006 Feb;12(2):178-80.

126. Alegre ML, Frauwirth KA, Thompson CB. T-cell regulation by CD28 and CTLA-4. Nat Rev Immunol. 2001 Dec;1(3):220-8.

127. Ewing MM, Karper JC, Abdul S, de Jong RCM, Peters H a. B, de Vries MR, et al. T-cell co-stimulation by CD28CD80/86 and its negative regulator CTLA-4 strongly influence accelerated atherosclerosis development. Int J Cardiol. 2013 Oct 3;168(3):1965-74.

128. Moreland L, Bate G, Kirkpatrick P. Abatacept. Nat Rev Drug Discov. 2006 Mar;5(3):185-6. 
129. Genovese MC, Becker J-C, Schiff M, Luggen M, Sherrer Y, Kremer J, et al. Abatacept for rheumatoid arthritis refractory to tumor necrosis factor alpha inhibition. N Engl J Med. 2005 Sep 15;353(11):1114-23.

130. Vincenti F, Dritselis A, Kirkpatrick P. Belatacept. Nat Rev Drug Discov. 2011 Sep;10(9):655-6.

131. Wojciechowski D, Vincenti F. Belatacept in kidney transplantation. Curr Opin Organ Transplant. 2012 Dec;17(6):640-7.

132. http://www.medigene.com.

133. Doesch AO, Zhao L, Gleissner CA, Akhavanpoor M, Rohde D, Okuyucu D, et al. Inhibition of B7-1 (CD80) by RhuDex $^{\oplus}$ reduces lipopolysaccharide-mediated inflammation in human atherosclerotic lesions. Drug Des Devel Ther. 2014;8:447-57.

134. Zhang X, Schwartz J-CD, Almo SC, Nathenson SG. Crystal structure of the receptor-binding domain of human B7-2: insights into organization and signaling. Proc Natl Acad Sci U S A. 2003 Mar 4;100(5):2586-91.

135. Schwartz JC, Zhang X, Fedorov AA, Nathenson SG, Almo SC. Structural basis for co-stimulation by the human CTLA-4/B7-2 complex. Nature. 2001 Mar 29;410(6828):604-8.

136. Sugamura K, Ishii N, Weinberg AD. Therapeutic targeting of the effector T-cell co-stimulatory molecule OX40. Nat Rev Immunol. 2004 Jun;4(6):420-31.

137. Compaan DM, Hymowitz SG. The crystal structure of the costimulatory OX40-OX40L complex. Struct Lond Engl 1993. 2006 Aug;14(8):1321-30.

138. Peters AL, Stunz LL, Bishop GA. CD40 and autoimmunity: The dark side of a great activator. Semin Immunol. 2009 Oct;21(5):293-300.

139. Liossis S-NC, Sfikakis PP. Costimulation blockade in the treatment of rheumatic diseases. BioDrugs. 2004;18(2):95-102.

140. Kanmaz T, Fechner JJH, Torrealba J, Kim HT, Dong Y, Oberley TD, et al. Monotherapy with the novel human anti-CD154 monoclonal antibody ABI793 in rhesus monkey renal transplantation model. Transplantation. 2004 Mar 27;77(6):914-20.

141. Kasran A, Boon L, Wortel CH, Hogezand RA, Schreiber S, Goldin E, et al. Safety and tolerability of antagonist anti-human CD40 Mab ch5D12 in patients with moderate to severe Crohn's disease. Aliment Pharmacol Ther. 2005 Jul 15;22(2):111-22.

142. Beatty GL, Torigian DA, Chiorean EG, Saboury B, Brothers A, Alavi A, et al. A phase I study of an agonist CD40 monoclonal antibody (CP-870,893) in combination with gemcitabine in patients with advanced pancreatic ductal adenocarcinoma. Clin Cancer Res. 2013 Nov 15;19(22):6286-95.

143. Hassan SB, Sørensen JF, Olsen BN, Pedersen AE. Anti-CD40-mediated cancer immunotherapy: an update of recent and ongoing clinical trials. Immunopharmacol Immunotoxicol. 2014 Apr;36(2):96-104.

144. De Vos S, Forero-Torres A, Ansell SM, Kahl B, Cheson BD, Bartlett NL, et al. A phase II study of dacetuzumab (SGN-40) in patients with relapsed diffuse large B-cell lymphoma (DLBCL) and correlative analyses of patientspecific factors. J Hematol OncolJ Hematol Oncol. 2014;7(1):44.

145. https://clinicaltrials.gov/ct2/show/NCT01103635?intr=CP-870\%2C893\&rank=2.

146. Byrd JC, Kipps TJ, Flinn IW, Cooper M, Odenike O, Bendiske J, et al. Phase I study of the anti-CD40 humanized monoclonal antibody lucatumumab (HCD122) in relapsed chronic lymphocytic leukemia. Leuk Lymphoma. 2012 Nov;53(11):2136-42.

147. Bensinger W, Maziarz RT, Jagannath S, Spencer A, Durrant S, Becker PS, et al. A phase 1 study of lucatumumab, a fully human anti-CD40 antagonist monoclonal antibody administered intravenously to patients with relapsed or refractory multiple myeloma. Br J Haematol. 2012 Oct;159(1):58-66.

148. Fanale M, Assouline S, Kuruvilla J, Solal-Céligny P, Heo DS, Verhoef G, et al. Phase IA/II, multicentre, openlabel study of the CD40 antagonistic monoclonal antibody lucatumumab in adult patients with advanced nonHodgkin or Hodgkin lymphoma. Br J Haematol. 2014 Jan;164(2):258-65.

149. https://clinicaltrials.gov/ct2/show/NCT01561911?intr=ChiLob+7\%2F4\&rank=1.

150. Raab CP. Passive immunization. Prim Care. 2011 Dec;38(4):681-91, viii.

151. Hansson GK, Nilsson J. Vaccination against atherosclerosis? Induction of atheroprotective immunity. Semin Immunopathol. 2009 Jun;31(1):95-101.

152. Orange JS, Hossny EM, Weiler CR, Ballow M, Berger M, Bonilla FA, et al. Use of intravenous immunoglobulin in human disease: A review of evidence by members of the Primary Immunodeficiency Committee of the American Academy of Allergy, Asthma and Immunology. J Allergy Clin Immunol. 2006 Apr;117(4, Supplement):S525-53.

153. Nicoletti A, Kaveri S, Caligiuri G, Bariéty J, Hansson GK. Immunoglobulin treatment reduces atherosclerosis in apo E knockout mice. J Clin Invest. 1998 Sep 1;102(5):910-8.

154. Schiopu A, Bengtsson J, Söderberg I, Janciauskiene S, Lindgren S, Ares MPS, et al. Recombinant human antibodies against aldehyde-modified apolipoprotein B-100 peptide sequences inhibit atherosclerosis. 
Circulation. 2004 Oct 5;110(14):2047-52.

155. Schiopu A, Frendéus B, Jansson B, Söderberg I, Ljungcrantz I, Araya Z, et al. Recombinant antibodies to an oxidized low-density lipoprotein epitope induce rapid regression of atherosclerosis in apobec-1(-/-)/lowdensity lipoprotein receptor(-/-) mice. J Am Coll Cardiol. 2007 Dec 11;50(24):2313-8.

156. http://www.clinicaltrials.gov/ct2/show/NCT01258907.

157. Hermansson A, Johansson DK, Ketelhuth DFJ, Andersson J, Zhou X, Hansson GK. Immunotherapy with tolerogenic apolipoprotein B-100-loaded dendritic cells attenuates atherosclerosis in hypercholesterolemic mice. Circulation. 2011 Mar 15;123(10):1083-91.

158. Hermansson A, Ketelhuth DFJ, Strodthoff D, Wurm M, Hansson EM, Nicoletti A, et al. Inhibition of T cell response to native low-density lipoprotein reduces atherosclerosis. J Exp Med. 2010 May 10;207(5):1081-93.

159. Fredrikson GN, Söderberg I, Lindholm M, Dimayuga P, Chyu K-Y, Shah PK, et al. Inhibition of atherosclerosis in apoE-null mice by immunization with apoB-100 peptide sequences. Arterioscler Thromb Vasc Biol. 2003 May 1;23(5):879-84.

160. http://www.cardiovax.com.

161. Nilsson J, Fredrikson GN, Björkbacka H, Chyu K-Y, Shah PK. Vaccines modulating lipoprotein autoimmunity as a possible future therapy for cardiovascular disease. J Intern Med. 2009 Sep;266(3):221-31.

162. Binder CJ, Hörkkö S, Dewan A, Chang M-K, Kieu EP, Goodyear CS, et al. Pneumococcal vaccination decreases atherosclerotic lesion formation: molecular mimicry between Streptococcus pneumoniae and oxidized LDL. Nat Med. 2003 Jun;9(6):736-43.

163. Damoiseaux J, Rijkers G, Tervaert JWC. Pneumococcal vaccination does not increase circulating levels of IgM antibodies to oxidized LDL in humans and therefore precludes an anti-atherogenic effect. Atherosclerosis. 2007 Jan 1;190(1):10-1.

164. Suthers B, Hansbro P, Thambar S, McEvoy M, Peel R, Attia J. Pneumococcal vaccination may induce antioxidized low-density lipoprotein antibodies that have potentially protective effects against cardiovascular disease. Vaccine. 2012 Jun 8;30(27):3983-5.

165. Xu Q. Role of Heat Shock Proteins in Atherosclerosis. Arterioscler Thromb Vasc Biol. 2002 Jan 10;22(10):154759.

166. Xu Q, Dietrich H, Steiner HJ, Gown AM, Schoel B, Mikuz G, et al. Induction of arteriosclerosis in normocholesterolemic rabbits by immunization with heat shock protein 65. Arterioscler Thromb. 1992 Jul;12(7):789-99.

167. Maron R, Sukhova G, Faria A-M, Hoffmann E, Mach F, Libby P, et al. Mucosal administration of heat shock protein-65 decreases atherosclerosis and inflammation in aortic arch of low-density lipoprotein receptordeficient mice. Circulation. 2002 Sep 24;106(13):1708-15.

168. Xiong Q, Li J, Jin L, Liu J, Li T. Nasal immunization with heat shock protein 65 attenuates atherosclerosis and reduces serum lipids in cholesterol-fed wild-type rabbits probably through different mechanisms. Immunol Lett. 2009 Jun 30;125(1):40-5.

169. Klingenberg R, Ketelhuth DFJ, Strodthoff D, Gregori S, Hansson GK. Subcutaneous immunization with heat shock protein-65 reduces atherosclerosis in Apoe ${ }^{-{ }^{-}}$mice. Immunobiology. 2012 May;217(5):540-7.

170. Haanstra KG, Endell J, Estévâo D, Kondova I, Jonker M. Blocking T cell co-stimulation using a CD80 blocking small molecule reduces delayed type hypersensitivity responses in rhesus monkeys. Clin Exp Immunol. 2009 Oct;158(1):91-8.

171. https:/clinicaltrials.gov/ct2/show/NCT00516217?term=Galiximab\&rank=6.

172. Ström A, Fredrikson GN, Schiopu A, Ljungcrantz I, Söderberg I, Jansson B, et al. Inhibition of injury-induced arterial remodelling and carotid atherosclerosis by recombinant human antibodies against aldehyde-modified apoB-100. Atherosclerosis. 2007 Feb;190(2):298-305.

173. De Jager SCA, Kuiper J. Vaccination strategies in atherosclerosis. Thromb Haemost. 2011 Nov;106(5):796-803.

174. Duivenvoorden R, Tang J, Cormode DP, Mieszawska AJ, Izquierdo-Garcia D, Ozcan C, et al. A statin-loaded reconstituted high-density lipoprotein nanoparticle inhibits atherosclerotic plaque inflammation. Nat Commun. 2014;5:3065.

175. Vaughan CJ, Gotto AM, Basson CT. The evolving role of statins in the management of atherosclerosis. J Am Coll Cardiol. 2000 Jan;35(1):1-10.

176. Catapano AL, Farnier M, Foody JM, Toth PP, Tomassini JE, Brudi P, et al. Combination therapy in dyslipidemia: Where are we now? Atherosclerosis. 2014 Sep 30;237(1):319-35.

177. Van Diepen JA, Berbée JFP, Havekes LM, Rensen PCN. Interactions between inflammation and lipid metabolism: relevance for efficacy of anti-inflammatory drugs in the treatment of atherosclerosis. Atherosclerosis. 2013 Jun;228(2):306-15. 


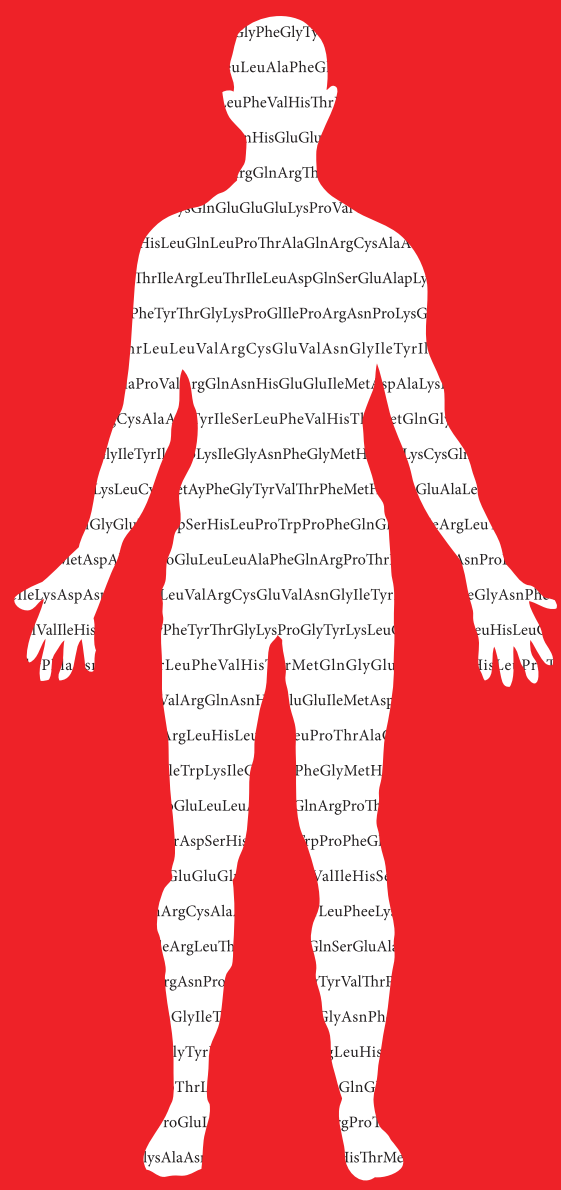




\section{Chapter}

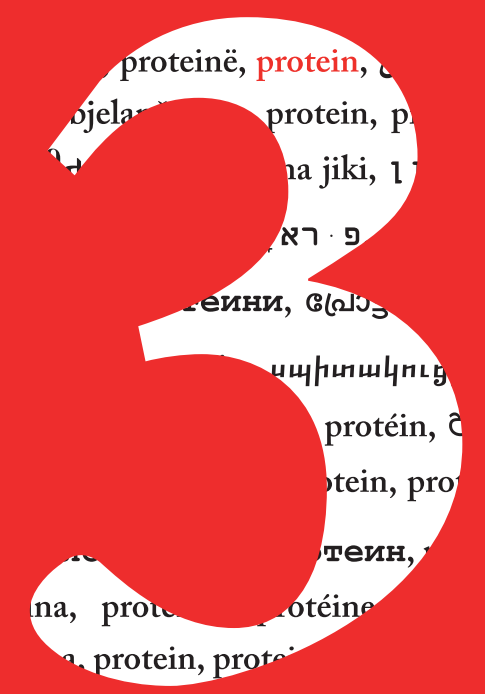

\section{Stabilization of protein - protein interaction complexes through small molecules}

B. Zarzycka, M.A. Kuenemann, G.A.F. Nicolaes, M. Miteva, G. Vriend, O. Sperandio Submitted to Drug Discovery Today 


\begin{abstract}
The human interactome has been estimated to contain around 650,000 (1) protein - protein. Stabilization of protein- protein interactions (PPIs) by small molecule binding is a promising way to interfere with many important biological processes. Many inhibitors of PPIs have been described, while literature on PPI stabilizers is still scarce. We review a series of small molecule binding studies in which the biological role of PPIs were successfully stimulated or inhibited. We suggest a scheme for the classification of PPI stabilizers based on their mode of binding and the architecture of the complex.
\end{abstract}




\section{Introduction}

The human interactome has been estimated to contain around 650,000 (1) protein - protein interactions, of which only few PPIs have been used as targets for drug design. The human interactome thus provides a huge potential for innovative therapeutic interventions. Most small molecule medicines are so-called orthosteric binders, i.e., they bind in or near to the active site of the molecule for which function modulation is desired. In the past decade small molecule medicines also have been developed that function allosterically, i.e., they bind at a distance from the active site but nevertheless modulate its function. PPIs can be modulated in many different ways, and the complexity of the thermodynamics of this interaction makes it complicated to describe them uniquely in terms of orthosteric and allosteric binding. Whereas the identification of small molecule inhibitors of PPIs has witnessed an impressive number of success stories (e.g. (2-4) and references therein), literature on PPI stabilizers is still rare.

Recent literature brought the possibility to our attention to stabilize PPIs through binding of small molecules, peptides, or proteins (5). A general strategy for the medicinal use of small molecules to modulate the biological function of PPIs through Stabilization rather than through interference, though, is still lacking.

In the literature, compounds are often described as inducing or inhibiting multimer formation. Thermodynamically speaking, it would be more precise to actually describe the process as stabilizing (by the law of mass action) the dimers so much that they become observable by biophysical techniques while their multimer concentration remains below the detection limit

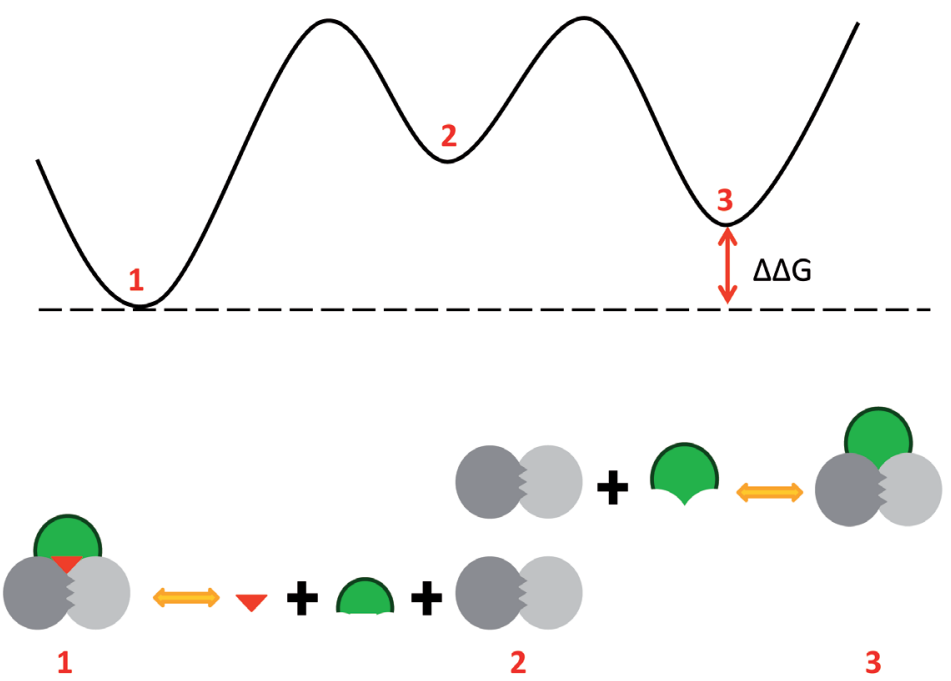

Figure 1. State diagram for a trimeric complex in the presence and absence of a PPI modulator. The grey dimer (2) can bind to the green molecule in the presence (1) or absence (3) of the small red PPI modulator. The $\Delta \Delta \mathrm{G}$ of binding the small red modulator is indicated. This figure illustrates the thermodynamic concept that binding always leads to stabilization. For this hypothetical case that means that in the presence of the small red modulator there will be more trimer present than in its absence. 
in the absence of the compound. Figure 1 shows the state function for the hypothetical formation of a protein trimer in the presence and absence of a PPI modulator.

Interference with a PPI interface has several advantages over classical drug design in which a small molecule binds to one target protein. Small molecule PPI stabilizers often do not need to bind in the low nanomolar range to elicit physiological response (6); Jasmonate compounds, for example, elicit a biological response despite binding only in the micromolar range (7) (table 1). PPIs display greater sequence diversity than enzyme active sites, and therefore it is easier to obtain high specificity for PPI stabilizers than for enzyme ligands (6). A study of rimexposed PPI cavities revealed that they are physico-chemically highly similar to cavities observed in classical drug design targets (8). We believe, additionally, that stabilizers of PPIs often will require no more than binding a small molecule anywhere (but the active site) at the exposed rim between the PPI partner proteins, and this seems considerably easier to achieve than binding the right molecule at the one single right position.

Inhibiting the formation of a protein complex by binding a small molecule to one of the partners at the prospective protein - protein interface is beyond the scope of this review.

Given the advantages of therapeutic intervention by PPI stabilizers, it is not surprising that we observe a growing interest in PPI stabilizing compounds - both natural and synthetic that are identified through various techniques including virtual ligand screening (VLS), and high throughput screening (HTS). In this review, we describe several targets for which such compounds have been identified. We will discuss their modulation mechanisms, the associated pathologies, techniques used for their discovery, and the architecture of the resulting PPImodulator complexes. We use this information to suggest a conceptual scheme for the classification of stabilized PPI complexes that can be used as a decision support tool to assist bioscientists working on the structure-based design of PPI stabilizers. In classical drug design, input from many different disciplines is needed to prioritise the questions that need to be addressed along the path towards marketing a successful medicine. We hope that this decision tree might help to prioritize questions that have to be addressed when designing PPI stabilizers.

\section{Description of PPI modulator complexes}

PPI complexes can be heteromers, homomers, or quasi homomers. Quasi homomers are multimers consisting of homologous monomers in which the individual proteins perform identical or highly similar functions, like MDM2/MDMX (9), or c-Myc/Max (9). So far, all heteromers and quasi homomers observed actually were dimers, while the homomers were also observed with higher protein copy numbers. Our literature survey of a series of diverse PPI targets that were successfully stabilized through the binding of small molecules revealed several strong trends in the mode of binding of those small molecules and in the global architecture of the resulting complexes. Indeed, the majority of PPI complexes can be described well using simple descriptors. The main descriptor is the symmetry relation between the associated protein partners. Homomers are mostly $n$-fold symmetric where $n$ is the copy 
number of the monomer in the complex. The second descriptor is the location of the cavity in which stabilizers can bind. Two types of locations were observed. Peripheral cavities are located at, or in the direct vicinity of the interface, are solvent exposed, and often are formed by two of the monomers in the complex, while enclosed cavities are completely buried in the core of the PPI complex. The stoichiometry of the stabilizer - PPI complex is not used as descriptor because of its unpredictability. For a significant number of complexes more than one copy of a given stabilizer was found to bind to the protein complex. This was observed mostly in homomers and quasi homomers. These two descriptors for stabilized PPI complexes combined with structural data (X-ray crystallography, NMR) naturally lead to a classification of all PPI stabilizers that exert their stabilizing effect through binding at or very near to the PPI interface.

Figure 2 summarizes the six PPI-stabilizer classes and sub-classes that result from the analysis of all sixteen PPI complexes with known three-dimensional structure using the aforementioned descriptors. Class A stabilizers are associated with heteromer complexes. Class B stabilizers are associated with homomers and quasi homomers. Class $\mathrm{M}$ stabilizers are oligomers of more than two monomers. Subclasses 1 and 2 relate to the cavity type being either peripheral or enclosed.
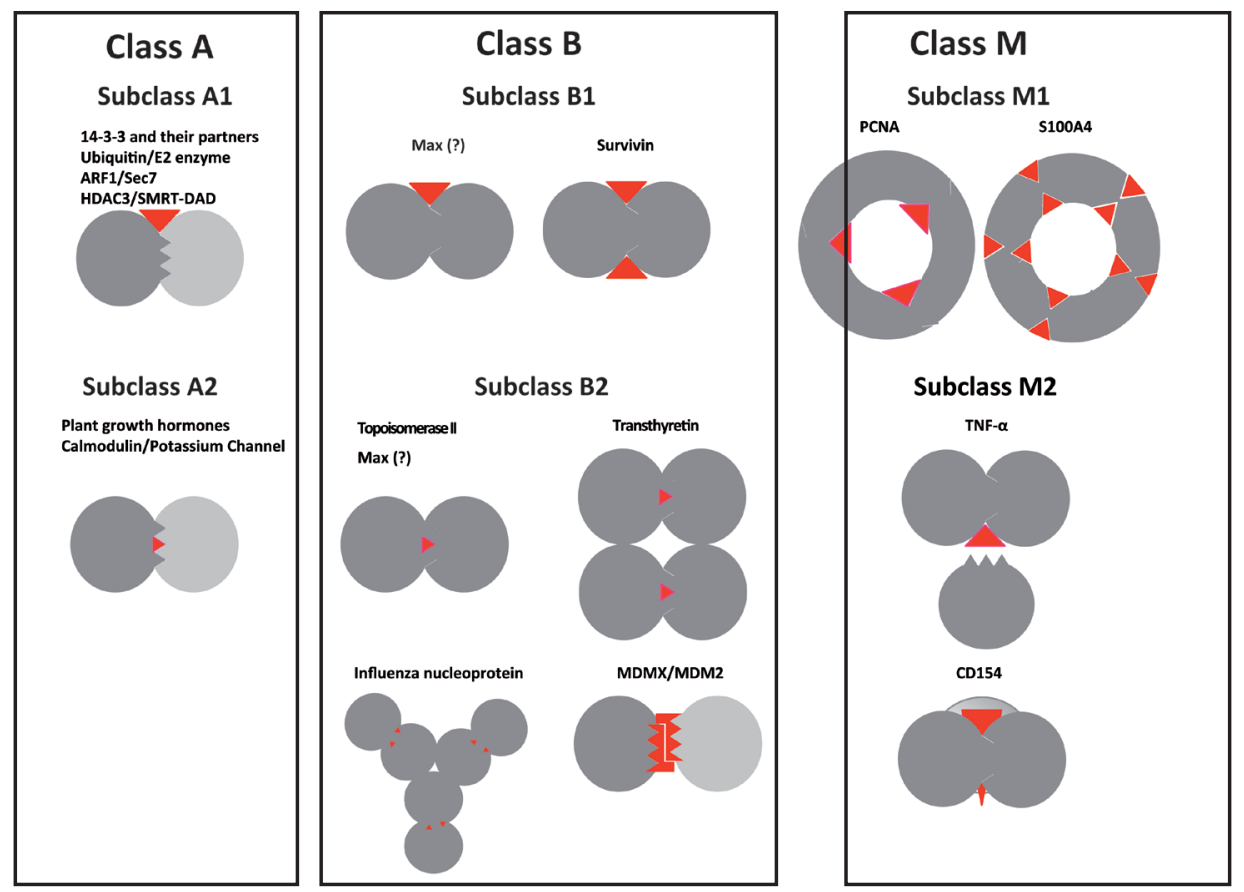

Figure 2. Schematic representation of classes of stabilizer - PPI complexes. Class A stabilizers bind to heterodimers. Class B compounds binds to homodimers or quasi homodimer. Class M stabilizers binds to homo-oligomers with more than two partners. Subclasses 1 and 2 describe the type of binding cavity that can be peripheral or enclosed, respectively. Proteins are in grey and small molecules are in red. The exceptional transthyretin dimer of dimers and influenza nucleoprotein trimer of dimers are explained in the text. 


\section{Class A - Heterodimers}

At the time of this study, four complexes fell in Class A1 (the 14-3-3 proteins with four different partners, Ubiquitin/E2 ubiquitin conjugating enzyme, ARF1/Sec7, and HDAC3/ SMRT-DAD complexes) and two in Class A2 (the plant growth hormones and SK2-CaM). With four complexes, the 14-3-3 family was the largest of all families studied.

\section{Subclass A1}

\section{4-3-3 protein complexes}

14-3-3 proteins are a family of highly conserved adaptor proteins that bind a vast number of different regulatory proteins involved in apoptosis, cell cycle regulation, and signal transduction (10). The complex of 14-3-3 and plant plasma membrane ATPase 2 (PMA2) is stabilized by natural products such as Fusicoccin (FC) and CotyleninA (CoA). These compounds that activate the proton pump which opens a plant's gas exchange stomatal pores and lead to plant wilting $(11,12)$ are hard to synthesize in the lab. A VLS campaign has been used to find synthetically more accessible herbicides. This work resulted in two compounds: epibestatin and pyrrolinone1 (13). Pyrrolinonel subsequently served as a template for structure-based optimization that resulted in a compound with improved activity (compound 37; table 1) (14). The 14-3-3/C-RAF complex can, just as the PMA2/14-3-3 complex, be stabilized by CoA. This complex binds to the inhibitory site of RAF thereby inhibiting proproliferation by the Ras-RAF-MEK-ERK pathway (15). Treatment with CoA in combination with an anti-EGFR antibody suppresses both in vitro and in vivo tumour growth (15). The 14-3-3/ERa complex plays an important role in the proliferation of breast cancer cells (16). FC inhibits interaction of ER $\alpha$ with chromatin, which leads to inhibition of gene expression resulting in a significant inhibition of cell proliferation (16). The last example of a protein that can form a complex with 14-3-3 is potassium channel TASK-3. TASK-3 is expressed in neurons and other cell types that play a role in membrane protein trafficking (17). TASK-3 recruits 14-3-3 via a mode-III binding motif located at the C-terminus of TASK-3 (18). This complex increases expression of TASK-3 channels (18). FC and its derivatives (table 1) increase the stability of the TASK-3/14-3-3 complex (17). One of the derivatives, FC-THC is selective for the mode-III motif and increases stability of the 14-3-3/TASK-3 complex by approximately 18 fold. FC-THC increased TASK-3 channel expression in an in vitro surface expression experiment (17).

Analysis of X-ray crystal structures revealed that the small molecules that interact with 14-33 complexes are located in binding pockets created at the interface of the 14-3-3 protein and its binding partner $(13-15,17,19)$. Although most of the binding energy comes from interactions with the 14-3-3 protein, the small molecule cannot bind without the partner protein (PM2, TASK-3, or ER $\alpha$ ) being present. Rose et al (13) indicated that these pockets can be very large and can be divided into subpockets, and they can accommodate chemically very 
diverse compounds. Based on the architecture of the complexes and the type of cavity to which the 14-3-3 stabilizers can bind, we place this target in class A1. Importantly, stabilization of 14-3-3 protein complexes can lead to either an increase or a decrease of function.

\section{Ubiquitin/E2 ubiquitin conjugating enzyme}

Ubiquitin is a regulatory protein that is involved in endocytic trafficking, inflammation, and DNA repair (20). It is responsible for protein degradation via the ubiquitin-proteasome system (UPS). In the proteasome, ubiquitin is covalently conjugated to a lysine residue of its substrate by E1, E2, and E3 enzymes, subsequently. The ubiquitin activating enzyme (E1) activates the ubiquitin and creates a thioester which transfers it to the catalytic cysteine of ubiquitin-conjugating enzyme - E2 that forms the ubiquitin thioester and interacts with ubiquitin ligase - E3 that, in turn, conjugates ubiquitin to the substrate. Alterations in UPS lead to dysregulation of cellular homeostasis and results in diseases such as cancer, inflammation, or autoimmune disorders (20). CC0651 (table 1) was discovered as an allosteric inhibitor of Cdc34A that inhibits the proliferation of human cancer cell lines (21). The X-ray crystal structure of the ubiquitin- Cdc34A-CC0651 complex revealed that CC0651 binds to the solvent exposed pocket created at the ubiquitin-Cdc34A interface, stabilizes this weak interaction, and inhibits UPS activity (22). This complex therefore belongs in class A1. Stabilization of the ubiquitin-Cdc34A complex reduces ubiquitin activity.

\section{ARF1/Sec7}

The ADP-ribosylation factor 1 (ARF1) is a member of the Ras superfamily of GTP-binding proteins. ARF1 is activated by ARF nucleotide-binding site opener (ARNO), which is a specific guanine nucleotide exchange factors (GEFs). The ARNO catalytic domain, Sec7, catalyses nucleotide exchange on ARF1 and recruits proteins to the membrane of the Golgi apparatus (23). ARF1 plays a pivotal role in the regulation of cellular trafficking in fundamental biological processes such as endocytosis, cytokinesis, cell adhesion, and tumour-cell invasion (24). Brefeldin A (BFA) is a macrocycle produced by the fungus Eupenicillium brefeldianum. It stabilizes ARF1/Sec7 complex formation, deactivates ARF1, and inhibits protein secretion (25). The ARF1/Sec7 complex can also be stabilized by the small drug-like molecule LM11 (table 1). LM11 was discovered in a VLS campaign. It inhibits the GDP/GTP exchange activity of ARF1 and thereby impedes cellular trafficking.

The X-ray structure of the BFA-ARF1/Sec7 complex revealed that BFA binds to a solvent exposed pocket at the ARF1/Sec7 interface. An NMR and mutagenesis study showed that LM11 binds to the same cavity as BFA (25). These two complexes belong in class A1. Both BFA and LM11 reduce the ARF1-dependent cellular trafficking.

\section{HDAC3/SMRT-DAD}

HDAC3 is a member of one of four histone deacetylases (HDACs) classes. These enzymes play key roles in the regulation of gene expression in eukaryotic cells. HDAC3 recruits the 
co-repressor protein SMRT and creates a complex with the deacetylase activation domain (DAD) of SMRT (26). Watson et al. discovered that $\operatorname{Ins}(1,4,5,6) \mathrm{P}_{4}$ (table 1$)$ is involved in activation of HDAC3 (27).

The X-ray structure of the HDAC3-SMRT-DAD-Ins $(1,4,5,6) \mathrm{P}_{4}$ complex revealed that this small molecule binds to the solvent exposed cavity at the interface of HDAC3 and SMRTDAD. It binds between the monomers where it prevents electrostatic repulsion (27). Based on the structural information we placed this complex in class $\mathrm{A} 1$. The $\operatorname{Ins}(1,4,5,6) \mathrm{P}_{4}$ activates HDAC3, which results in repression of gene expression.

\section{Subclass A2}

\section{Plant growth hormones}

Phytohormones regulate growth and development of plants by modulation of gene expression involved in developmental processes (28). The identification of receptors for the phytohormones auxin, jasmonate (JA), and brassinolide (BL) led to the discovery of their signalling mechanisms, and their role in ubiquitination $(7,29,30)$. Binding of Auxin, JA, or BL to their receptors transport inhibitor response 1 (TIR1), coronatine-insensitive 1 (COI1), and brassinosteroid insensitive 1 (BRI1), respectively, causes recruitment of the corresponding degradation substrates: auxin-indoleacetic acid (AUX-IAA), JA-ZIM domain (JAZ), and somatic embryogenesis receptor kinase (SERK), respectively. These activated receptor complexes trigger downstream events that lead to substrate degradation $(7,29,30)$. The coronatine-insensitive 1 receptor, surprisingly, also binds coronatine, a phytotoxin produced by Pseudomonas syringae, which is chemically similar to JA isoforms, can also elicit Jasmonate signalling (7).

The X-ray structures of the COI1-JAZ-JA, TIR1-AUX-IAA-Auxin, and BRI1-SERK-BL complexes revealed that compounds bind in hydrophobic pockets that get enclosed by binding of the degradation substrates $(7,29,30)$. These phytohormone stabilizers were therefore placed in class A2. The stabilization of the receptor-degradation protein complexes by hormone binding activates phytohormone signalling.

\section{SK2-CaM}

Small conductance $\mathrm{Ca}^{2+}$-activated potassium channel 2 (SK2) plays an important role in the regulation of membrane excitability (31). SK2 is activated by the binding of $\mathrm{Ca}^{2+}$-bound Calmodulin (CaM) to its Calmodulin Binding Domain (CaMBD) (31). The SK2-CaM complex activates the channel opening that plays a role in the function of cardiovascular and central nervous systems (31). Dysfunction of this potassium channel can lead to diseases such as atrial fibrillation (32) and several neurological disorders (33). The small molecules 1-EBIO and PHU (table 1) stabilize the SK2-CaM complex (34) and thus increase channel opening. 1-EBIO and PHU due to the low potency and lack of selectivity were further optimized resulting in the compounds NS309, CyPPA, and DCEBIO, that are now commonly used for 
SK2 channel activity modulation (34).

Inspection of the X-ray structures of the SK2-CaM-PHU and SK2-CaM-NS309 complexes revealed that compounds bind to the druggable pocket at the interface of SK2 and CaM (34, 35). Since these compounds are located in an enclosed pocket at the SK2-CaM interface, they belong in class A2. Stabilization of the SK2-CaM complex results in an increase of the SK2 channel activity and decreases the neuronal excitability.

\section{Class B - homodimers}

At the time of this study, one complex fell in Class B1 (Survivin) and four complexes in Class A2 (Topoisomerase II, Transthyretin, Influenza nucleoprotein, and MDMX/MDM2). The Max homodimer belongs in class B, but lacking any structural data it is not possible to decide in which sub-class it belongs.

\section{Subclass B1}

\section{Survivin homodimer}

Survivin is a member of the inhibitor of apoptosis proteins (IAP) family that is overexpressed in the majority of human cancers. It is either present as a homodimer or in complex with Borealin and INCENP to create the chromosomal passenger complex CPC (36). The survivin homodimer has two distant modulator binding sites: the site located in the BIR domain is recognized by the Smac-peptide, while the endogenous ligand for the site located at the dimerization interface is not yet known. Abbott Laboratories used HTS-NMR and AM/MS assays and discovered the small molecule Abbott8 (table 1) that binds near the dimerization interface (37).

The NMR structure revealed that Abbott8 interacts with both monomers. The stoichiometry of the Abbott8 - survivin monomer is 1:1, indicating that the compound is present twice at the homodimer interface. This target belongs in class B1. The functional role of homodimer stabilization is still unknown (38) and it is equally unclear whether Abbott8 leads to inhibition or activation of any biological function.

\section{Subclass B2}

\section{Topoisomerase II homodimer}

Topoisomerase II cuts double-stranded DNA in an ATP-dependent manner (39). It is a wellknown target for anticancer therapy. One of the drugs approved for the treatment of cancer is ICRF-187 (table 1) (40) that inhibits the catalytic activity of topoisomerase II by homodimer stabilization (41).

The X-ray structure of the topoisomerase homodimer - ICRF-187 complex revealed that each monomer of topoisomerase II has a cavity that accommodates one of the two piperazinedione rings of the compound. ICRF-187 is bound in an enclosed cavity between the two monomers (42). Topoisomerase II thus belongs in class B2. Stabilization of this homodimer results in a reduction of topoisomerase II activity, and cancer cells proliferation. 


\section{Transthyretin}

Transthyretin (TTR) is secreted from the liver into the blood stream where it binds, and transports thyroxine (T4) and vitamin A (43). Mutations in TTR decrease its stability leading to monomer misfolding and aggregation that may cause amyloid diseases (44). Tafamidis is an approved medicine. This small molecule stabilizes TTR by binding selectively to two T4 binding sites in the TTR tetramer that is better described as a dimer of dimers.

The X-ray structures of wild-type TTR and the V122I mutant in complex with tafamidis suggest that the tetramer is stabilized by preventing the dissociation of the weaker binding dimer-dimer interface. For this reason, and because each compound is buried in an enclosed pocket created by a TTR dimer (45), TTR belongs in class B2. Stabilization of TTR results in reduction of misfolding. TTR was tested in a clinical trial for the treatment of Transthyretin Type Familial Amyloid Polyneuropathy (TTR-FAP) and decreased progression of disease in patients with the V30M TTR mutation (45).

\section{Influenza nucleoprotein}

The influenza nucleoprotein (NP) is a major component of the viral ribonucleoprotein complex and plays a crucial role in viral replication. It is a well-known target for anti-viral therapies (46). The NP inhibitors listed in table 1 that were discovered via an in vitro polymerase assay stabilize the NP oligomer and inhibit viral replication (47).

The X-ray structure of NP co-crystalized with compound 3 revealed that NP is present as hexamer with inhibitor molecules binding to two distinct druggable enclosed pockets located at each of the three homodimer interfaces (47). Based on this structural information NP belongs in class B2. Stabilization of NP oligomers results in reduction of viral replication.

\section{MDMX/MDM2}

MDMX and MDM2 are down regulators of $\mathrm{p} 53$. They are frequently overexpressed in tumours with intact p53 and therefore are good anti-tumour targets. Inhibition of binding to p53 of both MDM2 and MDMX thus seems a good strategy to bring the tumour suppressive function of p53 back to healthy levels (48). RO-2443 (table 1) was discovered in a HTS tumour suppressant screen. Its chemical optimization resulted in an analogue with improved solubility and slightly better potency (RO-5963; table 1). In cellular assays, RO-5963 increased apoptosis of MDMX overexpressing breast cancer cells (49).

$\mathrm{X}$-ray structures have been determined for RO-2443 in complex with MDM2 and MDMX homodimers, respectively. RO-2443 binds to the p53 binding pockets of these dimers. In both protein dimers the core contains a large pocket that facilitates binding of two copies of RO2443 that symmetrically interact with both monomers and with each other through extensive $\pi-\pi$ stacking interaction of the indolyl hydantoin groups. The X-ray structure was solved only for the two homodimers, but modelling studies (49) suggest that RO-2443 will bind equally well to the MDMX/MDM2 quasi dimer. Since the enclosed binding pocket is located between 
the monomers MDMX/MDM2 belongs in class B2. Stabilization of the dimer leads to reduction of binding to $\mathrm{p} 53$ and thus to activation of p53's tumour suppressor activity, which results in inhibition of cancer cell growth.

\section{Subclass unknown}

\section{Max homodimer}

Max is an activation partner in the c-Myc-Max pathway, which is overactive in Burkitt's lymphoma, neuroblastoma, breast-, pancreatic-, and lung-cancers (50). One of the strategies to down-regulate the c-Myc-Max pathway is to disrupt the c-Myc-Max complex by binding a small molecule to one of the protein partners (51). Another strategy is to stabilize the Max homodimer, which reduces the amount of Max available for c-Myc activation by c-Myc-Max formation. Compounds stabilizing Max/Max interactions were found via VLS. NSC13728 (table 1), for example, stabilizes Max/Max homodimers, and thus downregulates the c-Myc-Max pathway (52).

There is no X-ray or NMR structure data available for the Max/Max-NSC13728 complex. However, the competitive inhibition experiment with Myc protein suggests that the compound binds Max at its Myc interface. Max is therefore placed in class B. Without further information we cannot yet decide whether it should be subclass 1 or 2. Max homodimer stabilization leads to inhibition of the c-Myc-Max pathway which results in inhibition of DNA-binding, transcriptional activation, and oncogenic transformation.

\section{Class M - oligomers}

Class $\mathrm{M}$ holds at this moment only homotrimers and homopentamers. It seems likely that in due time also other multimeric states will be discovered. Two examples exist for both subclasses, M1 and M2. The two examples found for subclass M2 exhibit rather different ligand binding modes. Altogether, it seems that Class $\mathrm{M}$ is most likely to grow beyond two subclasses in the near future.

\section{Subclass M1}

\section{PCNA homotrimer}

Proliferating cell nuclear antigen (PCNA) regulates DNA replication and plays a pivotal role in diverse cellular processes, including cell proliferation. Functional PCNA is present as a ring-shaped homotrimer in complex with chromatin (53). A druggable pocket has been predicted at the monomer interfaces and PCNA inhibitors have been discovered in VLS study (54). PCNA-I1 selectively binds to PCNA and promotes formation of a stable trimer. PCNA stabilization leads to a reduction of binding to chromatin, which results in inhibition of cancer cell proliferation presumably because PCNA-I1 reduces chromatin assembly (54).

The structure of the apo PCNA trimer has been solved by X-ray (55), but no structure data are available for PCNA with a bound compound. The druggable pocket can be seen well at the 
monomeric interfaces in the ring-shaped homotrimer, and in figure 2 we show that PCNA-I1 can nicely be docked in these pockets. We therefore placed this PCNA in class M1. Stabilization of PCNA results in inhibition of cancer cell proliferation (54).

\section{S100A4 homopentamer}

S100A4 is involved in regulatory processes such as cell cycle progression and differentiation. It is overexpressed in several diseases such as cancer, rheumatoid arthritis, kidney fibrosis, and cardiac hypertrophy (56). S1004A binding to Myosin-IIA causes its depolymerisation. Trifluoperazine (TFP) (table 1) stabilizes the S100A4 oligomer, which cannot bind to myosinIIA (57).

The X-ray structure of the S100A4-TFP complex reveals that S100A4 creates a ring-shaped homopentamer with two druggable pockets at each of the five dimer interfaces. TFP is observed in each pocket. Since TFP binds to peripheral cavities, it belongs in class M1. Stabilization of the S100A4 oligomer results in reduction of depolymerisation of myosin (58), and thus has potential to inhibit biological effect of several human pathologies.

\section{Subclass M2}

\section{CD154 homotrimer}

CD154-CD40 interactions are involved in humoral and cell-mediated immune responses, and play a pivotal role in chronic inflammatory diseases like atherosclerosis, inflammatory bowel disease, and rheumatoid arthritis. CD154 forms a trimer that activates the CD40 signalling pathway upon binding to the trimeric form of the CD40 receptor (59). BIO8898 (table 1) is a small molecule that binds to a non-productive CD154 trimer thereby reducing the amount of CD154 available for CD154-CD40 interactions (60).

The X-ray structure of the CD154 trimer-BIO8898 complex reveals a three-fold symmetric, deep, druggable pocket near the three-fold dyad. Surprisingly, BIO8898 binds to a pocket located mainly between two monomers (figure 3) so that it breaks the 3 -fold symmetry of the CD154 trimer, and thus disrupts binding to its three-fold symmetric receptor (60). Since BIO8898 binds in a cavity that essentially is enclosed, it belongs in class M2. Stabilization of the non-symmetric form of the CD154 homotrimer results reduced availability of the symmetric CD154 trimer needed for CD154-CD40 interaction and thus of the entire CD40 signalling pathway. Follow-up studies will have to reveal the potential of BIO8898 as a medicine for inflammatory diseases.

\section{TNF- $\alpha$ homodimer}

Tumor necrosis factor $\alpha$ (TNF- $\alpha$ ) is a pro-inflammatory cytokine that is expressed in response to acute inflammation. It is involved in inflammatory diseases such as rheumatoid arthritis, inflammatory bowel disease, and psoriatic arthritis. The TNF receptor 1 (TNFR1) signalling pathway gets activated when the TNF- $\alpha$ trimer binds to the receptor (61). He et al. described 
a compound (table 1) that inhibits in vitro TNF-a binding to TNFR1 (62). This compound actually binds to a TNF- $\alpha$ dimer thereby preventing the formation of the biologically active TNF- $\alpha$ trimer.

The X-ray structure of the TNF- $\alpha$ dimer-compound complex reveals that the small molecule binds in a shallow pocket at the dimer surface (figure 3c). The pocket appears peripheral, but the residues that together form the cavity in the dimer structure actually lie in an enclosed cavity in the trimer structure in which the compound presumably does not fit. We place this case in class M2. The dimer stabilization and the concomitant reduction of the trimer concentration leads to the inhibition of the TNF-a signalling pathway, and thus to a reduction of acute inflammation.

\section{Allosteric stabilizers}

The previous three sections discussed examples of orthosteric binding of PPI stabilizers. There are, however, many more mechanisms possible to stabilize multimers. We present two examples of compounds that stabilize PPIs in an allosteric manner (Tubulin; SOD1), and the much more complex situation in nuclear hormone receptors (NR).

\section{Tubulin}

Tubulin is a poly heterodimer consisting of $\alpha$ and $\beta$ chains. It is the major component of the microtubule, a cytoskeletal polymer that regulates a variety of cellular processes including the cell cycle (63). Taxol is a stabilizer of tubulin that is used in the treatment of ovarian-, breast-, and lung-cancer (64). The cryo-electron microscopy structure of the complex of $\alpha \beta$ tubulin dimer with taxol reveals that taxol binds to a peripheral druggable pocket at the $\beta$-chain of the tubulin heterodimer. Taxol allosterically modulates the interdimer interface resulting in stabilization of polymer (65).

\section{SOD1}

Superoxide dismutase-type 1 (SOD1) catalyses the dismutation of superoxide into oxygen and hydrogen peroxide. Familial amyotrophic lateral sclerosis (FALS) is caused by mutations in SOD1 that destabilize the native SOD1 structure and, in vitro, stimulate its aggregation (66). A druggable pocket was predicted at the interface between the two monomers and SOD1 dimer stabilizers (table 1) that were predicted by in silico screening inhibited in vitro aggregation and denaturation of the SOD1 mutant. Ray et al. performed mutagenesis studies to confirm that compounds are indeed binding to the predicted druggable pocket (67). X-ray crystallography, however, later revealed that the compounds bind in a completely different pocket than predicted, therefore, stabilize the SOD1 dimer interface in an allosteric manner (68). This example underlines the crucial importance of experimental structural data in unravelling the binding mode of small molecules, and it holds a stern warning for users of our schema in figure 3. 

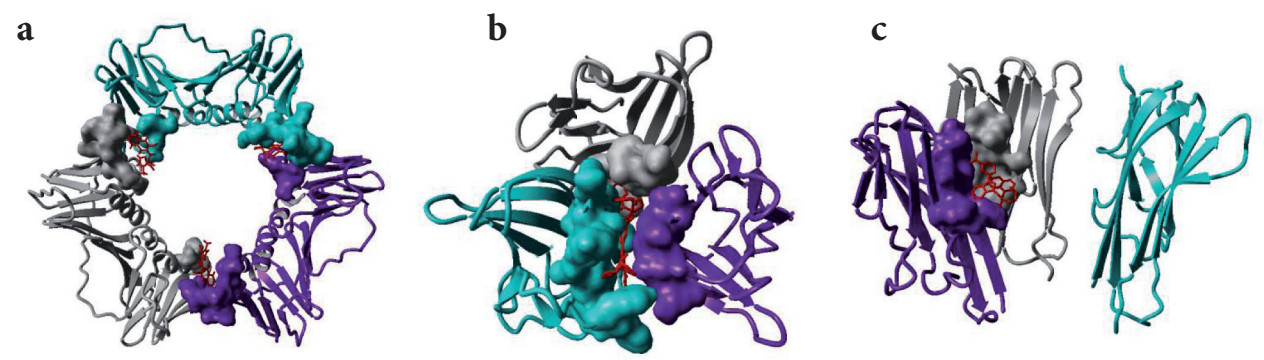

Figure 3. Different ways of stabilizing trimers. (a) PCNA (b) CD154 (c) TNF- $\alpha$. Each monomer is coloured in grey, cyan, and blue. The druggable pocket is shown as a molecular surface coloured according to the associated monomers. The small molecules are coloured red.

\section{Nuclear hormone receptors and co-regulators}

The inhibition and activation of nuclear hormone receptors (NRs) is associated with conformational changes induced by ligand binding and the recruitment of co-activators or co-repressors. Activation of NRs results in down or up-regulation of gene transcription.

NRs have a ligand binding domain (LBD) that can accommodate agonists as well as antagonists. A crucial part of the NRs is a so-called Helix 12 (H12) that is mobile and undergoes conformational changes upon ligand binding (69). Germain et al. discovered an inverse agonist (BMS493) for the retinoic acid receptor (RAR). BMS493 is considered an inverse agonist because it's binding results in inhibition of retinoic gene expression. The X-ray structure of this complex showed that BMS493 binds to the druggable pocket created by RAR and its co-repressor (CoR). In this sense, BMS493 can be considered as a 'normal' PPI modulator. However, inhibition of gene expression is not only the result of stabilization of the RAR-CoR complex. BMS493 binding also prevents the conformational change of $\mathrm{H} 12$ that is responsible for co-activator binding (70). Finally, inverse agonist binding generally exerts allosteric effects on the NR-NR dimer interface (71). Since the inhibition of NR is a result of both complex stabilization and a series of conformational changes, it forms in fact a hybrid of allosteric and orthosteric effects and therefore belongs in neither class exclusively.

\section{Dimerizers}

Inducers of dimerization, aka dimerizers are compounds that can bind to two proteins, utilizing two distinct binding pockets, thereby bringing the proteins in close spatial proximity without necessarily making them form a stable dimer. One example is FK506, a FDA-approved immunosuppressive drug that induces the formation of a FKBP12-Calcineurin complex. This inactivates the function of Calcineurin and inhibits signal transduction in the T-lymphocyte transduction pathway (72). Dimerizers are designed as bivalent compound connected by a linker and bind to two druggable pockets. Their design does not take into account one newly formed druggable pocket, which is why we decided to leave them out of the classification.

\section{Guidelines to design stabilizers using structure-based approaches}


Whereas the design of PPI inhibitors is now well-studied (2-4), the design of PPI stabilizers is still underexploited (6). The design of PPI inhibitors is, conceptually at least, rather straightforward, and Chène (73) presented a simplified and practical decision tree to support this work. The design of PPI stabilizers, on the other hand, is conceptually more complicated due to the presence of a large number of possible solutions as was shown in figure 2 . There is still very little literature on the design of stabilizers, despite several initial attempts to rationally design this type of modulators $(54,74)$, albeit that there were no rules of thumb available yet for this design. Figure 4 shows a simple decision tree that helps with PPIs classification, and thus provides a start for rational stabiliser design. The tree is reminiscent to the one produced

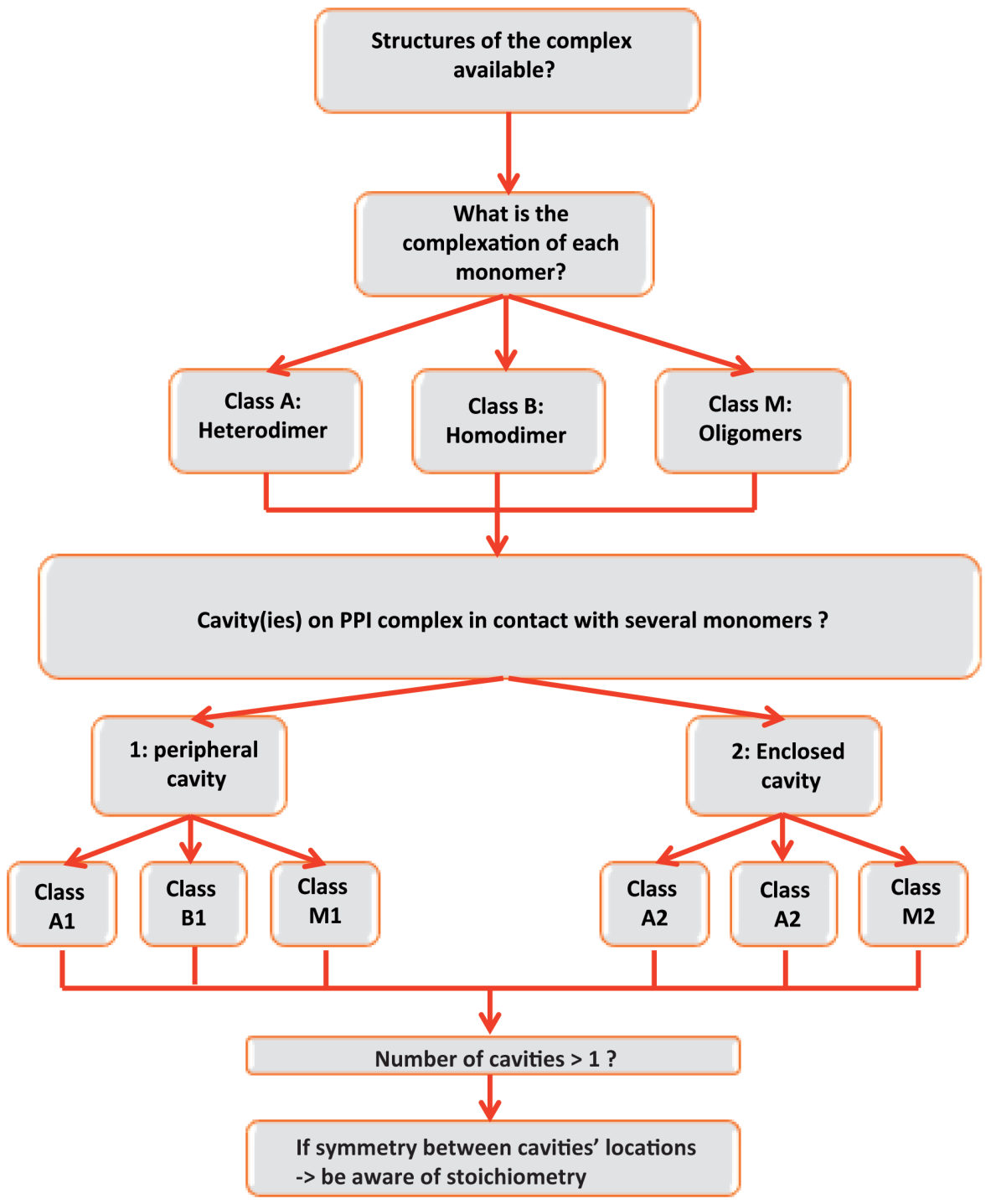

Figure 4. Conceptual decision tree for PPI target classification. 
by Chène (73) in 2006 to support inhibitor design.

The first and most crucial question is whether structural information is available? Optimally, several high resolution X-ray structures are available of the apo multimer and several holo multimeric complexes with different stabilizer bound. But the other extreme, that only a poor quality homology model can be obtained of the apo multimer, is already enough to continue along the decision tree. Visual inspection of the structure information has to lead to a description of the target and to classification as illustrated in figure 2. Standard software from 'classical drug design' can be used to detect druggable pockets after which visual inspection should determine whether these are peripheral or enclosed, and whether these are located at or near protein interfaces or not. Finally, the number and symmetry of binding cavities around the PPI interface should be considered, because this might influence the stoichiometry of binding. Obviously, in case of homomers with a symmetric conformation several identical binding cavities will exist, which will influence the number of copies present in the holo form of the complex. This conceptual decision tree holds a number of questions. If any question is answered with "No" or cannot be answered, then the process breaks down and PPI modulator design is likely not going to be easy. However, in such a case the bioscientists at least know either which information to pursue in order to continue, or why continuation is impossible. The field of PPI stabilizer design is still in its infancy, but we hope that this overview of presently available knowledge will enable it to grow into a mature science that can produce tools for therapeutic interventions in human health and thus improve our quality of life. 
Table 1. List of targets and compounds from class A and B and M.

\begin{tabular}{|c|c|c|c|c|}
\hline TARGET & COMPOUND & ASSAY & ACTIVITY & REF \\
\hline \multicolumn{5}{|c|}{ CLASS A } \\
\hline \multicolumn{5}{|c|}{ Subclass A1 } \\
\hline \multirow[t]{6}{*}{ 14-3-3/PMA2 } & FC & ITC & $\mathrm{K}_{\mathrm{d}}=700 \mathrm{nM}$ & (19) \\
\hline & $\mathrm{CoA}$ & ITC & $\mathrm{K}_{\mathrm{d}}=2.5 \mu \mathrm{M}$ & $(12)$ \\
\hline & Epibestatins & SPR & $\mathrm{K}_{\mathrm{d}}=1.8 \mu \mathrm{M}$ & (13) \\
\hline & Pyrrolinone1 & SPR & $\mathrm{K}_{\mathrm{d}}=80 \mu \mathrm{M}$ & (13) \\
\hline & & Surface-based assay & $\mathrm{EC}_{50}=101 \mu \mathrm{M}$ & (14) \\
\hline & Compound 37 & Surface-based assay & $\mathrm{EC}_{50}=33 \mu \mathrm{M}$ & (14) \\
\hline 14-3-3/C-RAF & $\mathrm{CoA}$ & Anisotropy measurement & $\mathrm{K}_{\mathrm{d}}=20 \mathrm{nM}$ & (15) \\
\hline $14-3-3 / \mathrm{ER} \alpha$ & FC & Competitive anisotropy & $\mathrm{K}_{\mathrm{d}}=0.1 \mu \mathrm{M}$ & (16) \\
\hline \multirow[t]{12}{*}{ 14-3-3/TASK3 } & $\mathrm{FC}$ & FP binding assay & $\mathrm{K}_{\mathrm{d}}=0.05 \mu \mathrm{M}$ & (17) \\
\hline & & FP binding assay & $\mathrm{EC}_{50}=1.9 \mu \mathrm{M}$ & (17) \\
\hline & FC-J-aglycone & FP binding assay & $\mathrm{K}_{\mathrm{d}}=0.56 \mu \mathrm{M}$ & (17) \\
\hline & & FP binding assay & $\mathrm{EC}_{50}=262.8 \mu \mathrm{M}$ & (17) \\
\hline & FC-A-aglycone & FP binding assay & $\mathrm{K}_{\mathrm{d}}=0.48 \mu \mathrm{M}$ & (17) \\
\hline & & FP binding assay & $\mathrm{EC}_{50}=209.6 \mu \mathrm{M}$ & $(17)$ \\
\hline & 16-O-Me-FC-H & FP binding assay & $\mathrm{K}_{\mathrm{d}}=0.07 \mu \mathrm{M}$ & (17) \\
\hline & & FP binding assay & $\mathrm{EC}_{50}=6.2 \mu \mathrm{M}$ & (17) \\
\hline & FC-H & FP binding assay & $\mathrm{K}_{\mathrm{d}}=0.55 \mu \mathrm{M}$ & (17) \\
\hline & & FP binding assay & $\mathrm{EC}_{50}=186.9 \mu \mathrm{M}$ & (17) \\
\hline & FC-THF & FP binding assay & $\mathrm{K}_{\mathrm{d}}=0.08 \mu \mathrm{M}$ & (17) \\
\hline & & FP binding assay & $\mathrm{EC}_{50}=12.4 \mathrm{mM}$ & (17) \\
\hline \multirow[t]{2}{*}{ Ubiquitin-E2 } & CC0651 & Ubiquitination assay & $\mathrm{IC}_{50}=2.5 \mu \mathrm{M}$ & $(21)$ \\
\hline & & Binding assay & $\mathrm{EC}_{50}=51 \mu \mathrm{M}$ & $(21)$ \\
\hline \multirow[t]{2}{*}{ ARF1-Sec7 } & BFA & Fluorescence anisotropy & $\mathrm{K}_{\mathrm{i}}=15 \mu \mathrm{M}$ & (25) \\
\hline & LM11 & Fluorescence anisotropy & $\mathrm{IC}_{50}=50 \mu \mathrm{M}$ & $(25)$ \\
\hline HDAC3-SMRT-DAD & $\operatorname{Ins}(1,4,5,6) \mathrm{P}_{4}$ & No data & No data & $(27)$ \\
\hline \multicolumn{5}{|c|}{ Subclass A2 } \\
\hline \multirow[t]{3}{*}{ TIR1-auxin-IAA } & Auxin & Competitive binding & $\mathrm{K}_{\mathrm{d}}=84 \mathrm{nM}$ & $(75)$ \\
\hline & $2,4-\mathrm{D}$ & Competitive binding & $\mathrm{IC}_{50}=1.4 \mu \mathrm{M}$ & $(75)$ \\
\hline & 1-NAA & Competitive binding & $\mathrm{IC}_{50}=1.3 \mu \mathrm{M}$ & $(75)$ \\
\hline \multirow[t]{3}{*}{ COI1-JAZ6 } & 7S-Jasmonate & Competitive binding & $\mathrm{K}_{\mathrm{i}}=1.8 \mu \mathrm{M}$ & (7) \\
\hline & 7R-Jasmonate & Competitive binding & $\mathrm{K}_{\mathrm{i}}=18 \mu \mathrm{M}$ & (7) \\
\hline & Coronatine & Radio-ligand binding assay & $\mathrm{K}_{\mathrm{d}}=68 \mathrm{nM}$ & (7) \\
\hline BRI1-SERK & Brassinolide & Binding competition assay & $\mathrm{IC}_{50}=80 \mathrm{nM}$ & (76) \\
\hline \multirow[t]{2}{*}{ CaM-SK2 } & 1-EBIO & Electrophysiology & $\mathrm{EC}_{50}=395.5 \mu \mathrm{M}$ & $(34)$ \\
\hline & PHU & Electrophysiology & $\mathrm{EC}_{50}=1.61 \mu \mathrm{M}$ & $(34)$ \\
\hline
\end{tabular}




\begin{tabular}{|c|c|c|c|c|}
\hline TARGET & COMPOUND & ASSAY & ACTIVITY & REF \\
\hline & NS309 & Electrophysiology & $\mathrm{EC}_{50}=0.44 \mu \mathrm{M}$ & $(34)$ \\
\hline & СyPPA & Electrophysiology & $\mathrm{EC}_{50}=6.04 \mu \mathrm{M}$ & $(34)$ \\
\hline & DCEBIO & Electrophysiology & $\mathrm{EC}_{50}=21.5 \mu \mathrm{M}$ & $(34)$ \\
\hline \multicolumn{5}{|c|}{ CLASS B } \\
\hline \multicolumn{5}{|c|}{ Subclass B1 } \\
\hline Max homodimer & NSC13728 & Analytical ultracentrifugation & $\mathrm{K}_{\mathrm{d}}=7 \mathrm{nM}$ & $(52)$ \\
\hline Survivin homodimer & Abbott 8 & HTS-NMR screen & $\mathrm{K}_{\mathrm{d}}=75 \mu \mathrm{M}$ & $(38)$ \\
\hline \multicolumn{5}{|c|}{ Subclass B2 } \\
\hline $\begin{array}{l}\text { Topoisomerase II } \\
\text { homodimer }\end{array}$ & ICRF-187 & Topoisomerase II inhibition assay & $\mathrm{IC}_{50}=13 \mu \mathrm{M}$ & $(41)$ \\
\hline $\begin{array}{l}\text { Transthyretin } \\
\text { homotetramer }\end{array}$ & Tafamidis & ITC & $\begin{array}{l}\mathrm{K}_{\mathrm{d} 1} \sim 3 \mathrm{nM} \\
\mathrm{K}_{\mathrm{d} 2} \sim 278 \mathrm{nM}\end{array}$ & $(45)$ \\
\hline NP homodimer & O-Metoxy-nucleozin & In vitro polymerase assay & $\mathrm{IC}_{50}=0.17 \mu \mathrm{M}$ & $(47)$ \\
\hline \multirow{2}{*}{$\begin{array}{l}\text { MDMX, MDM2 } \\
\text { homodimer or MDMX- } \\
\text { MDM2 heterodimer }\end{array}$} & RO-2443 & In vitro $\mathrm{p} 53-\mathrm{MDMX}$ binding assay & $\begin{array}{l}\text { for MDM2 } \\
\mathrm{IC}_{50}=33 \mathrm{nM} \\
\text { for MDMX } \\
\mathrm{IC}_{50}=41 \mathrm{nM}\end{array}$ & (49) \\
\hline & RO-5963 & In vitro $\mathrm{p} 53-\mathrm{MDMX}$ binding assay & $\begin{array}{l}\text { for MDM2 } \\
\mathrm{IC}_{50}=17 \mathrm{nM} \\
\text { for MDMX } \\
\mathrm{IC}_{50}=24 \mathrm{nM}\end{array}$ & (49) \\
\hline \multicolumn{5}{|c|}{ CLASS M } \\
\hline \multicolumn{5}{|c|}{ Subclass M1 } \\
\hline \multirow[t]{2}{*}{ PCNA } & PCNA-I1 & SPR & $\mathrm{K}_{\mathrm{d}}=0.14 \mu \mathrm{M}$ & (54) \\
\hline & & PCNA binding assay & $\mathrm{K}_{\mathrm{d}} \sim 0.2-0.4 \mu \mathrm{M}$ & $(54)$ \\
\hline S100A4 & TFP & Competition assay & $\mathrm{EC}_{50}=55 \mu \mathrm{M}$ & $(58)$ \\
\hline \multicolumn{5}{|c|}{ Subclass M2 } \\
\hline CD154 homotrimer & BIO8898 & In vitro inhibition assay & $\mathrm{IC}_{50}=25 \mu \mathrm{M}$ & $(60)$ \\
\hline $\begin{array}{l}\text { TNFa } \\
\text { homodimer }\end{array}$ & TNF- $\alpha$ inhibitor & Cell-based assay & $\mathrm{IC}_{50}=22 \mu \mathrm{M}$ & $(62)$ \\
\hline
\end{tabular}

Abbreviations: FC, Fusicoccin; CoA, Cotylenin A; ITC, isothermal titration calorimetry; FP, fluorescence polarization; SPR, surface plasmon resonance; TFP, trifluoperazine; 


\section{References}

1. Stumpf MPH, Thorne T, de Silva E, Stewart R, An HJ, Lappe M, et al. Estimating the size of the human interactome. Proc Natl Acad Sci U S A. 2008 May 13;105(19):6959-64.

2. Morelli X, Bourgeas R, Roche P. Chemical and structural lessons from recent successes in protein-protein interaction inhibition (2P2I). Curr Opin Chem Biol. 2011 Aug;15(4):475-81.

3. Labbé CM, Laconde G, Kuenemann MA, Villoutreix BO, Sperandio O. iPPI-DB: a manually curated and interactive database of small non-peptide inhibitors of protein-protein interactions. Drug Discov Today. 2013 Oct;18(19-20):958-68.

4. Higueruelo AP, Jubb H, Blundell TL. TIMBAL v2: update of a database holding small molecules modulating protein-protein interactions. Database (Oxford). 2013;2013:bat039.

5. Pommier Y, Cherfils J. Interfacial inhibition of macromolecular interactions: nature's paradigm for drug discovery. Trends Pharmacol Sci. 2005 Mar;26(3):138-45.

6. Thiel P, Kaiser M, Ottmann C. Small-molecule stabilization of protein-protein interactions: an underestimated concept in drug discovery? Angew Chem Int Ed Engl. 2012 Feb 27;51(9):2012-8.

7. Sheard LB, Tan X, Mao H, Withers J, Ben-Nissan G, Hinds TR, et al. Jasmonate perception by inositolphosphate-potentiated COI1-JAZ co-receptor. Nature. 2010 Nov 18;468(7322):400-5.

8. Block P, Weskamp N, Wolf A, Klebe G. Strategies to search and design stabilizers of protein-protein interactions: a feasibility study. Proteins. 2007 Jul 1;68(1):170-86.

9. Giordanetto F, Schäfer A, Ottmann C. Stabilization of protein-protein interactions by small molecules. Drug Discov Today. 2014 Nov;19(11):1812-21.

10. Hermeking H, Benzinger A. 14-3-3 proteins in cell cycle regulation. Semin Cancer Biol. 2006 Jun;16(3):183-92.

11. Piotrowski M, Morsomme P, Boutry M, Oecking C. Complementation of the Saccharomyces cerevisiae plasma membrane $\mathrm{H}+$-ATPase by a plant $\mathrm{H}+$-ATPase generates a highly abundant fusicoccin binding site. J Biol Chem. 1998 Nov 6;273(45):30018-23.

12. Ottmann C, Weyand M, Sassa T, Inoue T, Kato N, Wittinghofer A, et al. A structural rationale for selective stabilization of anti-tumor interactions of 14-3-3 proteins by cotylenin A. J Mol Biol. 2009 Mar 6;386(4):913-9.

13. Rose R, Erdmann S, Bovens S, Wolf A, Rose M, Hennig S, et al. Identification and structure of small-molecule stabilizers of 14-3-3 protein-protein interactions. Angew Chem Int Ed Engl. 2010 Jun 1;49(24):4129-32.

14. Richter A, Rose R, Hedberg C, Waldmann H, Ottmann C. An optimised small-molecule stabiliser of the 14-33-PMA2 protein-protein interaction. Chem Weinh Bergstr Ger. 2012 May 21;18(21):6520-7.

15. Molzan M, Kasper S, Röglin L, Skwarczynska M, Sassa T, Inoue T, et al. Stabilization of physical RAF/14-3-3 interaction by cotylenin A as treatment strategy for RAS mutant cancers. ACS Chem Biol. 2013 Sep 20;8(9):1869-75.

16. De Vries-van Leeuwen IJ, da Costa Pereira D, Flach KD, Piersma SR, Haase C, Bier D, et al. Interaction of 143-3 proteins with the estrogen receptor alpha F domain provides a drug target interface. Proc Natl Acad Sci U S A. 2013 May 28;110(22):8894-9.

17. Anders C, Higuchi Y, Koschinsky K, Bartel M, Schumacher B, Thiel P, et al. A semisynthetic fusicoccane stabilizes a protein-protein interaction and enhances the expression of $\mathrm{K}+$ channels at the cell surface. Chem Biol. 2013 Apr 18;20(4):583-93.

18. Zuzarte M, Heusser K, Renigunta V, Schlichthörl G, Rinné S, Wischmeyer E, et al. Intracellular traffic of the K+ channels TASK-1 and TASK-3: role of N- and C-terminal sorting signals and interaction with 14-3-3 proteins. J Physiol. 2009 Mar 1;587(Pt 5):929-52.

19. Würtele M, Jelich-Ottmann C, Wittinghofer A, Oecking C. Structural view of a fungal toxin acting on a 14-3-3 regulatory complex. EMBO J. 2003 Mar 3;22(5):987-94.

20. Nalepa G, Rolfe M, Harper JW. Drug discovery in the ubiquitin-proteasome system. Nat Rev Drug Discov. 2006 Jul;5(7):596-613.

21. Ceccarelli DF, Tang X, Pelletier B, Orlicky S, Xie W, Plantevin V, et al. An allosteric inhibitor of the human Cdc34 ubiquitin-conjugating enzyme. Cell. 2011 Jun 24;145(7):1075-87.

22. Huang H, Ceccarelli DF, Orlicky S, St-Cyr DJ, Ziemba A, Garg P, et al. E2 enzyme inhibition by stabilization of a low-affinity interface with ubiquitin. Nat Chem Biol. 2014 Feb;10(2):156-63.

23. Frank S, Upender S, Hansen SH, Casanova JE. ARNO is a guanine nucleotide exchange factor for ADPribosylation factor 6. J Biol Chem. 1998 Jan 2;273(1):23-7.

24. D'Souza-Schorey C, Chavrier P. ARF proteins: roles in membrane traffic and beyond. Nat Rev Mol Cell Biol. 2006 May;7(5):347-58.

25. Viaud J, Zeghouf M, Barelli H, Zeeh J-C, Padilla A, Guibert B, et al. Structure-based discovery of an inhibitor of Arf activation by Sec7 domains through targeting of protein-protein complexes. Proc Natl Acad Sci U S A. 2007 Jun 19;104(25):10370-5. 
26. Wen YD, Perissi V, Staszewski LM, Yang WM, Krones A, Glass CK, et al. The histone deacetylase-3 complex contains nuclear receptor corepressors. Proc Natl Acad Sci U S A. 2000 Jun 20;97(13):7202-7.

27. Watson PJ, Fairall L, Santos GM, Schwabe JWR. Structure of HDAC3 bound to co-repressor and inositol tetraphosphate. Nature. 2012 Jan 19;481(7381):335-40.

28. Davies PJ. The Plant Hormones: Their Nature, Occurrence, and Functions. 2009;1-15.

29. Tan X, Calderon-Villalobos LIA, Sharon M, Zheng C, Robinson CV, Estelle M, et al. Mechanism of auxin perception by the TIR1 ubiquitin ligase. Nature. 2007 Apr 5;446(7136):640-5.

30. Santiago J, Henzler C, Hothorn M. Molecular mechanism for plant steroid receptor activation by somatic embryogenesis co-receptor kinases. Science. 2013 Aug 23;341(6148):889-92.

31. Adelman JP, Maylie J, Sah P. Small-conductance Ca2+-activated K+ channels: form and function. Annu Rev Physiol. 2012;74:245-69.

32. Ellinor PT, Lunetta KL, Glazer NL, Pfeufer A, Alonso A, Chung MK, et al. Common variants in KCNN3 are associated with lone atrial fibrillation. Nat Genet. 2010 Mar;42(3):240-4.

33. Faber ESL, Sah P. Functions of SK channels in central neurons. Clin Exp Pharmacol Physiol. 2007 Oct;34(10):1077-83.

34. Zhang M, Pascal JM, Schumann M, Armen RS, Zhang J-F. Identification of the functional binding pocket for compounds targeting small-conductance $\mathrm{Ca}^{2+}$-activated potassium channels. Nat Commun. 2012;3:1021.

35. Zhang M, Pascal JM, Zhang J-F. Unstructured to structured transition of an intrinsically disordered protein peptide in coupling $\mathrm{Ca}^{2+}$-sensing and SK channel activation. Proc Natl Acad Sci U S A. 2013 Mar 19;110(12):4828-33.

36. Fukuda S, Pelus LM. Survivin, a cancer target with an emerging role in normal adult tissues. Mol Cancer Ther. 2006 May;5(5):1087-98.

37. Chettiar SN, Cooley JV, Park I-H, Bhasin D, Chakravarti A, Li P-K, et al. Design, synthesis and biological studies of survivin dimerization modulators that prolong mitotic cycle. Bioorg Med Chem Lett. 2013 Oct 1;23(19):5429-33.

38. Wendt MD, Sun C, Kunzer A, Sauer D, Sarris K, Hoff E, et al. Discovery of a novel small molecule binding site of human survivin. Bioorg Med Chem Lett. 2007 Jun 1;17(11):3122-9.

39. Roca J, Wang JC. The capture of a DNA double helix by an ATP-dependent protein clamp: a key step in DNA transport by type II DNA topoisomerases. Cell. 1992 Nov 27;71(5):833-40.

40. Weiss G, Loyevsky M, Gordeuk VR. Dexrazoxane (ICRF-187). Gen Pharmacol. 1999 Jan;32(1):155-8.

41. Hasinoff BB, Kuschak TI, Yalowich JC, Creighton AM. A QSAR study comparing the cytotoxicity and DNA topoisomerase II inhibitory effects of bisdioxopiperazine analogs of ICRF-187 (dexrazoxane). Biochem Pharmacol. 1995 Sep 28;50(7):953-8.

42. Classen S, Olland S, Berger JM. Structure of the topoisomerase II ATPase region and its mechanism of inhibition by the chemotherapeutic agent ICRF-187. Proc Natl Acad Sci U S A. 2003 Sep 16;100(19):1062934.

43. Monaco HL, Rizzi M, Coda A. Structure of a complex of two plasma proteins: transthyretin and retinol-binding protein. Science. 1995 May 19;268(5213):1039-41.

44. Sacchettini JC, Kelly JW. Therapeutic strategies for human amyloid diseases. Nat Rev Drug Discov. 2002 Apr;1(4):267-75.

45. Bulawa CE, Connelly S, Devit M, Wang L, Weigel C, Fleming JA, et al. Tafamidis, a potent and selective transthyretin kinetic stabilizer that inhibits the amyloid cascade. Proc Natl Acad Sci U S A. 2012 Jun 12;109(24):9629-34.

46. Chenavas S, Crépin T, Delmas B, Ruigrok RWH, Slama-Schwok A. Influenza virus nucleoprotein: structure, RNA binding, oligomerization and antiviral drug target. Future Microbiol. 2013 Dec;8:1537-45.

47. Gerritz SW, Cianci C, Kim S, Pearce BC, Deminie C, Discotto L, et al. Inhibition of influenza virus replication via small molecules that induce the formation of higher-order nucleoprotein oligomers. Proc Natl Acad Sci U S A. 2011 Sep 13;108(37):15366-71.

48. Wade M, Wahl GM. Targeting Mdm2 and Mdmx in cancer therapy: better living through medicinal chemistry? Mol Cancer Res MCR. 2009 Jan;7(1):1-11.

49. Graves B, Thompson T, Xia M, Janson C, Lukacs C, Deo D, et al. Activation of the p53 pathway by smallmolecule-induced MDM2 and MDMX dimerization. Proc Natl Acad Sci U S A. 2012 Jul 17;109(29):11788-93.

50. Berg T. Small-molecule modulators of c-Myc/Max and Max/Max interactions. Curr Top Microbiol Immunol. 2011;348:139-49.

51. Kiessling A, Sperl B, Hollis A, Eick D, Berg T. Selective inhibition of c-Myc/Max dimerization and DNA binding by small molecules. Chem Biol. 2006 Jul;13(7):745-51. 
52. Jiang H, Bower KE, Beuscher AE, Zhou B, Bobkov AA, Olson AJ, et al. Stabilizers of the Max homodimer identified in virtual ligand screening inhibit Myc function. Mol Pharmacol. 2009 Sep;76(3):491-502.

53. Kelman Z. PCNA: structure, functions and interactions. Oncogene. 1997 Feb 13;14(6):629-40.

54. Tan Z, Wortman M, Dillehay KL, Seibel WL, Evelyn CR, Smith SJ, et al. Small-molecule targeting of proliferating cell nuclear antigen chromatin association inhibits tumor cell growth. Mol Pharmacol. 2012 Jun;81(6):811-9.

55. Kontopidis G, Wu S-Y, Zheleva DI, Taylor P, McInnes C, Lane DP, et al. Structural and biochemical studies of human proliferating cell nuclear antigen complexes provide a rationale for cyclin association and inhibitor design. Proc Natl Acad Sci U S A. 2005 Feb 8;102(6):1871-6.

56. Schneider M, Hansen JL, Sheikh SP. S100A4: a common mediator of epithelial-mesenchymal transition, fibrosis and regeneration in diseases? J Mol Med Berl Ger. 2008 May;86(5):507-22.

57. Malashkevich VN, Dulyaninova NG, Ramagopal UA, Liriano MA, Varney KM, Knight D, et al. Phenothiazines inhibit S100A4 function by inducing protein oligomerization. Proc Natl Acad Sci U S A. 2010 May 11;107(19):8605-10.

58. Garrett SC, Hodgson L, Rybin A, Toutchkine A, Hahn KM, Lawrence DS, et al. A biosensor of S100A4 metastasis factor activation: inhibitor screening and cellular activation dynamics. Biochemistry (Mosc). 2008 Jan 22;47(3):986-96.

59. Schönbeck U, Libby P. The CD40/CD154 receptor/ligand dyad. Cell Mol Life Sci CMLS. 2001 Jan;58(1):4-43.

60. Silvian LF, Friedman JE, Strauch K, Cachero TG, Day ES, Qian F, et al. Small molecule inhibition of the TNF family cytokine CD40 ligand through a subunit fracture mechanism. ACS Chem Biol. 2011 Jun 17;6(6):636-47.

61. Palladino MA, Bahjat FR, Theodorakis EA, Moldawer LL. Anti-TNF-alpha therapies: the next generation. Nat Rev Drug Discov. 2003 Sep;2(9):736-46.

62. He MM, Smith AS, Oslob JD, Flanagan WM, Braisted AC, Whitty A, et al. Small-molecule inhibition of TNFalpha. Science. 2005 Nov 11;310(5750):1022-5.

63. Ludueńa RF, Shooter EM, Wilson L. Structure of the tubulin dimer. J Biol Chem. 1977 Oct 25;252(20):7006-14.

64. Jordan MA, Wilson L. Microtubules as a target for anticancer drugs. Nat Rev Cancer. 2004 Apr;4(4):253-65.

65. Alushin GM, Lander GC, Kellogg EH, Zhang R, Baker D, Nogales E. High-resolution microtubule structures reveal the structural transitions in $\alpha \beta$-tubulin upon GTP hydrolysis. Cell. 2014 May 22;157(5):1117-29.

66. Brown RH. Amyotrophic lateral sclerosis: recent insights from genetics and transgenic mice. Cell. 1995 Mar 10;80(5):687-92.

67. Ray SS, Nowak RJ, Brown RH, Lansbury PT. Small-molecule-mediated stabilization of familial amyotrophic lateral sclerosis-linked superoxide dismutase mutants against unfolding and aggregation. Proc Natl Acad Sci U S A. 2005 Mar 8;102(10):3639-44.

68. Wright GSA, Antonyuk SV, Kershaw NM, Strange RW, Samar Hasnain S. Ligand binding and aggregation of pathogenic SOD1. Nat Commun. 2013;4:1758.

69. Mangelsdorf DJ, Thummel C, Beato M, Herrlich P, Schütz G, Umesono K, et al. The nuclear receptor superfamily: the second decade. Cell. 1995 Dec 15;83(6):835-9.

70. Le Maire A, Teyssier C, Erb C, Grimaldi M, Alvarez S, de Lera AR, et al. A unique secondary-structure switch controls constitutive gene repression by retinoic acid receptor. Nat Struct Mol Biol. 2010 Jul;17(7):801-7.

71. Gronemeyer H, Gustafsson J-Å, Laudet V. Principles for modulation of the nuclear receptor superfamily. Nat Rev Drug Discov. 2004 Nov;3(11):950-64.

72. Siekierka JJ, Hung SH, Poe M, Lin CS, Sigal NH. A cytosolic binding protein for the immunosuppressant FK506 has peptidyl-prolyl isomerase activity but is distinct from cyclophilin. Nature. 1989 Oct 26;341(6244):755-7.

73. Chène P. Drugs targeting protein-protein interactions. ChemMedChem. 2006 Apr;1(4):400-11.

74. Zhang Z, Martiny V, Lagorce D, Ikeguchi Y, Alexov E, Miteva MA. Rational design of small-molecule stabilizers of spermine synthase dimer by virtual screening and free energy-based approach. PloS One. 2014;9(10):e110884.

75. Dharmasiri N, Dharmasiri S, Estelle M. The F-box protein TIR1 is an auxin receptor. Nature. 2005 May 26;435(7041):441-5.

76. Wang ZY, Seto H, Fujioka S, Yoshida S, Chory J. BRI1 is a critical component of a plasma-membrane receptor for plant steroids. Nature. 2001 Mar 15;410(6826):380-3. 


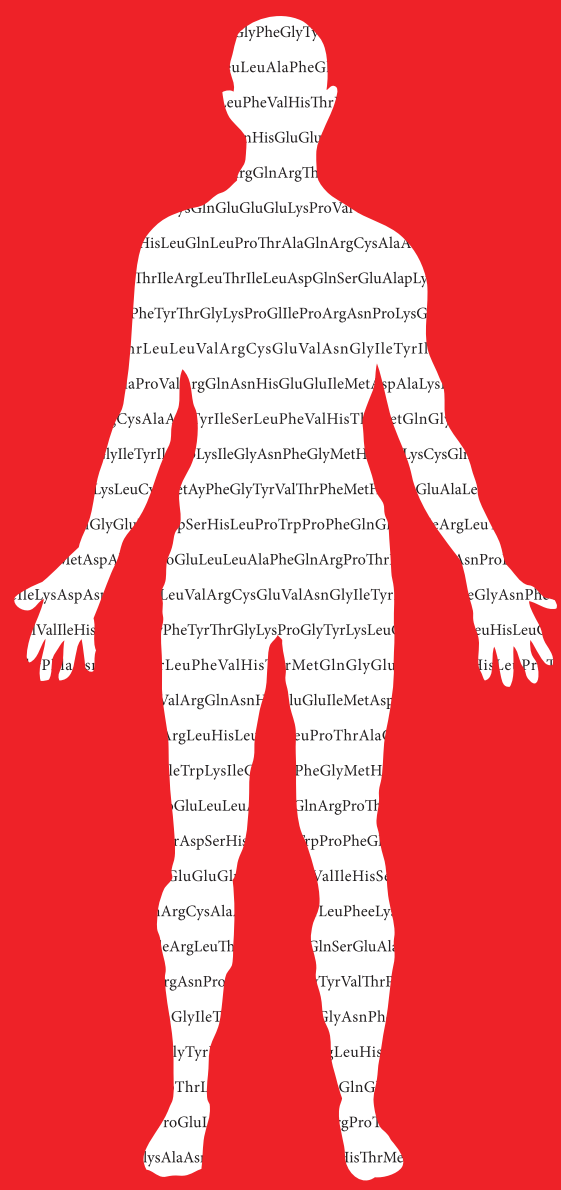




\section{Chapter}

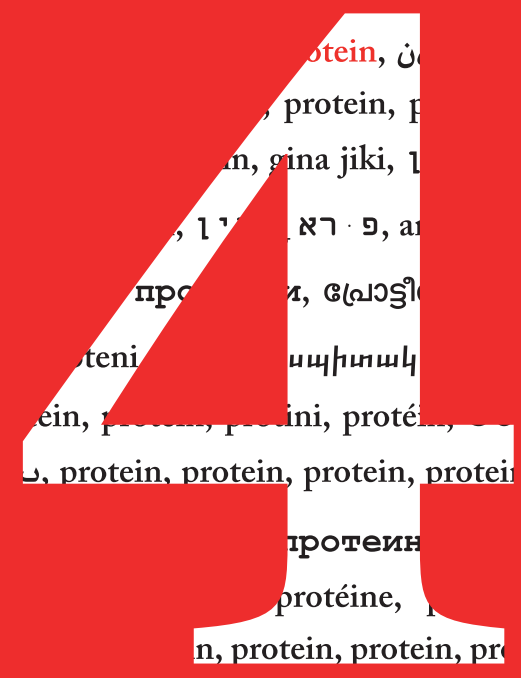

\section{Chemical space of small molecule stabilizers of protein - protein interactions}

B. Zarzycka, M.A. Kuenemann, M. Miteva, T.M. Hackeng, G. Vriend, G.A.F. Nicolaes, O. Sperandio

Manuscript in preparation 


\begin{abstract}
Protein - protein interactions (PPIs) regulate biological processes in all living organisms. In the recent years, PPIs have become a new class of drug targets, as their modulation showed novel opportunities for the therapeutical interventions. The last two decades resulted in numerous inhibitors of PPIs, from which several have reached clinical trials. But the inhibition of PPIs is not the only route open for modulation. Indeed, stabilization of PPIs is getting more momentum and is clearly underexploited. As the number of success stories using small molecule stabilizers (sPPIs) is increasing rapidly, a retrospective analysis of their physicochemical properties thus defining a so-called chemical space is both achievable and necessary. Here, we present a chemoinformatics analysis of small molecule sPPIs that have been collected from the literature. Our results suggest a list of significant differences with respect to the inhibitors of PPI (e.g. modest size and hydrophobicity) that could open new ways to tackle PPI targets without raising inherent difficulties in terms of drug development. We hope that such an initiative might facilitate future design of this type of modulators in drug discovery projects.
\end{abstract}




\section{Introduction}

Protein - protein interactions (PPIs) are pivotal components of biological processes in all living organisms. The estimated human interactome consists of 650000 interactions (1). PPIs are considered as a new class of putative targets that might provide diverse opportunities for therapeutical interventions. PPIs are characterized by very large ( 1,500 to 3,000 $)$, shallow and hydrophobic interfaces $(2,3)$. The interfaces of PPIs differ from the binding pockets of conventional drug targets such as enzymes, and PPIs for a long time were considered as "undruggable" $(4,5)$. Thus, designing small molecule inhibitors, compounds that bind to one protein and at the same time compete with protein partner, was considered as reaching highhanging fruits (6). However, the last 20 years brought impressive number of inhibitors of PPIs (iPPIs) from which some reached clinical trials $(6,7)$. The iPPIs are collected in a few databases, such as iPPI-DB (8), 2P2IDB (9), and Timbal (10), respectively. These collections of iPPIs allowed the scientific community to characterize the chemical space of small molecule iPPIs and revealed that iPPIs have significantly higher molecular weight (MW), hydrophobicity, and aromatic character than conventional drugs $(11,12)$. Additionally, the analysis of $3 \mathrm{D}$ molecular shape of iPPIs showed that ideal iPPI candidate should be globular, have a high capacity to bind hydrophobic patches, and have a low proportion of exposed polar groups. Finally, it should have exposed polar groups at one end (13). Current databases of small molecules are rather designed to fulfil physico-chemical properties of Lipinski rule-of five (RO5) (14) that are applied to the commonly known targets like enzymes. However, the analysis of chemical space of iPPIs showed that they significantly violet from the RO5 (11). Thus, focused libraries enriched in putatitve iPPIs might increase the hit rates in both virtual ligand screening and experimental studies (12).

PPIs complexes can be modulated not only by competitive inhibition, where small molecule binds to the interface of one protein partner, but also by stabilization, where a small molecule binds to both protein partners, working as a molecular glue (15). Concept of stabilizing PPIs was underestimated for the long time, but recent success stories show its high potential (1517). There are a few indisputable advantages of stabilization over inhibition of PPI complexes. One of them is characteristic of binding pockets. Preliminary research showed that pockets targeted by stabilizers share more similarities with pockets of conventional drug targets, such as enzymes, than with interfaces of PPIs (18). Thus, designing stabilizers might be less challenging than designing inhibitors of PPIs. Second, stabilizers of PPI complexes can be present in micromolar range to trigger physiological effects (15). Additionally, pocket created by two proteins presents more specificity than interface of PPI complexes (15). The number of stabilizers is growing, and some of them are already collected in databases e.g. Timbal (10). However, until this moment, detailed analysis of the physico-chemical properties of PPI small molecule stabilizers is not present.

Recently, we collected small molecule sPPIs and suggested classification based on their place 
of binding and architecture of the complex. Additionally, we proposed decision tree that might guide bioscientists in structure-based design of stabilizers (chapter 3). Here, we characterized chemical space of sPPIs and compared them with iPPIs and conventional drugs. It revealed that sPPIs meet RO5 criteria, thus, resemble profile of conventional drug more than of iPPIs. Additionally, we identified 3D shape of sPPIs, showing that ideal sPPIs are rather flat molecules, less charged; have less positive partial charges and less negative charged weighted surface. They are also less hydrophilic that is expressed by lower amount of patches with polar atoms and smaller hydrophilic regiones on van der Waals surface of the molecule than iPPIs and conventional drugs. Finally, we showed that sPPIs do not require tailored made focused libraries. In conclusion, our study will facilitate the design of new stabilizers of PPI complexes.

\section{Methods}

\section{D sPPIs ligand dataset}

Stabilizers of protein - protein interactions were collected from the literature, according to a few criteria. First, we focused only on small molecules, rejecting peptides and peptide-like compounds. Second, we collected compounds with confirmed location of binding by X-ray crystallography, NMR, or mutagenesis study. Third, we aimed at an affinity threshold of 30 $\mu \mathrm{M}$, however, to keep a higher number of targets; we included six compounds with affinity threshold of $80 \mu \mathrm{M}$. In total, our collection consists of 123 compounds for 20 targets (see names of the complexes in the supplementary materials, table 1). A chemical diversity filter, using Functional Class Fingerprints (FCFP4) with the similarity threshold of 0.7, was used to obtain chemically diverse 2D datasets and prevent the overrepresentation of some chemical series. FCFP4 was implemented in the PipelinePilot V 8.5. In total, our dataset consists of 74 chemically diverse compounds. However, this database contains 35 compounds that bind to Trans target. This target is overrepresented and might bias analysis; thus we chose only five compounds that bind to Trans. Our final database consists of 44 chemically diverse compounds.

\section{D iPPIs ligand dataset}

Inhibitors of protein - protein interactions were collected from the iPPI-DB (8) and filtered through abovementioned diversity filter. The total collection of chemically diverse iPPIs consisted of 354 compounds from 13 families of PPI targets.

\section{D eDrug dataset}

Conventional drugs were collected from the eDrugs3D (version June 2012) (19), filtered with aforementioned diversity filter and kept only orally bioavailable. The total collection of chemically diverse conventional drugs, which we called 'eDrug', consisted of 698 compounds. 


\section{D ligand datasets}

To create 3D sPPIs database, X-ray structures of protein in complex with stabilizers were retrieved from PDBredo database (20), structures absent in PDBredo database were retrieved from Protein Databank (PDB) (21). Partial charges were calculated using the MMFF94 force field implemented in the MOE program (version 2012.10) (22). Proteins were deleted and compounds were collected into dataset. Our 3D ligand database consists of 54 3D compounds (supplementary materials, table 2). There were a few PDB files with more than one copy of a compound; in these cases, all copies were collected. The total number of $3 \mathrm{D}$ dataset used for the analysis consists of 100 bioactive conformations.

The 3D iPPIs database consisted of 84 compounds, 3D non-iPPIs dataset consisted of 1282 compounds (enzymes, receptors, and kinase inhibitors), they were designed as previously described (13).

\section{Molecular descriptors 2D and 3D}

To analyze 2D principal component analysis (PCA), set of 43 different 2D descriptors (supplementary materials, table 3) was calculated with a java program using ChemAxon JChem library (version 5.10.1, academic package) (23). To analyse 3D PCA, a set of 106 3D descriptors was calculated using MOE program (version 2012.10) (22). The selection of the most discriminative $3 \mathrm{D}$ descriptors was used according to the previously described protocol (13) and resulted in five sPPIs specific descriptors.

\section{Molecular Descriptor Analysis}

Both univariate and multivariate analysis were used to investigate physico-chemical properties of $2 \mathrm{D}$ dataset. Analysis were done using R program (version 2.15.1) (24). Student's t-tests determined statistical significance of datasets discrimination. $\mathrm{P}$-values $<0.05$ were considered significant.

\section{Results and Discussion}

\section{sPPIs ligands dataset}

Stabilizers are still underexploited as a route to pharmacologically modulate PPI targets, and the only sparse collection of stabilizers is present in TIMBAL database (10). We collected small molecule orthosteric stabilizers of PPIs available in the literature (until March 2014). As orthosteric stabilizers, we defined compounds that bind to a druggable pocket created by at least two proteins. The challenge of identifying stabilizers of PPIs was due to the fact that they might lead to inhibition or activation of biological processes. In literature, very often, compounds binding to at least two proteins and inhibiting biological processes were named inhibitors. According to our definition of sPPIs, compounds that inhibit biological function can still be classified as stabilizers. It resulted in the dataset consisted of 74 compounds for 20 targets (figure 1). Targets are not equally populated (figure 1). Only two targets, Surv, and 
Trans, have more than five chemically diverse compounds, which are seven, and 35, respectively (figure 1). PCNA has five compounds, whereas the rest of the targets have three or fewer compounds. Since compounds binding to Trans constituted $47 \%$ of the whole database, they might bias the analysis. Therefore, we decided to represent this target with only five, randomly chosen compounds. Our final dataset called unbiased diverse dataset consists of 44 chemically diverse compounds. Low number of compounds per target did not allow for the target-based analysis.

\section{Physico-chemical analysis of sPPIs versus iPPIs, and versus eDrug}

Inhibitors of PPI significantly differ from conventional drugs that are mostly inhibitors of enzymes $(8,13)$. Thus, inhibitors of PPIs require screening libraries that differ from the one used for the conventional targets. However, the physico-chemical properties of stabilizers of PPIs are still unknown. Here, we analysed physico-chemical properties of sPPIs and compare them with those of both iPPIs and conventional drugs collected in eDrug dataset.

\section{Full data set $\square$ Diverse data set $\square$ Unbiased diverse data set}

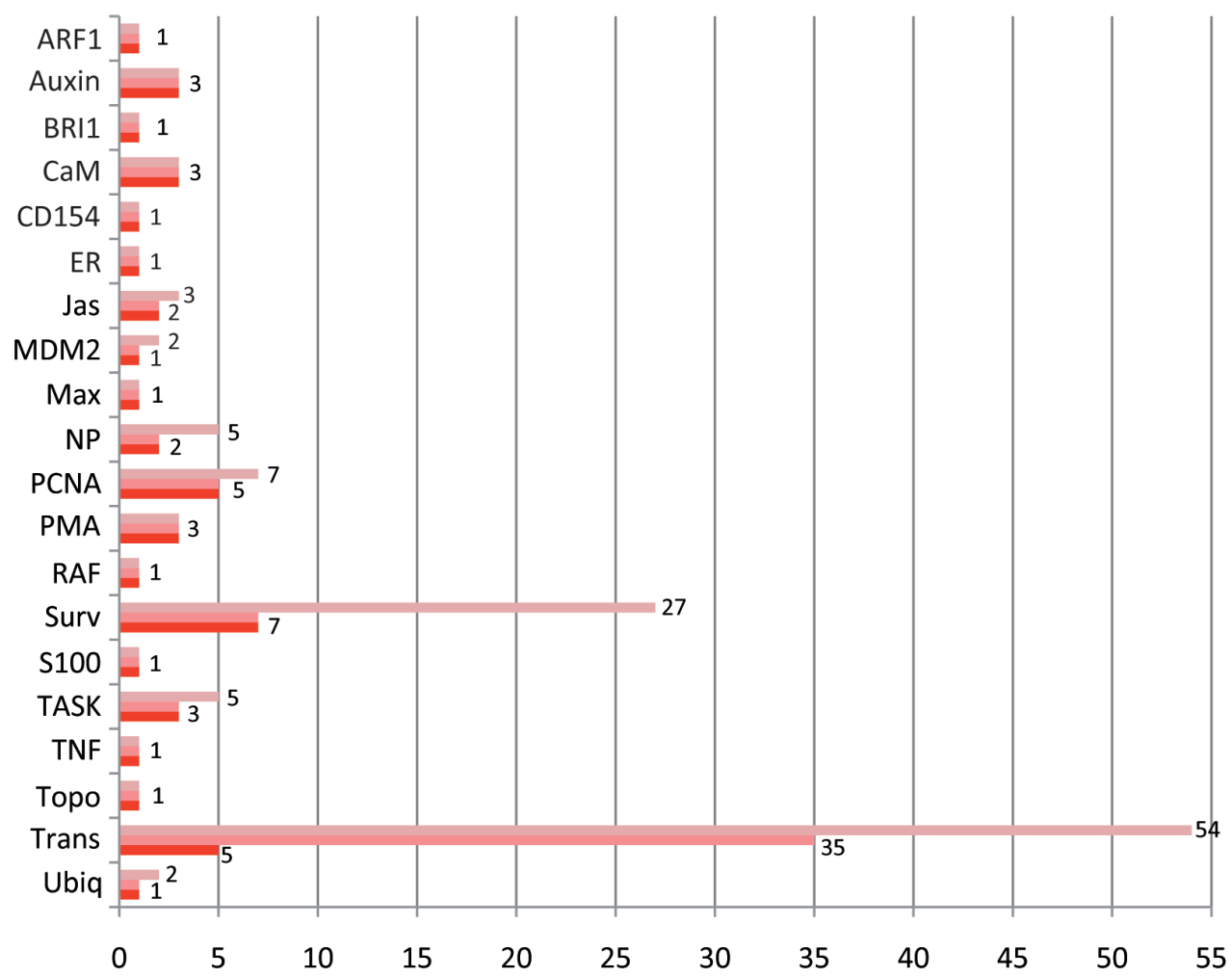

Figure 1. Dataset of sPPI per target. Full dataset (123 compounds), diverse dataset (74 compounds), and unbiased diverse dataset used for the analysis (44 compounds). In this figure, we used code for the PPI complexes; the full names are present in supplementary materials, table 1. 


\section{Size}

Distribution of MW revealed that sPPIs are significantly smaller than iPPIs, $\left(\right.$ mean $_{\text {sPPIs }}=386.1$ $\pm 149.4 \mathrm{Da}$, whereas mean ${ }_{\mathrm{iPPIs}}=514.7 \pm 130.6 \mathrm{Da}$, with $\left.\mathrm{P}<0.0001\right)$, figure 2 , table 1 . But, they are significantly bigger than eDrugs $\left(\right.$ mean $_{\text {eDrug }}=335.2 \pm 141.1 \mathrm{Da}$, with $\mathrm{P}=0.0211$ ), figure 2, table 1 . The mean value of sPPIs might be biased by the compound binding to CD154 target, which is bigger than the rest of compounds present in the dataset (MW $=908.5 \mathrm{Da})$, figure 3 . However, unbiased dataset, without CD154 compound, has mean ${ }_{\text {sPIs }}=374 \pm 127.3$ Da that is in agreement with previous dataset. The size of CD154 compound might be explained by the size of its druggable pocket with buried surface area of $1950 \AA^{2}(25)$ that is located between three subunits of trimer. Interestingly, two compound binding to Auxin have MW below 200 Da (186.1 and 175.1 Da), figure 3. Typically such low-molecular-weight compounds are considered as fragments commonly used in fragment-based drug design rather than drugslike compounds. We decided to keep these compounds in our dataset, because one of these compounds has natural origin, whereas the other is its analog, and both of them trigger signal transduction in plants. Additionally, small size of these compounds might be explained by the fact that they bind to the druggable pocket located in the core of the rim of PPIs, creating socalled "enclosed pocket". This type of pocket restricts size of compounds and separates them from the solvent. Other compounds that bind to enclosed pockets have MW only slightly higher than mean value of eDrug (322.2 and 441.1 Da for Jas and NP, respectively). The only exception is compound binding to CD154 target; however, this might be caused by abovementioned target architecture.

\section{Hydrophobicity}

Distribution of octanol/water partition coefficient $(\log P)$ and topological surface area (TPSA) revealed that sPPIs are also less hydrophobic than iPPIs, but more hydrophobic than eDrug. The sPPIs $\log \mathrm{P}$ is significantly lower $\left(\operatorname{mean}_{\mathrm{sPPIs}}=3.2 \pm 1.9\right)$ than iPPIs $\left(\operatorname{mean}_{\mathrm{iPPIs}}=4.6 \pm 2.0\right.$, with $\mathrm{P}<0.0001$ ), but significantly higher than eDrug $\left(\right.$ mean $_{\text {eDrug }}=2.2 \pm 2.5$ with $\mathrm{P}=0.0052$ ), figure 2, table 1. Additionally, the sPPIs TPSA is slightly lower $\left(\right.$ mean $\left._{\text {sPPIs }}=79.8 \pm 42.9\right)$ than iPPIs ( mean $_{\mathrm{iPPIs}}=87.9 \pm 31.3$, but $\left.\mathrm{P}>0.05\right)$, but slightly higher than eDrug $\left(\right.$ mean $_{\mathrm{eDrug}}=74.5 \pm$ 47.3 , but $\mathrm{P}>0.05$ ), figure 2 , table 1 . On one hand, the $\log \mathrm{P}$ value might be biased by the compound binding to Topo target. It is the only compound in our dataset that has LogP value below zero (-2.7). This compound is water soluble (26) but has very poor membrane permeability. However, it is clinically approved drug, administered intravenously for the treatment of cancer patients (26). On the other hand, mean value of LogP might be biased by two compounds (binding to Max and TNF target) with relatively high LogP value (above 6). Even though $\log \mathrm{P}$ values suggest high lipophilicity of these compounds, there was no

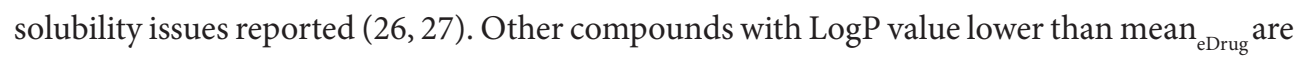
compounds binding to ER, and TASK targets, with $\log$ P values of 1.4 , and 1.2, respectively 
(figure 3). The relatively low hydrophobicity of these compounds might be explained by the fact that these compounds were not designed for the drug discovery projects, but were inspired by nature. Thus, they can become a good starting point for the chemical optimization.

\section{Aromatic character}

Distribution of descriptors revealed that aromatic profile of sPPIs is lower than iPPIs, but higher than eDrug. The sPPIs have significantly lower number of aromatic bonds than iPPIs (median $_{\text {sPPIs }}=12 \pm 7.8$, median $_{\mathrm{iPPIs}}=18 \pm 6.3$, with $\mathrm{P}<0.0001$ ), but higher than eDrugs (median $_{\mathrm{eDrug}}=10 \pm 6.1$, with $\mathrm{P}=0.0034$ ), Additionally, sPPIs have lower number of rings (median $_{\text {sPPIs }}$ is $3 \pm 1.6$ ) than iPPIs ( median $_{\text {iPPIs }}=4 \pm 1.2$, with $\mathrm{P}<0.0001$ ), but the same number of rings as eDrug (median ${ }_{\mathrm{eDrug}}=3 \pm 1.4$, with $\mathrm{P}=0.0027$ ). On one hand, compounds binding to ER, RAF, TASK, Topo, and BRI targets do not have aromatic bonds. On the other hand, compounds binding to Max, TNF, CD154, and PMA targets have more than 20 aromatic bonds. This discrepancy might be explained by the origin of the compounds. Natural products are known to be characterized by low aromatic character (29). In accordance, the set of compounds with zero aromatic bonds has only one synthetic compound, binding to Topo target. Similar trend was observed in the distribution of rings. Amongst compounds with number of rings below the mean ${ }_{\mathrm{sPPIs}}$ value are Ubiq, Auxin, CaM, Jas, Trans, and Topo target the majority constitute natural products. In contrast, compound with number of rings above eight, binding to CD154 target, has synthetic origin. Distribution of unsaturation index (Ui), which describes unsaturated bonds such as double, triple and aromatic bonds, respectively, showed that Ui of sPPIs is lower than iPPIs, but higher than eDrug (medium $_{\text {sPIs }}=3.6 \pm 1.0$, medium $_{\text {iPPIs }}=4.4 \pm 0.4$, with $\mathrm{P}<0.0001$, and medium ${ }_{\mathrm{eDrug}}=3.3 \pm 1.0$ with $\mathrm{P}=0.0486$ ). The aromatic ratio of $\mathrm{sPPI}$ is the same as iPPIs (medium $_{\mathrm{sPPIs}}=0.3 \pm 0.2$, medium $_{\mathrm{iPPIs}}=0.3 \pm 0.1$ with

Table 1. Summary of physico-chemical properties of sPPIs versus iPPIs and versus eDrug.

\begin{tabular}{lllllllllllll}
\hline & \multicolumn{3}{c}{ sPPIs } & \multicolumn{1}{c}{ iPPIs } & \multicolumn{5}{c}{ eDrug } \\
\hline & Mean Median & SD & Mean & Median & SD & P-value & Mean Median & SD & P-value \\
\hline MW & 386.1 & 363.6 & 149.4 & 514.7 & 496.1 & 130.6 & $\mathrm{P}<0.0001$ & 335.2 & 312.2 & 141.1 & $\mathrm{P}=0.0211$ \\
LogP & 3.2 & 3.3 & 1.9 & 4.6 & 4.7 & 2.0 & $\mathrm{P}<0.0001$ & 2.2 & 2.3 & 2.5 & $\mathrm{P}=0.0052$ \\
TPSA & 79.8 & 73.1 & 42.9 & 87.9 & 82.4 & 31.3 & $\mathrm{P}>0.05$ & 74.5 & 66.9 & 47.3 & $\mathrm{P}>0.05$ \\
NbHAcc & 5.6 & 5 & 3.1 & 6.9 & 7 & 2.2 & $\mathrm{P}<0.0001$ & 5.3 & 5 & 3.2 & $\mathrm{P}>0.05$ \\
NbHDon & 1.9 & 2 & 1.4 & 2.0 & 2 & 1.6 & $\mathrm{P}>0.05$ & 2.0 & 2 & 1.8 & $\mathrm{P}=0.06$ \\
NbAromaticBonds & 11.8 & 12 & 7.8 & 18.7 & 18 & 6.3 & $\mathrm{P}<0.0001$ & 9.0 & 10 & 6.1 & $\mathrm{P}=0.0034$ \\
NbRings & 3.3 & 3 & 1.6 & 4.5 & 4 & 1.2 & $\mathrm{P}<0.0001$ & 2.7 & 3 & 1.4 & $\mathrm{P}=0.0027$ \\
NbBenzeneLikeRings & 1.5 & 2 & 1.0 & 2.3 & 2 & 1.0 & $\mathrm{P}<0.0001$ & 1.1 & 1 & 0.9 & $\mathrm{P}=0.0013$ \\
NbDoubleBonds & 2.2 & 2 & 1.6 & 2.3 & 2 & 1.5 & $\mathrm{P}>0.05$ & 1.9 & 2 & 1.7 & $\mathrm{P}>0.05$ \\
\hline Ui & 3.6 & 3.8 & 1.0 & 4.4 & 4.4 & 0.4 & $\mathrm{P}<0.0001$ & 3.3 & 3.6 & 1.0 & $\mathrm{P}=0.0486$ \\
AromaticRatio & 0.3 & 0.3 & 0.2 & 0.3 & 0.3 & 0.1 & $\mathrm{P}>0.05$ & 0.2 & 0.2 & 0.1 & $\mathrm{P}<0.0001$ \\
\hline NbRotatableBonds & 4.5 & 4 & 3.1 & 6.6 & 6 & 3.0 & $\mathrm{P}<0.0001$ & 4.9 & 4 & 3.7 & $\mathrm{n} . \mathrm{s}$. \\
\hline
\end{tabular}


$\mathrm{P}>0.05$ ), but higher than eDrug (medium ${ }_{\mathrm{eDrug}} 0.2 \pm 0.1$, with $\mathrm{P}<0.0001$ ). The number of double bonds is the same as sPPIs, iPPIs, and eDrug (median ${ }_{\text {sPIs }, \text { PPIs,eDrug }}=2 \pm 1.6,1.5,1.7$, respectively, but with $\mathrm{P}>0.05$ ). The number of benzene like rings of sPPIs is the same as $\mathrm{iPPIs}$ ( median $_{\text {sPIs,iPPIs }}$ $=2 \pm 1.0,1.0$, respectively, with $\mathrm{P}<0.0001)$ and higher than eDrug $\left(\right.$ median $_{\mathrm{eDrug}}=1 \pm 0.9$, with $\mathrm{P}=0.0013$ ), figure 2, table 1 . The following descriptors show similar trend. Distribution of aromatic ratio showed that compounds binding to ER, RAF, TASK, Jas, Topo, and BRI1 targets have mean value of zero (figure 3). All of them, besides compound binding to Topo target, have natural origins. On the other hand, compounds with aromatic ratio higher than mean bind to Surv, TNF, PCNA, Auxin, and Trans targets, besides Auxin, are synthetic. Considering the number of double bonds, there is only one compound, binding to Max target, which does not have any double bonds. A few compounds have number of double bonds higher than mean value (2 double bonds), such as compounds binding to ER, ARF, CD154, Jas, Topo, and NP target. However, there is no clear trend considering the origin of compounds. Similarly to aromatic ratio descriptor, zero benzene like rings showed compounds binding to ER, RAF, TASK, Jas, Topo, and BRI1 target. These compounds, besides compound binding to Topo, have natural origins. In contrast, compounds with higher median value of benzene like rings are binding to PMA, TNF, and MDM2 targets, from which only PMA is semisynthetic, whereas the rest are synthetic.

\section{Flexibility of compounds}

Distribution of rotatable bonds showed that sPPIs tend to be flatter than iPPIs and conventional drugs. The sPPIs have significantly lower number of rotatable bonds than iPPIs and the same

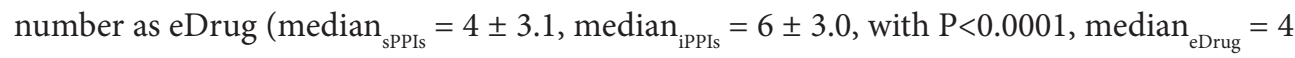
\pm 3.7 , but P-value is not significant), figure 2, table 1 . Considering the lack of statistical significance in sPPIs versus eDrug, it is suggested that there is no real difference in the flexibility of sPPIs and conventional drugs. One reason why they are flatter is because of the high aromatic ratio. The clear sPPIs outliers are compounds binding to CD154 and ER targets, with 15 and 14 rotatable bonds, respectively.

\section{PCA sPPIs versus iPPIs and versus eDrug}

To visualize the chemical space of PPIs stabilizers versus PPIs inhibitors and versus conventional drugs (eDrug database) we used principal component analysis (PCA) with 40 2D descriptors (supplementary material, table 3). Datasets of sPPIs, iPPIs, and eDrug consisted of 74, 354, and 698 chemically diverse compounds, respectively. The two first axis of the PCA represent $60.6 \%$ of the total variance, which allows for a reliable visualization. The first axis is described by MW, SumAtomPolar, NbC, NbAtom, and NbRings descriptors. The second axis is characterized by AromaticRatio, NbAromaticBonds, NbBenzeneLikeRings, and Ui descriptors (figure 4a). The global position of the sPPIs population is located in the upper left part of the distribution of three populations (figure $4 \mathrm{~b}$ ). It shows that as a general 

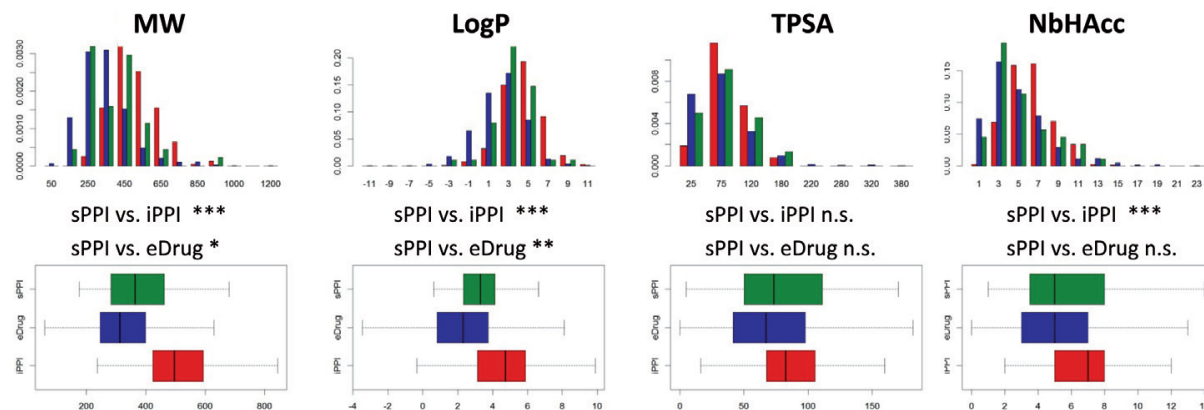

SPPI vs. iPPI $* * *$

sPPI vs. eDrug **

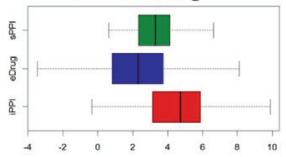

sPPI vs. iPPI n.s.

SPPI vs. iPPI $* * *$

sPPI vs. eDrug n.s.

sPPI vs. eDrug n.s.
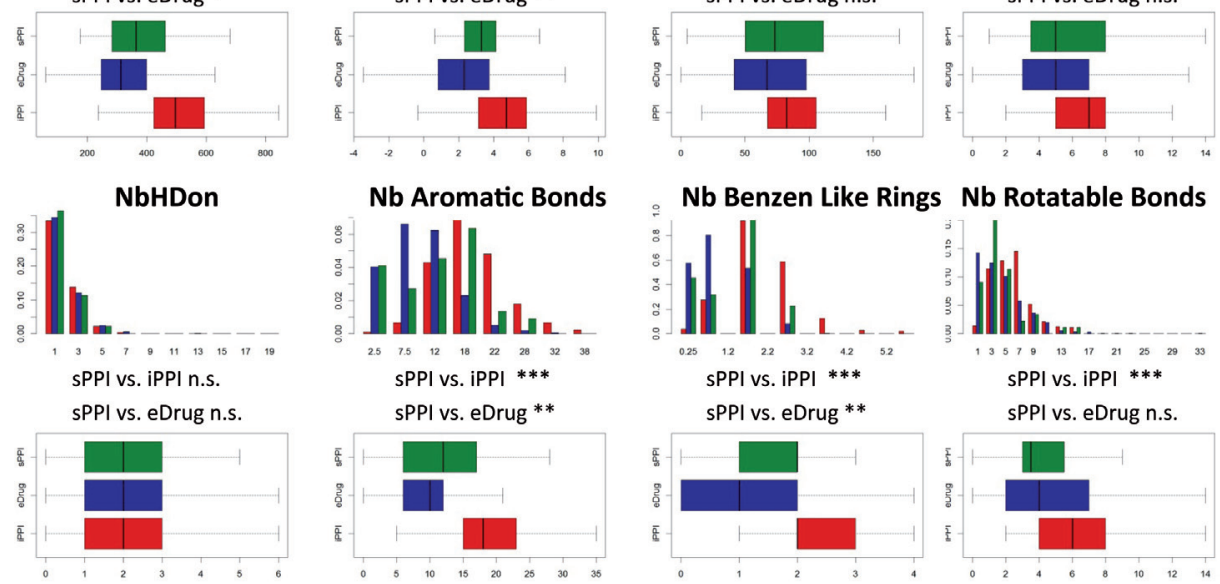

Nb Aromatic Bonds

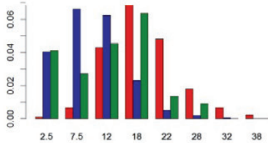

Nb Benzen Like Rings Nb Rotatable Bonds

SPPI vs. iPPI $* * *$

sPPI vs. eDrug **
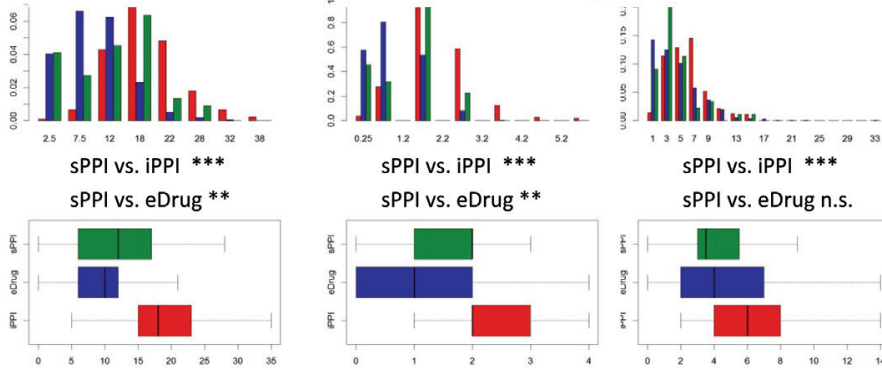

SPPI vs. iPPI $* * *$

sPPI vs. IPPI ***

sPPI vs. eDrug **

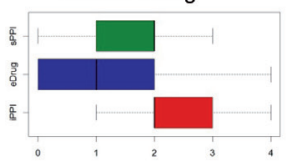

sPPI vs. eDrug n.s.

Nb Double Bonds

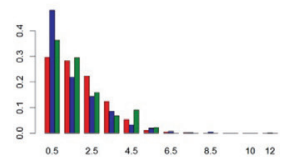

Nb Rings

Aromatic Ratio
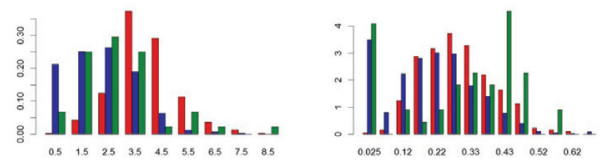

SPPI vs. IPPI ***

sPPI vs. IPPI n.s.

sPPI vs. eDrug n.s.
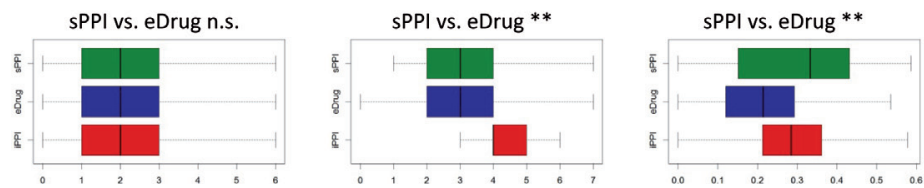

Figure 2. Distribution of eleven basic descriptors amongst diverse dataset of iPPI (in green) vs. unbiased diverse dataset of sPPI (in red) vs. diverse dataset of eDrugs (in blue). P-value $<0.001$ is indicated by $^{* * *}$, P-value $<0.01$ is indicated by ${ }^{* *}$, P-value $<0.05$ is indicated by ${ }^{*}$, and $\mathrm{P}$-value $>0.05$ is considered as not significant and indicated as n.s.

trend sPPIs are more similar to conventional drugs than to iPPIs. However, it is not the case for all of PPIs stabilizers. There are a few compounds (binding to CD154, Max, and TNF targets) that share more characteristic of iPPIs. It might be explained by the higher MW of these compounds (CD154 MW = 908.5 Da, TNF MW = 547.2 Da). To our knowledge, this is the first analysis of chemical space of stabilizers of PPI complexes. Due to limited number of compounds per target it is difficult to draw the target-dependent conclusions.

\section{D shape of sPPI ligands}

To characterize 3D shape of sPPIs and compare them with iPPIs, we collected dataset of sPPIs co-crystalized with their PPI complexes. We retrieved 54 X-ray structures of stabilizers in 


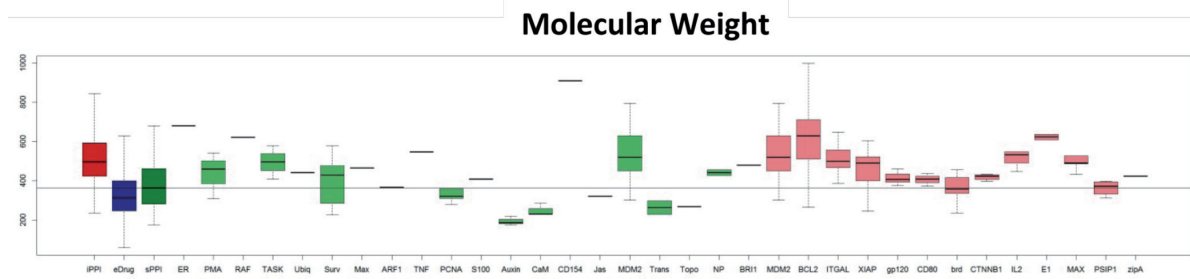

LogP

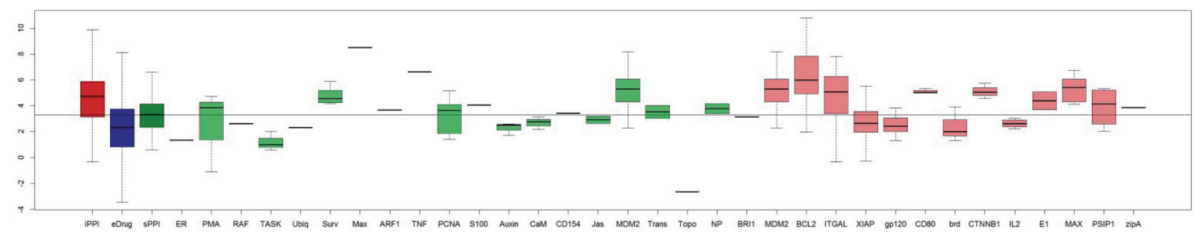

TPSA

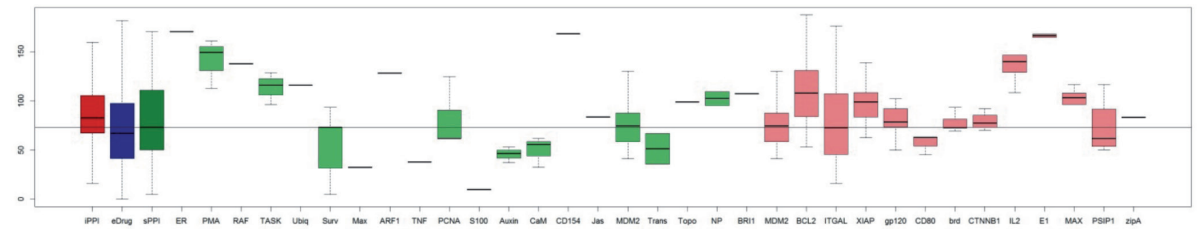

$\mathrm{Nb}$ H Acceptor

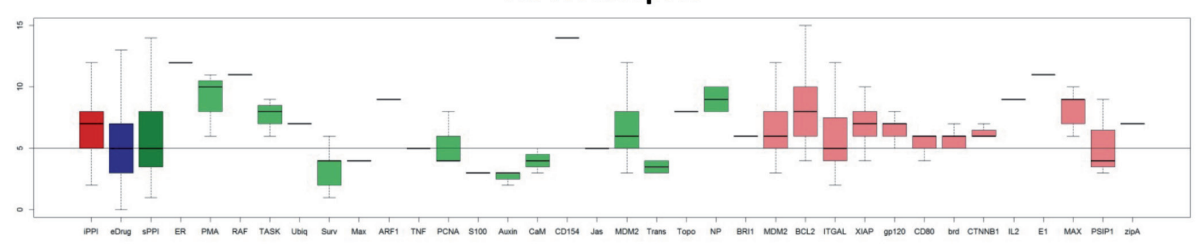

Nb H Donor

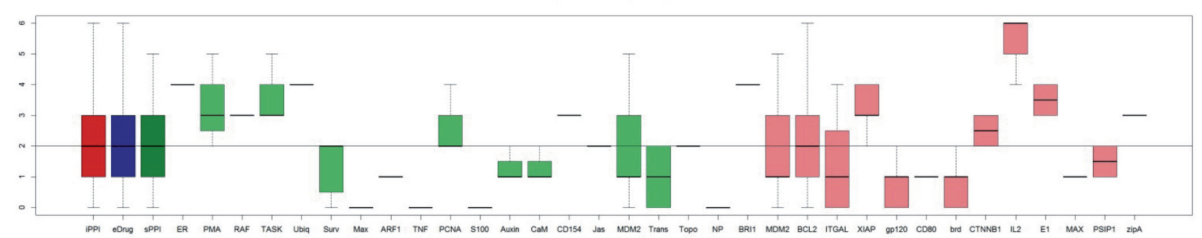

$\mathrm{Nb}$ Aromatic Bonds

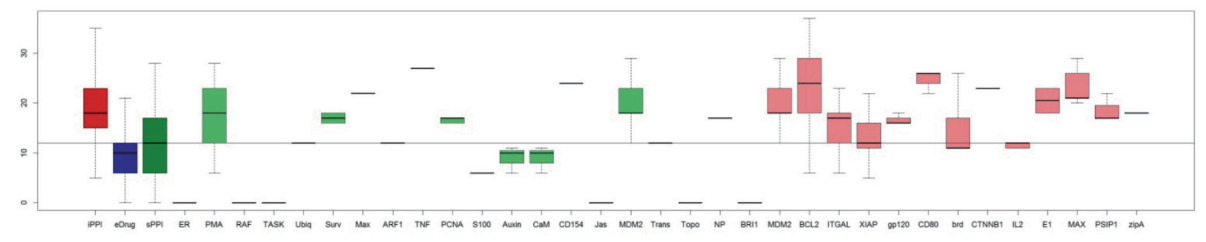




\section{Nb Benzen Like Rings}

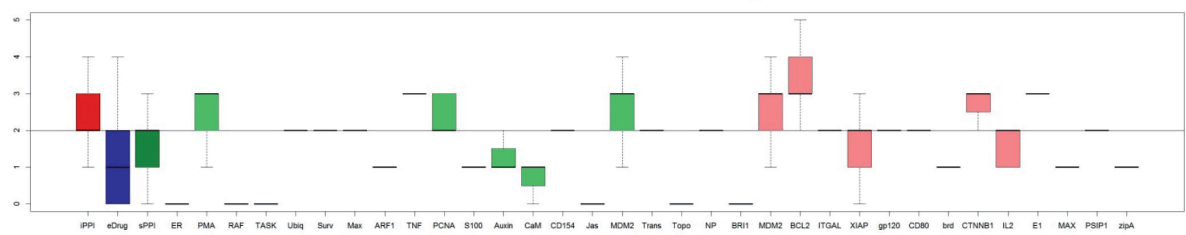

Nb Rotatable Bonds



Nb Double Bonds

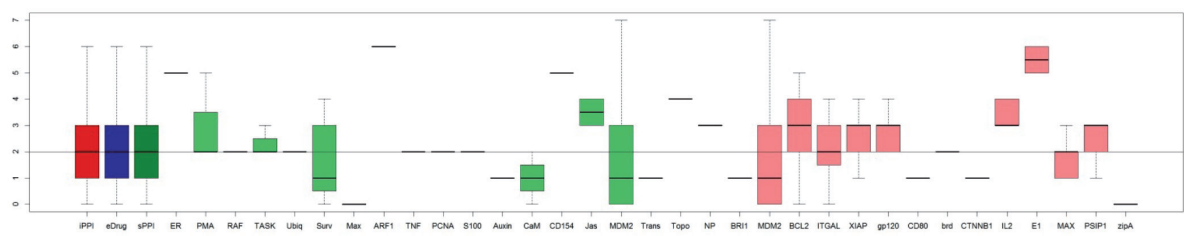

Nb Rings

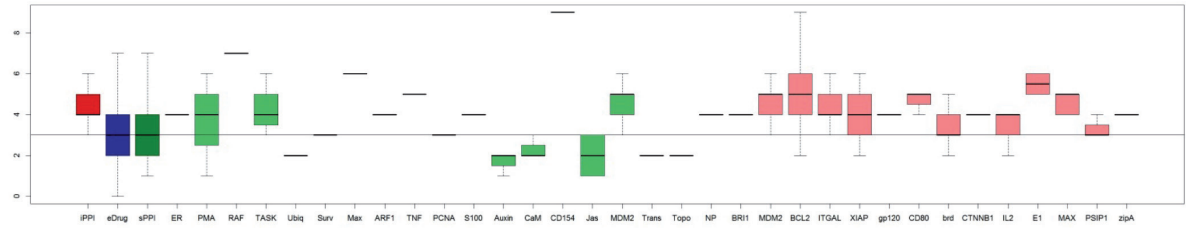

Aromatic Ratio

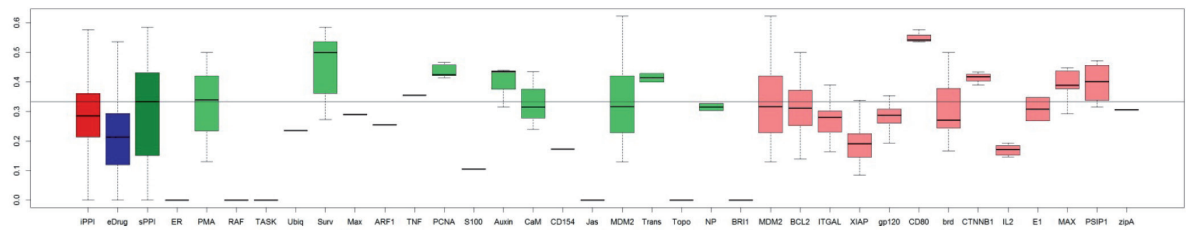

Figure 3. Distribution of nine basic descriptors amongst diverse dataset of iPPI (in green) vs sPPI (in red) vs eDrugs (in blue). sPPI and iPPI databases are distinguished per target in light green and light red, respectively.

complex with their proteins. Some of the X-ray complexes contained more than one copy of stabilizer. We compared the multiple copies of the same ligand and found differences in their RMSD values. Thus, we collected all of the copies, in total our dataset consisted of $1003 \mathrm{D}$ conformations for fifteen targets (figure 5). In an attempt to determine specific 3D shapebased properties for SPPI, and similarily to what was recently done for iPPIs (13), we calculated $3 \mathrm{D}$ descriptors of sPPIs and compared them to a set of non-sPPIs (conventional inhibitors) 
a

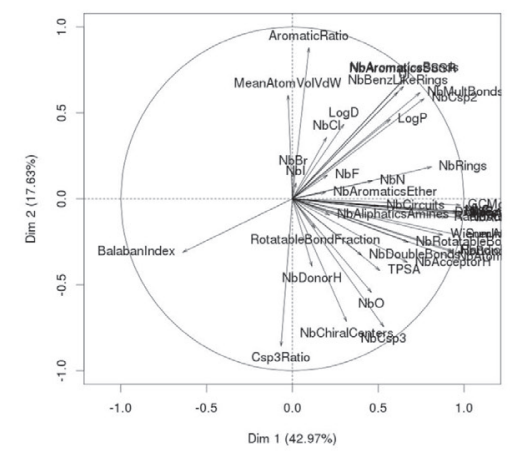

b

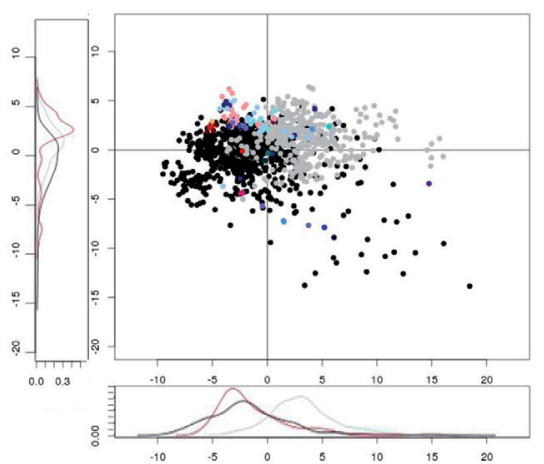

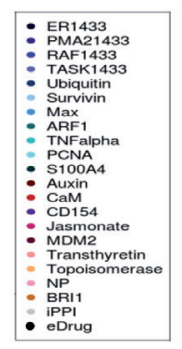

Figure 4. Principal component analysis (PCA) of sPPIs vs. iPPIs vs. eDrug. (a) variable map (b) distribution of sPPIs (multiple colours), iPPIs (grey), and eDrug (black). Density curves are located next to the $\mathrm{X}$ and $\mathrm{Y}$ axis. They represent differences according to each axis between sPPIs (red), iPPIs (grey), and eDrug (black).

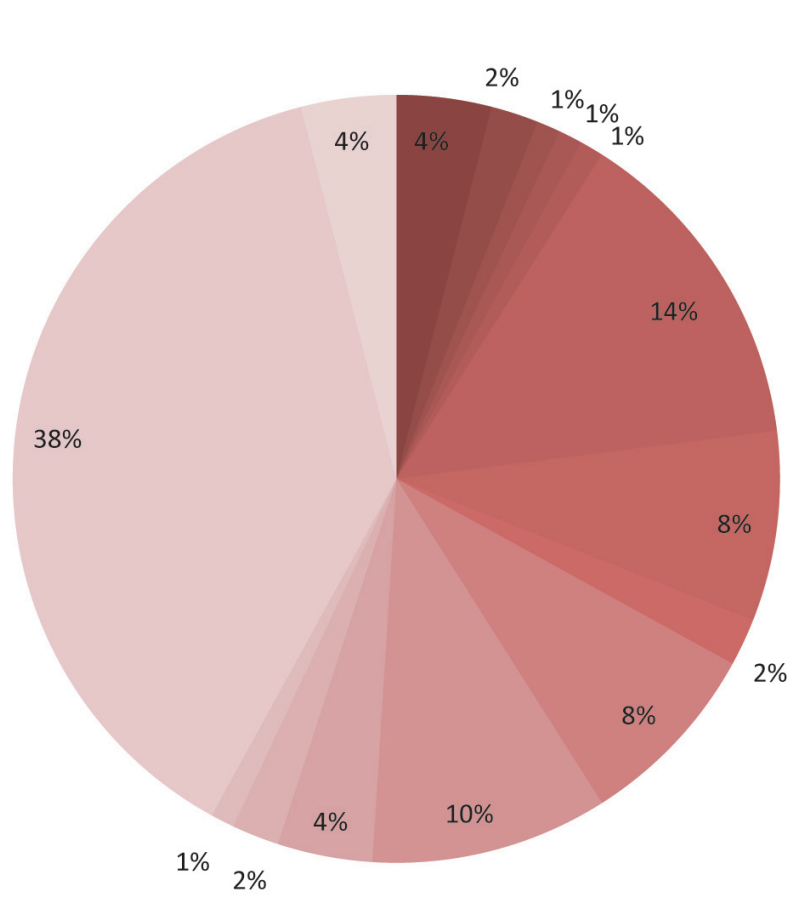

Figure 5. 3D sPPIs dataset per target.

Auxin

BRI1

CaM

- CD154

ER

Jas

- MDM2

nP

- PMA

RAF

S100

TNF

Topo

Trans

Ubiq

and iPPIs. To choose 3D descriptors that are discriminative between these two populations we calculated 106 3D descriptors. We selected five discriminatory descriptors for sPPIs: ASA+ (water accessible surface area of all atoms with positive partial charge), ASA_P (water accessible area of all polar atoms), CASA- (negative charge weighted surface area), rgyr (radius of gyration), and vsurf_Wp2 (total polar volume on the van der Waals surface of the 


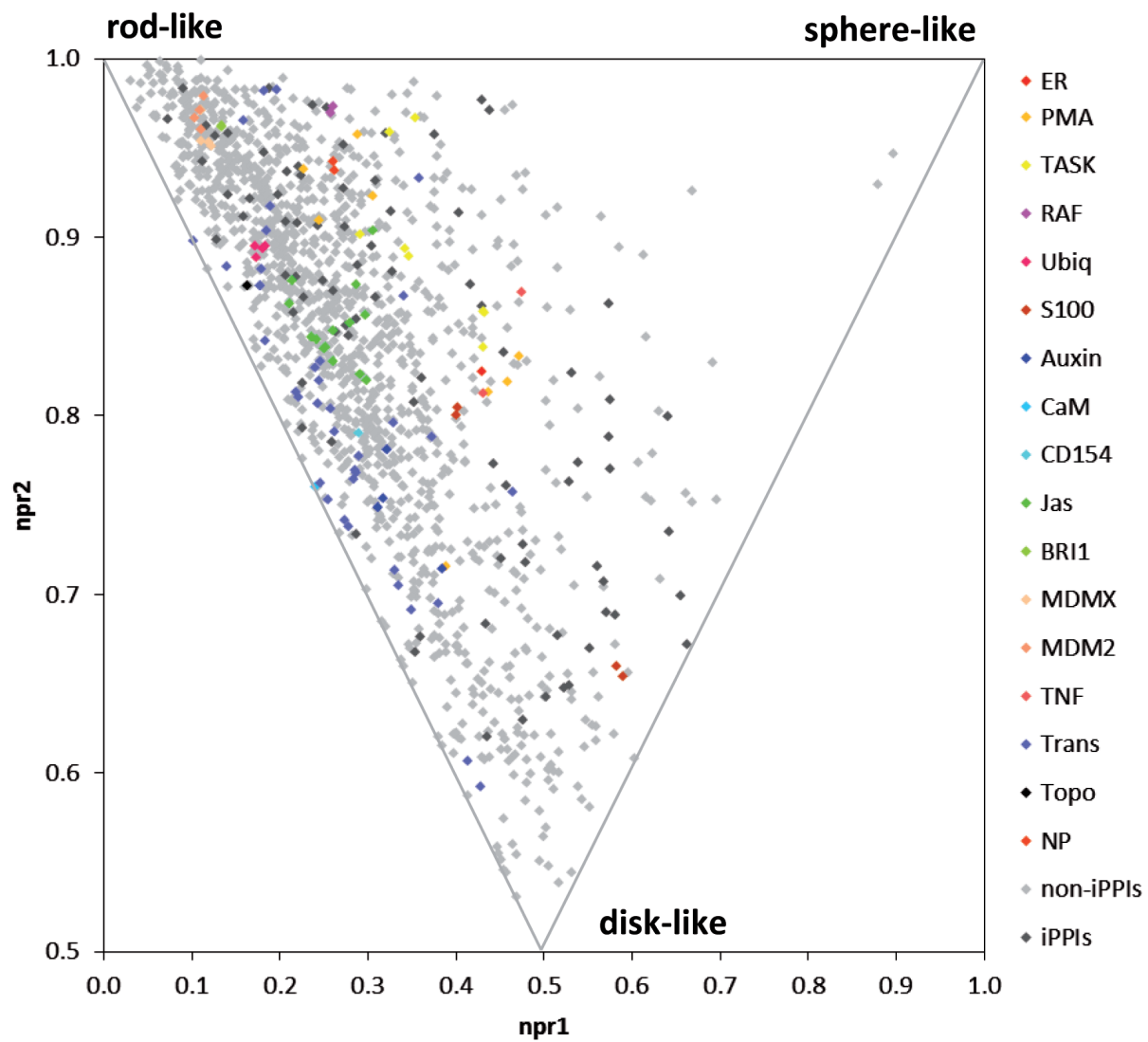

Figure 6. Principal moments of inertia plot of the normalized principal moments of inertia $\mathrm{X}$-axis, npr1, Y-axis, npr2 of sPPIs (colored per target) versus iPPIs (dark grey) and versus non-sPPIs (light grey).

molecule), respectively. Interestingly, rgyr, ASA+, CASA-, and vsurf_Wp2 descriptors showed correlation with the size of sPPIs (suplementary material, table 4). However, these descriptors still describe different sPPIs properties.

To show disribution of the 3D space of sPPIs, we used principal moment of inertia (PMI) plot of the normalized moment of inertia (npr1 and npr2) of sPPIs and compare them with iPPIs and non-iPPIs. The PMI plot represents also overall shape of compounds described as rodelike, sphare-like, or disk-like. In the general trend, majority of sPPIs resemble rode-like shape. With mean sPPIs npr $1=0.3 \pm 0.1$ and mean sPPIs npr2 $=0.9 \pm 0.1$. Only a few compounds binding to NP and Topo targets show more disk-like shape (figure 6). First axis, npr1, show that sPPIs versus iPPIs reveal lower rode-like shape than iPPIs ( mean $_{\text {iPPIs npr } 1}=0.4 \pm 0.2$ ), this comparison is discriminative with $\mathrm{P}_{\text {npr } 1}=0.00038$ However, second axis, npr2, did not show discriminative values between $s$ PPIs and iPPIs, $\mathrm{P}_{\text {npr2 }}=0.49$. Comparison both first and second axis, between sPPIs and non-iPPIs is not discriminatve, based on $\mathrm{P}_{\text {npr1 }}=0.89$, and $\mathrm{P}_{\text {npr2 }}=0.87$.

Distribution of five discriminative 3D shape-based descriptors created overview of the sPPIs 
molecular shape. First descriptor, radius of gyration (rgyr) is the mass weighted root-meansquare average distance of all atoms in the molecule from the centre of mass. It measures molecular compactness. The sPPIs is characterized by significantly lower radius of gyration than iPPIs and non-iPPs, (means sPPIs $=4.1 \pm 0.8$, whereas mean iPPIs $=4.8 \pm 1.2$, with $\mathrm{P}=1.3 \mathrm{E}$ 06 , mean $_{\text {non-PPIs }}=4.6 \pm 1.0$, with $\mathrm{P}=1.93 \mathrm{E}-08$ ), figure 7 , table 2 . It means that on average sPPIs are less spherical than iPPIs and non-iPPIs. Thus, sPPIs are considered to be rather flat molecules.

The sPPIs can by characterized by the descriptors evaluating their charges. ASA+, indicates water accessible surface area of all atoms with positive partial charge (strictly greater than 0 ). This i3D (internal coordinate dependent) molecular descriptor encodes each molecule accessible surface area (ASA) by atoms with positive charge. Distribution of ASA+ revealed that sPPIs have significantly lower ASA with positive partial charge than iPPIs and non-iPPIs $\left(\right.$ mean $_{\text {sPPIs }}=138.3 \pm 80.8$, mean $_{\text {iPPIs }}=245.5 \pm 77$, with $\mathrm{P}=1.15 \mathrm{E}-16$, and mean non-sPIs $=242 \pm$ 80.2 , with $\mathrm{P}=7.38 \mathrm{E}-23$ ), figure 7 , table 2 . It indicates that a larger ASA with positive partial charge has an enhancing effect on activity of iPPIs and non-iPPIs, but less of sPPIs. Another charge dependent 3D molecular descriptor is CASA-. It describes negative charge weighted
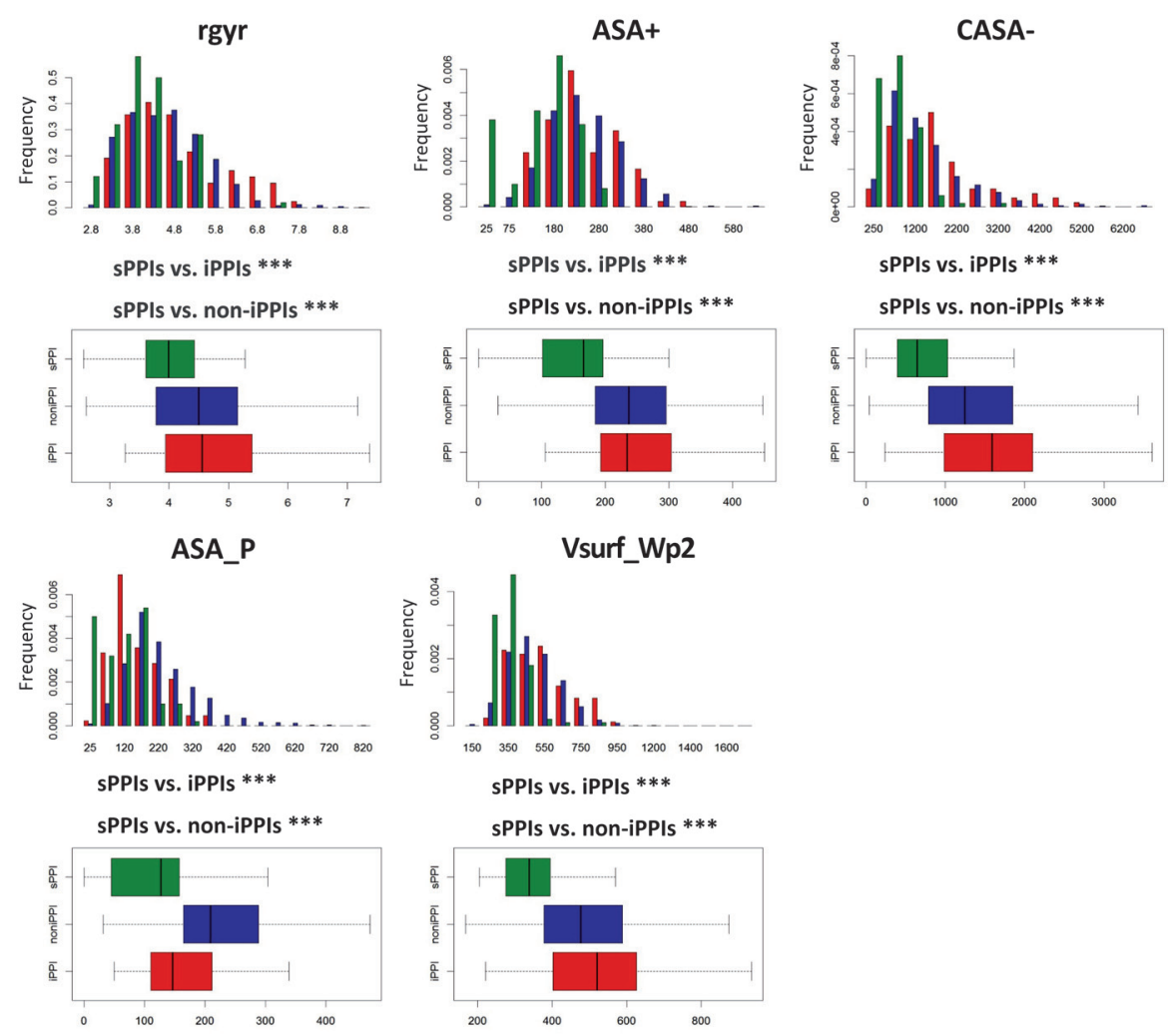

Figure 7. Distribution of five 3D descriptors amongst iPPI (green) vs. sPPI (red). P $<0.001$ is indicated by ${ }^{* * *}$. 
Table 2. Summary of shaped-based 3D descriptors of sPPIs versus iPPIs and versus non-iPPIs.

\begin{tabular}{lllllllllllllr}
\hline & \multicolumn{3}{c}{ sPPIs } & \multicolumn{4}{c}{ iPPIs } & \multicolumn{4}{c}{ Non-iPPIs } \\
\hline & Mean & Median & SD & Mean & Median & SD & P-value & Mean & Median & SD & P-value \\
\hline Rgyr & 4.1 & 4.0 & 0.8 & 4.8 & 4.6 & 1.15 & $1.3 \mathrm{E}-06$ & 4.6 & 4.5 & 1.0 & $1.93 \mathrm{E}-08$ \\
ASA+ & 138.3 & 162.9 & 81.2 & 245.5 & 235.4 & 77 & $1.15 \mathrm{E}-16$ & 242.0 & 236.6 & 80.2 & $7.38 \mathrm{E}-23$ \\
CASA- & 721 & 642.1 & 576.5 & 1778.8 & 1591.2 & 1084.4 & $7.1 \mathrm{E}-13$ & 1484.8 & 1247.8 & 988.1 & $1.41 \mathrm{E}-23$ \\
ASA_P & 114.1 & 127.1 & 77.1 & 166.1 & 147.8 & 72.4 & $6.02 \mathrm{E}-6$ & 233.9 & 209.4 & 108.0 & $2.78 \mathrm{E}-28$ \\
VsurfWp2 & 350 & 334.9 & 96.4 & 532.6 & 525.6 & 166.8 & $3.84 \mathrm{E}-15$ & 493.6 & 475.8 & 156.2 & $5.85 \mathrm{E}-28$ \\
\hline
\end{tabular}

surface area. It encodes features that are responsible for polar interatomic interactions. Distribution of CASA- showed that sPPI has significantly lower negative charged weighted surface than iPPIs and than non-iPPIs $\left(\right.$ mean $_{\text {sPPIs }}=721 \pm 576.5$, mean $_{\text {iPPIs }}=1778.8 \pm 1084.4$, with $\mathrm{P}=7.1 \mathrm{E}-13$, and mean non-iPPIs $=1484.8 \pm 988.1$, with $\mathrm{P}=1.41 \mathrm{E}-23)$, figure 7 , table 2 . It suggests that sPPIs have lower electron density that represent charged contact surface that can create polar intermolecular interactions than iPPIs and non-iPPIs.

Next descriptor, water accessible surface area of all polar atoms (ASA_P) represents favourable energy of polar atoms ( $\mathrm{N}$ and $\mathrm{O}$ ) for solvation in water than for the interior of the protein. ASA_P for sPPIs is significantly lower than for iPPIs and non-iPPIs ( mean $_{\text {sPIs }}=114.1 \pm 77.1$,

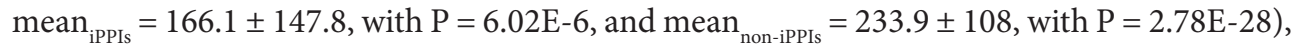
figure 7 , table 2. It means that sPPIs have fewer patches with polar atoms, $\mathrm{O}$ and $\mathrm{N}$, i.e. potential H-bond acceptors, which could interact with solvent (water), than iPPIs and noniPPIs. It might be explain that druggable pockets of sPPIs are not as wide open and solvent exposed, as interfaces of iPPIs and conventional drugs.

Last descriptor, total polar volume on the van der Waals surface of the molecule (vsurf_Wp2) defines the polar volume of the molecule and is calculated on $2.0 \mathrm{kcal} / \mathrm{mol}$ energy level. This descriptor might be explained as molecular envelope that is accessible by water molecules. Size of hydrophilic/polar regions on sPPIs is significantly smaller than on iPPIs and on non-iPPIs. Distribution of vsurf_Wp2 revealed mean $_{\text {sPPIs }}=350 \pm 96.4$, mean $_{\text {iPPIs }}=532.6 \pm$ 166.8, with $\mathrm{P}=3.84 \mathrm{E}-15$, and mean non-iPIs $=493.6 \pm 156.2$, with $\mathrm{P}=5.85 \mathrm{E}-28$, figure 7 , table 2 . It suggests that sPPIs have smaller hydrophilic patches needed for interactions with druggable pockets than iPPIs and non-iPPIs.

Concluding, 3D shape analysis showed that sPPIs are less spherical than iPPIs and non-iPPIs (lower rgyr), are less charged that iPPIs and non-iPPIs, have a less positive partial charge (lower ASA+), and have less negative charged weighted surface (lower CASA-) than iPPIs and non-iPPIs. Additionally, sPPIs have fewer patches with polar atoms, $\mathrm{O}$ and $\mathrm{N}$, i.e. potential $\mathrm{H}$-bond acceptors, which could interact with solvent (water) (lower ASA_P) than iPPIs and non-iPPIs. In accordance, sPPIs have smaller hydrophilic/polar regions on van der Waals surface of the molecule (lower vsurf_Wp2) iPPIs and on non-iPPIs. 


\section{D shape of iPPIs versus sPPIs}

Recent study evaluated 3D shape of iPPIs (13). It was shown that iPPI might be described by four descriminative descriptors EDmin (local interaction minimum), IW4 (integy moment), CW2 (capacity fator), and glob (globularity) respectively. These describtors revealed that ideal iPPIs is more globular than conventional drugs, has a stronger capacity to bind hydrophobic patches with a smaller proportion of exposed hudrophilic regions, and on the contrary with hydrophilic regions one extrimity of the compound (13). Our analysis showed that sPPIs are characterized by different 3D shape-based descriptors. However, we also compare sPPIs with the descriptors descriminative towards iPPIs. It showed that sPPIs are less globular than iPPIs , but resembles conventional drugs, glob mean ${ }_{\text {sPPIs }}=0.1 \pm 0.07$, mean $_{\text {iPPIs }}=0.2 \pm 0.1, \mathrm{P}=2.4 \mathrm{E}$ 07 , mean $_{\text {non-iPI }}=0.1 \pm 0.07, \mathrm{P}=0.1$. sPPIs have lower capacity to bind hydrophobic patches than iPPIs, EDmin 3 , mean $_{\text {sPPIs }}=-2.5 \pm 0.3 \mathrm{kcal} / \mathrm{mol}$, mean $_{\text {iPPIs }}=-2.9 \pm 0.2 \mathrm{kcal} / \mathrm{mol}, \mathrm{P}=4.7 \mathrm{E}$ 22 , mean $\left._{\text {non-PPI }}=-2.6 \pm 0.4 \mathrm{kcal} / \mathrm{mol}, \mathrm{P}=0.001\right)$. Additionally, sPPIs have a bigger proportion of exposed hydrophilic regions than iPPIs, CW2, mean $_{\text {sPPIs }}=2.1 \pm 0.2$, mean $_{\text {iPPIs }}=1.9 \pm 0.2, \mathrm{P}$ $=0.005$, mean $_{\text {non-iPPI }}=2.2 \pm 0.3, \mathrm{P}=0.003$. Finally, concentration of the hydrophilic regions is not exposed to one extremity of the compound as it is in case of iPPIs, IW4, mean ${ }_{\text {sPPIs }}=2.5 \pm$

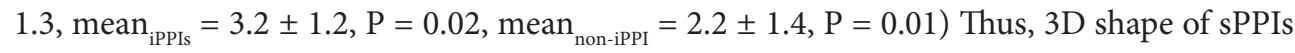
significantly differ from the inhibitors of PPIs.

\section{Conclusions}

PPI complexes are a new, very potent therapeutical target. In the last 20 years, dream of finding iPPIs became the reality $(7,30)$. Currently, stabilization of PPI complexes is becoming a new trend. There are already several success stories of finding small molecule stabilizers of PPIs (31). We collected small molecule sPPIs present in literature and analysed their physicochemical properties. Our analysis revealed that sPPIs meet the criteria of RO5, thus, resemble more profile of conventional drug than iPPIs. There are characterized by the MW of $386.1 \mathrm{Da}$, hydrophobicity represented by $\log P$ value of 3.2, hydrogen bond donors median value of 2 , hydrogen bond acceptors median value of 5 , rotatable bonds median value of 3 , and aromatic character represented by aromatic ratio value of 0.3 . These results imply that sPPIs in contrast to iPPIs do not require focued libraries. Commonly used small molecule databases might be used for the finding new stabilizers of PPIs. We also identified 3D shape stabilizers specific descriptors such as ASA+, ASA_P, CAS-, rgyr, and vsurf_Wp2, respectively. They revealed that ideal sPPIs are rather flat molecules, less charged; have less positive partial charges and less negative charged weighted surface. They are also less hydrophilic that is expressed by lower amount of patches with polar atoms and smaller hydrophilic regiones on van der Waals surface of the molecule than iPPIs and conventional drugs.

To our knowledge, this is the first analysis of sPPIs and the number of the collected small molecules allows only for analysis on the global level. However, the lesson learned from the 
iPPIs showed that the first rationalization of chemical space might boost the design of new compounds, which will allow for more specific, target-based chemical space analysis. Additionally, presented here physico-chemical properties of sPPIs might be cross analysed with their druggable pocket classified in our previous study (chapter 3 ). Thus, future analysis might allow for the design of the sPPIs according to binding place of compound and architecture of PPI complexes.

\section{Supplementary Materials}

Table 1. Names of PPI complexes.

\begin{tabular}{|c|c|c|}
\hline Number & Code of PPI complex & Name of PPI complex \\
\hline 1 & ARF1 & ARF1-Sec7 complex \\
\hline 2 & Auxin & TIR1-auxin-IAA complex \\
\hline 3 & BRI1 & BRI1-SERK complex \\
\hline 4 & $\mathrm{CaM}$ & SK2-CaM complex \\
\hline 5 & CD154 & CD154 homotrimer \\
\hline 6 & ER & 14-3-3-ER complex \\
\hline 7 & Jas & COI1-JAZ6 complex \\
\hline 8 & $\operatorname{Max}$ & Max homodimer \\
\hline 9 & MDM2 & MDM2/MDMX quasi-dimer \\
\hline 10 & NP & Influenza nucleoprotein homodimer \\
\hline 11 & PCNA & PCNA homotrimer \\
\hline 12 & PMA & 14-3-3-PMA complex \\
\hline 13 & RAF & 14-3-3-RAF complex \\
\hline 14 & Surv & Survivin homodimer \\
\hline 15 & S100 & S100A4 homopentamer \\
\hline 16 & TASK & 14-3-3-TASK complex \\
\hline 17 & TNF & TNFalpha homodimer \\
\hline 18 & Topo & Topoisomerase homodimer \\
\hline 19 & Trans & Transthyretin homotetramer \\
\hline 20 & Ubiq & Ubiquitin-E2ubiquitin conjugating enzyme complex \\
\hline
\end{tabular}


Table 2. Target and compound retrieved from PDB redo or PDB database $\left(^{*}\right)$ with their PDB IDs.

\begin{tabular}{|c|c|c|c|c|c|}
\hline Number & Target & PDB ID & Number & Target & PDB ID \\
\hline 1 & Auxin & $2 \mathrm{P} 1 \mathrm{~N}$ & 37 & Trans & $1 \mathrm{ICT}^{*}$ \\
\hline 2 & Auxin & $2 \mathrm{P} 1 \mathrm{O}$ & 38 & Trans & $2 \mathrm{~B} 77^{*}$ \\
\hline 3 & Auxin & $2 \mathrm{P} 1 \mathrm{Q}$ & 39 & Trans & $2 \mathrm{~B}^{\circ} \mathrm{A}^{*}$ \\
\hline 4 & BRI1 & 4LSX & 40 & Trans & $2 \mathrm{~F} 7 \mathrm{I}^{\star}$ \\
\hline 5 & $\mathrm{CaM}$ & 4J9Z & 41 & Trans & $2 \mathrm{G} 5 \mathrm{U}^{*}$ \\
\hline 6 & CD154 & $3 \mathrm{LKJ}$ & 42 & Trans & $3 \mathrm{CFN}$ \\
\hline 7 & ER & $4 \mathrm{JDD}$ & 43 & Trans & $3 \mathrm{CFT}$ \\
\hline 8 & Jas & 3OGL & 44 & Trans & $3 \mathrm{CN} 1$ \\
\hline 9 & Jas & 3OGM & 45 & Trans & $3 \mathrm{CN} 2$ \\
\hline 10 & MDMX & $3 \mathrm{U} 15$ & 46 & Trans & $3 \mathrm{CN} 3$ \\
\hline 11 & MDM2 & 3BVG & 47 & Trans & $3 \mathrm{CN} 4$ \\
\hline 12 & NP & 3RO5 & 48 & Trans & $3 \mathrm{D} 2 \mathrm{~T}$ \\
\hline 13 & PMA & $1 \mathrm{O} 9 \mathrm{~F}$ & 49 & Trans & $3 \mathrm{ESN}$ \\
\hline 14 & PMA & $3 \mathrm{M} 50$ & 50 & Trans & $3 \mathrm{ESO}$ \\
\hline 15 & PMA & 3M51 & 51 & Trans & 3ESP \\
\hline 16 & PMA & 4DX0 & 52 & Trans & $4 \mathrm{ABU}$ \\
\hline 17 & PMA & 2098 & 53 & Trans & $4 \mathrm{ABV}$ \\
\hline 18 & PMA & $3 \mathrm{E} 6 \mathrm{Y}$ & 54 & Ubiq & $4 \mathrm{MDK}$ \\
\hline 19 & RAF & $4 \mathrm{IHL}$ & & & \\
\hline 20 & S100 & $3 \mathrm{KO} 0$ & & & \\
\hline 21 & TASK & $3 \mathrm{SPR}$ & & & \\
\hline 22 & TASK & 3SMO & & & \\
\hline 23 & TASK & $3 \mathrm{P} 1 \mathrm{O}$ & & & \\
\hline 24 & TASK & 3SMM & & & \\
\hline 25 & TASK & $3 \mathrm{SMN}$ & & & \\
\hline 26 & TASK & $3 \mathrm{SML}$ & & & \\
\hline 27 & TASK & $3 \mathrm{UX0}$ & & & \\
\hline 28 & TASK & $4 \mathrm{FR} 3$ & & & \\
\hline 29 & TNF & $2 \mathrm{AZ} 5$ & & & \\
\hline 30 & Topo & 1QZR & & & \\
\hline 31 & Trans & 1BM7 & & & \\
\hline 32 & Trans & $1 \mathrm{DVS}^{*}$ & & & \\
\hline 33 & Trans & $1 \mathrm{DVT}^{*}$ & & & \\
\hline 34 & Trans & $1 \mathrm{DVX}^{*}$ & & & \\
\hline 35 & Trans & $1 \mathrm{DVY}^{\star}$ & & & \\
\hline 36 & Trans & $1 \mathrm{DVZ}^{*}$ & & & \\
\hline
\end{tabular}


Table 3. List of 2D descriptors used in the PCA analysis.

\begin{tabular}{|c|c|c|}
\hline Number & Abbreviation of $2 \mathrm{D}$ descriptors & Name of 2D descriptors \\
\hline 1 & AromaticRatio & $\begin{array}{l}\text { Number of aromatic rings divided by the number of heavy } \\
\text { atoms }\end{array}$ \\
\hline 2 & BalabanIndex & $\begin{array}{l}\text { the Balaban distance connectivity of the molecule, which is } \\
\text { the average distance sum connectivity }\end{array}$ \\
\hline 3 & Csp3Ratio & Number of carbon $\mathrm{sp} 3$ divided by the number of carbons \\
\hline 4 & DiamGraphNonHydrogenPetitjean & Computation of the diameter of a molecular graph \\
\hline 5 & GCMolarRefractivity & $\begin{array}{l}\text { Gas chromatography retention time used for the } \\
\text { calculation of molar refractivity }\end{array}$ \\
\hline 6 & $\log \mathrm{D}$ & Log of distribution coefficient \\
\hline 7 & $\log P$ & Log of the octanol/water partition coefficient \\
\hline 8 & MeanAtomVolVanderWaals & $\begin{array}{l}\text { Calculates mean of atoms for the van der Waals surface of } \\
\text { the molecule }\end{array}$ \\
\hline 9 & MolecularWeight & Molecular Weight of the compound \\
\hline 10 & $\mathrm{NbAcceptorH}$ & Number of atom acceptor of hydrogen \\
\hline 11 & NbAliphaticsAmines & Number of aliphatic amines \\
\hline 12 & NbAromaticsBonds & Number of aromatic bonds \\
\hline 13 & NbAromaticsEther & Number of aromatic ether \\
\hline 14 & NbAromaticsSSSR & $\begin{array}{l}\text { Number of aromatic rings calculated from the smallest set } \\
\text { of smallest aromatic rings (SSSAR) }\end{array}$ \\
\hline 15 & NbAtom & Number of atoms \\
\hline 16 & NbAtomNonH & Number of atoms without hydrogen atoms \\
\hline 17 & NbBenzeneLikeRings & Number of benzene like rings \\
\hline 18 & NbBonds & Number of bonds \\
\hline 19 & NbBondsNonH & Number of bonds without-bonds of hydrogen atoms \\
\hline 20 & $\mathrm{NbBr}$ & Number of Bromine atoms \\
\hline 21 & $\mathrm{NbC}$ & Number of Carbon atoms \\
\hline 22 & NbChiralCenter & Number of chiral center \\
\hline 23 & NbCircuits & Number of circuits \\
\hline
\end{tabular}




\begin{tabular}{|c|c|c|}
\hline Number & Abbreviation of 2D descriptors & Name of $2 \mathrm{D}$ descriptors \\
\hline 24 & $\mathrm{NbCl}$ & Number of Chlorine atoms \\
\hline 25 & NbCsp2 & Number of carbon sp2 \\
\hline 26 & NbCsp3 & Number of carbon sp3 \\
\hline 27 & NbDonorH & Number of atom donor of hydrogen \\
\hline 28 & NbDoubleBonds & Number of double bonds \\
\hline 29 & $\mathrm{NbF}$ & Number of Fluorine atoms \\
\hline 30 & $\mathrm{NbI}$ & Number of Iodine atoms \\
\hline 31 & NbMultipleBonds & Number of multiple bonds \\
\hline 32 & $\mathrm{NbN}$ & Number of Nitrogen atoms \\
\hline 33 & $\mathrm{NbO}$ & Number of Oxygen atoms \\
\hline 34 & NbRings & Number of rings \\
\hline 35 & NbRotatableBonds & Number of rotatable bonds \\
\hline 36 & RadiusGraphNonHPetitjean & Computation of the radius of a molecular graph \\
\hline 37 & RandicIndex & $\begin{array}{l}\text { Harmonic sum of the geometric means of the node degrees } \\
\text { for each edge. }\end{array}$ \\
\hline 38 & RotatableBondFraction & $\begin{array}{l}\text { Number of rotatable bonds divided by the number of heavy } \\
\text { atoms }\end{array}$ \\
\hline 39 & SumAtomPolar & Sum of polar atoms \\
\hline 40 & SumAtomVolumeVanderWaals & $\begin{array}{l}\text { Calculates sum of atoms for the van der Waals surface of } \\
\text { the molecule }\end{array}$ \\
\hline 41 & TPSA & Topological surface area \\
\hline 42 & $\mathrm{Ui}$ & Unsaturated index \\
\hline 43 & WienerIndex & $\begin{array}{l}\text { The average topological atom distance (half of the sum of } \\
\text { all atom distances) in the molecule }\end{array}$ \\
\hline
\end{tabular}


Table 4. Correlation of shaped-based 3D descriptors with their $\log P$ and MW.

\begin{tabular}{|c|c|c|c|c|c|c|c|}
\hline & rgyr & ASA+ & CASA- & ASA_P & vsurf_Wp2 & $\log P$ & MW \\
\hline rgyr & 1.0 & 0.6 & 0.6 & 0.3 & 0.8 & 0.6 & 0.8 \\
\hline ASA+ & 0.6 & 1.0 & 0.5 & 0.3 & 0.8 & 0.3 & 0.5 \\
\hline CASA- & 0.6 & 0.5 & 1.0 & 0.6 & 0.6 & 0.4 & 0.8 \\
\hline ASA_P & 0.3 & 0.3 & 0.6 & 1.0 & 0.4 & -0.2 & 0.3 \\
\hline vsurf_Wp2 & 0.8 & 0.8 & 0.6 & 0.4 & 1.0 & 0.4 & 0.7 \\
\hline $\log P$ & 0.6 & 0.3 & 0.4 & -0.2 & 0.4 & 1.0 & 0.6 \\
\hline MW & 0.8 & 0.5 & 0.8 & 0.3 & 0.7 & 0.6 & 1.0 \\
\hline
\end{tabular}

\section{Acknowledgments}

This work was supported by a medium investment grant (to G.N.), the Cardiovascular Research Institute Maastricht (to G.N.), the European Union Grant KBBE-2011-5 289350, AllBio, and EFRO (to G.V.), the Transnational University Limburg (to G.N.), and Cyttron II [FES0908 (to G.N.). 


\section{References}

1. Stumpf MPH, Thorne T, de Silva E, Stewart R, An HJ, Lappe M, et al. Estimating the size of the human interactome. Proc Natl Acad Sci U S A. 2008 May 13;105(19):6959-64.

2. Jones S, Thornton JM. Principles of protein-protein interactions. Proc Natl Acad Sci U S A. 1996 Jan 9;93(1):1320.

3. Lo Conte L, Chothia C, Janin J. The atomic structure of protein-protein recognition sites. J Mol Biol. 1999 Feb 5;285(5):2177-98.

4. Pérot S, Sperandio O, Miteva MA, Camproux A-C, Villoutreix BO. Druggable pockets and binding site centric chemical space: a paradigm shift in drug discovery. Drug Discov Today. 2010 Aug;15(15-16):656-67.

5. Fuller JC, Burgoyne NJ, Jackson RM. Predicting druggable binding sites at the protein-protein interface. Drug Discov Today. 2009 Feb;14(3-4):155-61.

6. Wells JA, McClendon CL. Reaching for high-hanging fruit in drug discovery at protein-protein interfaces. Nature. 2007 Dec 13;450(7172):1001-9.

7. Arkin MR, Tang Y, Wells JA. Small-molecule inhibitors of protein-protein interactions: progressing toward the reality. Chem Biol. 2014 Sep 18;21(9):1102-14.

8. Labbé CM, Laconde G, Kuenemann MA, Villoutreix BO, Sperandio O. iPPI-DB: a manually curated and interactive database of small non-peptide inhibitors of protein-protein interactions. Drug Discov Today. 2013 Oct;18(19-20):958-68.

9. Basse MJ, Betzi S, Bourgeas R, Bouzidi S, Chetrit B, Hamon V, et al. 2P2Idb: a structural database dedicated to orthosteric modulation of protein-protein interactions. Nucleic Acids Res. 2013 Jan;41(Database issue):D824-7.

10. Higueruelo AP, Jubb H, Blundell TL. TIMBAL v2: update of a database holding small molecules modulating protein-protein interactions. Database J Biol Databases Curation. 2013;2013:bat039.

11. Sperandio O, Reynès $\mathrm{CH}$, Camproux A-C, Villoutreix BO. Rationalizing the chemical space of protein-protein interaction inhibitors. Drug Discov Today. 2010 Mar;15(5-6):220-9.

12. Reynès C, Host H, Camproux A-C, Laconde G, Leroux F, Mazars A, et al. Designing focused chemical libraries enriched in protein-protein interaction inhibitors using machine-learning methods. PLoS Comput Biol. 2010 Mar;6(3):e1000695.

13. Kuenemann MA, Bourbon LML, Labbé CM, Villoutreix BO, Sperandio O. Which three-dimensional characteristics make efficient inhibitors of protein-protein interactions? J Chem Inf Model. 2014 Nov 24;54(11):3067-79.

14. Lipinski CA, Lombardo F, Dominy BW, Feeney PJ. Experimental and computational approaches to estimate solubility and permeability in drug discovery and development settings. Adv Drug Deliv Rev. 2001 Mar 1;46(13):3-26.

15. Thiel P, Kaiser M, Ottmann C. Small-molecule stabilization of protein-protein interactions: an underestimated concept in drug discovery? Angew Chem Int Ed Engl. 2012 Feb 27;51(9):2012-8.

16. Molzan M, Kasper S, Röglin L, Skwarczynska M, Sassa T, Inoue T, et al. Stabilization of physical RAF/14-3-3 interaction by cotylenin A as treatment strategy for RAS mutant cancers. ACS Chem Biol. 2013 Sep 20;8(9):1869-75.

17. Anders C, Higuchi Y, Koschinsky K, Bartel M, Schumacher B, Thiel P, et al. A semisynthetic fusicoccane stabilizes a protein-protein interaction and enhances the expression of $\mathrm{K}+$ channels at the cell surface. Chem Biol. 2013 Apr 18;20(4):583-93.

18. Block P, Weskamp N, Wolf A, Klebe G. Strategies to search and design stabilizers of protein-protein interactions: a feasibility study. Proteins. 2007 Jul 1;68(1):170-86.

19. Pihan E, Colliandre L, Guichou J-F, Douguet D. e-Drug3D: 3D structure collections dedicated to drug repurposing and fragment-based drug design. Bioinforma Oxf Engl. 2012 Jun 1;28(11):1540-1.

20. Joosten RP, Salzemann J, Bloch V, Stockinger H, Berglund A-C, Blanchet C, et al. PDB_REDO: automated rerefinement of X-ray structure models in the PDB. J Appl Crystallogr. 2009 Jun 1;42(Pt 3):376-84.

21. Bernstein FC, Koetzle TF, Williams GJ, Meyer EF, Brice MD, Rodgers JR, et al. The Protein Data Bank: a computer-based archival file for macromolecular structures. J Mol Biol. 1977 May 25;112(3):535-42.

22. MOE; Chemical Computing Group: Montreal, Quebec, Canada, 2012.

23. Chemaxon, www.chemaxon.com.

24. R Core Team (2013). R: A language and environment for statistical computing. R Foundation for Statistical Computing, Vienna, Austria.

25. Silvian LF, Friedman JE, Strauch K, Cachero TG, Day ES, Qian F, et al. Small molecule inhibition of the TNF family cytokine CD40 ligand through a subunit fracture mechanism. ACS Chem Biol. 2011 Jun 17;6(6):636-47.

26. Weiss G, Loyevsky M, Gordeuk VR. Dexrazoxane (ICRF-187). Gen Pharmacol. 1999 Jan;32(1):155-8. 
27. Jiang H, Bower KE, Beuscher AE, Zhou B, Bobkov AA, Olson AJ, et al. Stabilizers of the Max homodimer identified in virtual ligand screening inhibit Myc function. Mol Pharmacol. 2009 Sep;76(3):491-502.

28. He MM, Smith AS, Oslob JD, Flanagan WM, Braisted AC, Whitty A, et al. Small-molecule inhibition of TNFalpha. Science. 2005 Nov 11;310(5750):1022-5.

29. Comprehensive Natural Products II: Chemistry and Biology: 10 Volume Set. Newnes; 2010. 7945 p.

30. Arkin MR, Wells JA. Small-molecule inhibitors of protein-protein interactions: progressing towards the dream. Nat Rev Drug Discov. 2004 Apr;3(4):301-17.

31. Giordanetto F, Schäfer A, Ottmann C. Stabilization of protein-protein interactions by small molecules. Drug Discov Today. 2014 Nov;19(11):1812-21. 



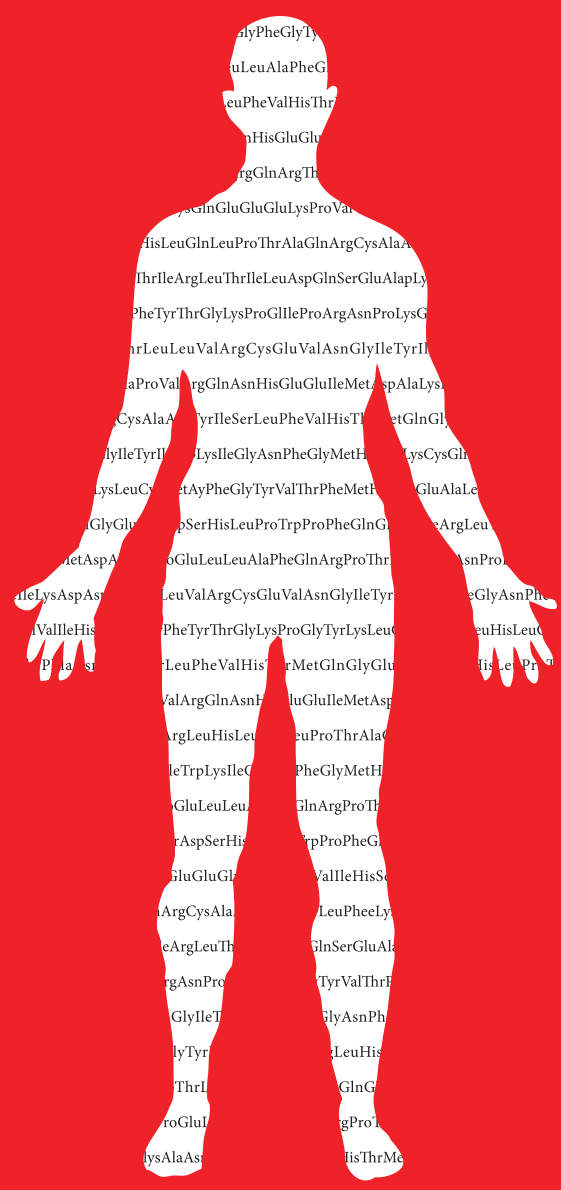




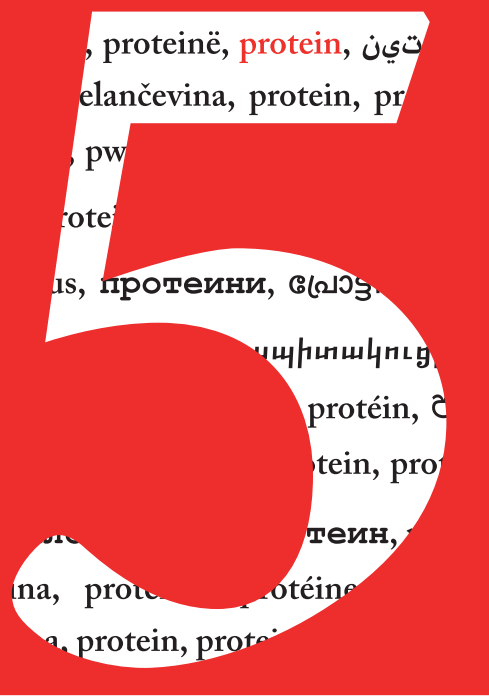

\section{Discovery of Small Molecule CD40-TRAF6 Inhibitors}

B. Zarzycka*, T. Seijkens ${ }^{*}$, S.B. Nabuurs, T. Ritschel, J. Grommes, O. Soehnlein, R. Schrijver, C.M. van Tiel, T.M. Hackeng, C. Weber, F. Giehler, A. Kieser, E. Lutgens", G. Vriend", G.A.F. Nicolaes", ${ }^{*}$ equal contribution

J Chem Inf Model, 2015; 23;55(2):294-307 


\begin{abstract}
The CD154-CD40 receptor complex plays a pivotal role in several inflammatory pathways. Attempts to inhibit the formation of this complex have resulted in systemic side-effects. Downstream inhibition of the CD40 signalling pathway therefore seems a better way to ameliorate inflammatory disease. To relay a signal, the CD40 receptor recruits adapter proteins called tumor necrosis factor receptor-associated factors (TRAFs). CD40-TRAF6 interactions are known to play an essential role in several inflammatory diseases. We used in silico, in vitro, and in vivo experiments to identify and characterise compounds that block CD40-TRAF6 interactions. We present in detail our drug docking and optimization pipeline and show how we used it to find lead compounds that reduce inflammation in models of peritonitis and sepsis. These compounds appear to be good leads for drug development, given the observed absence of side-effects and their demonstrated efficacy for peritonitis and sepsis in mouse models.
\end{abstract}




\section{Introduction}

CD40 is a transmembrane protein receptor that belongs to the tumour necrosis factor (TNF) receptor super-family and is primarily present on antigen presenting cells. It can be activated by its ligand CD154 (also known as CD40L or GP39), which is a transmembrane glycoprotein. CD154 is transiently expressed on activated T-cells and other non-immune cells under inflammatory conditions, and is also found in a soluble form. Binding results in CD40 homotrimerization and intracellular recruitment of TNF receptor-associated factors (TRAFs) that subsequently elicit signalling (1). CD40 can bind TRAF1, 2, 3, 5, and 6. Two different binding sites have been determined in the intracellular domain of CD40, one for TRAF2, 3, and 5, and one for TRAF6 (2). The 180 amino acid long C-domain of the TRAF family proteins can bind to the cytosolic domain of CD40 (3). CD40 signalling can activate downstream pathways such as the NFkB, C-Jun N-terminal kinase (JNK), or the p38 mitogen activated protein (MAP) kinase pathway, depending on which TRAFs gets recruited (2). CD154-CD40 interactions play a pivotal role in immunity by, for example, promoting T-cell activation and immunoglobulin isotype switching (1). Moreover, the CD154-CD40 complex is involved in the pathogenesis of (chronic) inflammatory diseases (4) like atherosclerosis, inflammatory bowel disease, psoriasis, systemic lupus erythematosus, rheumatoid arthritis, allograft rejection, and obesity-associated inflammation and insulin resistance. The CD154-CD40 complex has been shown to be a good target for drug design projects, and antibodies for CD154 and CD40 have reached phase I and phase II clinical trials in the development of drug treatments for multiple sclerosis, psoriasis (5), lupus nephritis (6), and systemic lupus erythematosus (7). Long-term inhibition of CD154-CD40 interactions by small molecule ligands (8) or monoclonal antibodies (9) is not clinically feasible, because of envisioned immune-suppression or, for CD154, thrombo-embolic complications (9). More downstream inhibition of the CD40 signalling pathway therefore seems a better approach.

We have shown that interaction of CD40 with TRAF6 (but not with TRAF 2, 3, and 5 is involved in the development of atherosclerosis (10) and obesity-associated insulin resistance (11). These interactions occur downstream from CD40, making them a better entry point for pharmacological intervention because some of the other functions of CD40-signalling would remain intact, presumably limiting immunosuppressive side effects (10). One of the compounds that functionally blocks CD40-TRAF6 signalling is a potent (and safe) inhibitor in obesity-associated insulin resistance in mouse models (11). Here, we present comprehensive details of the drug selection pipeline and extend it by inclusion of two additional ligand optimization strategies that resulted in new compounds with different scaffolds. We also show that the compounds are active, ameliorating peritonitis and sepsis in addition to diet-induced obesity. 


\section{Materials and Methods}

\section{Protein target preparation}

The X-ray structure of the TRAF6 C-domain in complex with a CD40 fragment (PDB ID: 1LB6; resolution $1.80 \AA(12)$ ) and the TRAF6 C-domain apo structure (PDB ID: 1LB4; resolution $2.40 \AA$ (12)) were retrieved from the Protein Databank (PDB (13)), as described before (11). The YASARA-WHAT IF Twinset package (14) was used to add hydrogen atoms and optimize their positions. This optimization includes the WHAT IF (15) procedure that predicts His, Glu, and Asp ionization states (all of which were normal) and side chain flips of His, Asn, and Gln (three Gln, five His, and one Asn side chain were flipped). The co-crystallized CD40 fragment was removed before the hydrogen optimization and all solvent molecules were removed afterwards. During structure optimization the YASARA-WHAT IF Twinset additionally removes atomic clashes with an unrestrained steepest descent energy minimization, and normalizes extreme bond lengths and angles.

$\mathrm{X}$-ray structures were superposed with the MOTIF algorithm (16) as implemented in the YASARA-WHAT IF Twinset package. Arg466 is missing in the apo structure (PDB ID: 1LB4) suggesting that this residue is very flexible. Arg466 is involved in interactions with the CD40 peptide fragment, which causes it to be located inside the druggable pocket in the holo structure (PDB ID: 1LB6). We used YASARA's backbone dependent rotamer library (17) to guide the manual placement of Arg466 outside this pocket.

ICM PocketFinder (18) and Q-SiteFinder (19) were used to detect druggable pockets. ICM PocketFinder explores possible binding pockets using an algorithm based on a transformation of the Lennard-Jones potential. The Q-SiteFinder program uses interaction energies between the protein and a van der Waals probe to determine favourable binding sites. Both programs were used with default settings for all parameters.

\section{Ligand database preparation}

The drug selection pipeline depicted in figure 1 starts with an in silico small molecule collection that was retrieved from the Express Pick ChemBridge database (20) (June 2010 version). This version of the library contained 400,000 well described and commercially available compounds.

The collection of small molecules was filtered (step 1a in figure 1) using the FAF-Drugs2 (21) (version June 2010), ADME/tox (administration, delivery, metabolism, extraction, and toxicity) filter that eliminates non-drug-like molecules using a Lipinski rule of five filter (molecular weight $\leq 500, c \log \mathrm{P} \leq 5$, number of $\mathrm{H}$-bond donors $\leq 5$, number of acceptors $\leq 10$, and number of rotatable bonds $\leq 5$ ), while accepting molecules that maximally violate one of these rules. Additionally, compounds containing reactive groups (e.g. nitro derivatives) or toxic groups (e.g. aniline) (22) were rejected. Salts and counter ions were removed from the small molecule files with the DeSalt utility of the FAF-Drugs2 program (23). 
The OMEGA software (OpenEye, v 2.1.0; (24)) was used in step $1 \mathrm{~b}$ in figure 1 to generate 3D multi-conformers. OMEGA was also used to add hydrogen atoms and Gasteiger partial charges to the ligands. OMEGA uses a modified version of the MMFF94s force field with omitted Coulomb terms. Defaults were used for all parameters including the ewindow value that determines the strain energy range, and the root mean square deviation (RMSD) parameter that determines minimally required conformer similarity. The maximum number of conformers per compound was 50 .

\section{Virtual ligand screening (VLS)}

The virtual ligand screening (VLS) pipeline consists of a multistep protocol $(11,25,26)$, including rigid-body docking, flexible docking, and 2D similarity searches $(27,28)$.

The first docking (step 1c in figure 1) was performed with the rigid-body docking program FRED (Fast Rigid Exhaustive Docking) (v 2.2.5, (27)). FRED was used first because it is fast enough to dock more than one million conformations in the multi-conformer library that were generated by the OMEGA software. FRED generates one pose for each compound, independent of the number of conformers in the multi-conformer. Resulting poses were

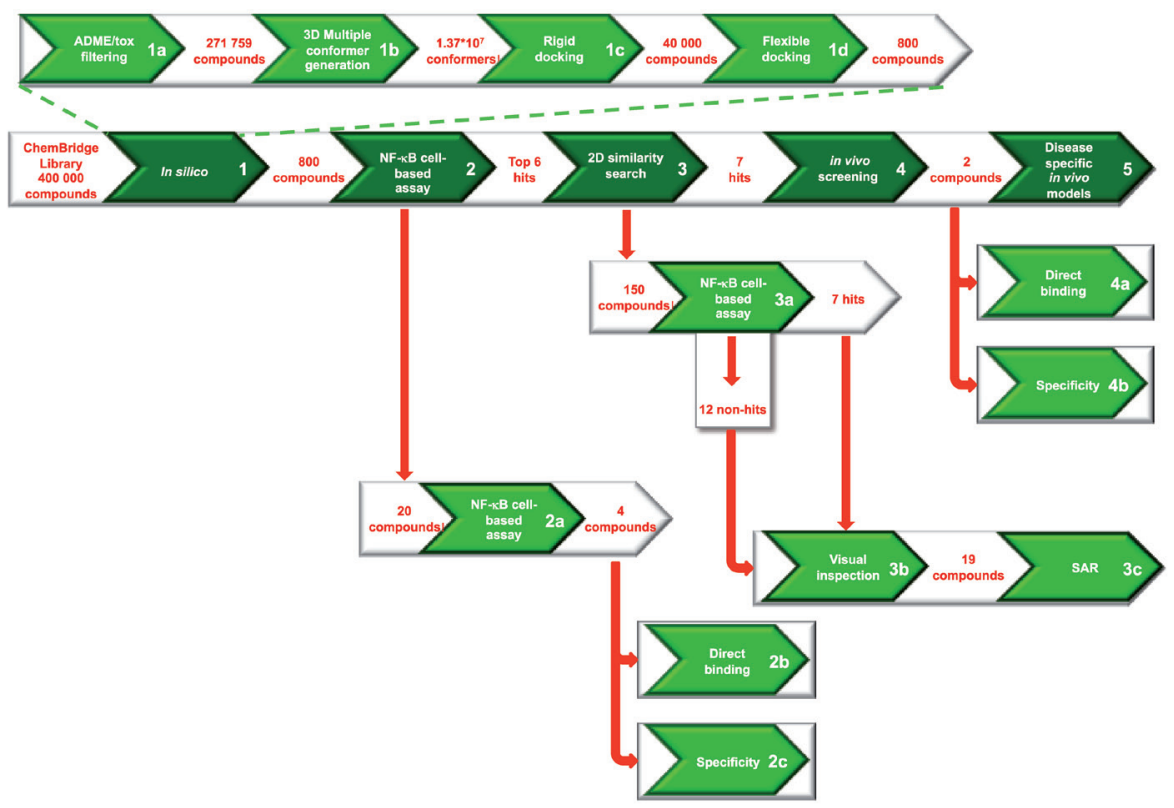

Figure 1. Schematic of the drug selection pipeline. Illustration of step-by-step the process of extracting a small subset of candidate lead compounds from the ChemBridge library of 400,000 compounds. The main pathway in dark green consists of (1) in silico reduction of the dataset; (2) in vitro cell based assay; (3) in silico similarity searches;(4) in vivo screening (peritonitis model); (5) in vivo disease specific (sepsis, insulin resistance, arteriosclerosis, multiple sclerosis) tests. In Step 1, the in silico data reduction consists of (1a) ADME/tox filtering, (1b) 3D conformer generation, (1c) rigid docking, and (1d) flexible docking. The additional steps in the pipeline (direct binding studies, visual inspection, specificity measurements, and SAR, depicted in $2 \mathrm{a}, \mathrm{b}, 3 \mathrm{~b}, \mathrm{c}$, and $4 \mathrm{a}, \mathrm{b}$ ) all are aimed at ligand optimization and at a better understanding of how the ligand binds. 
ranked using FRED's consensus scoring function (27). The 40,000 highest-ranked compounds were passed on to the next step in the pipeline, which employed Surflex-Dock (v 2.514, (29)) for flexible docking. Surflex-Dock requires that an active site is pre-defined. We determined this active site by a consensus residue-based approach, using residues previously detected with ICM PocketFinder and Q-SiteFinder. Docking in Surflex-Dock was done with default parameters and the Surflex scoring function. For each compound, Surflex-Dock returns the best-scoring pose and its corresponding score. The 800 top-ranked compounds were purchased for in vitro screening.

\section{D similarity searches}

Compound similarity searches were performed using the on-line search tool www.hit2lead. com (28) in the ChemBridge software suit. The top six compounds from the in vitro analyses were used as search queries to find analogues. Analogues were accepted when their Tanimoto coefficient (30) was greater than 0.8 .

\section{Off-target prediction}

Off-target predictions were done with KRIPO (Key Representation of Interaction in POckets) (31). KRIPO requires both the target protein and each protein in its search database to be available as a complex structure with a reference ligand that is presented in the PDB file as a hetero-group. It is used to define the binding site of the receptor, and thus cannot work with PDB files in which a bound peptide is presented as a macromolecule. Because we did not have an X-ray structure of compound 6877002 bound to TRAF6, we used the complex of TRAF6 with this compound docked as described in the VLS section (table 2, compound 6), for the binding site determination. The features that represent possible interactions in the binding site (aromatic interactions, hydrogen bond acceptors and donors, hydrophobic contacts, and positive and negative charges) were converted into a pharmacophore. The pharmacophore was stored in a fingerprint format, which was used as a query to search for off-targets (modified Tanimoto coefficient, threshold 0.45 (31)). For the off-target prediction, we used the March 2014 version of the KRIPO database of target-ligand complexes, which contained all proteinligand complexes deposited in the PDB before April 2014.

\section{Binding mode prediction}

Docking calculations with inclusion of full ligand flexibility and side chain rotamer flexibility for a limited number of key residues were performed with Fleksy (32), using default parameters. Fleksy requires a reference ligand to define the binding site of the receptor. As the reference ligand we used the above mentioned compound from the Surflex-Dock run (compound ID 6877002), the same as in the KRIPO search.

\section{Cell-based assay}

For the lipopolysaccharide (LPS)-induced NFkB luciferase assay, the mouse monocyte/ 
macrophage cell line (RAW 264.7) was stably transfected with the $3 \mathrm{x}-\kappa$ Bluc plasmid (33). Cells were incubated with compounds at $10 \mu \mathrm{M}$ for $1 \mathrm{~h}$. Compounds were then tested individually in 96-well plates. CD40 expression was induced with LPS $(10 \mathrm{ng} / \mathrm{ml})$ from E. coli (Sigma Aldrich). After 2 hrs, cells were lysed and incubated with a substrate containing luciferin according to the PNT9019D protocol by Applied Biosystems. Reaction with luciferin results in the emission of a light signal that is proportional to the amount of NFKB signalling activation and that can be measured at $450 \mathrm{~nm}$ with a Wallac Victor II luminometer.

For CD40-induced macrophage activation, bone marrow (BM) cells were isolated from the femurs and tibias of C57BL/6 mice and cultured in RPMI with 15 \% L929-conditioned medium to generate BM-derived macrophages. The CD40 antibody (FGK45) was used (25 $\mu$ / $\mathrm{ml}$ for $6 \mathrm{~h}$ ) to activate BM-derived macrophages. Cells were incubated with $10 \mu \mathrm{M}$ compound for 1 h. Expression of IL1 $\beta$ and IL6 was analysed using real-time PCR.

\section{Protein expression and purification}

The isolated C-domains of TRAF2 (residues 311-501), TRAF3 (residues 375-568) and TRAF6 (residues 310-522) were expressed and purified according to previously described methods (34), (35). The C-domain of TRAF1 (residues 226-416) were cloned via PCR (primer sequences are available on request) into a pET17-vector together with N-terminal His-tag. Protein expression and purification was carried out as described for the other TRAFs. The intracellular part of CD40 (residues 216-277) was expressed in E.coli. The bacteria were lysed by sonication in phosphate-buffered saline with Triton X-100 (PBST) buffer. Cleared lysate was incubated for $4-6 \mathrm{~h}$ at $4^{\circ} \mathrm{C}$ to bind to glutathione S-transferase (GST)-beads. Subsequently, protein was washed 3 times with the PBST buffer and eluted with $10 \mathrm{mM}$ glutathione. Purification followed the previously described procedure for the other TRAFs.

\section{Direct binding}

The C-domains of TRAF1, 2, 3, and 6 were immobilized on a CM5 sensor chip using the amine-coupling method from GE Healthcare. The coupling reaction was continued until a total binding density of $\sim 10200, \sim 11500, \sim 9800$, and $\sim 11200$ response units (RU) was achieved for TRAF1, TRAF2, TRAF3, and TRAF6 respectively. Compounds were dissolved in DMSO and diluted in phosphate-buffered saline (PBS) buffer $(10 \mathrm{mM}$ phosphate, $\mathrm{pH}=6.8)$ to a final concentration of $5 \% \mathrm{v} / \mathrm{v} \mathrm{DMSO}$, and final $\mathrm{pH}=7.4$. Compounds were diluted into seven different concentrations. All experiments were done at $25^{\circ} \mathrm{C}$ in Surface Plasmon Resonance (SPR) running buffer (PBS, $0.05 \%$ Tween 20, $5 \%$ (v/v) DMSO, pH 7.4) with a flow rate of 50 $\mu \mathrm{l} \cdot \mathrm{min}^{-1}$. Binding curves were corrected by subtraction of the level of SPR signal observed on the empty reference flow channel during injection of the compounds. As a positive binding control, we used binding of the intracellular part of CD40 to the C-domains of TRAF1, 2, 3, and 6. Equilibrium dissociation constants $\left(\mathrm{K}_{\mathrm{ds}}\right)$ were determined with the steady-state affinity model (36) (average of at least two independent runs with seven different concentration for 
each compound) using the BIAevaluation software from GE Healthcare (v 1.0).

\section{Peritonitis}

To examine the influence of compounds on the acute inflammation response, we used an in vivo model of peritoneal inflammation. Inflammation was induced in male C57Bl/6 mice ( $\mathrm{n}$ =6-8 per compound) by intraperitoneal injection with $3 \mathrm{ml} 4 \%$ sodium thioglycolate (Sigma) in PBS. Mice received intraperitoneal injection of compounds $(10 \mu \mathrm{mol} / \mathrm{kg})$ dissolved in vehicle (5 \% DMSO in PBS) 0, 6, 12, and 15 hours after induction of inflammation. Injections with the vehicle only were used as a control. Euthanasia took place $18 \mathrm{hrs}$ after induction of inflammation. Blood and peritoneal cells were collected. Leukocytes were analysed, according to the flow cytometry protocol described below.

\section{Flow cytometry}

To determine the effect of compounds on the acute inflammation response we analysed blood cells. At the time of sacrifice, blood was obtained from the heart using EDTA-coated syringes. Erythrocytes were lysed by addition of a hypotonic buffer $\left(8.4 \mathrm{~g}\right.$ of $\mathrm{NH}_{4} \mathrm{Cl}$ and $0.84 \mathrm{~g}$ of $\mathrm{NaHCO}_{3}$ per litre of distilled water). Non-specific antibody binding was prevented by preincubation with a Fc-receptor blocking antibody (eBioscience). Leukocytes were labelled with CD3-FITC (eBioscience), B220-V500 (eBioscience), CD11b-PeCy7 (BD), Ly6G-PE (BD), and Ly6C-APC (Miltenyi Biotec). Cells were analysed on a FACS Canto II flow cytometer (BD).

\section{Toxicity}

Cytotoxicity of compounds was tested on RAW 264.7 cells incubated with $10 \mu \mathrm{M}$ compounds for $1 \mathrm{~h}$, followed by analysis using a Casy Cell Counter according to the manufacturer's protocol (Roche Applied Science). In vivo toxicity was tested on male C57Bl/6 mice with peritoneal inflammation. Mice received intraperitoneal injection of compounds $(10 \mu \mathrm{mol} / \mathrm{kg})$ for 7 days, as described in aforementioned peritonitis method section. The absolute peripheral blood leukocyte counts were analysed using a scil Vet ABC Plus hematology analyzer (Scil Animal Care Company B.V.). 13 organs were prepared in paraformaldehyde (4\%, overnight), sectioned at $4 \mu \mathrm{m}$, and stained with eosin and hematoxylin for histological studies.

\section{Sepsis}

Sepsis was induced by cecal ligation and puncture (CLP) (37). Mice were anesthetized with an intraperitoneal injection of ketamine ( $125 \mathrm{mg} / \mathrm{kg}$ body weight; Sanofi-Cefa GmbH Düsseldorf, Germany) and xylazine (12.5 mg/kg body weight; Phoenix Scientific). The abdomen was opened by longitudinal midline incision, then the cecum was filled with feces, ligated $1 \mathrm{~cm}$ behind the tip and punctured with a 22 gauge needle, followed by the pressing out of a small amount of feces. Fascia, abdominal musculature and skin were closed by running sutures. Sham mice underwent the same surgical procedure without inducing sepsis (i.e. placebo 
surgery). Mice were treated with either compound 6877002 or $6860766(10 \mu \mathrm{mol} / \mathrm{kg})$ or with just the vehicle, during CLP and 12 hours after CLP via intraperitoneal injection.

\section{Study approval.}

All animal experiments were approved by the local Animal Experimentation Committees.

\section{Results}

\section{Protein target preparation}

Many small differences were observed between the TRAF6 apo and holo structures that could be interpreted as conformational changes resulting from binding of the CD40-peptide. We decided to use the holo structure comprising the TRAF6 C-domain structure after CD40 peptide deletion for VLS, because in this structure the conformations of amino acid side chains in the pocket corresponds to those of the ligand bound state of the TRAF6 C-domain, which minimizes the chance that major pocket changes are still needed to accommodate a ligand (38).

Pro465, Arg466, Asn467, and Pro468, located in a loop that lines the peptide binding groove, are not present in the X-ray structure of the apo TRAF6 C-domain, presumably because mobility or disorder precluded them from being seen in the electron density maps. On the other hand, these same residues are present in the CD40-TRAF6 C-domain complex structure. The absence of these residues in the apo structure strengthens the observation that the conformation of these residues in the holo structure is the result of interactions with the short CD40 peptide. In the holo structure, Arg466 is located in the peptide binding groove in an area where full-length CD40 presumably binds (figure 2a), but which is unbound in the apo structure. We therefore chose to select a side chain conformation for Arg466 such that the chosen rotamer leaves the pocket as widely open as possible (figure $2 b$ ).

ICM PocketFinder predicted four druggable pockets in the receptor model (11) (figure 3a). The pocket which we selected for targeting has a volume of $158 \AA^{3}$ (figure $3 b$ ). This pocket was selected because it has one of the largest predicted pocket volumes. Q-SiteFinder detected several druggable pockets. The pocket located closest to the peptide groove has a volume of $139 \AA^{3}$ and was approximately in the same location as the largest pocket predicted by the ICM PocketFinder. Thus, the pocket that was chosen for the VLS was the consensus from the best pockets predicted by both programs. Moreover, this pocket appears to be part of what can be seen as an extended binding groove along the central axis of the molecule to which the CD40 peptide is also bound (figures $2 \mathrm{a}$ and $3 \mathrm{a}$ ). We hypothesized that binding of small molecules to this pocket could therefore interfere with CD40-TRAF6 interaction.

\section{Ligand selection}

Our in silico drug selection pipeline consisted of a Lipinski filter, quick and dirty rigid docking, intermediately precise flexible docking, and exhaustive docking with inclusion of full 
flexibility. The full pipeline also included in vitro and in vivo validation steps. We previously used this pipeline to find a ligand that showed efficacy in a diet-induced insulin resistance mouse model (11). Here, we extend this pipeline with steps aimed at selecting more ligands and steps aimed at optimization of the ligand structures. Figure 1 illustrates the extended pipeline. The results of steps la-d were described before (11) and will not be repeated here.

The 800 best-docking compounds were purchased from ChemBridge (www.chembridge. com) for in vitro testing (figure 1 step 2). The number 800 was a compromise between the price of compounds and labour costs of in vitro testing on the one hand, and on the other hand the desire to obtain a considerable number of hits (in previous drug design projects we often experienced hit rates around 1-2 \% e.g. $(40,41))$. Similar financial constraints restricted the number of compounds in all following steps (figure 1 step 2).

The top six compounds from the initial in vitro scan that are listed in table 1 show some similarities. All six compounds share a linker that is three to six atoms long, that contain $\mathrm{N}$
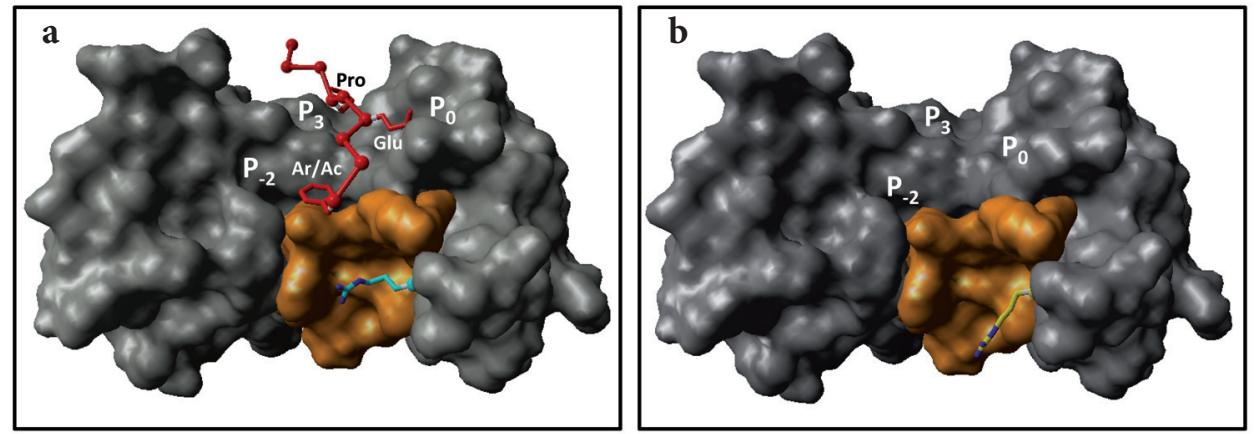

Figure 2. (a) Molecular surface of the TRAF6 C-domain. TRAF6 C-domainin in complex with a CD40 peptide fragment (red Ca-trace) (grey, PDB ID: 1LB6). The residues of the Pro-X-Glu-X-(aromatic/ acidic) motif that bind to the subpockets $\mathrm{P}_{-2}$ (Pro), $\mathrm{P}_{0}$ (Glu), and $\mathrm{P}_{3}$ (aromatic/acidic) are labelled (39). The Arg466 side chain is shown coloured by atom type. In (b) the Arg466 side chain has been manually moved as described in the text, opening up the druggable pocket that is coloured orange.
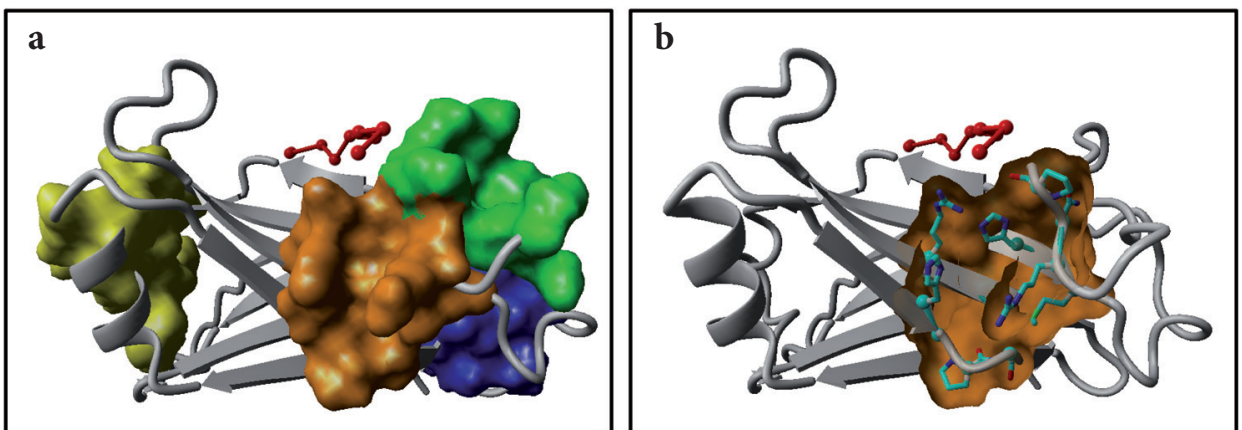

Figure 3. Predicted druggable pockets. (a) ICM PocketFinder - 4 druggable pockets were predicted with the following volumes and areas: $158 \AA^{3}$ and $177 \AA^{2}$ (orange); $127 \AA^{3}$ and $140 \AA^{2}$ (green); $104 \AA^{3}$ and $116 \AA^{2}$ (blue); $163 \AA^{3}$ and $218 \AA^{2}$ (yellow). (b) The selected pocket (orange) is surrounded by the following amino acid residues: His376, Pro378, Gly379, Cys390, Arg392, His412, Met414, Arg466, Asn467, and Pro468. 
and $\mathrm{O}$ atoms, and that connects two, often substituted six-membered rings. The docking poses are presented in the figure 1 of the supplementary material. The six compounds were used as a search query for a 2D similarity search that led to 151 new compounds. These 151 compounds were tested using the cell-based luciferase NFKB assay. Eight of the 151 compounds inhibited NFKB signalling by more than $25 \%$ at $10 \mu \mathrm{M}$, and six of these eight compounds showed dose-dependent behaviour. These six best compounds were analogues of compound 6877002 , and together with the single query compound that was used to retrieve them in the $2 \mathrm{D}$ similarity search, all of them showed inhibition with $\mathrm{IC}_{50}$ values in the low $\mu \mathrm{M}$ range. These seven compounds are referred to as the 'seven hits' and are summarized in table 2.

The seven compounds listed in table 2 are less diverse than the six compounds identified in the primary screening, in that they all share an identical four-atom long linker containing a Michael acceptor functionality and an N-H group. This linker connects two five- or sixatom rings that are often ortho- or para-substituted with the small groups $\mathrm{CH}_{3}, \mathrm{Br}$, or $\mathrm{Cl}$. When we inspected the non-binders and poor binders among the 151 compounds that resulted from the $2 \mathrm{D}$ similarity search, we detected twelve additional compounds with exactly the same linker and highly similar five- or six-atom substituted rings. These twelve compounds (table 3) have in common that one of the two rings is meta-substituted, hinting at a possible understanding of the structure activity relationship for these small molecules. All twelve have an $\mathrm{IC}_{50}$ higher than the detection limit of $100 \mu \mathrm{M}$.

\section{Biological evaluation}

Pro-inflammatory cytokines play a pivotal role in the inflammatory response. We used primary BM-derived macrophages and stimulated them with the CD40-agonist FGK45 (11), to determine the change in mRNA expression of IL6 and IL1 $\beta$ upon incubation with the seven best compounds shown in table 2. It was only used for the seven best hits because it is more laborious and much more expensive than the LPS-induced NFKB assay used for the primary screen. All seven hits inhibited the expression of IL1 $\beta$ and IL6 cytokines in primary $\mathrm{BM}$-derived macrophages in a dose-dependent manner, with $\mathrm{IC}_{50} \mathrm{~s}$ in the range 0.2 to $>100$ $\mu \mathrm{M}$ (table 4).

The primary data used for the calculation of $\mathrm{IC}_{50}$ values presented in table 4 are shown in figure 2 of the supplementary materials.

\section{The binding mode of inhibitors}

The seven hits that were characterised with the two cell-based assays (figure 1) and their twelve inactive analogues, were docked on the TRAF6 target structure with Fleksy (32). Fleksy requires a reference compound to define the binding site. We used the coordinates of compound 6877002 docked with Surflex-Dock. Fleksy produced 20 poses for each compound and calculated a consensus score (42). We manually compared all 380 poses, looking for common protein-ligand interaction motifs. For eight compounds we found a common 
Table 1. Structures of the six initial hits obtained after the in silico steps 1a-d and the luciferase NFkB cell-based assay.

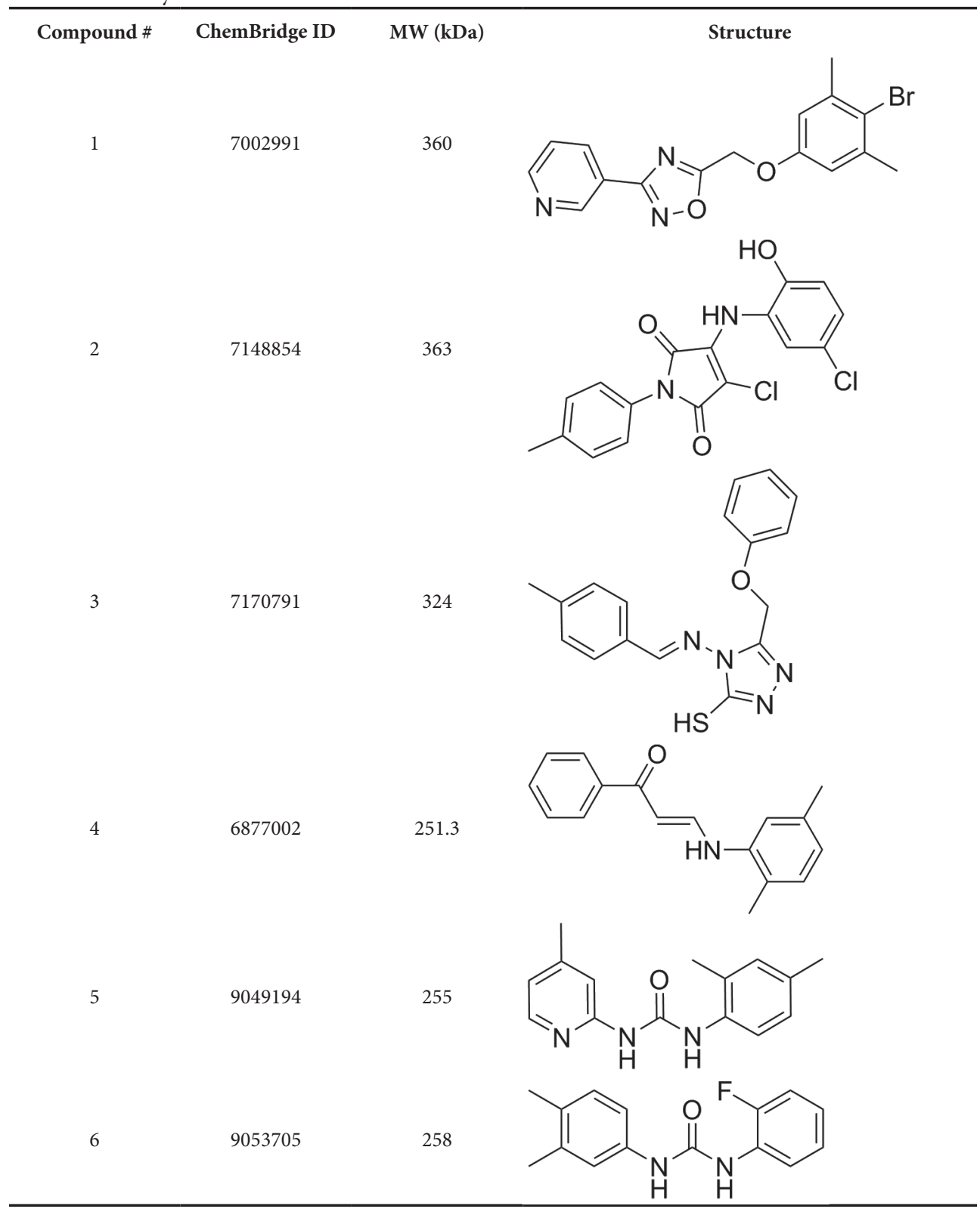

binding mode that includes hydrogen bonds with residues Asn467 and Cys390, and $\pi-\pi$ stacking of Arg466 and His376 on the ligand's R1 ring (figure 4). The seven good inhibitory compounds were among these eight. Six of the other twelve compounds did not include a hydrogen bond with Asn467, while five of the twelve did not resemble the common binding mode at all. 
Table 2. Structures and $\mathrm{IC}_{50}$ values $(\mu \mathrm{M})$ of the 'seven hits' from the NFkB assay.

Compound \# ChemBridge ID $\mathrm{MW}(\mathrm{kDa})$

As previously described (11), the 19 compounds all have a similar topology - they possess the same linker that connects two similar rings. We hypothesized that all active compounds will bind in a similar manner and we assumed that the inactive compounds are inactive because they cannot adopt that same binding mode. To validate this idea, all compounds were exhaustively docked with Fleksy, with the additional constraint that their common cores had to align to the common core of the active compound 7805351. This compound is one of the seven good inhibitors among the 19 in the NFkB assay (table 2). The docking poses obtained in this manner looked plausible except for one inter-atomic clash between the groups at the 
Table 3. Compounds similar to the seven hits that have an $\mathrm{IC}_{50}$ higher than the detection limit of 100 $\mu \mathrm{M}$.

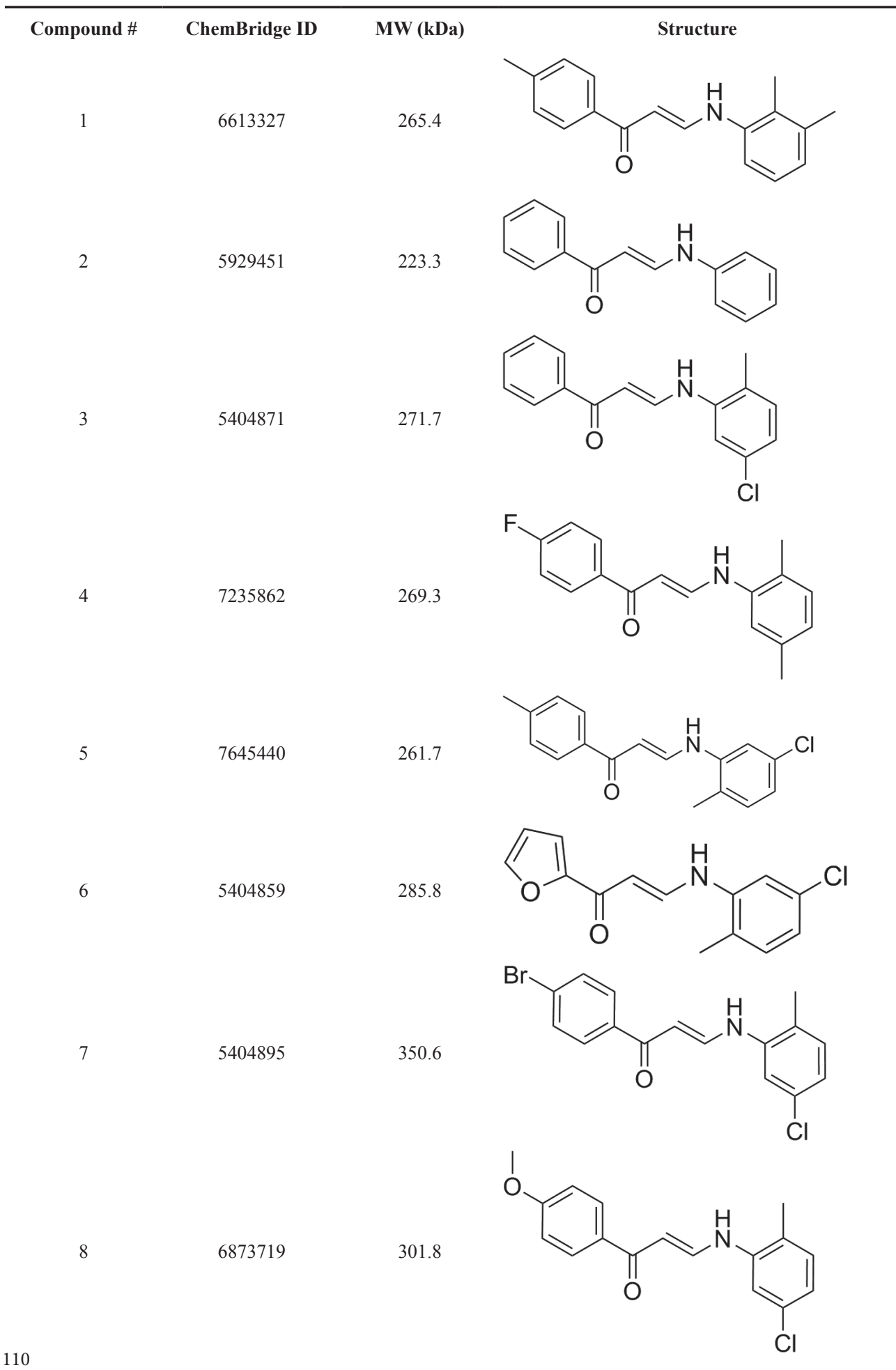


9

6875452

6876201

6876350

6876773<smiles>Cc1ccc(Cl)cc1N/C=C/C(=O)c1ccc(Cl)cc1</smiles><smiles>Cc1ccc(C)c(N/C=C/C(=O)c2ccc(Br)cc2)c1</smiles>

330.2<smiles>COc1ccc(C(=O)/C=C/Nc2cc(C)ccc2C)cc1</smiles>

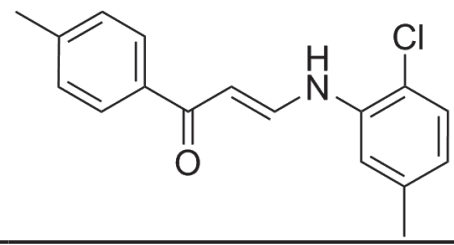

meta position of the R1 ring of the ligand and Pro468. Indeed, good activity of the compounds appears to correlate with the absence of meta substituents, and to a lesser extend also with the presence of substituents at either the ortho or para position. Compound 5929451 does not have substituents at either the $\mathrm{R} 1$ or the $\mathrm{R} 2$ ring. This compound has an $\mathrm{IC}_{50}$ value above 100 $\mu \mathrm{M}$, suggesting that substituents at the $\mathrm{R} 1$ ring are crucial to obtaining low $\mathrm{IC}_{50}$ values.

\section{Structure activity relationship (SAR)}

To unravel the structure-activity relationship (SAR) of the inhibitors of CD40-TRAF6 interaction, an additional set of 25 compounds was synthesized (43). There are analogues of compound 7805351 with different substitution groups present only at the R1 ring. We proposed ten compounds based on the ligand analysis and twelve compounds based on the structure analysis of the previously proposed binding mode. Three compounds with very big substitution groups in both ortho and para positions were chosen as proposed negative controls of our binding mode hypothesis. Out of these 25 compounds, only three compounds were weakly active and had $\mathrm{IC}_{50}$ values in the NFkB cell-based assay that were lower than 100 $\mu \mathrm{M}$ (table 5). These three compounds have substitution groups present at both the para and the ortho position. Compounds with substituents at only the ortho or only the para position 
Table 4. $\mathrm{IC}_{50}$ values $(\mu \mathrm{M})$ of seven hits that inhibited CD40-induced expression of IL1 $\beta$ and IL6 in bone marrow derived macrophages.

\begin{tabular}{cccc}
\hline Compound \# & Compound ID & $\operatorname{IL1} \boldsymbol{\beta}-\mathrm{IC}_{50}(\mu \mathrm{M})^{* *}$ & $\mathrm{IL6}^{*}-\mathrm{IC}_{50}(\boldsymbol{\mu M})^{\star *}$ \\
1 & $7805351^{*}$ & $>100$ & $>100$ \\
2 & 6860766 & 5.7 & 2.4 \\
3 & 6876358 & 24 & 21 \\
4 & 7493979 & 4.6 & 2.2 \\
5 & 7651589 & 1.9 & 0.3 \\
6 & 6877002 & 16 & 50 \\
7 & 6872674 & 1.4 & 0.2 \\
\hline
\end{tabular}

${ }^{\star}$ Activity of the compound 7805351 was above $100 \mu \mathrm{M}$ in this assay, however in the NFkB assay (see table 2) it had the best $\mathrm{IC}_{50}$ with value of $0.1 \mu \mathrm{M}$, thus we consider it as a good binder.

** The errors in the $\mathrm{IC}_{50}$ values might be up to factor of two because of biological variability between the experiments such as variation in the time of initiation of transcription of IL1 $\beta$ and IL6 after FGK45 binding, variation in medium composition among the experiments, variation in the differentiation of the bone marrow derived macrophages and their metabolic and inflammatory state, and many other natural differences between the mice from which the bone marrow was harvested.

were inactive. Compounds with very small, very big or charged substitution groups in these crucial positions were also inactive. These results are in agreement with our previous hypothesis that active compounds are characterized by R1 rings with moderate size substituents at the ortho and para positions.

\section{Compound optimization}

The seven hits (table 2) all have a Michael acceptor functionality that is known to covalently bind to cysteines (44). Therefore we cannot exclude off-target binding to cysteines in proteins involved in the NFKB signalling pathway. Even though the two final compounds perform excellently in in vivo test systems, we decided to investigate the possibilities of placing a nonreactive linker between the two ring systems to reduce the risk of off-target effects.

We hand-picked 20 compounds from the top $25 \%$ of compounds identified in the primary in vitro screen (step $2 \mathrm{a}$ in figure 1) that had a linker between the two rings consisting of two, three, or four atoms and no Michael acceptor functionality. These 20 compounds, structurally different to our previous set of compounds, were tested in the luciferase NFkB cell-based assay. Ten compounds showed more than $25 \%$ inhibition at $10 \mu \mathrm{M}$, and of those ten, four showed a dose-dependent response with an $\mathrm{IC}_{50}$ value in the range 3-10 $\mu \mathrm{M}$ (table 6 and step $2 \mathrm{~b}$ in figure 1). These four compounds are characterized by ortho or para substitutions with groups like $\mathrm{Cl}, \mathrm{CH}_{3}, \mathrm{CN}$ or $\mathrm{OH}$ in ring $\mathrm{R} 1$, or groups like $\mathrm{CH}_{3}$ or $\mathrm{Br}$ in ring $\mathrm{R} 2$. They have a range of different linkers, comprising two, three or four atoms. The only common factor in the linkers is the $\mathrm{C}=\mathrm{O}$ group. These four compounds were tested for direct binding to the C-domain of TRAF6. Compound 9078886 showed poor solubility at high concentrations and was removed from the experiment. Compounds 6576379 and 7113606 bind weakly (in the 
mM range) to the TRAF6 C-domain, whereas compound 5843084 has a $\mathrm{K}_{\mathrm{d}}$ value of $52 \mu \mathrm{M}$. This preliminary round of modifications suggests that the potentially reactive linker can be replaced by a non-reactive linker while preserving the inhibitory activity of the compounds and argues against the covalent binding of cysteines as a sole explanation of the activities observed in vitro and in vivo.

\section{In vivo models}

The CD40 pathway plays a pivotal role in the NFkB signalling that leads to inflammatory responses. Previously, we showed that compound 6877002 inhibits the NFKB cell-based assay and reduced diet-induced insulin resistance (11). Here we show how we verified the inhibitory activity of the seven hits, including compound 6877002 (table 1) in an in vivo model for acute inflammation, i.e. during peritonitis. We explain why we chose this compound for the other in vivo model, even though it did not show the best $\mathrm{IC}_{50}$ values in the cell-based assay. The CD40 signalling plays a pivotal role in the innate immune response to polymicrobial sepsis (45). Therefore, we show the effect of compound 6877002 and 6860766 in the treatment of sepsis.

\section{Peritonitis}

Inflammation of the peritoneum, peritonitis, is a model of acute inflammation. To assess the influence of our compounds on acute inflammation (step 4 in figure 1), we used a thioglycolateinduced peritonitis mouse model with the seven compounds listed in table 2. Treatment for one week with each compound induced an anti-inflammatory peritoneal monocyte profile with an increased anti-inflammatory/pro-inflammatory monocyte ratio (Ly6C-/low/Ly6C $\mathrm{C}^{\text {high }}$ ) that reduced inflammation ( $n=6-8$ per group) (figure 5 ). Data are presented as mean \pm SEM.
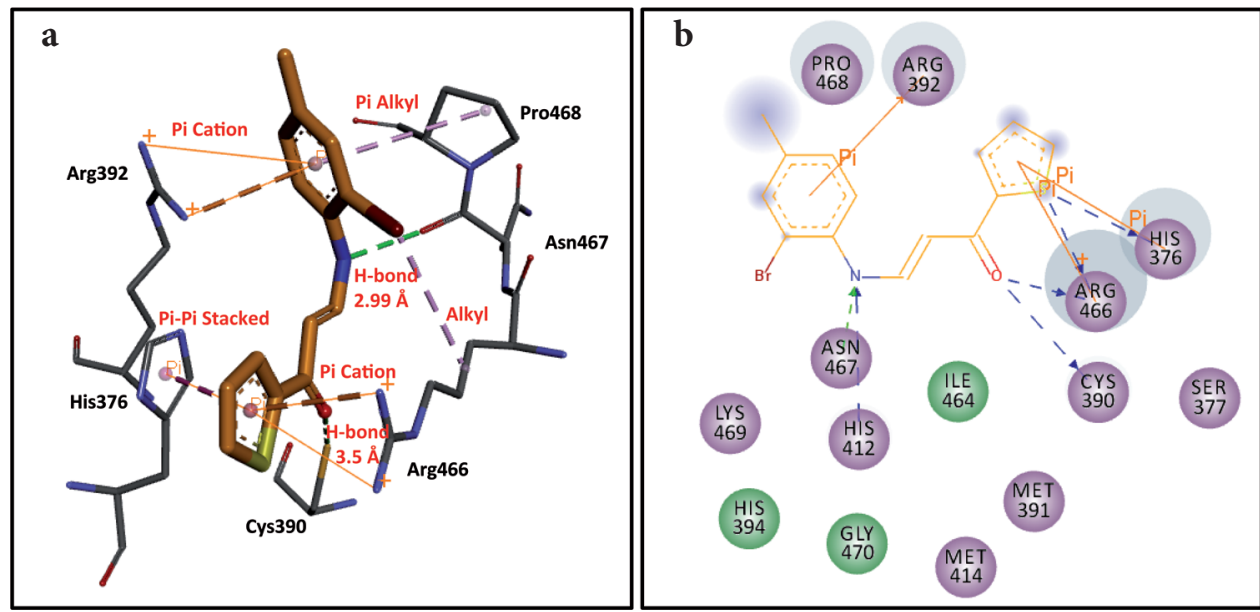

Figure 4. Docking pose of compound 7805351. (a) The 7805351 interactions with TRAF6 protein in a $3 \mathrm{D}$ representation (b) 2D representation, polar (magenta circles), Van der Waals (green circles), Hbond with acid side chain (blue arrow), H-bond with acid main chain (green arrow), pi-pi interactions (orange lines), pi alkyl and pi cation interactions (purple dashed lines). 
Table 5. Structures and $\mathrm{IC}_{50}$ values $(\mu \mathrm{M})$ of compound 7805351 analogues.

Compound \#

Data were analysed with a Student's two-tailed t-test. Differences between compounds and vehicle groups were considered significant if $\mathrm{P}$-value $<0.05$. Financial constraints restricted testing of compounds in the further in vivo test to only two compounds. We selected two compounds (6872674 and 6877002) that had the best observed efficacy in the peritonitis model. Unfortunately, compound 6872674 showed significant precipitation at high concentrations (required to limit the volume of injected compound), which had not been observed in the earlier experiments. As a result, this compound had to be excluded from further analyses and was replaced by the next best compound (6860766).

\section{Sepsis}

Polymicrobial sepsis, as a model for intensive systemic inflammation, was induced in C57Bl/6 mice by cecal ligation and puncture (CLP). After the CLP procedure, mice were treated with compound 6877002 or $6860766(10 \mu \mathrm{Mol} / \mathrm{kg}$ at $\mathrm{t}=0 \mathrm{~h}$. and $\mathrm{t}=12 \mathrm{~h}$.). Survival rates were increased by $150 \%$ (6877002) and $200 \%$ (6860766) (figure 6) showing that the compounds are protective against death from sepsis. Furthermore, this experiment showed that treatment with our inhibitors did not compromise systemic immunity.

Statistical significance of survival curves was determined using the Log-rank (Mantel-Cox) and Gehan-Breslow-Wilcoxon test. Differences between compounds and vehicle groups with P-values $<0.05$ were considered significant.

\section{Discussion}

Drug development has always mainly been a trial and error process with some of its greatest discoveries based on serendipity and clinical observations (46). The introduction of X-ray crystallography and computer power in the drug design process led to a paradigm shift from 
Table 6. $\mathrm{IC}_{50}$ values $(\mu \mathrm{M})$ of the compounds without a Michael acceptor in the linker.

Compound \# ChemBridge ID $\quad$ MW (kDa)

empirical to structure-based rational design (47). More recently, we have seen some success stories in the form of marketed drugs designed mainly via an in silico approach $(48,49)$. Here, we present the rational design of an inhibitor validated through in vivo models. Despite the fact that we have identified potential lead compounds for CD40-TRAF6 interaction that are safe and efficacious in animal models, there is still a long way to go before we have a drug that can be administered routinely to patients. Further tests are essential, including ADME-tox studies, pharmacokinetics, and long-term safety studies that are outside the scope of the present work. However, the relative ease with which we have achieved our results show that VLS approaches in combination with in vitro and in vivo screening like the one shown in figure 1 have great potential.

Our lead compounds have confirmed efficacy in a diet-induced obesity mouse model. Treatment with one of our lead compounds improved insulin sensitivity, reduced adipose tissue inflammation and decreased hepatosteatosis. These compounds are therefore considered good starting point for the design of a treatment for obesity-associated insulin resistance (11). The most active compounds do, however, contain a common linker that contains Michael acceptor functionality, which is known to include reactivity that can covalently bind to cysteines (44). Even though the Michael acceptor is considered to be a PAIN (Pan Assay 
INterference) (50) substructure, and the presence of this functional group is generally considered drawback (51), it has shown to be successful in kinase inhibitors that reached clinical phase III in breast cancer treatment (52). In the optimization process, we found that compound 5843084, similar to our lead compounds, has a linker of four atoms long, but lacks a Michael acceptor. This compound has an $\mathrm{IC}_{50}$ value of $8 \mu \mathrm{M}$ in the NFkB luciferase cellbased assay, and in SPR showed binding to the C-domain of TRAF6 with a $\mathrm{K}_{\mathrm{d}}$ value of $52 \mu \mathrm{M}$. This preliminary study made clear that the linker that contains the Michael acceptor can easily be replaced without loss of in vitro activity.

The NMR spectra for the compounds with a Michael acceptor shown in table 2 revealed that these compounds exist as cis and trans tautomers. Based on our in silico docking studies, we predicted that our compounds will bind as trans stereoisomers. $K_{d}$ values from the Biacore studies were higher than expected from in vitro assays. This inconsistency may result from the fact that we did not measure homogeneous compounds, but a mix of (trans) binders and (cis) non-binders. This problem was one of the reasons for the $2 \mathrm{D}$ similarity search for binders without a Michael acceptor.

We also observed systematic differences in $\mathrm{IC}_{50}$ values between the two types of in vitro assays that were used to assess the in vitro activity of compounds in this study. $\mathrm{IC}_{50}$ values from different assays are generally not fully reproducible, as they depend on many different parameters and may not be comparable (53). Apparent inconsistencies may well be due to the different origins of the cells used. The LPS-induced assay was performed in the mouse RAW 264.7 cell lines, whereas the CD40-induced assay used the mouse primary cells of BM-derived macrophages.

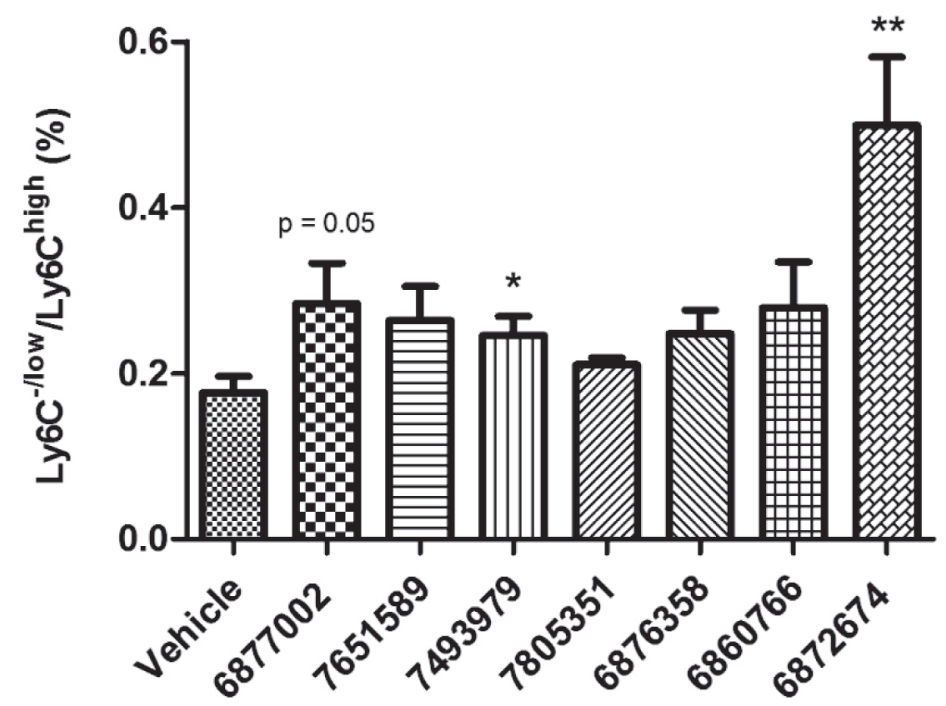

Figure 5. Increase of Ly6 $\mathrm{C}^{- \text {llow }} / \mathrm{Ly} 6 \mathrm{C}^{\text {high }}$ monocytes ratio in the peritonitis model ( $\mathrm{n}=6-8$ per group). P-value $<0.05$ is indicated by ${ }^{*}$, P-value $<0.01$ is indicated by ${ }^{* *}$. 


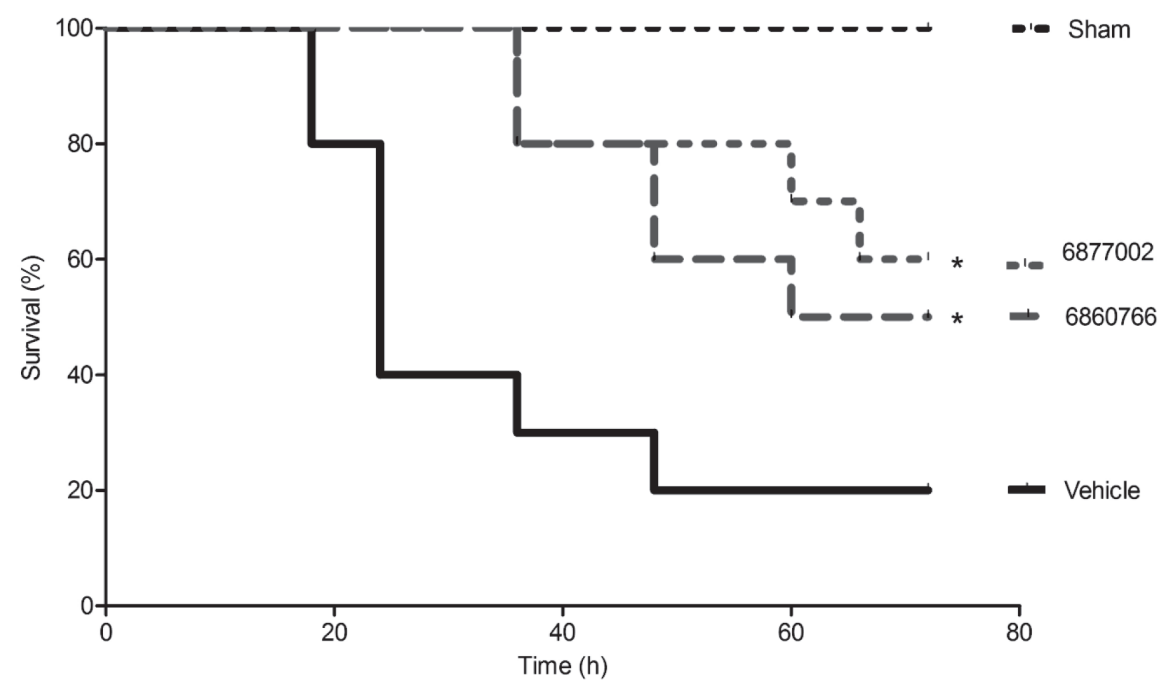

Figure 6. Compound treatment improved the survival of mice subjected to sepsis. Compound 6877002 treated and compound 6860766 treated mice subjected to cecal ligation and puncture exhibited increased survival rates, suggesting that the compounds did not compromise systemic immunity during polymicrobial sepsis ( $n=10$ per group). ${ }^{\star}, \mathrm{P}<0.05$ (vehicle vs. 6877002 or 6860766 ).

Even though our compounds were designed to bind to the TRAF6 protein, we cannot at this stage of project fully exclude off-target effects. To address potential off-target effects we used the KRIPO software for off-target prediction. The pharmacophore used by KRIPO in this query consisted of five features: a hydrogen bond acceptor from the backbone oxygen from Asn467, stacking interactions from His376 and His412, and hydrophobic contacts from Cys390 ( $\mathrm{SH}$ group in the side chain) and $\operatorname{Arg} 466$ ( $\mathrm{CH}_{2}$ groups in the side chain) (figure 7).

We obtained a hit list with 133 targets that share a similar pocket or sub-pocket with TRAF6. 11 predicted off-targets share a full binding pocket with TRAF6 (table 7). The other 122 offtargets only share a sub-pocket with TRAF6. These are listed in the supplemental material. None of these targets is known to be involved in the NFKB signalling pathway. For the 11 offtargets that share a full binding pocket with TRAF6, only the $a-\mathrm{N}$-acetylgalactosaminidase binding site is located at the enzyme's active site. The rest of the predicted binding sites are binding pockets located away from the main active site.

Off-target prediction with KRIPO resulted in relatively few pockets for TRAF6 compared to other KRIPO searches (31), suggesting that the binding pocket of TRAF6 is rather unique among the binding sites of protein-ligand complexes deposited in the PDB. There are more targets within the NFKB signalling pathway that are used for structure-based design of antiinflammatory drugs. The main one is IKK- $\beta$ (54). The KRIPO search did not reveal IKK- $\beta$ as an off-target for TRAF6 ligands. In addition, docking of the seven hits with Fleksy did not show any productive poses for this target. However, as KRIPO requires ligands to be present as hetero-groups in the PDB files in its database, we cannot exclude that peptide-binding off- 
targets such as E3 ubiquitin ligases, PDB ID: 2FOJ (55) exist.

TRAF6 mediates signalling from members of the TNF receptor superfamily such as the CD40 receptor, and from members of the Toll/IL-1 family such as the Toll-like receptor 4 (TLR4). It plays different roles in these two signalling pathways. In CD40 signalling, the C-domain of TRAF6 creates a protein - protein interaction complex with the intracellular part of the CD40 receptor, which results in activation of the NFKB signalling pathway. The RING-domain of TRAF6 serves as an E3 ukiquitin ligase and activates IKB kinase (IKK), contributing to TLR4 signalling in the NFKB pathway (56). Thus, inhibition of posttranslational modification such as ubiquitination can also inhibit inflammation (57). Such polypharmacological advantages, though, are beyond the scope of this article.

CD40 shows structural differences between binding to the C-domain of TRAF6 and TRAF2, 3 , and 5 (12). We hypothesized that structural differences between the TRAF6 and other TRAF proteins will facilitate the design of CD40-TRAF6 specific compounds. SPR experiments confirmed that compounds 6877002 and 6860766 bind to the C-domain of TRAF6 with $\mathrm{K}_{\mathrm{d}}$ values of $97 \mu \mathrm{M}(11)$ and $59 \mu \mathrm{M}$ (step 4a in figure 1), respectively. However, when the direct binding of these two compounds to the C-domain of TRAF1, 2, 3, and 6 was investigated via SPR, both compounds appeared to bind to the C-domain of all these TRAF proteins in the $\mu \mathrm{M}$ range (30-144 $\mu \mathrm{M})$ (table 8).

Since all the TRAF-proteins share similar structures, this finding is not unexpected in a nonbiological setting, where the interactions of the TRAF proteins with their different receptors (e.g. CD40, TLR4, CD27, Ox40L and RANKL) and the conformational changes that occur in real life are disregarded. Although we cannot fully rule out interference of our compounds with other receptor-TRAF interactions, we could confirm functional specificity for the CD40TRAF6, and not the CD40-TRAF2, 3, and 5 pathway, in vitro and in vivo (11).
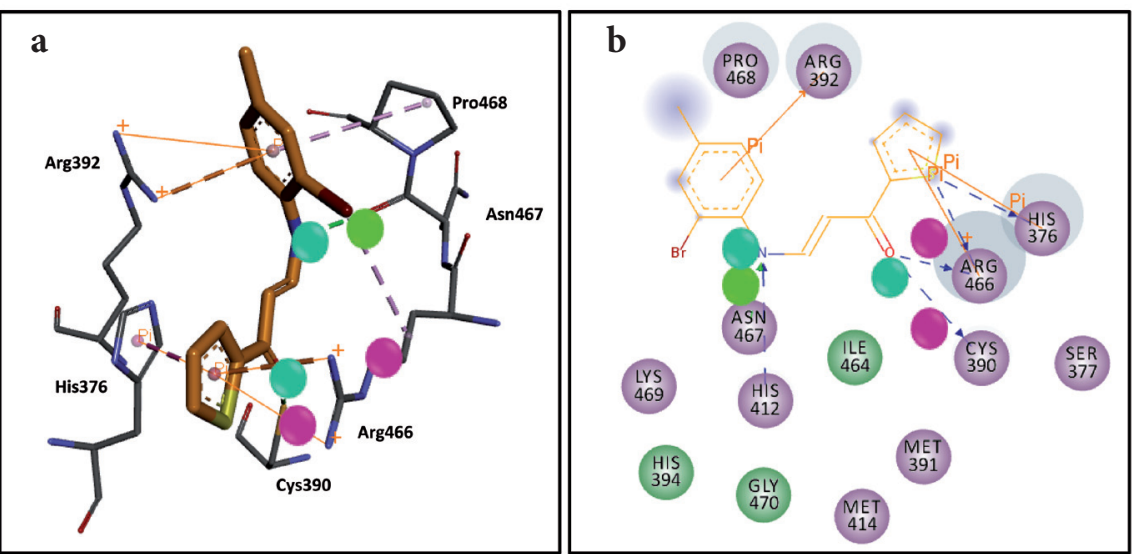

Figure 7. Predicted binding site with pharmacophore features: hydrophobic contacts (magenta ball), aromatic interactions (cyan ball), H-bond acceptor (green ball). Further lines and colours as in figure 4 . 
Previously, it has been shown that blocking the complete CD40 pathway leads to severe sideeffects (9). Therefore, our goal was to design specific compounds targeted at TRAF6 to block the TRAF6-CD40 interaction, while at the same time maintaining signalling of the CD40 pathway via other TRAFs. To verify possible toxicity, the RAW cells were incubated with compounds at $10 \mu \mathrm{M}$. Compounds did not induce any changes in cell viability. Further, compounds were administered in the mice at $10 \mu \mathrm{M} / \mathrm{kg}$. This treatment did not result in micro- or macroscopic abnormalities of $>13$ organs analysed, nor did it influence absolute or relative peripheral blood leukocyte counts. Histological analysis of vital organs showed no toxic, immunosuppressive or thromboembolic side effects of compound treatment. Therefore seven compounds did not show toxicity in an in vitro viability assay or in in vivo treatment. In addition, our compounds do not bind with affinities that would be high enough to completely block CD40 signalling. Like CD40-TRAF6 interactions, they bind in the $\mu \mathrm{M}$ range. This suggests that our relatively weak binding lead compounds can inhibit CD40-TRAF6 interactions with high efficacy, because they have the capacity to compete with a natural partner that binds in the same $\mu \mathrm{M}$ range (12).

We present an in silico screening pipeline to discover hit molecules that inhibit CD40 signalling. Both in vitro, and in vivo experiments showed that our compounds show efficacy without side-effects in mouse models for obesity-associated insulin resistance (11), peritonitis,

Table 7. Hit list with potential off-targets as identified by KRIPO (31).

\begin{tabular}{lll}
\hline Target \# & Name & PDB ID \\
\hline 1 & Amine oxidase & 2XFN \\
2 & Dimethylsulfonioproprionate demethylase & 3TFJ \\
3 & a-N-acetylgalactosaminidase & 2IXA \\
4 & Nitric oxide synthase, endothelial & 1DM6 \\
5 & Serine/threonine-protein kinase & $4 \mathrm{LKM}$ \\
6 & 50S ribosomal protein L1 & $2 \mathrm{HW} 8$ \\
7 & Xylose isomerase & $1 \mathrm{O} 1 \mathrm{H}$ \\
8 & Orotidine 5'-phosphate decarboxylase & $3 \mathrm{~N} 2 \mathrm{M}$ \\
9 & Proteorhodopsin & $4 \mathrm{JQ} 6$ \\
10 & NAD(P)H flavin oxidoreductase & $4 \mathrm{~B} 5 \mathrm{~N}$ \\
11 & Gramicidin A & $1 \mathrm{AV} 2$ \\
\hline
\end{tabular}

Table 8. SPR direct binding experiment with TRAF 1,2, 3, and 6 proteins.

\begin{tabular}{ccc}
\hline Target \# & $\mathbf{6 8 7 7 0 0 2} \mathbf{K}_{\mathbf{d}}[\boldsymbol{\mu M}]$ & $\mathbf{6 8 6 0 7 6 6} \mathbf{K}_{\mathbf{d}}[\boldsymbol{\mu M}]$ \\
\hline TRAF1 & 142 & 51 \\
TRAF2 & 144 & 30 \\
TRAF3 & 99 & 37 \\
TRAF6 & 141 & 59 \\
\hline
\end{tabular}


and sepsis. We showed that the compounds can be optimized, and have potential for the further development of treatment for (chronic) inflammatory diseases.

\section{Acknowledgments}

This work was supported by the Humboldt Foundation [Sofja Kovalevskaja grant (to E.L.)], the Netherlands Organisation for Scientific Research [vici grant (to E.L.), a medium investment grant (to G.N.)], the Netherlands Heart Foundation [Dr. E. Dekker grant (to T.S.) and an established investigator grant (to E.L.)], the Rembrandt foundation (to E.L.), the Deutsche Forschungsgemeinschaft [SFB914, SFB 1054 and SFB1123 (to E.L. O.S. and C.W.)], the Cardiovascular Research Institute Maastricht (to G.N.), the European Union [Grant KBBE-2011-5 289350, AllBio, and EFRO (to G.V.), the Transnational University Limburg (to G.N.), and Cyttron II [FES0908 (to G.N. and T.H.)]. We thank Jan Kelder and Hugo Kubinyi (who persuaded us to go from Step 2 to Step 2a and $2 \mathrm{~b}$ in our drug selection pipeline) for critical reading of the manuscript. We thank F. Albayrak for technical assistance. 


\section{References}

1. Schönbeck U, Libby P. The CD40/CD154 receptor/ligand dyad. Cell Mol Life Sci CMLS. 2001 Jan;58(1):4-43.

2. Arron JR, Pewzner-Jung Y, Walsh MC, Kobayashi T, Choi Y. Regulation of the subcellular localization of tumor necrosis factor receptor-associated factor (TRAF) 2 by TRAF1 reveals mechanisms of TRAF2 signaling. J Exp Med. 2002 Oct 7;196(7):923-34.

3. Zapata JM. TNF-recepto-associated factors as targets for drug development. Expert Opin Ther Targets. 2003 Jun;7(3):411-25.

4. Desideri G, Ferri C. Effects of obesity and weight loss on soluble CD40L levels. JAMA J Am Med Assoc. 2003 Apr 9;289(14):1781-2.

5. Kuwana M, Nomura S, Fujimura K, Nagasawa T, Muto Y, Kurata Y, et al. Effect of a single injection of humanized anti-CD154 monoclonal antibody on the platelet-specific autoimmune response in patients with immune thrombocytopenic purpura. Blood. 2004 Feb 15;103(4):1229-36.

6. Boumpas DT, Furie R, Manzi S, Illei GG, Wallace DJ, Balow JE, et al. A short course of BG9588 (anti-CD40 ligand antibody) improves serologic activity and decreases hematuria in patients with proliferative lupus glomerulonephritis. Arthritis Rheum. 2003 Mar;48(3):719-27.

7. Davis JC, Totoritis MC, Rosenberg J, Sklenar TA, Wofsy D. Phase I clinical trial of a monoclonal antibody against CD40-ligand (IDEC-131) in patients with systemic lupus erythematosus. J Rheumatol. 2001 Jan;28(1):95-101.

8. Silvian LF, Friedman JE, Strauch K, Cachero TG, Day ES, Qian F, et al. Small molecule inhibition of the TNF family cytokine CD40 ligand through a subunit fracture mechanism. ACS Chem Biol. 2011 Jun 17;6(6):636-47.

9. Kawai T, Andrews D, Colvin RB, Sachs DH, Cosimi AB. Thromboembolic complications after treatment with monoclonal antibody against CD40 ligand. Nat Med. 2000 Feb;6(2):114.

10. Lutgens E, Lievens D, Beckers L, Wijnands E, Soehnlein O, Zernecke A, et al. Deficient CD40-TRAF6 signaling in leukocytes prevents atherosclerosis by skewing the immune response toward an antiinflammatory profile. J Exp Med. 2010 Feb 15;207(2):391-404.

11. Chatzigeorgiou A, Seijkens T, Zarzycka B, Engel D, Poggi M, van den Berg S, et al. Blocking CD40-TRAF6 signaling is a therapeutic target in obesity-associated insulin resistance. Proc Natl Acad Sci U S A. 2014 Feb 18;111(7):2686-91.

12. Ye H, Arron JR, Lamothe B, Cirilli M, Kobayashi T, Shevde NK, et al. Distinct molecular mechanism for initiating TRAF6 signalling. Nature. 2002 Jul 25;418(6896):443-7.

13. Bernstein FC, Koetzle TF, Williams GJ, Meyer EF, Brice MD, Rodgers JR, et al. The Protein Data Bank: a computer-based archival file for macromolecular structures. J Mol Biol. 1977 May 25;112(3):535-42.

14. Krieger E, Koraimann G, Vriend G. Increasing the precision of comparative models with YASARA NOVA-a self-parameterizing force field. Proteins. 2002 May 15;47(3):393-402.

15. Hooft RW, Sander C, Vriend G. Positioning hydrogen atoms by optimizing hydrogen-bond networks in protein structures. Proteins. 1996 Dec;26(4):363-76.

16. Vriend G, Sander C. Detection of common three-dimensional substructures in proteins. Proteins. 1991;11(1):52-8.

17. Dunbrack RL, Cohen FE. Bayesian statistical analysis of protein side-chain rotamer preferences. Protein Sci Publ Protein Soc. 1997 Aug;6(8):1661-81.

18. An J, Totrov M, Abagyan R. Pocketome via comprehensive identification and classification of ligand binding envelopes. Mol Cell Proteomics MCP. 2005 Jun;4(6):752-61.

19. Laurie ATR, Jackson RM. Q-SiteFinder: an energy-based method for the prediction of protein-ligand binding sites. Bioinforma Oxf Engl. 2005 May 1;21(9):1908-16.

20. ChemBridge Corp. San Diego CA USA www.chembridge.com.

21. Lagorce D, Sperandio O, Galons H, Miteva MA, Villoutreix BO. FAF-Drugs2: free ADME/tox filtering tool to assist drug discovery and chemical biology projects. BMC Bioinformatics. 2008;9:396.

22. Rishton GM. Nonleadlikeness and leadlikeness in biochemical screening. Drug Discov Today. 2003 Jan 15;8(2):86-96.

23. Miteva MA, Violas S, Montes M, Gomez D, Tuffery P, Villoutreix BO. FAF-Drugs: free ADME/tox filtering of compound collections. Nucleic Acids Res. 2006 Jul 1;34(Web Server issue):W738-44.

24. Hawkins PCD, Skillman AG, Warren GL, Ellingson BA, Stahl MT. Conformer generation with OMEGA: algorithm and validation using high quality structures from the Protein Databank and Cambridge Structural Database. J Chem Inf Model. 2010 Apr 26;50(4):572-84.

25. Miteva MA, Lee WH, Montes MO, Villoutreix BO. Fast structure-based virtual ligand screening combining FRED, DOCK, and Surflex. J Med Chem. 2005 Sep 22;48(19):6012-22. 
26. Du J, Bleylevens IWM, Bitorina AV, Wichapong K, Nicolaes GAF. Optimization of compound ranking for structure-based virtual ligand screening using an established FRED-Surflex consensus approach. Chem Biol Drug Des. 2014 Jan;83(1):37-51.

27. McGann M. FRED pose prediction and virtual screening accuracy. J Chem Inf Model. 2011 Mar 28;51(3):57896.

28. ChemBridge Corp. San Diego CA USA www.hit2lead.com.

29. Jain AN. Surflex: fully automatic flexible molecular docking using a molecular similarity-based search engine. J Med Chem. 2003 Feb 13;46(4):499-511.

30. Tanimoto TT. IBM Internal Report. 1957 Nov 17.

31. Wood DJ, de Vlieg J, Wagener M, Ritschel T. Pharmacophore fingerprint-based approach to binding site subpocket similarity and its application to bioisostere replacement. J Chem Inf Model. 2012 Aug 27;52(8):203143.

32. Nabuurs SB, Wagener M, de Vlieg J. A flexible approach to induced fit docking. J Med Chem. 2007 Dec 27;50(26):6507-18.

33. Carlsen H, Moskaug JØ, Fromm SH, Blomhoff R. In vivo imaging of NF-kappa B activity. J Immunol Baltim Md 1950. 2002 Feb 1;168(3):1441-6.

34. Shkoda A, Town JA, Griese J, Romio M, Sarioglu H, Knöfel T, et al. The germinal center kinase TNIK is required for canonical NF- $\kappa B$ and JNK signaling in B-cells by the EBV oncoprotein LMP1 and the CD40 receptor. PLoS Biol. 2012;10(8):e1001376.

35. De Jong SJ, Albrecht J-C, Giehler F, Kieser A, Sticht H, Biesinger B. Noncanonical NF-kB activation by the oncoprotein Tio occurs through a nonconserved TRAF3-binding motif. Sci Signal. 2013 Apr 23;6(272):ra27.

36. BIACORE AB; Kinetics and affinity analysis using BIA - Level 1. 1997.

37. Grommes J, Vijayan S, Drechsler M, Hartwig H, Mörgelin M, Dembinski R, et al. Simvastatin reduces endotoxin-induced acute lung injury by decreasing neutrophil recruitment and radical formation. PloS One. 2012;7(6):e38917.

38. Seeliger D, de Groot BL. Conformational transitions upon ligand binding: holo-structure prediction from apo conformations. PLoS Comput Biol. 2010 Jan;6(1):e1000634.

39. Wu H, Arron JR. TRAF6, a molecular bridge spanning adaptive immunity, innate immunity and osteoimmunology. BioEssays News Rev Mol Cell Dev Biol. 2003 Nov;25(11):1096-105.

40. Sperandio O, Miteva MA, Segers K, Nicolaes GAF, Villoutreix BO. Screening Outside the Catalytic Site: Inhibition of Macromolecular Inter-actions Through Structure-Based Virtual Ligand Screening Experiments. Open Biochem J. 2008;2:29-37.

41. Segers K, Sperandio O, Sack M, Fischer R, Miteva MA, Rosing J, et al. Design of protein-membrane interaction inhibitors by virtual ligand screening, proof of concept with the C2 domain of factor V. Proc Natl Acad Sci. 2007 Jul 31;104(31):12697-702.

42. Charifson PS, Corkery JJ, Murcko MA, Walters WP. Consensus scoring: A method for obtaining improved hit rates from docking databases of three-dimensional structures into proteins. J Med Chem. 1999 Dec 16;42(25):5100-9.

43. Life Chemicals. http://www.lifechemicals.com/

44. Bergmann ED, Ginsburg D, Pappo R. The Michael Reaction. Organic Reactions. John Wiley \& Sons, Inc.; 2004.

45. Gold JA, Parsey M, Hoshino Y, Hoshino S, Nolan A, Yee H, et al. CD40 contributes to lethality in acute sepsis: in vivo role for CD40 in innate immunity. Infect Immun. 2003 Jun;71(6):3521-8.

46. Ban TA. The role of serendipity in drug discovery. Dialogues Clin Neurosci. 2006;8(3):335-44.

47. Hol WGJ. Protein Crystallography and Computer Graphics-toward Rational Drug Design. Angew Chem Int Ed Engl. 1986 Sep 1;25(9):767-78.

48. Villoutreix BO, Eudes R, Miteva MA. Structure-based virtual ligand screening: recent success stories. Comb Chem High Throughput Screen. 2009 Dec;12(10):1000-16.

49. Seifert MHJ, Lang M. Essential factors for successful virtual screening. Mini Rev Med Chem. 2008 Jan;8(1):6372.

50. Baell JB, Holloway GA. New substructure filters for removal of pan assay interference compounds (PAINS) from screening libraries and for their exclusion in bioassays. J Med Chem. 2010 Apr 8;53(7):2719-40.

51. Park BK, Boobis A, Clarke S, Goldring CEP, Jones D, Kenna JG, et al. Managing the challenge of chemically reactive metabolites in drug development. Nat Rev Drug Discov. 2011 Apr;10(4):292-306.

52. Solca F, Dahl G, Zoephel A, Bader G, Sanderson M, Klein C, et al. Target binding properties and cellular activity of afatinib (BIBW 2992), an irreversible ErbB family blocker. J Pharmacol Exp Ther. 2012 Nov;343(2):342-50.

53. Kalliokoski T, Kramer C, Vulpetti A, Gedeck P. Comparability of mixed IC 50 data - a statistical analysis. PloS One. 2013;8(4):e61007. 
54. Karin M, Yamamoto Y, Wang QM. The IKK NF-kappa B system: a treasure trove for drug development. Nat Rev Drug Discov. 2004 Jan;3(1):17-26.

55. Sheng Y, Saridakis V, Sarkari F, Duan S, Wu T, Arrowsmith CH, et al. Molecular recognition of p53 and MDM2 by USP7/HAUSP. Nat Struct Mol Biol. 2006 Mar;13(3):285-91.

56. Xie P. TRAF molecules in cell signaling and in human diseases. J Mol Signal. 2013;8(1):7.

57. Guédat P, Colland F. Patented small molecule inhibitors in the ubiquitin proteasome system. BMC Biochem. 2007;8 Suppl 1:S14. 
Supplementary Materials
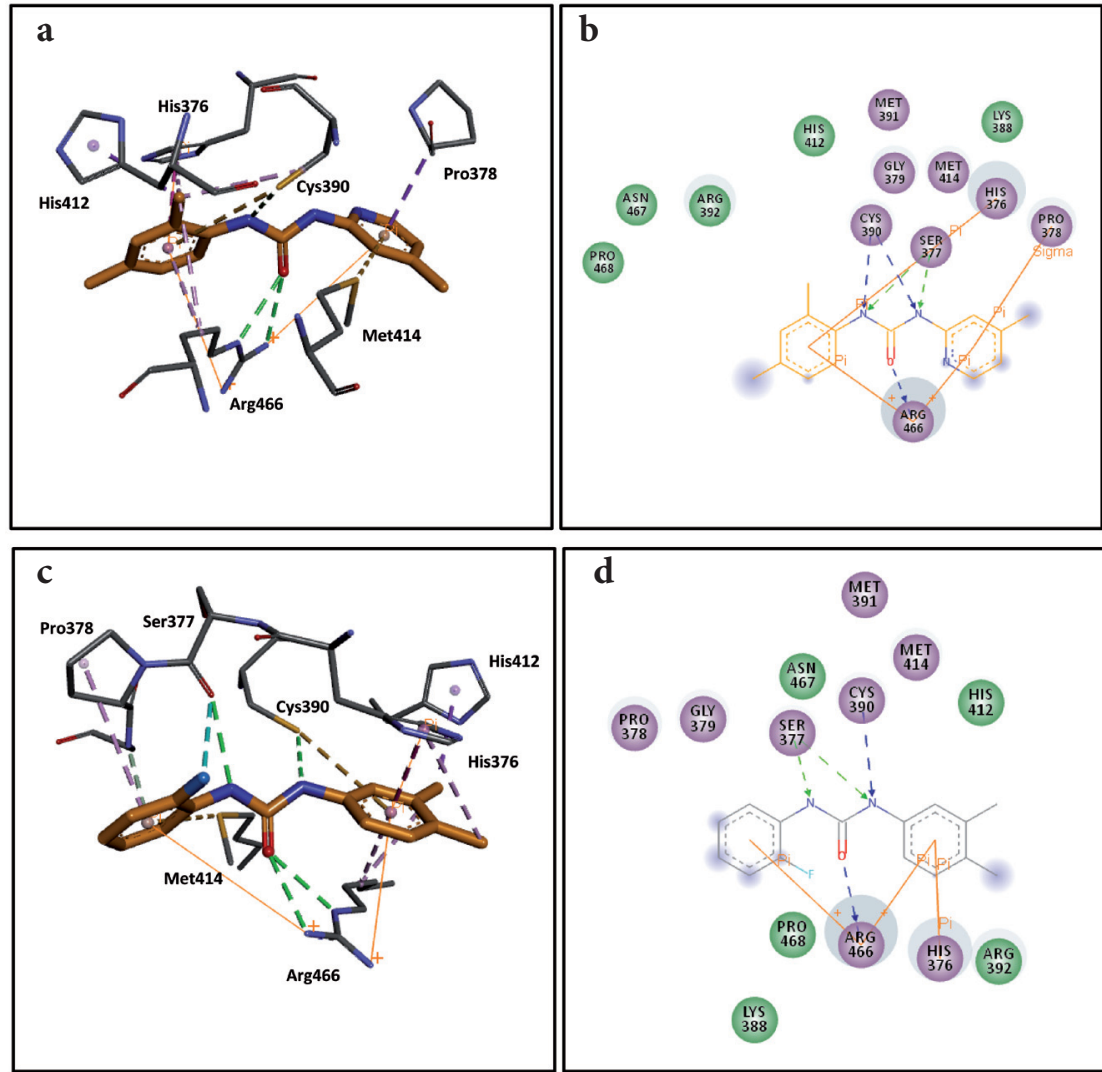

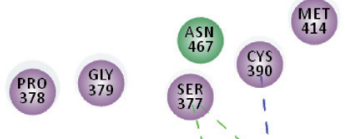

H15

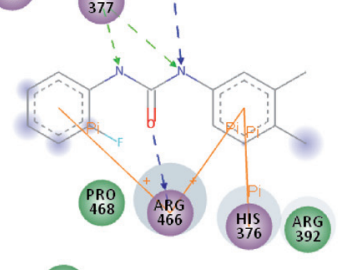

IYS





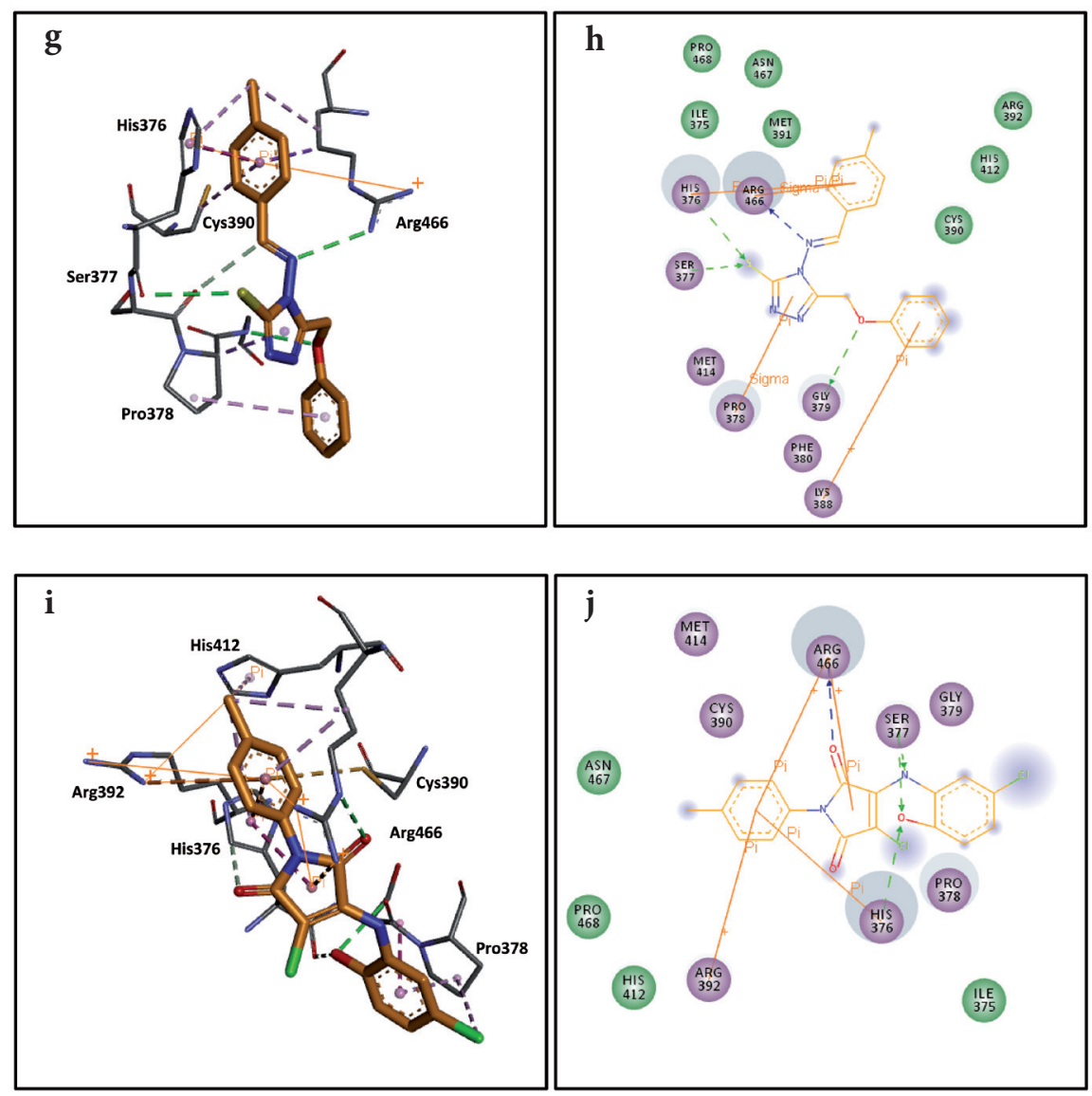

Supplementary Figure 1. The 3D representation and 2D representation of compounds interactions with TRAF6 protein obtained from the program Fleksy. (a, b) compound 9049194, (c, d) compound 9053705, (e, f) compound 7002991, (g, h) compound 7170791, (i, j) compound 7148854. Polar (magenta circles), van der Waals (green circles), H-bond with acid side chain (blue arrow), H-bond with acid main chain (green arrow), pi-pi interactions (orange lines) are indicated.

$\mathbf{a}$

\section{IL1b}

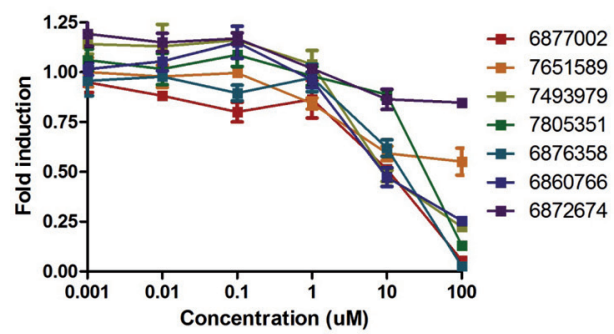

b

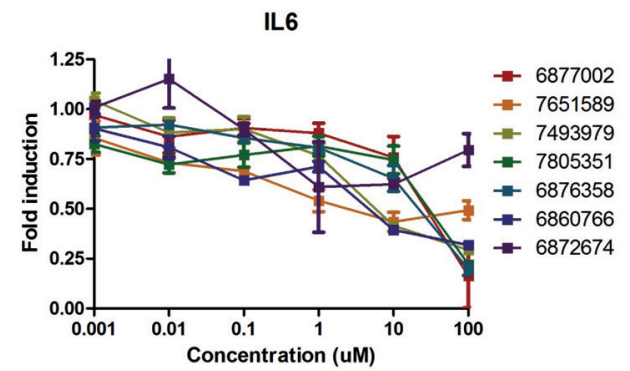

Supplementary Figure 2. Dose-dependent inhibition. (a) IL6 and (b) IL1 $\beta$ expression in agonistic CD40 antibody-stimulated BM-derived macrophages as presented in table 4, carried out as described in the Materials and Methods section. 


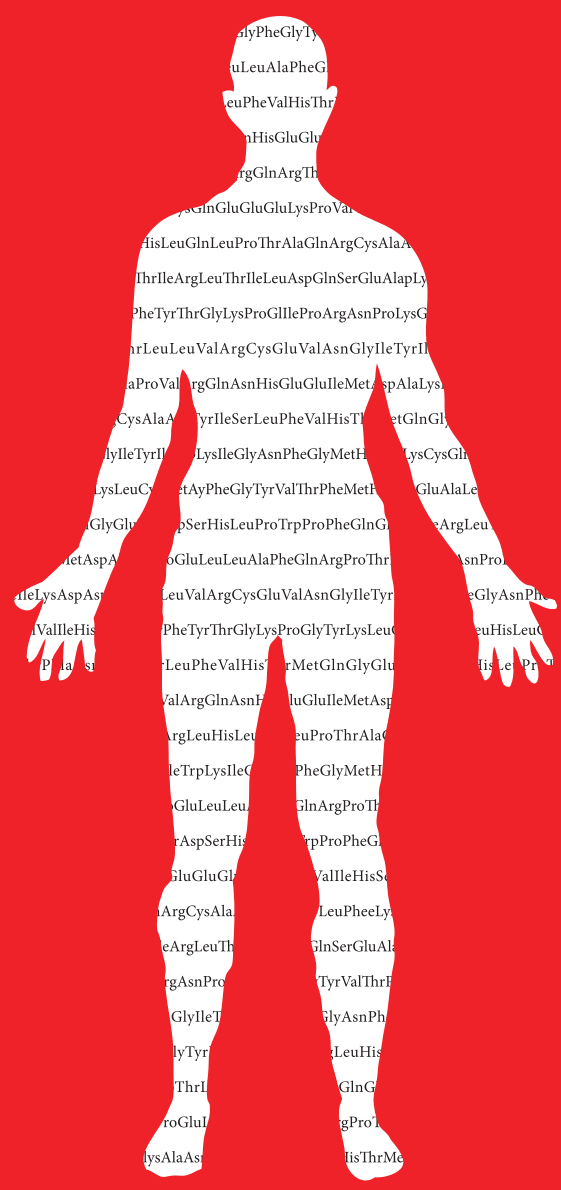




\section{Chapter}

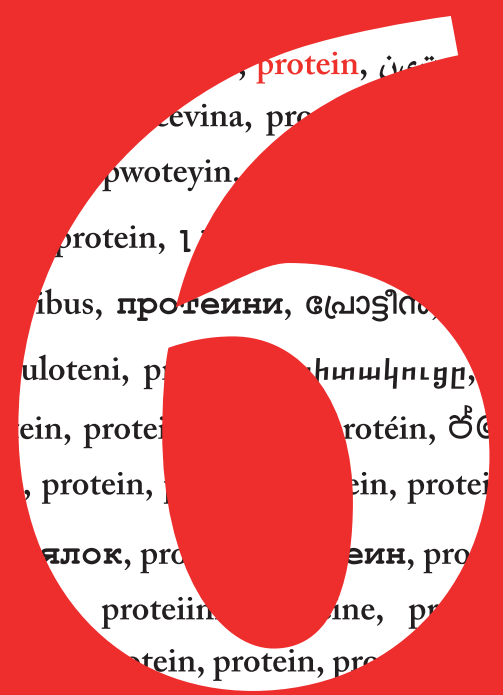

\section{Small-molecule inhibitors of the CD40-TRAF6 interaction as therapy for atherosclerosis}

B. Zarzycka ${ }^{\star}$, T. Seijkens ${ }^{*}$ O. Soehnlein, M.A. Hoeksema, L. Beckers, E. Smeets, S. Meiler, M.J. Gijbels, J. Grommes, R. Schrijver, L. Boon, T.M. Hackeng, G. Vriend, S.B. Nabuurs, N. Gerdes, M.P.J. de Winther, C. Weber, G.A.F. Nicolaes\#, E. Lutgens”, *\# equal contribution Manuscript in preparation 


\begin{abstract}
Inhibition of the co-stimulatory CD40-CD40L receptor/ligand dyad drastically reduces atherosclerosis. However, its long-term blockage results in immunosuppression. Inhibition of the CD40-CD40L dyad further downstream in the signalling pathway is therefore required. The interaction between CD40 and its signalling intermediate TNF receptor associated factor 6 (TRAF6) plays a pivotal role in atherosclerosis. Our CD40-TRAF6 inhibitors reduced atherosclerosis in $A p o E^{--}$mice by hampering monocyte and neutrophil recruitment. In accordance, expression of chemokines and cytokines was remarkably reduced in compound treated macrophages. These newly developed CD40-TRAF6 inhibitors can overcome the current limitations of long-term CD40 and CD40L inhibition in atherosclerosis and other inflammatory diseases.
\end{abstract}




\section{Introduction}

Atherosclerosis is a chronic inflammatory disease of the arterial wall (1). Current therapies aimed at preventing complications of the disease, for example, myocardial infarction or stroke, are restricted to the treatment of classical risk factors such as hypertension or hyperlipidemia. Strategies that directly target the inflammatory nature of atherosclerosis are sparse (2). The co-stimulatory CD40-CD40L receptor/ligand dyad is well known for its proinflammatory role in the development of atherosclerosis, as well as other chronic inflammatory diseases (3). Antibody-mediated inhibition of CD40 or CD40L drastically reduces atherosclerosis in hyperlipidemic mice (4-8). However, its long-term use results in immunosuppression and thromboembolic events and is therefore not clinically feasible $(3,9)$. Inhibition of the CD40-CD40L dyad further downstream in the signalling pathway is therefore required. Upon activation, CD40 recruits tumour necrosis factor receptor-associated factors (TRAFs) to elicit intracellular signalling (3). Studies on mice with a mutation in their CD40-TRAF binding sites reveal that only CD40-TRAF6 interactions are important for atherosclerosis, while CD40-TRAF2, 3, 5 interactions only play a minor role in atherosclerosis (6).

Here, we identified that our CD40-TRAF6 inhibitors halt atherogenesis by reducing chemokine-mediated leukocyte recruitment to the arterial wall and inhibiting cytokine production by monocytes/macrophages. Therapeutic inhibition of CD40-TRAF6 interactions by these compounds has the potential to become a treatment for atherosclerosis and other inflammatory diseases.

\section{Materials and Methods}

\section{In vitro macrophage culture}

Bone marrow (BM) cells were isolated from C57Bl/6 mice and cultured in RPMI supplemented with $15 \%$ L929-conditioned medium to generate BM-derived macrophages (10). BM-derived macrophages were activated by the agonistic CD40 antibody FGK45 (25 $\mu / \mathrm{ml}$, Bioceros BV) for 6 hours.

\section{Quantitative PCR}

RNA was isolated from BM-derived macrophages and reverse transcripted using an iScript cDNA synthesis kit (Bio-Rad). Quantitative (q)PCR was performed with a SYBR Green PCR kit (Applied Biosystems) on a ViiA 7 real-time PCR system (Applied Biosystems). Primer sequences are available upon request.

\section{Chromatin Immunoprecipitation (ChIP)}

BM-derived macrophages were activated using FGK45 and incubated with the compounds, as described above. For ChIP, 40 million BM-derived macrophages were used per condition. p65 ChIP was performed with $5 \mathrm{mg}$ antibody (SC-372, Santa Cruz) per 20 million cells, as described previously (11). ChIP-qPCR was performed on an ABI ViiA 7 PCR system using 
SYBR Green Fast (Applied Biosystems). Relative enrichments are presented as percentage of input. Primer sequences are available upon request.

\section{Animals}

Male C57Bl/6 and $A p o E^{-1-}$ (C57Bl/6 background) mice were purchased from Charles River or bred at the local animal facility (Maastricht University, Maastricht, The Netherlands; Amsterdam Medical Center, Amsterdam, The Netherlands; and Ludwig Maximilians University, Munich, Germany). Cx3crlegfp/+ApoE $E^{-/}$were bred at the LMU. All experiments were approved by the local Animal Experimentation Ethics Committees.

\section{Toxicity studies}

For in vivo toxicity studies, male $\mathrm{C} 57 \mathrm{Bl} / 6$ mice received a daily intraperitoneal injection IP of the small molecules $(10 \mu \mathrm{mol} / \mathrm{kg})$ for 6 weeks ( $A p o E^{-/-}$mice; atherosclerosis study). At sacrifice, absolute peripheral blood counts were determined using a scil Vet abc Plus+ hematology analyzer (Scil Animal Care Company B.V.). For histological analysis, organs were fixed in paraformaldehyde ( $4 \%$, overnight), sectioned at $4 \mu \mathrm{m}$, and stained with hematoxylin and eosin.

\section{Flow cytometry}

At sacrifice, blood was obtained from the heart in EDTA-coated syringes. Erythrocytes were lysed by incubation with a hypotonic buffer $\left(8.4 \mathrm{~g}\right.$ of $\mathrm{NH}_{4} \mathrm{Cl}$ and $0.84 \mathrm{~g}$ of $\mathrm{NaHCO}_{3}$ per liter of distilled water). Non-specific antibody binding was prevented by pre-incubation with a Fcreceptor blocking antibody (eBioscience). Leukocytes were labelled with CD3-FITC (eBioscience), B220-V500 (eBioscience), CD11b-PeCy7 (BD), Ly6G-PE (BD), and Ly6CAPC (Miltenyi Biotec). Cells were analysed on a FACSCanto II flow cytometer (BD).

\section{Atherosclerosis}

$A p o E^{-/-}$mice were i.p. injected with the compounds at $10 \mu \mathrm{mol} / \mathrm{kg} /$ day for 6 weeks, starting at the age of 12 weeks, and were fed a normal chow diet throughout the experiment. They were then sacrificed and the arterial tree was perfused. The aortic arch and its main branch points were excised, fixed overnight, and embedded in paraffin. Longitudinal sections of the aortic arch were analysed for plaque extent and morphology as previously described (6). For phenotypic analysis, immunohistochemistry (IHC) was performed for CD3 (Dako), CD45 (BD), Mac-3 (BD) and a-SMA (Sigma-Aldrich). Sirius red staining was performed as previously described. Morphometric analyses were performed using the Las4.0 software (Leica). Plasma cholesterol levels were measured enzymatically (Roche), and organs were analysed by haematoxylin and eosin staining.

\section{Intravital microscopy}

Intravital microscopy of the carotid artery was performed in $C \times 3 \mathrm{cr} 1 \mathrm{egfp} /{ }^{+} A p o E^{-/-}$mice for 6 weeks on $0.15 \%$ cholesterol diet as previously described (12). Mice received a single i.p. 
injection of the compound or vehicle. A PE-conjugated antibody to Ly6G (1A8, $1 \mu \mathrm{g})$ was instilled via a jugular vein catheter 5 minutes prior to recording. After recording of neutrophil and monocyte adhesion, rhodamine $6 \mathrm{G}$ was administered to visualize all adherent leukocytes. Intravital microscopy was performed using an Olympus BX51 microscope equipped with a beam splitter to enable synchronized dual-channel recording, a Hamamatsu 9100-02 EMCCD camera, and a 10x saline-immersion objective. Olympus cell software was used for image acquisition and analysis.

\section{Statistical analysis}

Data are presented as mean \pm SEM. Data were analysed by using either an unpaired Student's $t$ test, a Bonferoni-corrected Student's $t$ test, or an ANOVA as indicated, using the GraphPad Prism 5.0 software (GraphPad Software, Inc.). P-values $<0.05$ were considered significant.

\section{Results}

\section{Compound treatment reduces atherosclerosis}

To analyse the effects of these compounds on atherosclerosis, $A p o E^{-/-}$mice were treated with compounds 6877002 or 6860766 at $10 \mu \mathrm{mol} / \mathrm{kg} /$ day for 6 weeks, starting at the age of 12 weeks. This did not affect body weight or plasma cholesterol levels (supplementary material, figure S1a and b). In addition, we did not detect differences in peripheral blood leukocyte counts or immune cell distribution between compound-treated and vehicle-treated mice (supplementary material, figure S1c), indicating that long-term treatment with compound 6877002 and 6860766 did not cause leukocyte toxicity in vivo. 56 atherosclerotic lesions in the aortic arch of control-treated mice ( $n=15$, mean 3.73 plaques/aorta), 38 lesions of 6877002-treated mice ( $n=14$, mean 2.71 plaques/aorta), and 36 lesions of 6860766-treated mice ( $n=12$, mean 3 plaques/aorta) were analysed by histology. Compound treatment reduced total atherosclerotic plaque area per aortic arch by $47.1 \%$ (6877002) and $66.8 \%$ (6860766) compared to vehicle-treated mice (figure 1a,c). Aortas from treated mice contained less advanced atherosclerotic lesions (fibrous cap atheroma), compared to controls (figure 1b). Correspondingly, the frequency of initial atherosclerotic lesions (intimal xanthoma and pathological intimal thickening) was increased (figure 1b), indicating that the progression of atherosclerosis was inhibited. Compound treatment reduced the number of leukocytes per plaque by $43.1 \%$ (6877002) and $52.6 \%$ (6860766) (figure 1d). Leukocyte subset analysis revealed that monocyte/macrophage $\left(\mathrm{Mac}^{+}\right)$(figure $2 \mathrm{e}$ ), as well as granulocyte $\left(\mathrm{Ly}_{6 \mathrm{G}}{ }^{+}\right)$and T-cell $\left(\mathrm{CD}^{+}\right)$content had significantly decreased upon treatment with CD40-TRAF6 inhibiting compounds (supplementary material, figure S2a), For both compounds, no differences were observed in the number of apoptotic cells (TUNEL ${ }^{+}$), smooth muscle cells $\left(\mathrm{aSMA}^{+}\right)$and collagen (Sirius Red ${ }^{+}$) content (supplementary material, figure S2b-d). Treatment with either of the two compounds thus prevents the progression of atherosclerosis in mice and induces a favourable atherosclerotic plaque phenotype that is low in inflammation. 


\section{Compound treatment impairs leukocyte recruitment to the arterial wall}

To elucidate whether decreased plaque leukocyte numbers in compound-treated mice resulted from alterations in leukocyte recruitment to the endothelium, in vivo adhesion experiments were performed. Intravital microscopy demonstrated that the compounds reduced the recruitment of leukocytes, especially monocytes and granulocytes, to the arterial wall of $A p o E^{-/}$mice (figure 2a). Compound 6877002 and 6860766 reduced monocyte adhesion by $40.1 \%$ and $51.2 \%$ respectively (figure $2 \mathrm{~b}, \mathrm{~d}$ ), and neutrophil adhesion by $40.2 \%$ and 51.2 $\%$ respectively (figure $2 c, d$ ).

Chemokines play a pivotal role in leukocyte recruitment (13). We therefore analysed whether the compounds affected chemokine expression. Chromatin immunoprecipitation revealed that treatment with compound 6877002 or 6860766 reduces CD40-induced binding of p65 to the promoter of CCL2 by $83.9 \%$ and $45.4 \%$ respectively (supplementary material, figure S3a). The compounds also inhibited the expression of the chemokine pairs CCL2-CCR2 and CCL5CCR5 in bone marrow derived macrophages upon activation of CD40 signalling (figure 2e, f). Both chemokine pairs promote myeloid cell accumulation within the arterial wall during atherogenesis (13).

\section{Compound treatment improves the inflammatory phenotype of macrophages}

After adhesion to the activated endothelium, leukocytes critically contribute to the ongoing inflammation by secreting cytokines and reactive oxygen species (14). We therefore analysed whether compound treatment affected the expression of inflammatory mediators in bone marrow derived macrophages, because these account for the majority of leukocytes in atherosclerotic plaques. CD40-induced expression of TNFa, IL1 $\beta$, IL6, IL10 and IL12 significantly decreased in both 6877002 and 6860766 treated macrophages (figure $2 \mathrm{~g}$ ). Treatment with the compounds also reduced the expression of iNOS by $67.7 \%$ and $80.6 \%$ for 6877002 and 6860766 respectively (supplementary material, figure S3b). These data demonstrate that compound treatment attenuates the inflammatory propensity of macrophages.

\section{Discussion}

Atherosclerosis remains a major cause of mortality and morbidity, despite the aggressive lipid-lowering, antihypertensive and anti-thrombotic strategies that have been introduced in the past decades (2). Additional strategies that directly target the inflammatory nature of atherosclerosis are therefore required. The co-stimulatory receptor/ligand dyad CD40-CD40L is highly expressed in human atheroscleroticlesions(3).CD40-CD40Linteractions playa pivotal role in atherosclerosis by orchestrating the inflammatory response underlying plaque development (3). The therapeutic potential of CD40-CD40L targeting strategies is emphasized by the observation that antibody-mediated inhibition of CD40L in $A p o E^{-/-}$mice induced a plaque phenotype that is low in inflammatory cell content and high in fibrosis, representing 
the clinically favourable stable phenotype (4-8). However, clinical trials, evaluating the efficacy of anti-CD40L antibodies, were put on hold due to the occurrence of thromboembolic events (9). Additionally, long-term antibody-mediated inhibition of CD40 results in immunosuppression and is therefore not feasible for the treatment of chronic diseases (3). Therefore, more downstream inhibition of the CD40-CD40L signalling pathway is required. Upon binding of CD40L, CD40 recruits TRAFs to elicit intracellular signalling. Using mice with a mutated CD40-TRAF binding site, we previously demonstrated that only CD40TRAF6, and not CD40-TRAF2, 3, 5 interactions are important in atherogenesis (6).

a

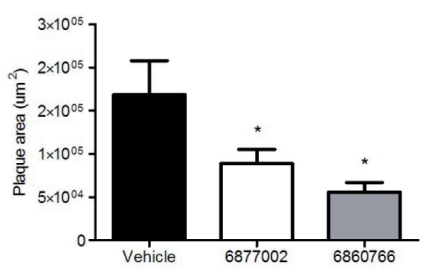

b

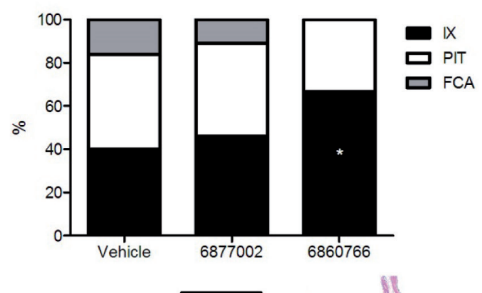

c


d
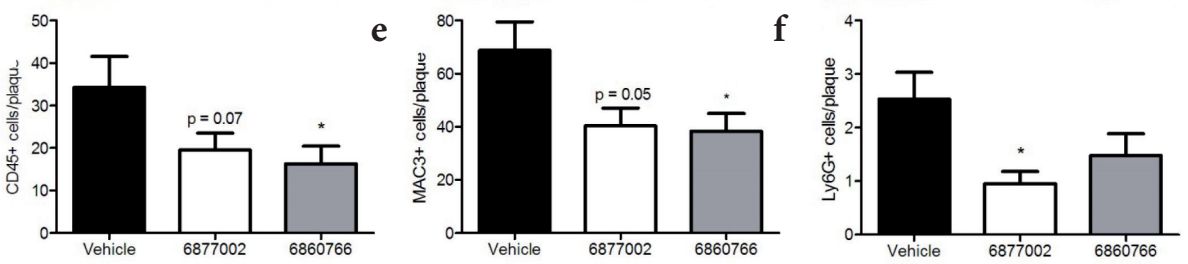

Figure 1. Compound treatment reduces atherosclerotic burden in $\mathrm{ApoE}^{-/-}$mice by limiting plaque inflammation. (a) Total plaque area in the aortic arch of 18 week old $A p o E^{-/}$mice is reduced by compound treatment $(10 \mu \mathrm{mol} / \mathrm{kg} /$ day $)$ for 6 weeks $(n=15$ for vehicle, $n=14$ for $6877002, n=12$ for 6860766). (b) Atherosclerotic plaques were classified as described previously (6). Compound 6860766 increased the incidence of initial lesions (intimal xanthoma (IX), pathological intimal thickening (PIT)) as it prevented the development of advanced lesions (fibrous cap atheroma (FCA)). ( $n=56$ for vehicle, $n=38$ for $6877002, n=36$ for 6860766). (c) Representative longitudinal images of the aortic arch and brachiocephalic trunk, stained with hematoxylin and eosin (HE). Compound treatment reduced plaque size and prevented the progression of initial lesions to more complex, advanced lesions. Scale bar: $2 \mathrm{~mm}$ (upper pictures) $100 \mu \mathrm{m}$ (lower pictures). (d-f) Compound-treatment reduced the number of leukocytes $\left(\mathrm{CD} 45^{+}\right.$cells), macrophages/monocytes $\left(\mathrm{MAC}^{+}\right)$, and granulocytes $\left(\mathrm{Ly}_{6 \mathrm{G}}{ }^{+}\right)$. All values represent mean \pm SEM. ${ }^{*}, \mathrm{P}<0.05$. 
a

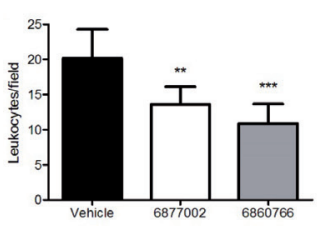

d

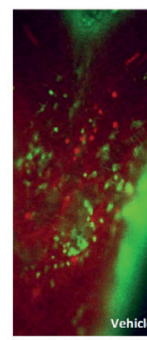

b

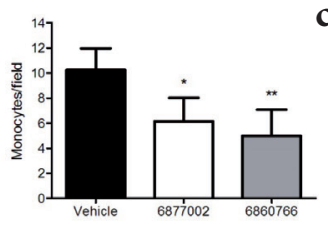

e c
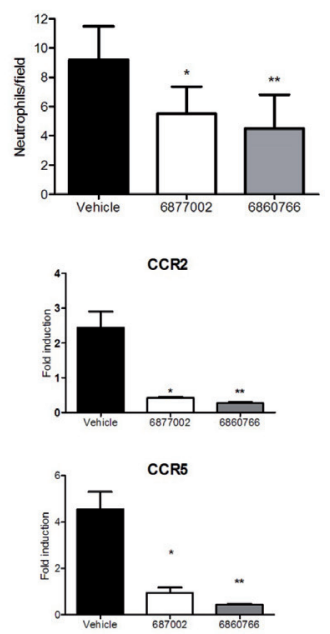

g

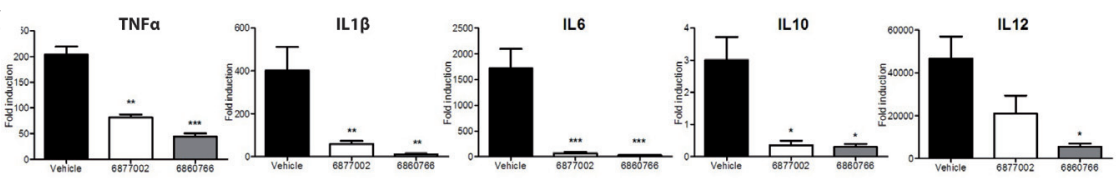

Figure 2. Compound treatment impairs arterial myeloid cell adhesion and decreases chemokine and cytokine expression. Intravital microscopy of the carotid artery in Cx3crlegfp/wt $A p o E^{-/-}$mice fed a high fat diet for 6 weeks. To visualize neutrophils an antibody to Ly6G was instilled. Leukocytes were stained by rhodamine $6 \mathrm{G}$ application. (a) Leukocyte adhesion to the endothelium was reduced in 6877002-treated and 6860766-treated $A p o E^{-/-}$mice. (b, c) In particular, monocyte (b) and granulocyte (c) adhesion was impaired in treated mice ( $n=5-8$ per group). (d) Visualization of leukocyte adhesion to the carotid artery of $\mathrm{Cx} 3 \mathrm{cr} 1$ egfp/wt $A p o E^{-/}$mice. $(\mathrm{e}, \mathrm{f})$ The $\mathrm{CD} 40$-induced expression of the chemokine pairs CCL2, CCR2, CCL5, CCR5 in bone marrow-derived macrophages was impaired by the compounds. (g) CD40-induced cytokine expression is prevented in compound treated bone marrowderived macrophages. ${ }^{\star}, \mathrm{P}<0.05 ;{ }^{* *}, \mathrm{P}<0.01{ }^{* * *}, \mathrm{P}<0.001$.

Our in vivo studies indicate that the compounds reduced atherosclerosis by hampering chemokine-mediated leukocyte recruitment to the arterial wall and reducing the release of inflammatory mediators by monocytes/macrophages.

Our results are consistent with previous observations in CD40-TRAF6 ${ }^{-1}$ mice, which showed reduced monocyte recruitment to the arterial wall and macrophages in these mice were characterized by an anti-inflammatory profile (6). In contrast, compound treatment did not decrease the number of circulating Ly6 $\mathrm{C}^{\text {high }}$ monocytes. However, in accordance with observations in $\mathrm{CD} 40$-TRAF6 ${ }^{-1-}$ monocytes, we found that the compounds inhibited activation of NFKB signalling and cytokine expression upon CD40 stimulation (15). The effects of CD40-TRAF2, 3, 5 interactions in vascular inflammation appear to be more balanced compared to CD40-TRAF6 interactions, CD40-TRAF2, 3, 5 ${ }^{--}$mice are characterized by increased $\mathrm{CD} 4^{+} \mathrm{T}$-cells and $\mathrm{CD} 8^{+} \mathrm{CD} 44^{\text {high }} \mathrm{CD} 62 \mathrm{~L}^{\text {low }}$ effector memory T-cells. However, this increase in pro-atherogenic leukocytes is compensated by increased numbers of antiatherogenic $\mathrm{CD}_{4}^{+} \mathrm{CD} 25^{+} \mathrm{FoxP}^{+}$regulatory T-cells, which protects these mice against excessive 
vascular inflammation (6). Although CD40-TRAF2, 3, 5 interactions are not involved in atherogenesis, these interactions essentially contribute to numerous humoral immune processes (16). In contrast to antagonistic CD40 antibodies, our compounds specifically target the pro-inflammatory CD40-TRAF6 interaction, thereby preserving the function of CD40-TRAF2, 3, 5 in immunity.

The therapeutic potential CD40-CD40L targeting strategies have been investigated in multiple inflammatory pathologies. For example, antagonistic CD40L monoclonal antibodies were successfully used for the treatment of SLE, Crohn's disease and renal allograft rejection in humans $(17,18)$. Additionally, antagonistic CD40 antibodies reduced disease severity in patients with moderate to severe Crohn's disease (19). The beneficial effects of CD40 and CD40L blocking antibodies may at least partly be attributed to reduced proinflammatory cytokine levels and suppression of T-cell activation and polarization (20). However, longterm treatment with these agents, as would be required for a chronic inflammatory disease as atherosclerosis, would induce immune suppression. In hemato-oncology, antibody-mediated blockage of CD40 signalling has potent anti-tumour activity in primary B-cell chronic lymphocytic leukaemia cells as well as in multiple myeloma-derived cell lines. The antitumour effects were at least partially due to the inhibition of NFkB-induced cytokine production, including IL6, IL10 and TNFa, which normally promote proliferation of malignant cells (21-23). As our compounds inhibit NFkB activation and subsequent cytokine production in macrophages, it will be of great interest to analyse possible effects on these tumour cells.

Although antibody-mediated inhibition of CD40L and CD40 showed great promise in clinical trials, the occurrence of thrombo-embolic events and immunosuppression prevented its further development as therapy for chronic inflammatory diseases $(3,9)$. We observed no thrombo-embolic complications in compound treated mice, as our compounds do not interfere with the CD40L- $\alpha_{\mathrm{IIb}} \beta_{3}$ interaction and hence do not induce destabilization of arterial thrombi. In addition, we show that compound treatment for 6 weeks did not induce leukocyte toxicity or immunosuppressive side effects. Compound treatment increased survival of mice subjected to polymicrobial sepsis. Although the mechanisms of these beneficial effects are currently unknown, the results show that these animals did not suffer from major immunosuppression. Nevertheless, systemic long-term administration of any antiinflammatory drugs could bear some risks. A potential concern regarding inhibition of the CD40-CD40L signalling pathway is impaired B-cell dependent immunity. In B-cells, CD40TRAF6 interactions are involved in immunoglobulin affinity maturation and the generation of long-lived plasma cells, whereas germinal center formation, early immunoglobulin production and proliferation are CD40-TRAF6 independent (16). Detailed analysis of these potential side effects is required before clinical application.

In addition to potential off-target effects, several questions need to be answered before 
translation of these results to the treatment of humans suffering from atherosclerosis. In the current study we investigated the effects of the compounds on the progression of early atherosclerosis. To determine the therapeutic potential of the compounds, additional studies are required to analyse the effects of the compounds on established atherosclerosis.

In conclusion, we have identified small molecule inhibitors of the CD40-TRAF6 interaction that successfully reduce atherosclerosis by hampering chemokine-mediated leukocyte recruitment to the arterial wall and inhibiting cytokine secretion by macrophages. These inhibitors will undoubtedly require further development and refinement before they can be used in a clinical setting. However, here we have shown that our newly identified CD40TRAF6 compounds can overcome the current limitations of long-term CD40 and CD40L inhibition in atherosclerosis and other inflammatory diseases.

\section{Acknowledgments}

We acknowledge the support from the Netherlands CardioVascular Research Initiative": the Dutch Heart Foundation, Dutch Federation of University Medical Centres, the Netherlands Organisation for Health Research and Development and the Royal Netherlands Academy of Sciences" for the GENIUS project "Generating the best evidence-based pharmaceutical targets for atherosclerosis" (CVON2011-19). This study was supported by the Humboldt Foundation (Sofja Kovalevskaja grant to E.L.), the Deutsche Forschungs Gemeinschaft (DFG809 and SFB 1054 to E.L.) the Netherlands Organization for Scientific Research, NWO (VENI grant to S.B.N., VIDI grant to E.L. and O.S., VICI grant to E.L. and C.W., medium investment grant to G.N.), the Dutch Heart Foundation (Dr. E. Dekker MD-grant to T.S., Dr. E. Dekker Established Investigator grant to E.L. and M.d.W.), the AMC (AMC fellowship to E.L. and M.d.W.), the Cardiovascular Research Institute Maastricht, CARIM (to G.N.), the EU (grant KBBE-2011-5 289350 to G.V.), the Transnational University Limburg (to G.N.), the DFG (SO876/3-1, FOR809, SFB914, TP B08 to O.S.), Cyttron II (FES0908 to G.N. and T.H.) and DZHK (MHA VD1.2 to C.W.). We thank M. Kulharia, F. Albayrak, and M. Frissen for technical assistance. 


\section{References}

1. Hansson GK, Hermansson A. The immune system in atherosclerosis. Nat Immunol. 2011 Mar;12(3):204-12.

2. Weber C, Noels H. Atherosclerosis: current pathogenesis and therapeutic options. Nat Med. 2011;17(11):141022.

3. Engel D, Seijkens T, Poggi M, Sanati M, Thevissen L, Beckers L, et al. The immunobiology of CD154-CD40TRAF interactions in atherosclerosis. Semin Immunol. 2009 Oct;21(5):308-12.

4. Lutgens E, Cleutjens KB, Heeneman S, Koteliansky VE, Burkly LC, Daemen MJ. Both early and delayed antiCD40L antibody treatment induces a stable plaque phenotype. Proc Natl Acad Sci U S A. 2000 Jun 20;97(13):7464-9.

5. Lutgens E, Gorelik L, Daemen MJ, de Muinck ED, Grewal IS, Koteliansky VE, et al. Requirement for CD154 in the progression of atherosclerosis. Nat Med. 1999 Nov;5(11):1313-6.

6. Lutgens E, Lievens D, Beckers L, Wijnands E, Soehnlein O, Zernecke A, et al. Deficient CD40-TRAF6 signaling in leukocytes prevents atherosclerosis by skewing the immune response toward an antiinflammatory profile. J Exp Med. 2010 Feb 15;207(2):391-404.

7. Schönbeck U, Sukhova GK, Shimizu K, Mach F, Libby P. Inhibition of CD40 signaling limits evolution of established atherosclerosis in mice. Proc Natl Acad Sci U S A. 2000 Jun 20;97(13):7458-63.

8. Mach F, Schönbeck U, Sukhova GK, Atkinson E, Libby P. Reduction of atherosclerosis in mice by inhibition of CD40 signalling. Nature. 1998 Jul 9;394(6689):200-3.

9. André P, Prasad KSS, Denis CV, He M, Papalia JM, Hynes RO, et al. CD40L stabilizes arterial thrombi by a beta3 integrin--dependent mechanism. Nat Med. 2002 Mar;8(3):247-52.

10. Kanters E, Gijbels MJJ, van der Made I, Vergouwe MN, Heeringa P, Kraal G, et al. Hematopoietic NF-kappaB1 deficiency results in small atherosclerotic lesions with an inflammatory phenotype. Blood. 2004 Feb 1;103(3):934-40.

11. Spann NJ, Garmire LX, McDonald JG, Myers DS, Milne SB, Shibata N, et al. Regulated accumulation of desmosterol integrates macrophage lipid metabolism and inflammatory responses. Cell. 2012 Sep 28;151(1):138-52.

12. Grommes J, Vijayan S, Drechsler M, Hartwig H, Mörgelin M, Dembinski R, et al. Simvastatin reduces endotoxin-induced acute lung injury by decreasing neutrophil recruitment and radical formation. PloS One. 2012;7(6):e38917.

13. Koenen RR, Weber C. Therapeutic targeting of chemokine interactions in atherosclerosis. Nat Rev Drug Discov. 2010 Feb;9(2):141-53.

14. Woollard KJ, Geissmann F. Monocytes in atherosclerosis: subsets and functions. Nat Rev Cardiol. 2010 Feb;7(2):77-86.

15. Mukundan L, Bishop GA, Head KZ, Zhang L, Wahl LM, Suttles J. TNF receptor-associated factor 6 is an essential mediator of CD40-activated proinflammatory pathways in monocytes and macrophages. J Immunol Baltim Md 1950. 2005 Jan 15;174(2):1081-90.

16. Elgueta R, Benson MJ, de Vries VC, Wasiuk A, Guo Y, Noelle RJ. Molecular mechanism and function of CD40/ CD40L engagement in the immune system. Immunol Rev. 2009 May;229(1):152-72.

17. Peters AL, Stunz LL, Bishop GA. CD40 and autoimmunity: the dark side of a great activator. Semin Immunol. 2009 Oct;21(5):293-300.

18. Lievens D, Eijgelaar WJ, Biessen EAL, Daemen MJAP, Lutgens E. The multi-functionality of CD40L and its receptor CD40 in atherosclerosis. Thromb Haemost. 2009 Aug;102(2):206-14.

19. Kasran A, Boon L, Wortel CH, Hogezand RA, Schreiber S, Goldin E, et al. Safety and tolerability of antagonist anti-human CD40 Mab ch5D12 in patients with moderate to severe Crohn's disease. Aliment Pharmacol Ther. 2005 Jul 15;22(2):111-22.

20. Howard LM, Miga AJ, Vanderlugt CL, Dal Canto MC, Laman JD, Noelle RJ, et al. Mechanisms of immunotherapeutic intervention by anti-CD40L (CD154) antibody in an animal model of multiple sclerosis. J Clin Invest. 1999 Jan;103(2):281-90.

21. Luqman M, Klabunde S, Lin K, Georgakis GV, Cherukuri A, Holash J, et al. The antileukemia activity of a human anti-CD40 antagonist antibody, HCD122, on human chronic lymphocytic leukemia cells. Blood. 2008 Aug 1;112(3):711-20.

22. Khubchandani S, Czuczman MS, Hernandez-Ilizaliturri FJ. Dacetuzumab, a humanized mAb against CD40 for the treatment of hematological malignancies. Curr Opin Investig Drugs Lond Engl 2000. 2009 Jun;10(6):57987.

23. Tai Y-T, Li X, Tong X, Santos D, Otsuki T, Catley L, et al. Human anti-CD40 antagonist antibody triggers significant antitumor activity against human multiple myeloma. Cancer Res. 2005 Jul 1;65(13):5898-906. 


\section{Supplementary Materials}

a

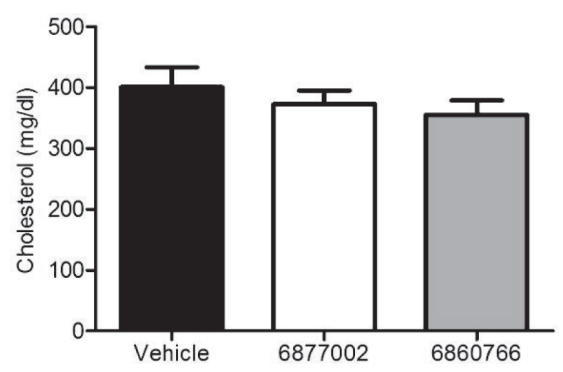

c

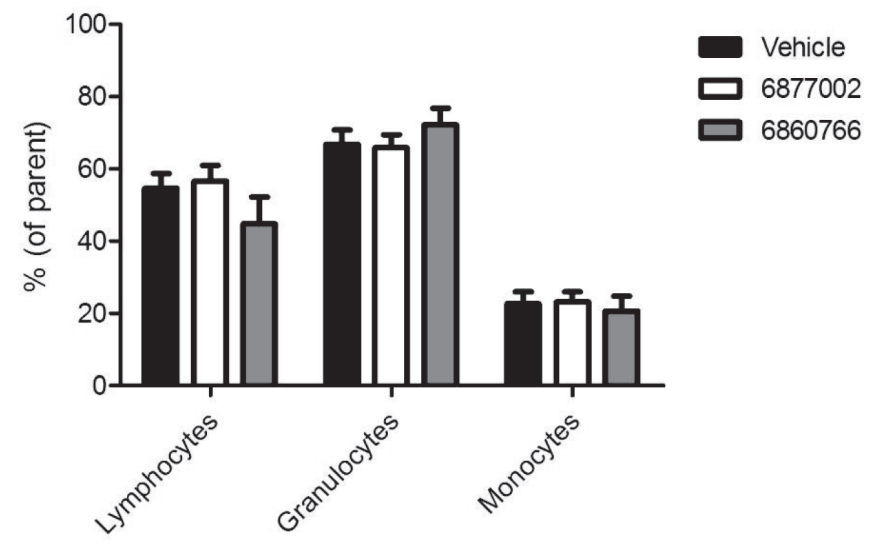

Supplementary Figure 1. Compound treatment did not affect cholesterol levels and immune cell distribution. ( $\mathrm{a}, \mathrm{b})$ Long-term (6 week) compound treatment did not affect bodyweight and plasma cholesterol levels in $\mathrm{ApoE}^{-/-}$mice. (c) No differences in peripheral blood lymphocytes, granulocytes, and monocytes were observed. b

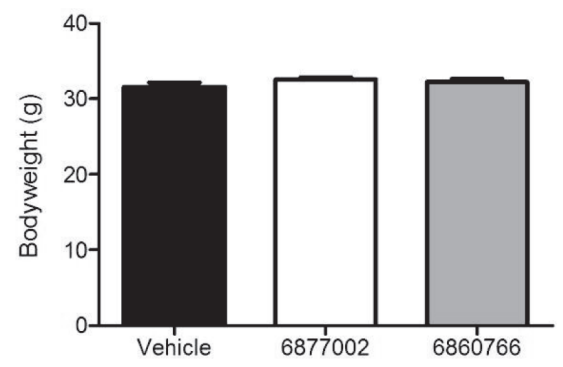


a

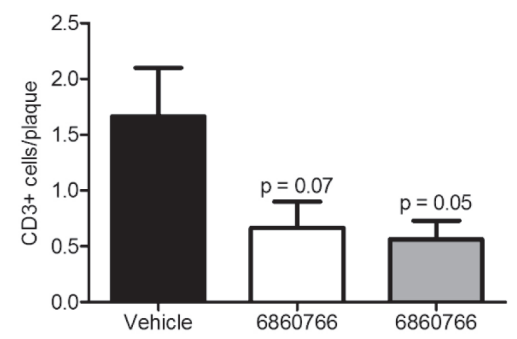

C

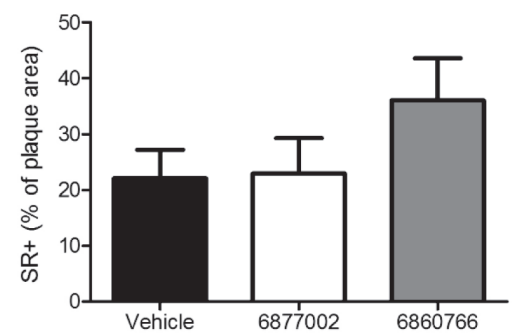

b

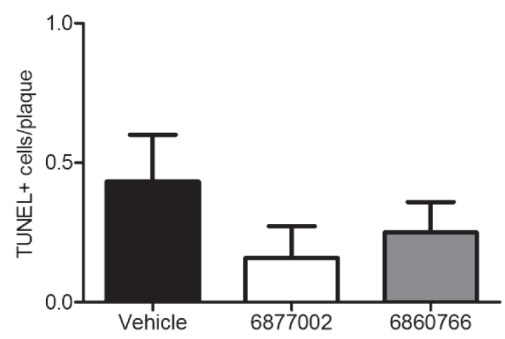

d

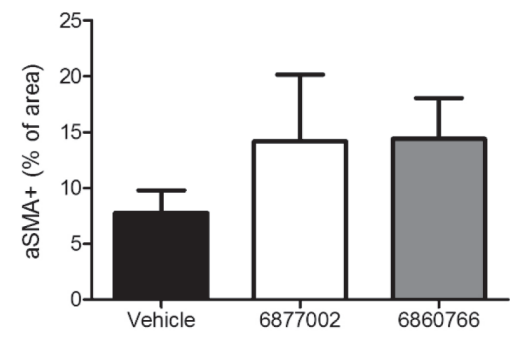

Supplementary Figure 2. Additional histological analysis of the atherosclerotic plaques. (a) Compound treatment reduced the number of T-cells in the plaque. (b) Compound treatment did not affect the number of apoptotic cells in atherosclerotic plaques, as assessed by TUNEL staining. (c, d) collagen and smooth muscle cell content was not affect by compound treatment.

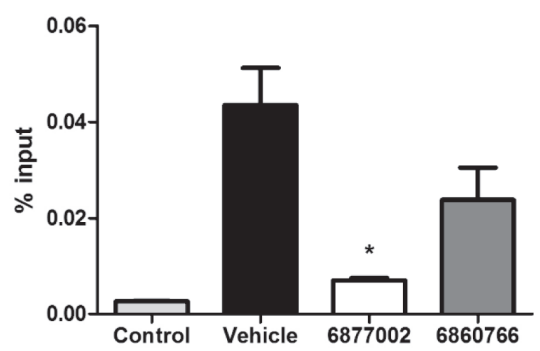

b

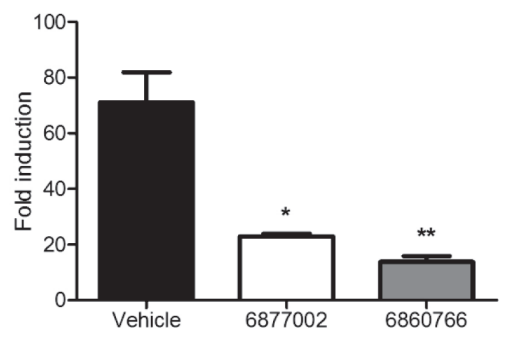

Supplementary Figure 3. Compound treatment reduced the inflammatory propensity of bone marrow-derived macrophages. (a) Chromatin immunoprecipitation revealed that the compounds reduced the binding of $\mathrm{p} 65$ to the promotor of CCL2. (b) CD40-induced iNOS expression is prevented in compound treated bone marrow-derived macrophages. ${ }^{\star}, \mathrm{P}<0.05$; ${ }^{* *}, \mathrm{P}<0.01$; 


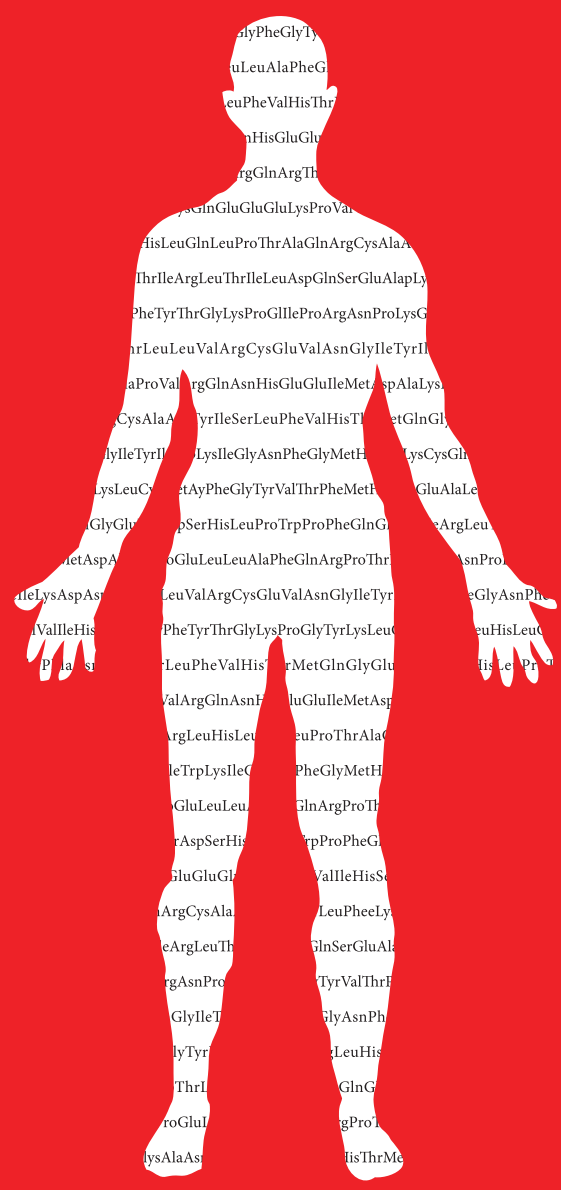




\section{Chapter}

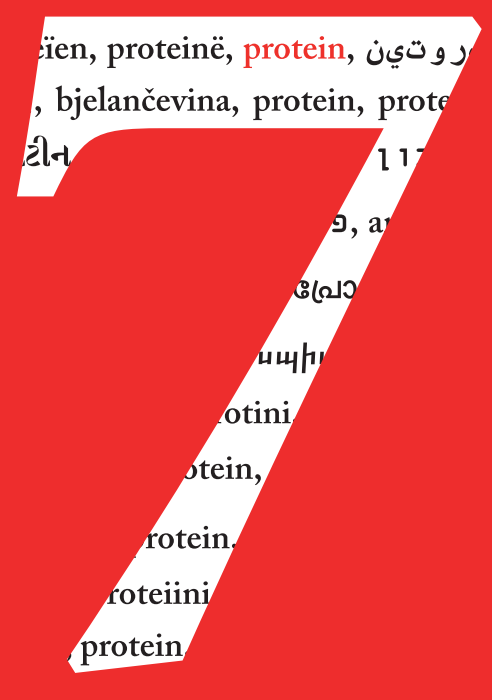

\section{Blocking CD40-TRAF6 signalling is a novel therapeutic target in obesity-associated insulin resistance}

Adapted from:

B. Zarzycka ${ }^{*}$, A. Chatzigeorgiou*, T. Seijkens ${ }^{*}$, D. Engel*, M. Poggi*, S.M. van den Berg, S.A.A. van den Berg, O. Soehnlein, H. Winkels, L. Beckers, D. Lievens, A. Driessen, P. Kusters, E. Biessen, R. Garcia-Martin, A. Klotzsche-von Ameln, M. Gijbels, R.J. Noelle, L. Boon, T.M. Hackeng, K.M. Schulte, A. Xu, G. Vriend, S.B. Nabuurs, K.J. Chung, K. Willems van Dijk, P.C.N. Rensen, N. Gerdes, M. de Winther, N.L. Block, A.V. Schally, C. Weber, S.R. Bornstein, G.A.F. Nicolaes ${ }^{\#}$, T. Chavakis ${ }^{\#}$, E. Lutgens ${ }^{\#},{ }^{*}$ equal contribution

Proc Natl Acad Sci USA, 2014, 111(7):2686-91 


\begin{abstract}
The immune system plays an instrumental role in obesity and insulin resistance. Here we unravel the role of the co-stimulatory molecule, CD40, and its signaling intermediates, TNFReceptor-Associated-Factors (TRAFs), in diet-induced obesity (DIO). Although not exhibiting increased weight gain, male $\mathrm{CD} 40^{-/}$mice in DIO displayed worsened insulin resistance, as compared to wild type mice. This was associated with excessive adipose tissue (AT) inflammation, characterized by increased accumulation of $\mathrm{CD}^{+} \mathrm{T}$-cells and M1 macrophages, and enhanced hepatosteatosis. Mice with deficient CD40-TRAF2, 3, 5 signaling in $\mathrm{MHCII}^{+}$cells exhibited a similar phenotype in $\mathrm{DIO}$ as $\mathrm{CD} 40^{-/-}$mice. In contrast, mice with deficient CD40-TRAF6 signaling in $\mathrm{MHCII}^{+}$cells displayed no insulin resistance, and showed a reduction in both AT inflammation and hepatosteatosis in DIO. To prove the therapeutic potential of CD40-TRAF6 inhibition in obesity, DIO mice were treated with a small-molecule inhibitor that we designed to specifically block CD40-TRAF6 interactions; this improved insulin sensitivity, reduced AT inflammation and decreased hepatosteatosis. Our study reveals that the CD40-TRAF2, 3, 5 signaling pathway in $\mathrm{MHCII}^{+}$cells protects against obesityassociated AT inflammation and metabolic complications, whereas CD40-TRAF6 interactions in $\mathrm{MHCII}^{+}$cells aggravate these complications. Inhibition of CD40-TRAF6 signaling by our newly developed compound may provide a novel therapeutic option in obesity-associated insulin resistance.
\end{abstract}




\section{Introduction}

Emerging evidence points to inflammation as a critical contributor to the pathogenesis of obesity-associated metabolic disorders. Obese adipose tissue (AT) shows hallmarks of chronic low-grade inflammation which is believed to facilitate the development of insulin resistance (IR) (1-3). Macrophages, especially pro-inflammatory M1-polarized macrophages, as well as different T-cell subsets and other immune cells play a major role (1-5). Cytokines derived from immune cells in the AT microenvironment can directly interfere with insulin signaling $(2,3,6)$. In addition, the actions carried out by these immune cells via cell-cell contact or paracrine crosstalk with adipocytes increases the expression of pro-inflammatory molecules such as chemokines and cytokines (7), which in turn further enhance leukocyte accumulation in the AT.

The co-stimulatory receptor ligand pair CD40-CD40L is crucial in the initiation and progression of inflammatory diseases by enhancing inflammation (8). CD40-CD40L interactions are also implicated in obesity-related inflammation. Elevated sCD40L levels are found in obese individuals (9). Moreover, CD40 is expressed on adipocytes and stimulation of adipocytes with CD40L resulted in a reduction of IRS-1 and GLUT4 and induction of adipokines (10), whereas the medium of CD40L-stimulated adipocytes activated endothelial cells (11). Importantly, we and others recently found that genetic ablation or pharmacological inhibition of CD40L ameliorated AT inflammation, IR and hepatic steatosis in a mouse model of diet-induced obesity $(12,13)$.

Since antibody-mediated inhibition of CD40L results in thromboembolic complications, which precludes its clinical use (14), targeting of CD40, the receptor for CD40L, or the CD40associated signaling intermediates, specifically, the TNF receptor associated factors (TRAFs), has become an interesting opportunity in inflammatory diseases.

In the present study, we investigated the effect of genetic CD40 deficiency on diet-induced obesity (DIO). Surprisingly, and in contrast to CD40L deficiency, we found that CD40 deficiency was not protective but rather aggravated IR and obesity-associated liver and AT inflammation. To understand this unexpected result, we explored the involvement of CD40TRAF signaling cascades. Whereas loss of CD40-TRAF2, 3, 5 signaling mimicked the phenotype of CD40-deficiency, inactivation of CD40-TRAF6 signaling rather protected against weight gain, AT inflammation and metabolic complications. This suggested that specific blockade of the CD40-TRAF6 pathway could be used to prevent obesity-associated IR. Indeed, we developed a compound specifically targeting the CD40-TRAF6 interaction which, strikingly, improved insulin sensitivity, associated with decreased M1 macrophage numbers in the AT of DIO mice and reduced hepatosteatosis. Thus, CD40-TRAF6 signaling inhibition may provide a novel therapeutic opportunity in obesity-associated IR. 


\section{Methods}

\section{Virtual Ligand Screening (VLS) and validation of the compound}

For VLS, the crystal structure of a human CD40-TRAF6 complex (PDB ID=1LB6 (15)) solved at resolution $1.80 \AA$ was used as a receptor template. Prior to its use in VLS, all solvent molecules, ions, and the co-crystallized CD40 peptide fragment were removed. Hydrogen atoms were added and their positions were optimized using the YASARA-WHATIF Twinset package (16). The TRAF6 apo-structure (PDB ID=1LB4 (15) solved at $2.40 \AA$ ) and the CD40TRAF6 complex structure were aligned with the 3D superposition module (17) implemented in the YASARA-WHATIF Twinset package. Based on analyses of the aforementioned 3D structural alignment, we changed the side chain conformation of the Arg466 residue present in the CD40-TRAF6 complex structure (1LB6) to represent the lowest energy rotamer. We retrieved the new rotamer from the YASARA backbone-dependent rotamer library (18). We used the programs ICM PocketFinder (19) and QSiteFinder (20) to predict a druggable pocket in the TRAF6 template. We used the in silico small molecules collection from the Express Pick ChemBridge database (http://www.chembridge.com), version November 2009, as a starting point for the ligand selection process. This library of commercially available compounds consists of approximately 400,000 compounds. The compound collection was filtered using 'Lipinski's rule of five' as implemented in the ADME/Tox open-source FAFDrugs2 program (21). We rejected compounds with 1 Lipinski violation or with reactive groups. The OpenEye OMEGA conformer generation software (22) was used to generate $3 \mathrm{D}$ multi-conformer structures for each of the small molecules and to add hydrogen atoms and Gasteiger partial charges (22). We used a hierarchical protocol that combines rigid and flexible docking methods, as described before (23). The FRED rigid-body docking program (24) was used to dock the pre-generated multi-conformer library on the target structure. After the scoring of all TRAF6-compound complexes, the top 40,000 compounds were subjected to flexible docking and scoring by the Surflex program (25). A similarity search was performed on the ChemBridge database using the online search tool Hit2lead (http://www.hit2lead. com) to identify compounds with better inhibitory activity. Finally, fully flexible docking was performed with the Fleksy program (26). All molecular graphics in the associated article were produced with the YASARA-WHATIF Twinset package.

\section{TRAF6 C-domain expression, purification and binding analyses}

His-tagged TRAF6 C-domain (residues 346-504) was expressed in E. coli using the pET21d expression vector (Novagen). Protein was purified via affinity chromatography, followed by gel filtration in running buffer ( $25 \mathrm{mM}$ TRIS, $200 \mathrm{mM} \mathrm{NaCl}$ and $0.5 \mathrm{mM}$ TCEP). The direct binding between the TRAF6 C-domain and the 6877002 compound was measured via SPR (Biacore T200, GE Healthcare). TRAF6 C-domain was immobilized on sensor chip CM5 using the amine coupling method. This reached a density of approximately 12,000 and 7,500 
RU. Compounds were dissolved in PBS buffer with $5 \%$ DMSO. All measurements were carried out at $25^{\circ} \mathrm{C}$ and with a flow rate of $50 \mathrm{ul} \mathrm{min}^{-1}$ in SPR running buffer (PBS, $0.05 \%$ Tween20, 5 \% DMSO, pH = 7.4). Sensorgrams were corrected by subtracting the initial level of SPR signal before injection of the compounds or the TRAF6 C-domain. Data were analyzed using the BIAevaluation software. Equilibrium dissociation constants $\left(\mathrm{K}_{\mathrm{ds}}\right)$ were determined from a model of the steady state affinity ( 3 independent runs were averaged).

\section{In vitro screen}

RAW 264.7 cells, stably transfected with the $3^{\mathrm{x}}-\kappa \mathrm{B}-\mathrm{luc}$ plasmid (27), were incubated with the small molecules for 1 hour at the indicated concentrations. Subsequently, cells were activated using lipopolysaccharide from E. coli (Sigma-Aldrich), a method to rapidly induce CD40expression on macrophages $(28,29)$. After 2 hours, cells were lysed and substrate was added according to the manufacturer's protocol (Luc-screen system, Applied Biosystems). Emission was measured at $450 \mathrm{~nm}$ using the Wallac Victor II luminometer.

\section{In vitro macrophage culture}

Bone marrow (BM) cells were isolated from C57BL/6 mice and cultured in RPMI supplemented with $15 \%$ L929-conditioned medium to generate BM-derived macrophages. Cells were incubated with the small molecule for 1 hour. BM-derived macrophages were activated by the agonistic CD40 antibody FGK45 (25 ug/ml, Bioceros BV) for 6 hours, and frozen for real time PCR analysis.

\section{Biochemical measurements and Insulin tolerance test}

An insulin tolerance test (ITT) was performed, and fasting insulin levels were measured. For the ITT, $5 \mathrm{~h}$ fasted mice were injected i.p. with insulin $(0.75-2 \mathrm{mU} / \mathrm{g}$, Actrapid, Novo Nordisk, Bagsvaerd, Denmark or Huminsulin, Lilly, Bad Homburg, Germany). Glucose levels were measured from whole blood using a glucometer (Roche Diagnostics, Basel, Switzerland) or a glucose meter device (Accu-Chek, Roche, Mannheim, Germany). Fasting insulin levels were measured in plasma by enzyme-linked immunoabsorbent assay (Mercodia, Uppsala, Sweden). Cholesterol levels were measured using a colorimetric assay (CHOD-PAP, Roche, Mannheim, Germany) and triglycerides, by enzymatic assay (Wako, Neuss, Germany).

\section{Body composition analysis}

Body composition was measured using $1^{\mathrm{H}}$ NMR spectroscopy (EchoMRI 3-in-1, Echo Medical Systems LTD, Houston, TX, USA). Data were analysed using the manufacturer's software.

\section{Indirect calorimetry/metabolic cage analysis}

CD40-Twt, CD40-T2, 3, 5 $5^{--}, C D 40-T 6^{-/-}$and CD40-T2, 3, 5, $6^{-/}$mice were subjected to indirect calorimetry/metabolic cage analysis (Phenomaster, TSE Systems, Bad Homburg, Germany). A period of at least 48 hours of acclimatization was included prior to initiation of the 
experiment. Oxygen consumption $\left(\mathrm{VO}_{2}\right)$ and carbon dioxide production $\left(\mathrm{VCO}_{2}\right)$ were determined at 20-minute intervals. Respiratory exchange ratio (RER) was calculated as the ratio between $\mathrm{VCO}_{2}$ and $\mathrm{VO}_{2}$. Energy expenditure (EE), fat oxidation (FAox) rate and carbohydrate oxidation (CHox) rate were calculated as previously reported (30). Food intake (EI) and activity levels were monitored at 1 minute intervals.

\section{Flow cytometry analysis}

The stromal-vascular fraction (SVF) was isolated from gonadal AT using collagenase (SigmaAldrich, Zwijndrecht, The Netherlands or Invitrogen, Darmstadt, Germany). The samples were incubated at $37^{\circ} \mathrm{C}$ with agitation until complete digestion, passed through a cell strainer (Falcon, distributed by BD biosciences, Breda, The Netherlands), washed and centrifuged to obtain the final SVF pellet. Spleens were washed after erythrocyte lysis. Fc-blocking (CD16/32 antibody) was performed prior to cell labeling. FACS for CD3, CD4, CD8, CD25, FoxP3, CD11c, CD11b, F4/80, CD206, CD44, CD45 and CD62L was performed on SVF (31, 32). All antibodies were purchased from e-Biosciences (San Diego, CA, USA), BD Pharmingen (distributed by BD Biosciences), Miltenyi Biotec (Bergisch Gladbach, Germany) or BioLegend (Fell, Germany). Analyses were performed on a FACS Canto II (BD, Heidelberg, Germany), using FACSDiva 6.1.3 software.

\section{Real time PCR}

Total RNA was extracted using Trizol (Invitrogen, Leek, the Netherlands). cDNA was synthesized using i-Script cDNA synthesis kit (BIO-RAD, Veenendaal, the Netherlands). PCRs were performed with a Bio-Rad instrument and software under standard conditions. The relative amounts of the different mRNAs were quantified by using the second derivate maximum method. In other experiments, relative expression levels of each gene were quantified by using the SsoFast EvaGreen Supermix (BioRad). Results were expressed relative to the control group, which was assigned a value of 1 . In addition, a TaqMan Mouse Immune Array from Applied Biosystems was used (Carlsbad, CA, USA). Analysis was performed according to the manufacturer's protocol. GAPDH, 36B4 and S18 were used as internal controls.

\section{Histochemistry}

Liver sections were stained with hematoxylin-eosin or Oil Red as previously described (12, 33).

\section{Statistical analysis}

Results are indicated as means \pm SEM. Data were analyzed by a Student's t-test, a Mann Whitney $U$ test or ANOVA, as appropriate. Significance was set at $\mathrm{P}<0.05$.

\section{Animals}

$\mathrm{CD} \mathrm{O}^{+/+}, \mathrm{CD} 40^{-/-}$mice (C57Bl/6 background) (34) as well as CD40-Twt, CD40-T2, 3, $5^{-/-}$and 
CD40-T6-1- mice (16) were fed SFD or HFD diets (SFD, $70 \% \mathrm{kcal}$ carbohydrate, $10 \% \mathrm{kcal}$ fat, $20 \%$ kcal protein, SDS Special Diets Services, Witham, UK or Research Diets, NJ, USA; HFD, $35 \% \mathrm{kcal}$ carbohydrate, $45 \% \mathrm{kcal}$ fat, $20 \% \mathrm{kcal}$ protein from SDS Special Diets Services or 20 $\% \mathrm{kcal}$ carbohydrate, $60 \% \mathrm{kcal}$ fat, $20 \% \mathrm{kcal}$ protein from Research Diets) for different time points up to 30 weeks (CD40 ${ }^{+/+}$and $C D 40^{-/}$mice, males; $60 \%$ kcal-HFD), or 20 weeks (CD40TRAF mice, males; $45 \%$ kcal-HFD) starting at the age of 6-8 weeks. In the CD40-TRAF6 small molecule inhibitor experiment, male C57Bl/6 mice (Janvier, Saint Berthevin Cedex, France) were fed the $60 \%$ kcal-HFD for 12 wks, receiving compound $6877002(10 \mu \mathrm{mol} / \mathrm{kg} /$ day) or vehicle control for 6 weeks i.p.

Body weight was measured weekly. After the experimental period, animals were euthanized, blood was collected and organs were dissected or stored at $-80^{\circ} \mathrm{C}$ for further analysis. Studies were approved by the animal experimental commission of the University of Maastricht, Amsterdam and Leiden and the Landesdirektion Dresden.

\section{Results}

\section{CD40-deficiency induces insulin resistance in DIO}

CD40-deficient male mice were subjected to the DIO model. CD40-deficient (34) and CD40sufficient mice were fed a high fat diet (HFD) for up to 30 wks. CD40 deficiency in mice did not result in increased total body weight (figure 1a), or a change in fasting glucose levels (data not shown) but did lead to worsened IR after 30 wks of HFD (figure 1b). While subcutaneous AT (scat) and gonadal AT (gonAT) weights were similar or decreased, liver weights increased slightly in CD40-deficiency (figure 1c). CD40-- mice exhibited significant obesity-related liver abnormalities with pronounced hepatosteatosis, as compared to CD40-sufficient mice (figure 1d). Accordingly, hepatic genes associated with steatosis (PPAR $\gamma$, PAI-1, CHREBP) as well as genes involved in the regulation of glycolysis and lipid uptake (GK, LPK, CD36), showed enhanced mRNA expression due to CD40 deficiency (figure 1e). On a standard-fat diet (SFD), $\mathrm{CD} 40^{-/-}$mice did not develop any metabolic abnormalities (figure 1).

\section{CD40-deficiency induces severe AT inflammation}

Given the importance of AT inflammation for the development of IR and the well-established role of CD40 in inflammation, we then continued to assess the role of CD40-deficiency in AT inflammation.

Flow cytometry analysis of the stromal vascular fraction (SVF) of the gonAT of the HFD group revealed that CD40-deficient mice had increased numbers of $\mathrm{CD} 45^{+}$cells (figure $2 \mathrm{a}$ ) and CD8 ${ }^{+} \mathrm{T}$-cells (figure $2 \mathrm{a}$ ). In addition, a significant increase in the amount of CD11 $\mathrm{b}^{+} \mathrm{F} 4 / 80^{+}$ macrophages was observed (figure $2 a$ ). Further subtyping showed that the fraction of the proinflammatory classically activated M1-polarized macrophages, characterized by expression of CD11c and absence of CD206, was higher in CD40-deficiency (figure 2a).

Quantitative PCR analysis revealed increased expression of IL6, IL12, TNF, MCP1, ICAM1 
a

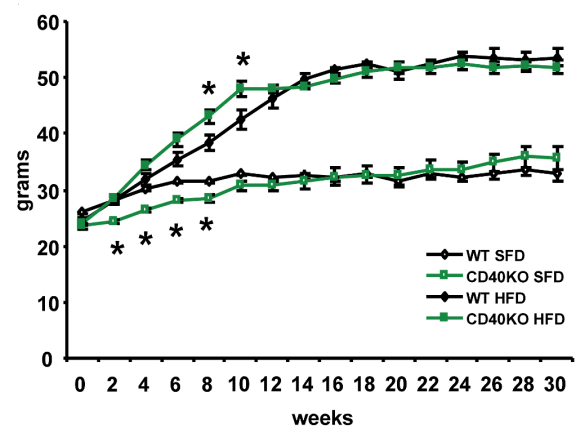

C

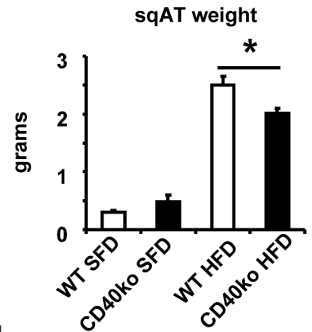

gonAT weight

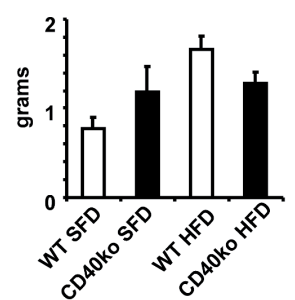

b

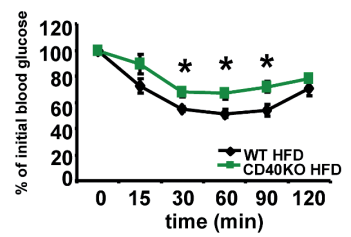

d

liver weight

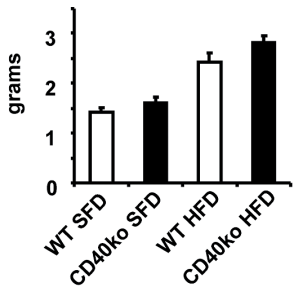

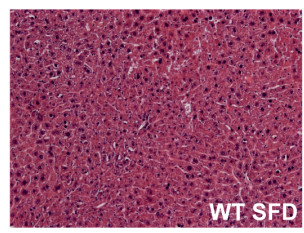


e
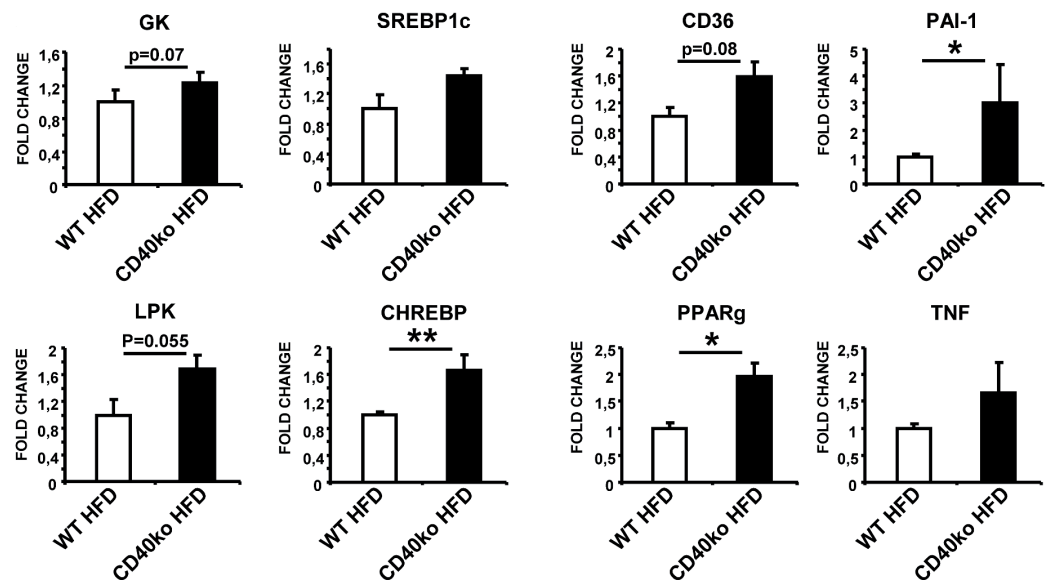

Figure 1. $\mathrm{CD} 40^{-/}$mice on HFD display aggravated metabolic dysregulation. Wild type (WT) and $C D 40^{-/}$male mice were fed with SFD or HFD for 30 weeks. (a) Body weight of WT and $C D 40^{-/}$mice on SFD ( $n=5)$ or HFD ( $n=6-7)$. (b) Insulin tolerance test in 5-h fasted WT and CD 40 ${ }^{-/}$mice fed a HFD for 30 weeks ( $\mathrm{n}=6-7$ ); (c) Subcutaneous (sc) and gonadal (epididymal, epi) AT and liver weight of WT and $C D 40^{--}$mice after 30 weeks on SFD $(n=5)$ or HFD $(n=6-7)$. (d) Representative H\&E-stained sections from liver of WT and CD40-- mice on SFD or HFD for 30 weeks. (e) Liver gene expression of $\mathrm{WT}$ and $\mathrm{CD} 40^{-/-}$mice on HFD for 30 weeks. The mRNA expression was normalized against $18 \mathrm{~S}$ and 
the gene expression of livers from WT HFD was set as $1(n=6-7) .{ }^{*} \mathrm{P}<0.05$ for comparison between WT and $C D 40^{-/}$mice fed the same diet.

and the macrophage and T-cell specific markers CD68, CD3 and CD8 in the gonAT of $\mathrm{CD}_{40}{ }^{-/}$mice (figure 2b). Adiponectin, leptin, GLUT4 and PPARy did not differ (figure 2b). The scAT showed a similar inflammatory profile (data not shown). On a SFD, no differences in immune cell accumulation and in inflammatory gene expression in the AT were observed due to CD40-deficiency. Although T-cell populations in the gonAT were similar between $C D 40^{-/}$and wild type mice on a SFD, CD40 ${ }^{-/}$mice had reduced numbers of CD4 ${ }^{+} \mathrm{T}$-cells and regulatory T-cells (Treg) in the spleen (figure S1). Together, CD40 deficiency leads to an aggravation of AT inflammation and development of obesity-associated IR in DIO. These data were unexpected given the phenotype of the $C D 40 \mathrm{~L}^{-/}$mouse (12).CD40 lacks intrinsic signaling capacity and requires adaptor molecules, the TRAFs, to elicit and steer the distinct CD40 downstream signaling pathways. To identify which CD40-TRAF signaling pathway is involved in metabolic regulation and AT inflammation in vivo, we used male CD40 deficient mice that contained a CD40 transgene under the control of the MHCII promoter, in which the TRAF2, 3, 5 or the TRAF6 binding sites on the CD40 C-terminal tail were mutated, rendering CD40-TRAF2, 3, $5^{-/}$and CD40-TRAF6-1- mice (35). As a control we engaged CD40-TRAFwt mice carrying the CD40 transgene without any mutations. These mice were subjected to a SFD or HFD.

Deficiency of CD40-TRAF2, 3, 5, but not CD40-TRAF6 signaling, exacerbates dietinduced obesity

When fed a HFD for 20 wks, male CD40-TRAF 2, 3, 5 - mice initially gained more weight as compared to their CD40-TRAFwt controls; the difference in weight gain was significant during the first weeks of HFD feeding (figure 3a). CD40-TRAF6--- mice experienced a milder weight gain (figure $3 \mathrm{a}$ ) and a delay in reaching their maximal weight. This delay may be caused by a more active brown adipose tissue (BAT), as reflected by increased uncoupling protein (UCP)-1 mRNA levels in the BAT of CD40-TRAF6-/ mice (figure S2). Body composition was studied using $1{ }^{\mathrm{H}} \mathrm{MRI}$ analysis after 5 wks of diet. Lean body mass did not differ between CD40-TRAF2, 3, 5-1, CD40-TRAF6-1, and CD40-TRAFwt mice (data not shown), but fat mass was significantly higher in CD40-TRAF2, 3, 5/- and significantly lower in CD40-TRAF6 ${ }^{-1-}$ mice, both as compared to CD40-TRAFwt mice (figure $3 \mathrm{~b}$ ).

CD40-TRAF2, 3, 5\% mice exhibited IR after 20 wks of HFD, with similar blood insulin levels as the CD40-TRAFwt mice (figure $3 \mathrm{c}$ and table 1 ). In addition, CD40-TRAF2, 3, 5- mice had increased plasma cholesterol and plasma triglyceride levels (table 1), showing the metabolic complications of obesity. CD40-TRAF6-1- mice did not develop IR, and they displayed no increase in baseline glucose levels (table 1). Moreover, these mice showed no aberrations in plasma cholesterol or triglyceride levels (table 1). No differences between the genotypes were observed after SFD feeding. 
a

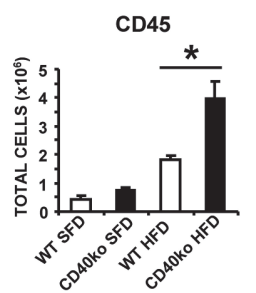

$\mathrm{CD} 11 \mathrm{~b}+\mathrm{F} 4 / 80+(\mathrm{M} \Phi)$

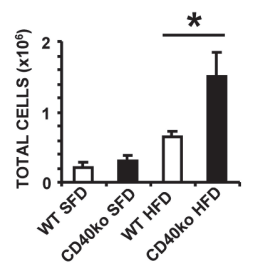

b
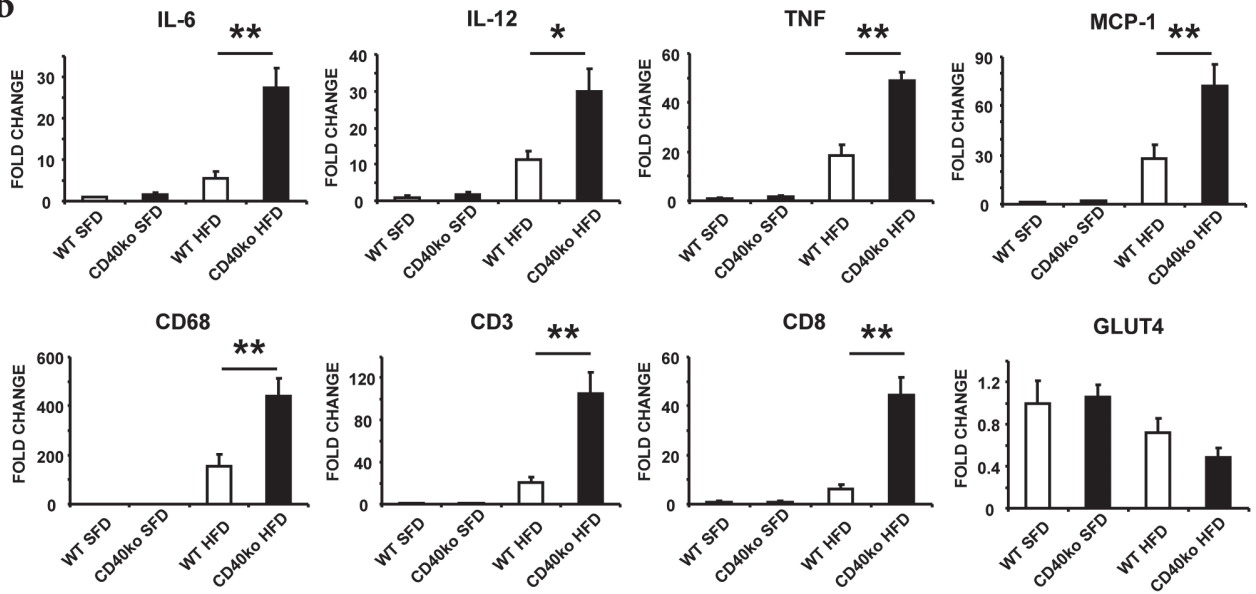

ADIPONECTIN

LEPTIN
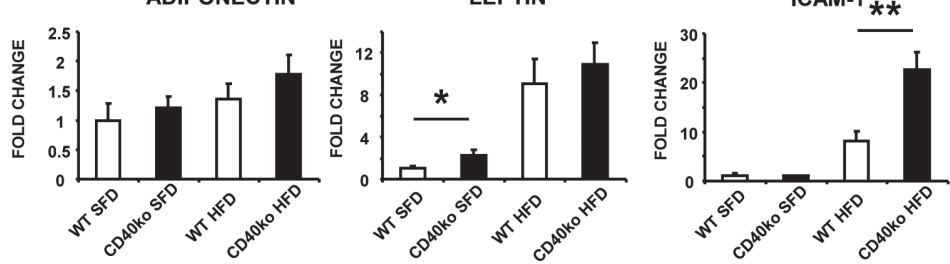

F4/80+CD11C-CD206+ (M2 MФ)
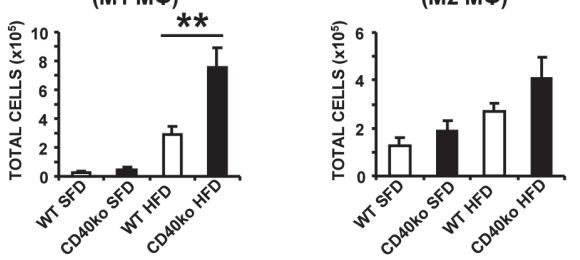

Figure 2. CD40 deficiency aggravates AT inflammation. (a) SVF cells were isolated from gonAT of WT or $C D 40 \%$ male mice fed a SFD or HFD for 18 weeks. CD $45+$ leukocytes, CD4+ or CD8+ lymphocytes, total macrophages (characterized as $\mathrm{CD}_{11} \mathrm{~b}^{+} \mathrm{F} 4 / 80^{+}$) and $\mathrm{M} 1$-macrophages (defined as $\mathrm{F} 4 / 80^{+} \mathrm{CD} 11 \mathrm{~b}^{+} \mathrm{CD} 11 \mathrm{c}^{+}$or $\mathrm{F} 4 / 80^{+} \mathrm{CD} 11 \mathrm{c}^{+} \mathrm{CD} 206^{-}$) or $\mathrm{M} 2$-macrophages (defined as $\mathrm{F} 4 / 80^{+} \mathrm{CD} 11 \mathrm{c}^{-}$ $\mathrm{CD}^{206^{+}}$) were analysed by flow cytometry. (b) Gene expression in the gonAT of male WT and CD40 - mice on SFD or HFD for 18 weeks. The mRNA expression was normalized against $18 \mathrm{~S}$ and the gene expression of adipose tissue from WT SFD was set as $1 . \mathrm{n}=4$ or more/group for SFD groups and $\mathrm{n}=7$ or more/group for HFD groups. ${ }^{\star} \mathrm{P}<0.05$ for comparison between WT and $C D 40^{-/}$mice fed the same diet. 
During the first week of HFD feeding, indirect calorimetry/metabolic cage analysis was performed in a group of mice separate from the long-term experimental groups. Both body weight and food intake were significantly higher in CD40-TRAF2, 3, $5^{-1}$ and lower in CD40-TRAF6 ${ }^{-1}$ mice, as compared to CD40-TRAFwt mice (table 1). Energy expenditure levels did not differ between groups, nor did ambulatory physical activity levels. Absolute fat oxidation rates were somewhat lower in CD40-TRAF2, 3, 5 $5^{--}$mice when compared to CD40TRAFwt mice, but did not differ in CD40-TRAF6-- mice. In contrast, absolute carbohydrate oxidation values were significantly higher in CD40-TRAF2, 3, $5^{-/-}$mice, as compared to CD40TRAFwt, but were similar in CD40-TRAF6--- mice, as compared to CD40-TRAFwt mice (table 1).

These data show that CD40-TRAF2, 3, 5 $5^{-1}$ mice are prone to obesity-related metabolic complications, thereby resembling CD40-deficient mice, whereas CD40-TRAF $6^{-1-}$ mice seem protected from obesity-associated complications.

Indirect calorimetry/metabolic cage analysis of high fat fed CD40-TRAFwt, CD40-TRAF2, 3, $5^{-1-}$ and CD40-TRAF6 ${ }^{-1}$ mice. EI: energy intake, EE: energy expenditure, RER: Respiratory exchange ratio, FAox: absolute fat oxidation rate, $\mathrm{CHox}$ : absolute carbohydrate oxidation rate, Act: spontaneous activity level (beam breaks). ${ }^{\star} \mathrm{P}<0.05$

\section{CD40-TRAF2, 3, $5^{-/-}$mice develop steatosis}

CD40-TRAF2, 3, $5^{-/}$, but not CD40-TRAF6 ${ }^{-/-}$mice, had an increase in liver weight, associated with pronounced steatosis, after 20 weeks of HFD (figure 3d, e). Histologic analysis revealed that all genotypes developed steatosis on a HFD. The severest phenotype was found in CD40TRAF2, 3, $5^{--}$mice whereby $87.5 \%$ of the mice developed grade 3 steatosis, as compared to only $62.5 \%$ of the CD40-TRAFwt mice (supplementary material, figure S3a). Deficiency of CD40-TRAF6 interactions resulted in a milder form of steatosis. CD40-TRAF6 ${ }^{-1}$ mice mostly developed grade 1 or 2 steatosis; this was localized at the central vein with limited expansion (figure S3a). Steatosis extended from the central vein to the periportal vein in $87.5 \%$ of the CD40-T2, 3, 5 - mice, but in only $37.5 \%$ of the CD40-Twt mice (figure S3a). All genotypes predominantly developed macrovesicular steatosis, with additional microvesicular steatosis seen in the CD40-TRAF2, 3, 5/- mice. The liver parenchyma showed grade 1 lobular inflammation in all genotypes, although $37.5 \%$ of the CD40-TRAF $6^{-1-}$ mice developed less than grade 1 inflammation (supplementary material, figure S3a). Portal inflammation, microgranulomasorlipogranulomaswerenotobserved.Ballooningofhepatocyteswasafrequent observation in all genotypes (87.5\% of CD40-TRAFwt and CD40-TRAF2, 3, 5-/ mice) but was less prominent in CD40-TRAF6-- mice (62.5\%) (supplementary material, figure S3a).

Consistent with these results, we found fundamental metabolism-associated genes to be altered in CD40-TRAF2, 3, 5/- mice. Genes involved in glycolysis, such as liver glucokinase (GK), and liver pyruvate kinase (LPK), but not glucose transporter 2 (GLUT2), were significantly elevated (figure S3b). Furthermore, we detected higher mRNA levels of the fatty 
a

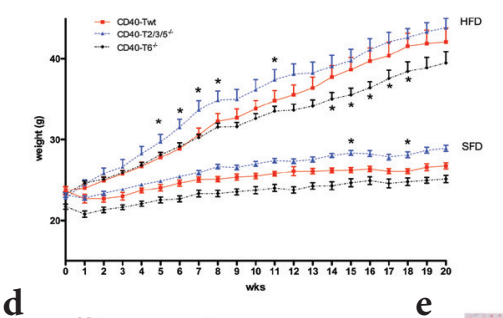

b

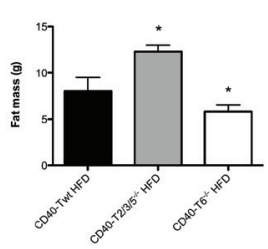

C

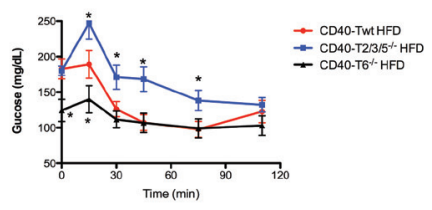

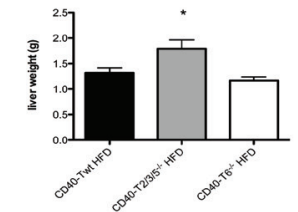
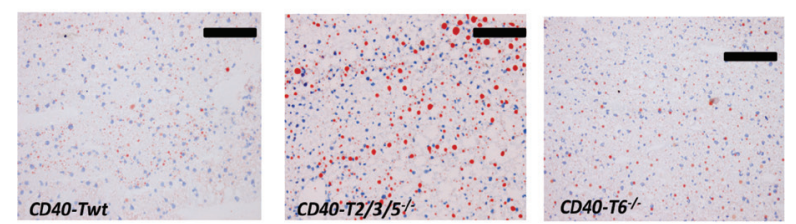

Figure 3. Deficiency of CD40-TRAF2, 3, 5 signalling aggravates obesity and promotes metabolic dysfunction and hepatosteatosis. (a) Body weight of CD40-TRAFwt, CD40-TRAF2, 3, 5 $5^{-1}$ and CD40TRAF6 $6^{--}$mice on SFD or HFD for 20 weeks $(\mathrm{n}=12-15)$. (b) Fat mass as determined by $1^{\mathrm{H}}$ NMR spectroscopy ( $\mathrm{n}=8$ per group). (c) Insulin tolerance test in 5-hr fasted CD40-Twt, CD40-TRAF2, 3, $5^{-/}, C D 40-T R A F 6^{--}$mice fed a HFD for 18 weeks ( $\mathrm{n}=8$ per group). (d) Liver weight and (e) Oil red O stained liver cryosections of CD40-TRAFwt, CD40-TRAF2, 3, $5^{-/}$and CD40-TRAF6 ${ }^{-1}$ mice fed a HFD for 20 wks. Scale bar $=100 \mu \mathrm{m}$. Values are mean \pm SEM. ${ }^{\star} \mathrm{P}<0.05$ for comparison with $C D 40$ TRAFwt mice.

Table 1: Metabolic parameters of HFD-fed CD40-TRAF mice.

\begin{tabular}{|c|c|c|c|}
\hline & CD40-TRAFwt & CD40-TRAF $2 / 3 / 5^{-/}$ & CD40-TRAF6 ${ }^{-1-}$ \\
\hline Body weight (g) & $32.4 \pm 2.7$ & $37.5 \pm 1.5^{\star}$ & $28.8 \pm 1.7^{\star}$ \\
\hline EI $(g / 24 h)$ & $1.63 \pm 0.18$ & $1.88 \pm 0.33^{*}$ & $1.39 \pm 0.09^{*}$ \\
\hline $\mathrm{EE}(\mathrm{kcal} / \mathrm{h})$ & $0.55 \pm 0.04$ & $0.59 \pm 0.03$ & $0.55 \pm 0.02$ \\
\hline RER & $0.86 \pm 0.02$ & $0.88 \pm 0.02$ & $0.86 \pm 0.03$ \\
\hline FAox (kcal/h) & $0.24 \pm 0.04$ & $0.20 \pm 0.03$ & $0.23 \pm 0.05$ \\
\hline CHox (kcal/h) & $0.32 \pm 0.04$ & $0.40 \pm 0.05^{\star}$ & $0.33 \pm 0.06$ \\
\hline Act (bb) & $109 \pm 42$ & $95 \pm 38$ & $106 \pm 42$ \\
\hline Plasma cholesterol (mg/dL) & $62 \pm 16$ & $103 \pm 40^{*}$ & $44 \pm 27$ \\
\hline Plasma TG $(\mu \mathrm{g} / \mathrm{dL})$ & $129 \pm 27$ & $160 \pm 46^{*}$ & $140 \pm 29$ \\
\hline Fasted blood glucose (mg/dL) & $157 \pm 35$ & $134 \pm 33$ & $103 \pm 28^{*}$ \\
\hline Plasma insulin $(\mu \mathrm{g} / \mathrm{dL})$ & $0.67 \pm 0.41$ & $0.66 \pm 0.31$ & $0.41 \pm 0.32$ \\
\hline HOMA-IR & $0.29 \pm 0.04$ & $0.30 \pm 0.02$ & $0.13 \pm 0.02^{*}$ \\
\hline
\end{tabular}

All values are mean $\pm \mathrm{SD} ;{ }^{*}$ bold $\mathrm{P}<0.05$

acid transporter, CD36, which stimulates glycolysis and lipogenesis (figure S3b). These findings imply an important function for CD40-TRAF2, 3, 5 signaling in liver metabolism in DIO.

Disruption of CD40-TRAF2, 3, 5, but not of CD40-TRAF6 signaling, exacerbates AT inflammation in DIO

Flow cytometry analysis of the SVF of the gonAT revealed an increased F4/80 ${ }^{\text {high }} \mathrm{CD} 11 \mathrm{~b}^{+}$ 
macrophage fraction in mice lacking CD40-TRAF2, 3, 5 signaling, as compared to CD40TRAFwt mice (figure 4a). In keeping with these findings, CD68 mRNA was also increased in CD40-TRAF2, 3, 5 $5^{-/}$mice (supplementary material, figure S4a). Analysis of cytokines revealed elevated levels of TNFa and IL1a (supplementary material, figure S4a) suggesting an M1biased response.

The percentage and number of $\mathrm{CD}^{+} \mathrm{T}$-cells were slightly elevated in CD40-TRAF2, 3, $5^{-1-}$ mice $\left(2.1 \pm 0.11^{\star} 10^{5} \mathrm{CD}^{+}\right.$cells; $\left.\mathrm{P}=0.08\right)$ compared to CD40-TRAFwt mice $\left(1.92 \pm 0.31^{\star} 10^{5}\right.$ $\mathrm{CD}^{+}$cells), while the percentage and numbers of $\mathrm{CD}^{+} \mathrm{T}$-cells in CD40-TRAF6-- mice (1.89 $\pm 0.48^{\star} 10^{5} \mathrm{CD}^{+}$cells) equaled the levels in CD40-TRAFwt mice. Remarkably, the increased percentage of $\mathrm{CD}^{+} \mathrm{T}$-cells was accompanied by an increase in the $\mathrm{CD} 8^{+} \mathrm{T}$-cell fraction, and a decrease in $\mathrm{CD}^{+} \mathrm{T}$-cells in the AT of CD40-TRAF2, 3, 5- mice (figure 4b). Accordingly, mRNA levels of CD3 as well as IL2 were elevated in the gonAT of these mice (supplementary material, figure S4b). In CD40-TRAF2, 3, $5^{-1-}$ mice, the fraction and number of Treg cells (CD40-TRAFwt: $4.2 \pm 0.6^{\star} 10^{4}$ vs CD40-TRAF2, 3, $5^{-/}: 1.7 \pm 0.2^{\star} 10^{4}$ Tregs; $\left.\mathrm{P}<0.05\right)$ in the gonAT was decreased (figure $4 \mathrm{c}$ ). In the spleen, CD40-TRAF6 ${ }^{-/}$mice had an increased Treg fraction $(6.8 \pm 0.3 \%$ in CD40-TRAFwt vs $9.4 \pm 0.2 \%$ in CD40-TRAF6-/ mice), while total splenic $\mathrm{CD}^{+}$and $\mathrm{CD} 4^{+} \mathrm{T}$-cell numbers were unchanged. The $\mathrm{CD} 8^{+} \mathrm{T}$-cell fractions in gonAT of CD40-TRAF2, 3, 5\% mice displayed an increase in CD44 ${ }^{\text {high }} \mathrm{CD} 62 \mathrm{~L}^{\text {low }}$ effector memory cells, with a concomitant decrease in $\mathrm{CD} 44^{\text {low }}{ }^{\mathrm{CD}} 62 \mathrm{~L}^{\text {high }}$ naïve T-cells (figure $4 \mathrm{~d}$ ). This T-cell profile is indicative of a more vigorous $\left(\mathrm{CD}^{+}\right) \mathrm{T}$-cell response, and a migratory potential, thereby likely resulting in aggravation of AT inflammation.

\section{CD40-TRAF2, 3, 5 deficiency changes inflammatory gene expression in DIO}

Analysis of gene expression in the gonAT of obese mice revealed a pro-inflammatory chemokine expression signature in CD40-TRAF2, 3, 5\% mice. Genes important in recruiting $\mathrm{T}$-cells and macrophages, and genes involved in activating $\mathrm{T}$ - and $\mathrm{B}$-cells, such as chemokine $\mathrm{C}-\mathrm{C}$ motif ligand 3 (CCL3), CCL5, and chemokine $\mathrm{C}-\mathrm{X}-\mathrm{C}$ motif receptor 3 (Cxcr3) were found up-regulated in CD40-TRAF2, 3, 5/- mice, as compared to CD40-TRAFwt mice (figure S4). Furthermore, we observed increased mRNA expression of the pro-inflammatory cytokines IL1 $\alpha$ and TNF in CD40-TRAF2, 3, 5/- mice (supplementary material, figure S4).

Remarkably, gonAT of CD40-TRAF6-- mice showed reduced inflammation. The expression of E-selectin as well as of chemokine $\mathrm{C}$-C motif receptor 7 (CCR7) were significantly reduced in CD40-TRAF6- mice, suggesting less inflammatory cell recruitment. Moreover, the costimulatory molecule CD28 and its counter receptor CD86 were also decreased in gonAT of CD40-TRAF6 ${ }^{-1-}$ mice (supplementary material, figure S4d).

No differences in immune cell accumulation and levels of inflammatory genes in the AT, as well as in the degree of hepatosteatosis were observed between the three genotypes on a SFD. These results showed aggravated metabolic dysregulation in CD40-TRAF2, 3, 5/-mice, which 
thus phenotypically resembled $C D 40^{-/}$mice; in contrast, blocking the CD40-TRAF6 pathway rather ameliorated metabolic complications and slightly reduced AT inflammation in DIO.

Pharmacologic inhibition of the CD40-TRAF6 pathway ameliorated obesity-related metabolic complications

We next explored whether the CD40-TRAF6 pathway could represent a therapeutic target for obesity-related metabolic dysfunction. To this end, we developed a small molecule inhibitor specifically targeting the CD40-TRAF6 interaction.

To identify drug-like molecules that can inhibit the CD40-TRAF6 interaction, we used an in silico structure-based virtual ligand screening (VLS) approach. The interaction between CD40 and TRAF6 was analyzed using the human TRAF6 apo-structure (PDB ID: 1LB4 (15) and the structure of the CD40-TRAF6 complex (PDB ID: 1LB6 (15)). These analyses revealed conformational changes in the TRAF6 peptide-binding groove upon binding of CD40. In this process, Arg466, which is located in the CD40 peptide-binding groove, seems to be most affected (figure 5a). Various orientations of this side chain were therefore explored to identify a potential druggable pocket in the CD40-TRAF6 interaction site (figure 5b, c). We utilized a multi-stage screening approach on the ChemBridge compound collection to identify
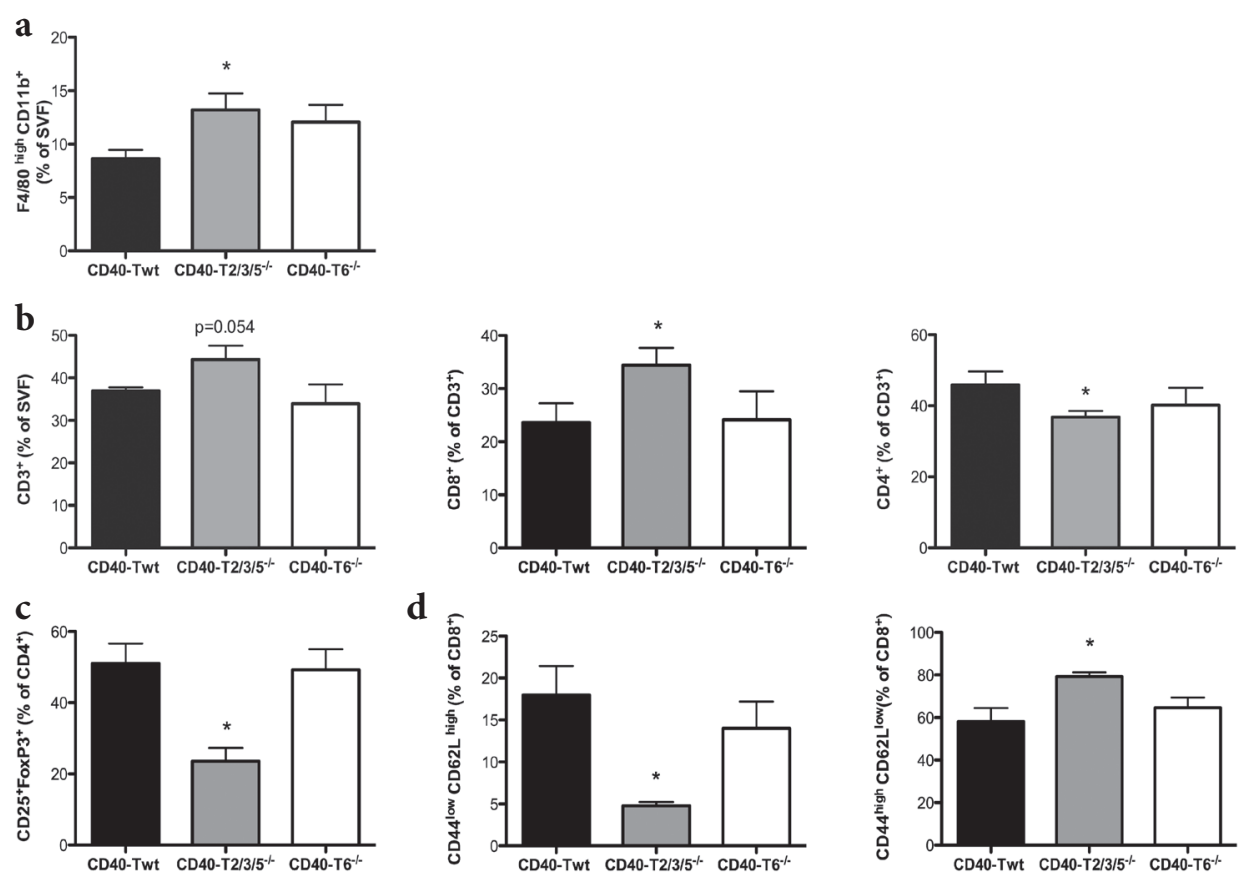

Figure 4. CD40-TRAF2, 3, 5 deficiency results in increased numbers of inflammatory cells in gonadal AT. (a) FACS analysis for F4/80highCD11 b ${ }^{+}$macrophages, (b) $\mathrm{CD}^{+} \mathrm{T}$-cells, $\mathrm{CD}^{+} \mathrm{T}^{-}$-cells and $\mathrm{CD} 4^{+}$ T-cells, (c) $\mathrm{CD}^{+} \mathrm{CD} 25^{+} \mathrm{FoxP} 3^{+}$Tregs, (d) $\mathrm{CD} 8^{+} \mathrm{CD} 44^{\text {low }} \mathrm{CD} 62 \mathrm{~L}^{\text {high }}$ naïve $\mathrm{T}$-cells and $\mathrm{CD} 8{ }^{+} \mathrm{CD} 44^{\text {high }} \mathrm{CD} 62 \mathrm{~L}^{\text {low }}$ effector memory T-cells. Values are mean $\pm \mathrm{SEM}$. ${ }^{\star} \mathrm{P}<0.05$ for comparison to CD40-Twt mice. $\mathrm{N}=8-10$ mice/group. 
inhibitors of this pocket (figure 6a). This screening cascade, consisting of rigid and flexible docking as well as in vitro analysis, reduced the number of compounds from 400,000 to 800 using computational approaches. The 800 top-scoring compounds in the flexible docking were analyzed in vitro, using a cell-based NFkB reporter gene assay. This resulted in the identification of 51 compounds that reduced $\mathrm{NF \kappa B}$ activation in a mouse leukemic monocyte/ macrophage cell line (RAW 264.7) by at least $50 \%$ at $10 \mu \mathrm{M}$.

The 6 compounds that most effectively reduced NFKB activation in vitro were used as a query for a similarity search in the ChemBridge database, which resulted in 150 analogs. The in vitro screen of these compounds revealed six additional bioactive compounds with equal or improved cellular activity compared to the initial best compound 6877002 (figure 6b). Compound 6877002 (figure 7) and these additional 6 identified bioactive analogs all inhibited $\mathrm{NF \kappa B}$ activation in RAW cells in a dose-dependent manner (figure 6b). Compound 6877002 also suppressed the CD40-induced expression of IL1 $\beta$ and IL6 cytokines in primary bone marrow derived macrophages in a dose-dependent way (figure 6c).

To elucidate the structure activity relationship (SAR) of the analogs of compound 6877002 we built a 3-dimensional TRAF6-compound interaction model using fully flexible docking of all bioactive hits containing the molecular scaffold of compound 6877002. These compounds all possess two ring systems (R1 and R2; figure 7) with different substituents and are rings are connected by the same linker. Based on this docking study, we hypothesize that the binding of this compound class to TRAF6 is stabilized by 2 hydrogen bonds with residues Asn467 and Cys390 and $\pi-\pi$ stacking interactions of the R2 ring with Arg466 and His376 (figure 6d). Cellular activity of these compounds appears to correlate with the presence of substituents at either the ortho- or para- position and the absence of a substituent at the meta- position. Substituents at the meta-position seem to clash with Pro468 (figure 6e). Compound 6877002 is the most active and most soluble with ortho- and meta- substituents, respectively. This compound was therefore selected for further studies.

Surface plasmon resonance (SPR) experiments were performed with 6877002 to confirm its direct binding to TRAF6. Its equilibrium dissociation constant $\left(\mathrm{K}_{\mathrm{d}}\right)$ to the TRAF6 C-domain is $97 \mu \mathrm{M}$ (figure 6f). This correlates well with the activities observed in the three cellular assays described above.

To assess whether this inhibitor could interfere with obesity-related metabolic abnormalities in a therapeutic setting (ie, after initiation of DIO), C57Bl/6 mice were fed a HFD for 6 wks, and then received the small molecule inhibitor 6877002 or vehicle for the next 6 wks. No side effects (blood counts, WBC composition or abnormalities in $>20$ organs analyzed) were observed (data not shown). Treatment with compound 6877002 resulted in improved insulin sensitivity, as compared to vehicle treated mice (figure 8a, b), whereas no alterations in weight, cholesterol, triglyceride, fasting glucose levels or insulin levels were observed (data not shown). Moreover, gonAT inflammation was decreased after treatment with 6877002, with 
a remarkable reduction in $\mathrm{CD} 11 \mathrm{~b}^{+} \mathrm{F} 4 / 80^{+} \mathrm{CD} 11 \mathrm{c}^{+}(\mathrm{M} 1)$ macrophages (figure $8 \mathrm{c}$ ). Interestingly, treatment with the CD40-TRAF6 inhibitor also reduced hepatosteatosis (figure $8 \mathrm{~d}$ ). These data indicate that the CD40-TRAF6 axis is a valuable therapeutic target in obesity, especially for ameliorating metabolic complications such as IR and hepatosteatosis.

\section{Discussion}

The co-stimulatory CD40-CD40L dyad is a powerful mediator of inflammation and immunity (30). We previously reported that CD40L-deficiency ameliorated AT inflammation and metabolic dysregulation in DIO, particularly by reducing the $\mathrm{CD} 8^{+} \mathrm{T}$-cell fraction and increasing the Treg content in obese AT (12). Wolf et al. reported a similar observation; $C D 40 L^{-1-}$ mice displayed reduced AT inflammation (13). Despite the well-established proinflammatory role of CD40, the receptor for CD40L, in different disorders, such as atherosclerosis, Crohn's disease and multiple sclerosis (36), we unequivocally demonstrate here the unexpected finding that genetic loss of CD40 does not mirror the effects of CD40L deficiency in DIO. On the contrary, CD40 deficiency aggravated obesity-related AT inflammation and caused metabolic dysregulation.

The increase in classically activated (M1) macrophages in the AT of CD40 $0^{-/}$mice, accompanied by the increased $\mathrm{CD}^{+} \mathrm{T}$-cell fraction, is likely the driving force underlying the exacerbated AT inflammation in $C D 40^{-/}$mice. Classically activated M1 macrophages are abundantly

a

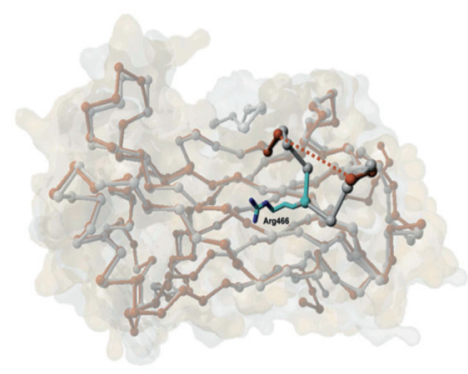

b

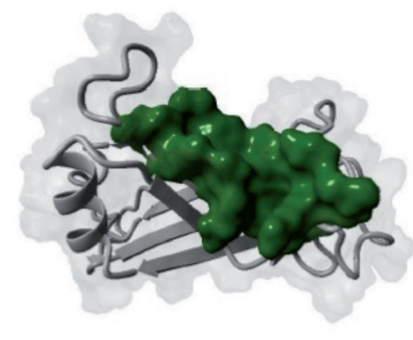

c b



Figure 5. CD40-TRAF6 complex and druggable pocket. (a) Superimposition of X-ray structure of apo-structure and CD40-TRAF6 complex structure (orange and grey, respectively). (b) Predicted druggable pocket (green). (c) Predicted pose of the compound located in the druggable pocket. 
present in obese AT and secrete a plethora of pro-inflammatory mediators $(3,6)$, thereby eliciting IR. CD8 ${ }^{+} \mathrm{T}$-cell accumulation within the AT is associated with AT inflammation and activation of AT macrophages (4). Loss of $\mathrm{CD}^{+} \mathrm{T}$-cells was also shown to diminish IR while adoptive transfer of $\mathrm{CD}^{+} \mathrm{T}$-cells aggravated metabolic dysfunction (4). Thus, the aggravation of metabolic complications in DIO in $\mathrm{CD}^{-1-}$ mice could be attributed to the pro-inflammatory AT phenotype of these mice.

The likely explanation of why the phenotype of the $C D 40 \mathrm{~L}^{-/}$mouse does not mirror the phenotype of the $C D 40^{--}$mouse in DIO could be the differential involvement of the CD40-TRAF-

$\mathbf{a}$

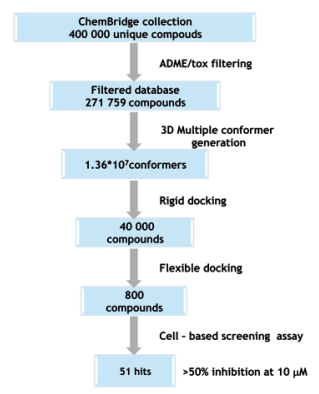

d

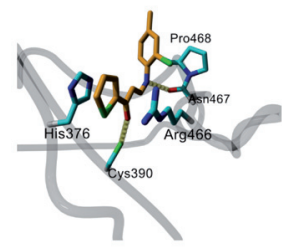

b

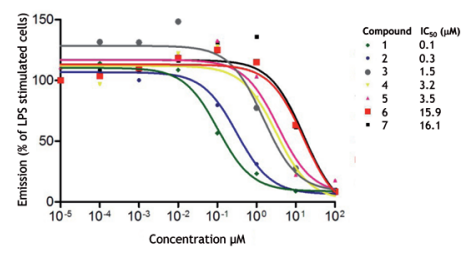

c


f

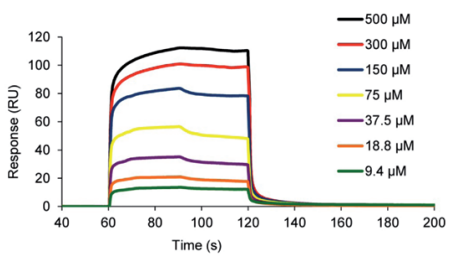

Figure 6. Compound identification and characterization. (a) The VLS pipeline. The 400,000 compounds collection was filtered based on absorption, distribution, metabolism, excretion, and toxicity (ADME/Tox) properties using 'Lipinski's rule of 5' which resulted in 271,759 compounds. Geometrical shape-fitting of structures, for each ligand all local energy minima in conformation space were calculated using a knowledge-based approach which resulted in $1.36 \times 10^{7}$ conformers. All 3D multi-conformers were submitted to the rigid docking protocol. The best-scoring 40,000 compounds were submitted to flexible docking. Subsequently, the top 800 compounds were submitted to the cell-based in vitro assay. (b) 7 compounds, all analogues of 6877002 dose-dependently reduced NFkB activation in LPS stimulated RAW cells. (c) Compound 6877002 dose-dependently inhibits IL1 $\beta$ and IL6 expression in FGK45 (agonistic CD40 antibody)-stimulated bone marrow derived macrophages. (d) Docking model of the predicted TRAF6-6877002 compound complex. Compound 6877002 (in orange) creates 2 hydrogen bonds (in yellow) with Asn 467 and Cys390 amino acids (in cyan) and a $\pi-\pi$ stacking interaction of the ring between Arg466 and His376 residues (in cyan). (e) Superposition of 19 TRAF6-compound complexes. Active compounds (in green) have substituents on the ortho- and para- positions, whereas weaker compounds (in magenta) have substituents on the meta- position. These substituents seem to result in a clash with residue Pro468. (f) SPR sensorgrams of compound 6877002 binding to immobilized TRAF6 C-domain. Data represent the average of three independent experiments. 


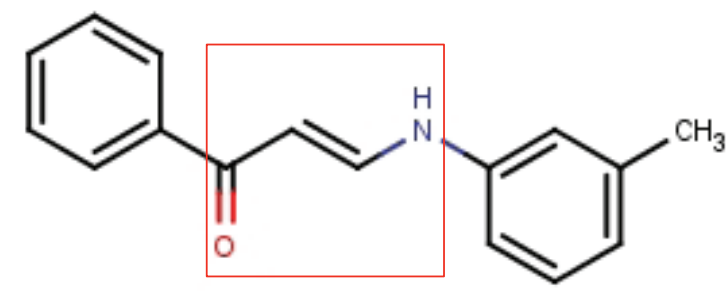

\section{R1 group}

R2 group

Figure 7. Compound 6877002. Structure of compound 6877002 represents common substructure of analogues consisted of two ring systems (R1 and R2) with different substituents connected by the same linker.

signaling intermediates in obesity-associated AT inflammation and metabolic dysfunction. CD40 precisely modulates cellular inflammation via distinct signaling pathways, which can be initiated through binding to the different TRAF molecules (36). As demonstrated here, CD40-TRAF2, 3, 5 and CD40-TRAF6 signaling have opposite roles in obesity-associated metabolic dysregulation. Whereas loss of CD40-TRAF2, 3, 5 signaling resembled the phenotype of CD40-deficiency in DIO, deficiency of CD40-TRAF6 signaling ameliorated obesityrelated IR, hepatosteatosis and AT inflammation. In other words, deficiency of CD40-TRAF6 signaling resembled the phenotype of CD40L-deficiency. These versatile actions of the CD40CD40L axis in DIO and IR development suggested that blocking the CD40-TRAF6 pathway specifically rather than the CD40-CD40L interaction could represent a promising therapy in DIO-associated metabolic dysfunction. To this end, we treated DIO-mice with a compound designed to block CD40-TRAF6 signaling and we could thereby partially reverse the DIOinduced IR and hepatosteatosis, which was accompanied by reduced numbers of M1-like inflammatory macrophages in the obese AT. M1 macrophages are crucial for development of IR and liver steatosis $(2,33,37)$. Therefore, by promoting macrophage polarization to the M1like inflammatory phenotype (32), CD40-TRAF6 signalling contributes to development of IR and liver steatosis

Previously, we demonstrated that specific deficiency in CD40-TRAF6 signaling, but not CD40-TRAF2, 3, 5 signaling, in $\mathrm{MHCII}^{+}$cells prevented neointima formation (38) as well as atherosclerosis and led to an anti-inflammatory immune profile (32). In atherosclerosis, inactivation of CD40-TRAF6 interactions reduced numbers of circulating Ly6 $\mathrm{C}^{\text {high }}$ monocytes, and prevented monocytes from entering the arterial wall. In parallel, deficiency of CD40TRAF2, 3, 5 interactions in atherosclerosis resulted in an increase in CD4 ${ }^{+}$effector cells, which was compensated by an increase in Treg cells, thereby leaving plaque burden unaffected (32).

The intriguing discrepancy between the opposite phenotypes observed in mice with CD40- 

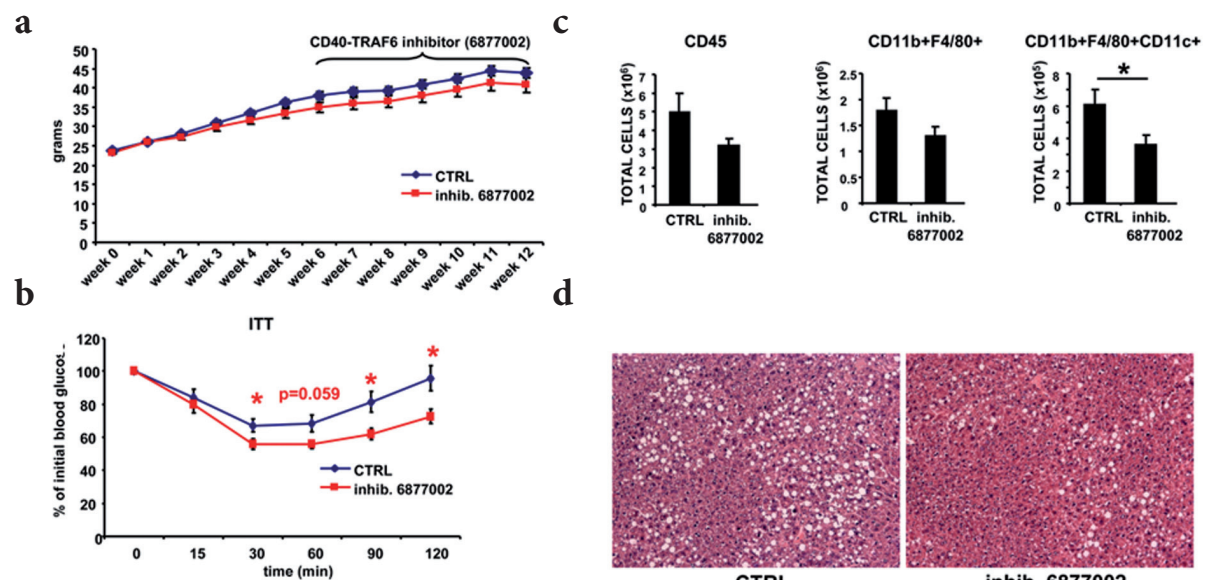

Figure 8. CD40-TRAF6 interaction inhibitor improves metabolic dysregulation and AT inflammation. WT male mice were fed a HFD for a total of $12 \mathrm{wks}$, receiving a CD40-TRAF6 interaction inhibitor (6877002) $(10 \mathrm{mmol} / \mathrm{kg} /$ day i.p.) or vehicle starting at week 6 of feeding. (a) Body weight of HFD-fed, inhibitor- or control-treated mice for 12 weeks. (b) Insulin tolerance test of HFD-fed, inhibitor- or control-treated mice for 12 weeks. (c) SVF cells from gonAT of control- or inhibitor-treated mice were analysed by FACS. CD45+ leukocytes and total macrophages or M1-macrophages, characterized as $\mathrm{CD} 11 \mathrm{~b}^{+} \mathrm{F} 4 / 80^{+}$and $\mathrm{F} 4 / 80^{+} \mathrm{CD} 11 \mathrm{~b}^{+} \mathrm{CD} 11 \mathrm{c}^{+}$, respectively, are shown. (d) Representative $\mathrm{H} \& \mathrm{E}$ stained sections from liver of control- or inhibitor-treated mice. ${ }^{*} \mathrm{P}<0.05$ for comparison with controltreated mice; $\mathrm{n}=7-8$ mice/group.

and CD40L-deficiency might also be explained by the fact that CD40L can engage functionally different receptors than CD40, for instance Mac-1 integrin. CD40 deletion in an atherosclerotic mouse model did not result in smaller lesions, whereas CD40L binding to Mac-1-integrin induced Mac-1-dependent adhesion and migration of leukocytes $(39,40)$. However, Mac- $1^{-1-}$ mice displayed an obesity phenotype (41). Thus, CD40L-Mac-1 interactions are an unlikely explanation for the discrepancy between the phenotypes of CD40- and CD40L-deficiency. Recently Guo et al also reported that $C D 40^{--}$mice have increased AT inflammation, but did not describe the underlying signaling mechanisms involved (42).

In conclusion, CD40-TRAF pathways in $\mathrm{MHCII}^{+}$cells potently regulate obesity-associated inflammation and metabolic dysfunction in mice. This opens new horizons for potential therapeutic strategies to combat obesity. Currently, agonistic CD40 antibodies are being evaluated in cancer patients, and could reduce the tumor load in pancreatic cancer (43). However, continuous activation of the entire CD40 pathway, as would be required for the chronic inflammatory nature of obesity, is therapeutically not feasible since long-term immune activation may result in substantial side effects. Therefore, targeting only parts of the CD40-signaling pathway, while leaving the rest of CD40-mediated immune actions intact, may be preferable. In the present paper we have provided evidence that specific targeting of the CD40-TRAF6 pathway represents a novel therapeutic mechanism in obesity-associated metabolic dysregulation as a small CD40-TRAF6 inhibitory compound counteracted the 
metabolic and inflammatory complications of DIO, such as IR and hepatic steatosis. The small compound approach is promising since only one of the CD40-TRAF pathways is blocked (i.e. CD40-TRAF6), whereas the other pathway (i.e. CD40-TRAF2, 3, 5) remains functional. The immune system therefore is less compromised and treatment is less likely to cause severe immune-suppressive side effects. However, the effects of such selective targeting strategies will have to be meticulously scrutinized, before being translated into a clinical setting.

\section{Acknowledgements}

We acknowledge the support from the Netherlands CardioVascular Research Initiative": the Dutch Heart Foundation, Dutch Federation of University Medical Centres, the Netherlands Organisation for Health Research and Development and the Royal Netherlands Academy of Sciences" for the GENIUS project "Generating the best evidence-based pharmaceutical targets for atherosclerosis" (CVON2011-19). This work was supported by the Humboldt Foundation (Sofja Kovalevskaja grant to EL), the Netherlands Organization for Scientific Research (NWO)(VIDI and VICI grant to EL, VIDI grant to OS, VICI grant to CW, medium investment grant to GN), the Netherlands Heart Foundation (Dr E. Dekker grant to TS, established investigator grant to EL, MdW and PCNR), the Rembrandt foundation (SMB, MdW, EL and PCNR), the German-Australian Institute for Translational Medicine (SRB), the Deutsche Forschungsgemeinschaft (DFG FOR809: LU1643/1-2, SO876/3-1, WE1913/11-2, SFB914-B08 and SFB 1054-B04 and B08 to EL, NG, OS, CW, CH279/5-1 to TC and KFO252 to TC and SRB), European Research Council Grants ( ${ }^{\circ} 281296$ to TC and ERC AdG ${ }^{\circ} 249929$ to CW) and by a grant from the German Federal Ministry of Education and Research to the German Center for Diabetes Research (DZD e.V.) (to TC) and DZHK (German Centre for Cardiovascular Research, MHA VD1.2 to CW), the Cardiovascular Research Institute Maastricht (to GN), the EU (grant KBBE-2011-5 289350 to GV), the Transnational University Limburg (to GN) and Cyttron II (FES0908 to GN and TH). Further support was received from the Medical Research Service of the Veterans Affairs Department, Departments of Pathology, and Medicine, Division of Hematology/Oncology of the Miller Medical School, University of Miami and South Florida Veterans Affairs Foundation for Research and Education (all to AVS) and by the L Austin Weeks Endowment for Urologic Research (to NLB). 


\section{References}

1. Osborn O, Sears DD, Olefsky JM. Fat-induced inflammation unchecked. Cell Metab. 2010 Dec 1;12(6):553-4.

2. Chatzigeorgiou A, Karalis KP, Bornstein SR, Chavakis T. Lymphocytes in obesity-related adipose tissue inflammation. Diabetologia. 2012 Oct;55(10):2583-92.

3. Gregor MF, Hotamisligil GS. Inflammatory mechanisms in obesity. Annu Rev Immunol. 2011;29:415-45.

4. Nishimura S, Manabe I, Nagasaki M, Eto K, Yamashita H, Ohsugi M, et al. CD8+ effector T cells contribute to macrophage recruitment and adipose tissue inflammation in obesity. Nat Med. 2009 Aug;15(8):914-20.

5. Feuerer M, Herrero L, Cipolletta D, Naaz A, Wong J, Nayer A, et al. Lean, but not obese, fat is enriched for a unique population of regulatory T cells that affect metabolic parameters. Nat Med. 2009 Aug;15(8):930-9.

6. Osborn O, Olefsky JM. The cellular and signaling networks linking the immune system and metabolism in disease. Nat Med. 2012 Mar;18(3):363-74.

7. Johnson AMF, Olefsky JM. The origins and drivers of insulin resistance. Cell. 2013 Feb 14;152(4):673-84.

8. Foy TM, Aruffo A, Bajorath J, Buhlmann JE, Noelle RJ. Immune regulation by CD40 and its ligand GP39. Annu Rev Immunol. 1996;14:591-617.

9. Guldiken S, Demir M, Arikan E, Turgut B, Azcan S, Gerenli M, et al. The levels of circulating markers of atherosclerosis and inflammation in subjects with different degrees of body mass index: Soluble CD40 ligand and high-sensitivity C-reactive protein. Thromb Res. 2007;119(1):79-84.

10. Poggi M, Jager J, Paulmyer-Lacroix O, Peiretti F, Gremeaux T, Verdier M, et al. The inflammatory receptor CD40 is expressed on human adipocytes: contribution to crosstalk between lymphocytes and adipocytes. Diabetologia. 2009 Jun;52(6):1152-63.

11. Missiou A, Wolf D, Platzer I, Ernst S, Walter C, Rudolf P, et al. CD40L induces inflammation and adipogenesis in adipose cells--a potential link between metabolic and cardiovascular disease. Thromb Haemost. 2010 Apr;103(4):788-96.

12. Poggi M, Engel D, Christ A, Beckers L, Wijnands E, Boon L, et al. CD40L deficiency ameliorates adipose tissue inflammation and metabolic manifestations of obesity in mice. Arterioscler Thromb Vasc Biol. 2011 Oct;31(10):2251-60.

13. Wolf D, Jehle F, Ortiz Rodriguez A, Dufner B, Hoppe N, Colberg C, et al. CD40L deficiency attenuates dietinduced adipose tissue inflammation by impairing immune cell accumulation and production of pathogenic IgG-antibodies. PloS One. 2012;7(3):e33026.

14. Kawai T, Andrews D, Colvin RB, Sachs DH, Cosimi AB. Thromboembolic complications after treatment with monoclonal antibody against CD40 ligand. Nat Med. 2000 Feb;6(2):114.

15. Ye H, Arron JR, Lamothe B, Cirilli M, Kobayashi T, Shevde NK, et al. Distinct molecular mechanism for initiating TRAF6 signalling. Nature. 2002 Jul 25;418(6896):443-7.

16. Krieger E, Koraimann G, Vriend G. Increasing the precision of comparative models with YASARA NOVA-a self-parameterizing force field. Proteins. 2002 May 15;47(3):393-402.

17. Vriend G, Sander C. Detection of common three-dimensional substructures in proteins. Proteins. 1991;11(1):52-8.

18. Dunbrack RL, Cohen FE. Bayesian statistical analysis of protein side-chain rotamer preferences. Protein Sci Publ Protein Soc. 1997 Aug;6(8):1661-81.

19. An J, Totrov M, Abagyan R. Pocketome via comprehensive identification and classification of ligand binding envelopes. Mol Cell Proteomics MCP. 2005 Jun;4(6):752-61.

20. Laurie ATR, Jackson RM. Q-SiteFinder: an energy-based method for the prediction of protein-ligand binding sites. Bioinforma Oxf Engl. 2005 May 1;21(9):1908-16.

21. Lagorce D, Sperandio O, Galons H, Miteva MA, Villoutreix BO. FAF-Drugs2: free ADME/tox filtering tool to assist drug discovery and chemical biology projects. BMC Bioinformatics. 2008;9:396.

22. Hawkins PCD, Skillman AG, Warren GL, Ellingson BA, Stahl MT. Conformer generation with OMEGA: algorithm and validation using high quality structures from the Protein Databank and Cambridge Structural Database. J Chem Inf Model. 2010 Apr 26;50(4):572-84.

23. Miteva MA, Lee WH, Montes MO, Villoutreix BO. Fast structure-based virtual ligand screening combining FRED, DOCK, and Surflex. J Med Chem. 2005 Sep 22;48(19):6012-22.

24. McGann M. FRED pose prediction and virtual screening accuracy. J Chem Inf Model. 2011 Mar 28;51(3):57896.

25. Jain AN. Surflex: fully automatic flexible molecular docking using a molecular similarity-based search engine. J Med Chem. 2003 Feb 13;46(4):499-511.

26. Nabuurs SB, Wagener M, de Vlieg J. A flexible approach to induced fit docking. J Med Chem. 2007 Dec 27;50(26):6507-18. 
27. Carlsen H, Moskaug JØ, Fromm SH, Blomhoff R. In vivo imaging of NF-kappa B activity. J Immunol Baltim Md 1950. 2002 Feb 1;168(3):1441-6.

28. Qin H, Wilson CA, Lee SJ, Zhao X, Benveniste EN. LPS induces CD40 gene expression through the activation of NF-kappaB and STAT-1alpha in macrophages and microglia. Blood. 2005 Nov 1;106(9):3114-22.

29. Vowinkel T, Wood KC, Stokes KY, Russell J, Krieglstein CF, Granger DN. Differential expression and regulation of murine CD40 in regional vascular beds. Am J Physiol Heart Circ Physiol. 2006 Feb;290(2):H631-9.

30. Péronnet F, Massicotte D. Table of nonprotein respiratory quotient: an update. Can J Sport Sci J Can Sci Sport. 1991 Mar;16(1):23-9.

31. Langer HF, Choi EY, Zhou H, Schleicher R, Chung K-J, Tang Z, et al. Platelets contribute to the pathogenesis of experimental autoimmune encephalomyelitis. Circ Res. 2012 Apr 27;110(9):1202-10.

32. Lutgens E, Lievens D, Beckers L, Wijnands E, Soehnlein O, Zernecke A, et al. Deficient CD40-TRAF6 signaling in leukocytes prevents atherosclerosis by skewing the immune response toward an antiinflammatory profile. J Exp Med. 2010 Feb 15;207(2):391-404.

33. Phieler J, Chung K-J, Chatzigeorgiou A, Klotzsche-von Ameln A, Garcia-Martin R, Sprott D, et al. The complement anaphylatoxin C5a receptor contributes to obese adipose tissue inflammation and insulin resistance. J Immunol Baltim Md 1950. 2013 Oct 15;191(8):4367-74.

34. Kawabe T, Naka T, Yoshida K, Tanaka T, Fujiwara H, Suematsu S, et al. The immune responses in CD40deficient mice: impaired immunoglobulin class switching and germinal center formation. Immunity. 1994 Jun;1(3):167-78.

35. Ahonen C, Manning E, Erickson LD, O'Connor B, Lind EF, Pullen SS, et al. The CD40-TRAF6 axis controls affinity maturation and the generation of long-lived plasma cells. Nat Immunol. 2002 May;3(5):451-6.

36. Engel D, Seijkens T, Poggi M, Sanati M, Thevissen L, Beckers L, et al. The immunobiology of CD154-CD40TRAF interactions in atherosclerosis. Semin Immunol. 2009 Oct;21(5):308-12.

37. Lumeng CN, Saltiel AR. Inflammatory links between obesity and metabolic disease. J Clin Invest. 2011 Jun;121(6):2111-7.

38. Donners MMPC, Beckers L, Lievens D, Munnix I, Heemskerk J, Janssen BJ, et al. The CD40-TRAF6 axis is the key regulator of the CD40/CD40L system in neointima formation and arterial remodeling. Blood. 2008 May $1 ; 111(9): 4596-604$.

39. Wolf D, Hohmann J-D, Wiedemann A, Bledzka K, Blankenbach H, Marchini T, et al. Binding of CD40L to Mac1's I-domain involves the EQLKKSKTL motif and mediates leukocyte recruitment and atherosclerosis--but does not affect immunity and thrombosis in mice. Circ Res. 2011 Nov 11;109(11):1269-79.

40. Zirlik A, Maier C, Gerdes N, MacFarlane L, Soosairajah J, Bavendiek U, et al. CD40 ligand mediates inflammation independently of CD40 by interaction with Mac-1. Circulation. 2007 Mar 27;115(12):1571-80.

41. Dong ZM, Gutierrez-Ramos JC, Coxon A, Mayadas TN, Wagner DD. A new class of obesity genes encodes leukocyte adhesion receptors. Proc Natl Acad Sci U S A. 1997 Jul 8;94(14):7526-30.

42. Guo C-A, Kogan S, Amano SU, Wang M, Dagdeviren S, Friedline RH, et al. CD40 deficiency in mice exacerbates obesity-induced adipose tissue inflammation, hepatic steatosis, and insulin resistance. Am J Physiol Endocrinol Metab. 2013 May 1;304(9):E951-63.

43. Beatty GL, Chiorean EG, Fishman MP, Saboury B, Teitelbaum UR, Sun W, et al. CD40 agonists alter tumor stroma and show efficacy against pancreatic carcinoma in mice and humans. Science. 2011 Mar 25;331(6024):1612-6. 


\section{Supplementary Materials}
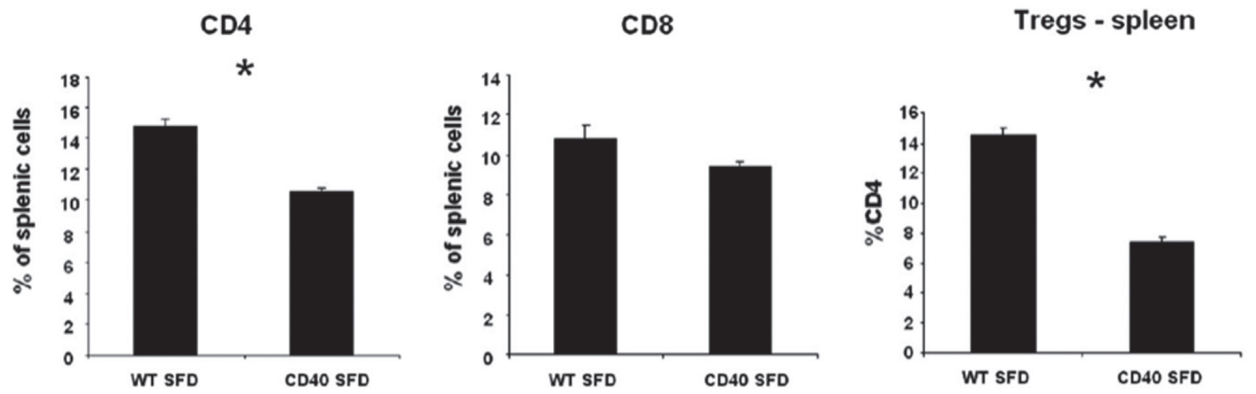

Supplementary Figure 1. T-cell numbers in spleens of WT and CD40 $0^{-/}$mice fed a SFD for 30wks. CD4 and CD8 T-cells are expressed as percentage of splenic cells, whereas CD4+CD25+Foxp3+ Treg cells are expressed as percentage of CD4 positive cells in the spleen. Data are mean $\pm \mathrm{SEM},{ }^{\star} \mathrm{P}<0.05$. ( $\mathrm{n}$ $=5$ /group)

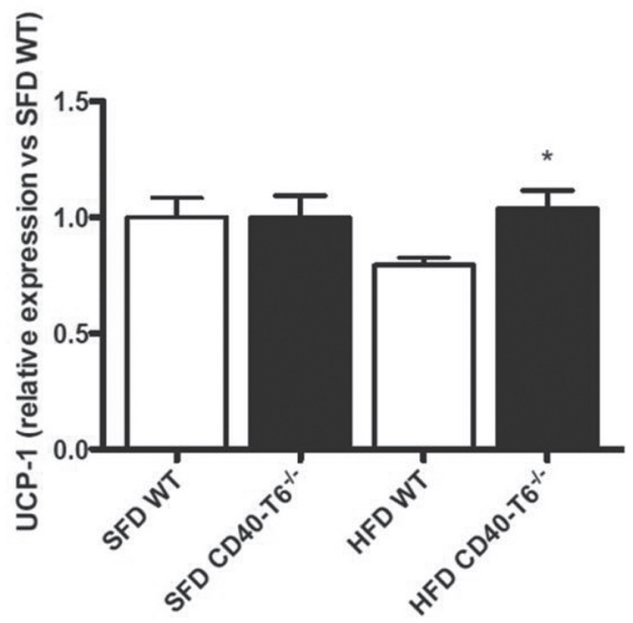

Supplementary Figure 2. Brown adipose tissue (BAT) activity is increased in CD40-TRAF6 ${ }^{-1}$ mice. UCP-1 mRNA expression in the BAT of CD40-TRAFwt and CD40-TRAF $6^{-1}$ mice fed a SFD or a HFD. Values are mean \pm SEM. ${ }^{\star} \mathrm{P}<0.05$ for comparison with CD40-TRAFwt mice. $\mathrm{n}=6$ /group. 
a
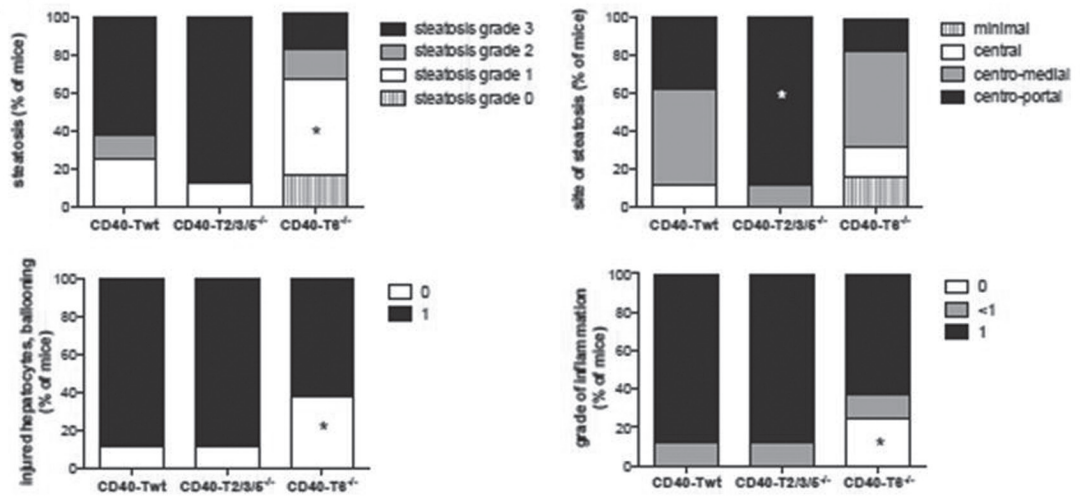

b
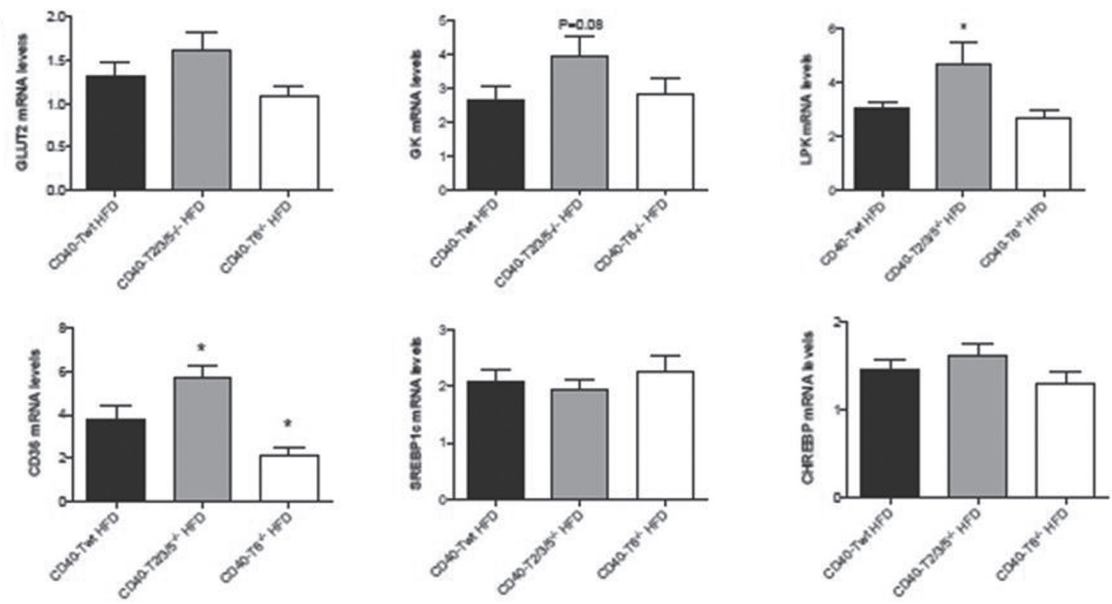

Supplementary Figure 3. CD40-TRAF2, 3, 5 deficiency aggravates obesity associated hepatosteatosis. (a) Hepatic steatosis was graded from 0 (mild) to 3 (severe). Steatosis was further classified as minimal steatosis, steatosis in the central vein area (c) or central vein-mid-portal (c-p). The presence of macro(ma) and microvesicular ( $\mathrm{mi}$ ) steatosis were graded as $\mathrm{ma} ; \mathrm{ma}>\mathrm{mi}$ and $\mathrm{ma}=\mathrm{mi}$ and $\mathrm{mi}$. The percentage of mice exhibiting hepatocyte injury, characterized by ballooning and lobular inflammation was also determined. (b) Hepatic mRNA levels of genes involved in glycolysis, lipolysis and lipogenesis (values are mRNA expression of the gene of interest / mRNA expression of housekeeping genes). Values are mean \pm SEM. ${ }^{\star} \mathrm{P}<0.05$ for comparison with CD40-TRAFwt mice. $\mathrm{n}=8$ - 12 mice/group. 
a
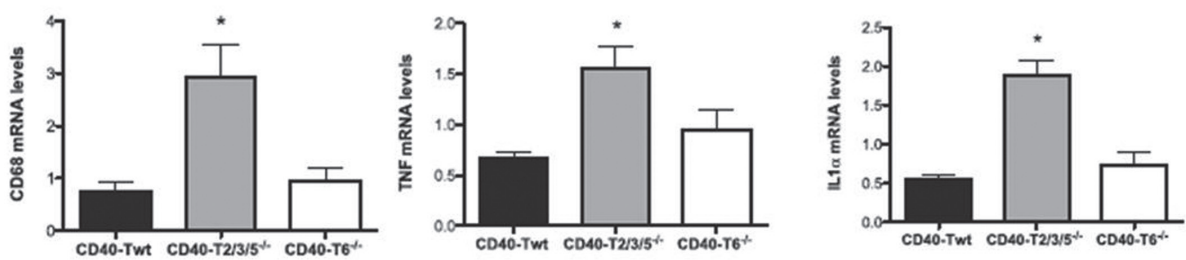

b
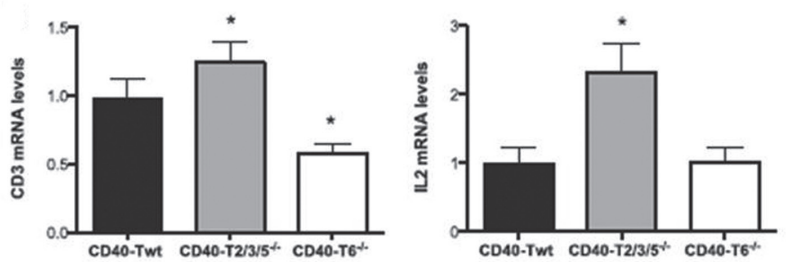

c
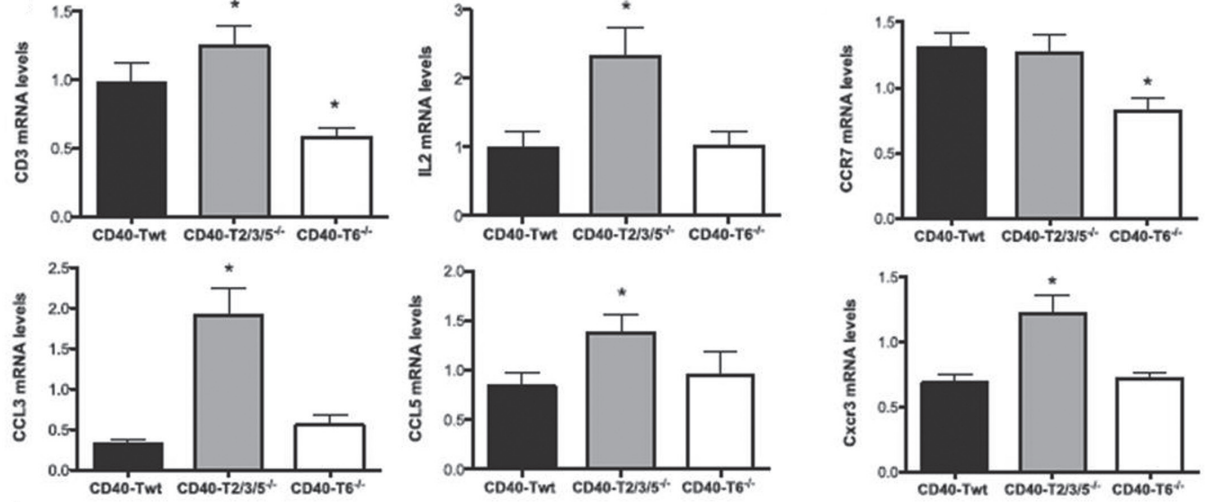

d
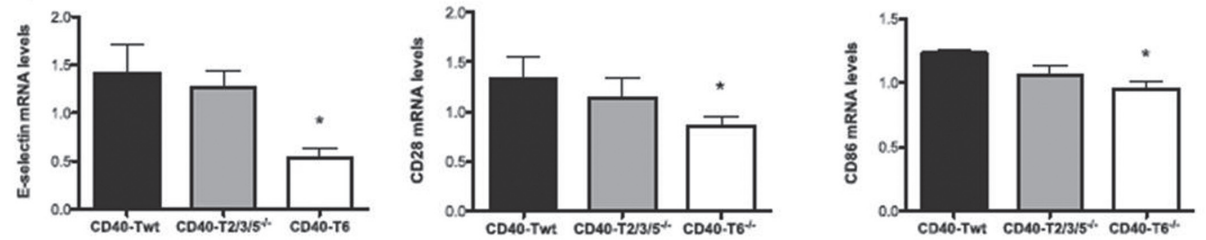

Supplementary Figure 4. CD40-TRAF2, 3, 5 deficiency results in increased inflammatory gene expression in gonadal AT. (a) mRNA levels of macrophage markers and genes involved in macrophage activation (CD68, TNF, IL1 $\beta$ ), (b) T lymphocyte markers and activators (CD3, IL2), (c) chemokines and chemokine receptors (CCR7, CCL3, CCL5, CXCR3), (d) genes downregulated in CD40-TRAF6 ${ }^{-1}$ mice (E-selectin, CD28, CD86). Values are mRNA expression of the gene of interest / mRNA expression of housekeeping genes. ${ }^{\star} \mathrm{P}<0.05$, for comparison to CD40-TRAFwt mice. $\mathrm{n}=6$ mice/group. 


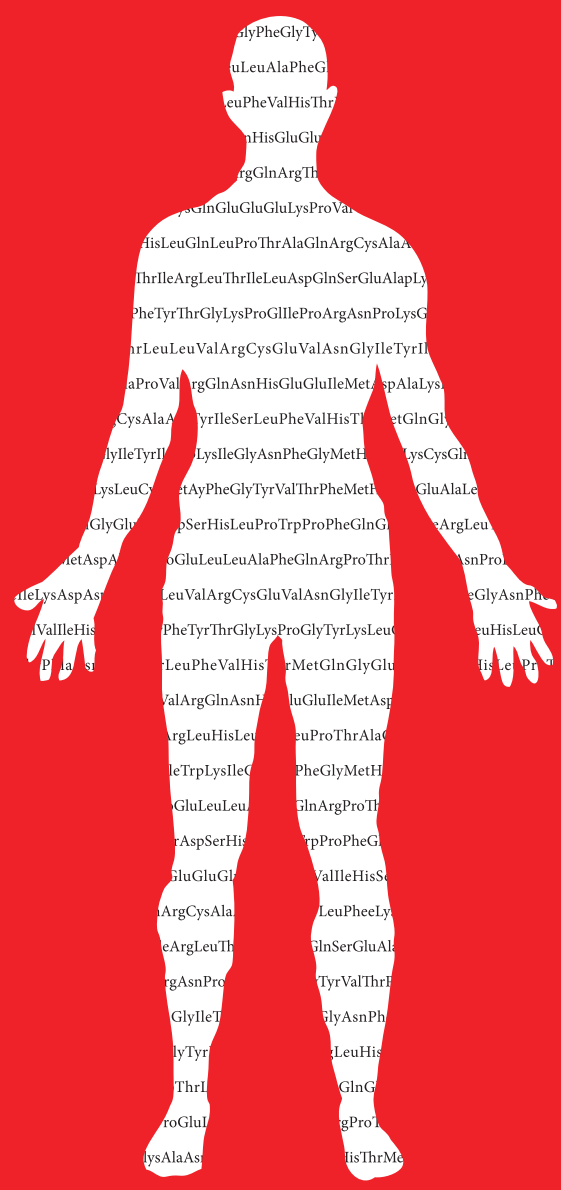




\section{Chapter}

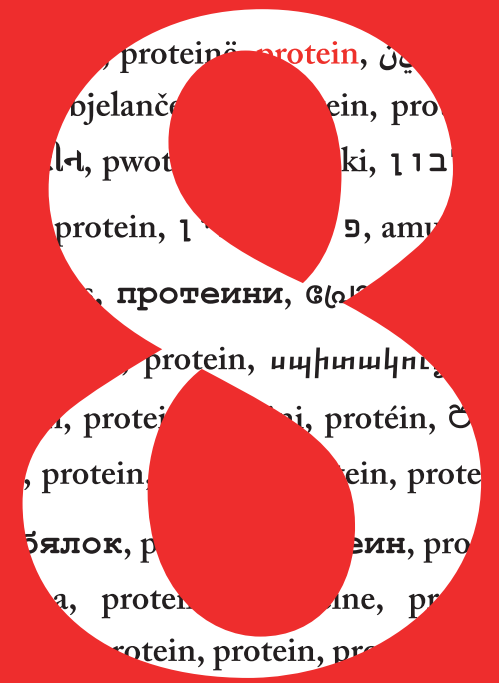

General discussion 
The scientific research that is described in this thesis aims at modulation of protein - protein interactions (PPIs) through stabilization or inhibition with a special focus on the CD40TRAF6 interactions and their role in (chronic) inflammatory diseases. In the first part of this thesis, we explored stabilization of PPIs. We suggested a classification of stabilizers of PPIs (sPPIs) which is based on their place of binding and architecture of their targets (I). Further, we analysed the chemical space of sPPIs (II). In the second part of this thesis, we explored inhibition of PPIs. We presented a drug discovery pipeline through which we found CD40TRAF6 inhibitors (III). Next, we validated these inhibitors in chronic inflammatory disease models for e.g. atherosclerosis, and diet-induced obesity (IV). Finally, we used our newly discovered inhibitors as a research tool to investigate the specificity of CD40-TRAF pathways in diet-induced obesity (V).

The main findings of this thesis are:

I. Stabilizers of PPI complexes can be categorized in three different classes: the classes A, $\mathrm{B}$, and $\mathrm{M}$.

II. Stabilizers of PPIs have physico-chemical properties that resemble the profile of conventional drugs.

III. The CD40-TRAF6 interaction can be disrupted by small molecule inhibitors that bind to the TRAF6 C-domain.

IV. Small molecule inhibitors of the CD40-TRAF6 interaction possess in vivo activities and reduce inflammation in (chronic) inflammatory diseases such as peritonitis, sepsis, diet-induced obesity, atherosclerosis, and multiple sclerosis.

V. The CD40-TRAF6 interaction improves insulin resistance and hepatic steatosis in diet-induced obesity, whereas CD40-TRAF2, 3, 5 interactions impair metabolic complications of diet-induced obesity. 


\section{Classification of stabilizers of PPIs}

Protein - protein interactions are key to the regulation of biological processes in all living organisms. Modulation of PPIs have shown novel opportunities for therapeutical interventions (1). Inhibitors of PPI (iPPIs) are long known, but stabilizers of PPI (sPPIs) have only recently entered the scientific literature (2). The last two decades have brought several success stories of iPPIs design (3). However, in recent years, also sPPIs are becoming increasingly popular (2, 4). The iPPIs are being studied thoroughly and are being collected in large databases $(5,6)$, their chemical space is rationalized (7), and decision trees are present to facilitate their design (8). In contrast, sPPIs still remain largely unexplored. Even though the design of stabilizers is becoming more prevalent, a systematic categorization of these molecules is not present. We suggest a structure-based classification of stabilizers, based on the architecture of their targets and their place of binding. Class A stabilizers are associated with heteromer complexes. Class B stabilizers are associated with homomers and quasi homomers. Class $M$ stabilizers are oligomers of more than two monomers. Subclasses 1 and 2 relate to type of cavity, peripheral, or enclosed, respectively (chapter 3 ). The proposed classification may help bioscienticsts to place their PPI complex into one of the classes and extrapolate this knowleadge to the PPI complex of their interest. To proceed with the rational design of stabilizers, the order of subsequent steps is of the upmost importance. Thus, we proposed the first decision tree to assist in the structure-based design of sPPIs (chapter3). We anticipate that our analysis will accelerate the design of new stabilizers.

\section{Physico-chemical characterization of small molecule stabilizers of protein - protein interactions}

Recent studies resulted in numerous inhibitors of PPIs (iPPIs), from which several reached clinical trials (3). The number of newly discovered iPPIs allowed for chemical space rationalization, which might facilitate structure-based virtual ligand screening $(7,9)$. In contrast, the number of discovered sPPIs has only since recently been increasing. There are a few review articles that describe different sPPIs types $(1,2,4)$, however small molecule collections of sPPIs are sparse (6). We collected small molecule stabilizers, excluding peptidelike and cyclic compounds. Our dataset consisted of 123 compounds, out of which 74 were chemically diverse. This is the first collection of small molecule stabilizers that was used for the analysis of their physico-chemical properties. The sPPIs are characterized by their molecular weight with an average value of $386.1 \mathrm{Da}$, hydrophobicity represented by $\log \mathrm{P}$ value of 3.2 , hydrogen bond donors median value of 2 , hydrogen bond acceptors median value of 5 , rotatable bonds median value of 3 , and aromatic character represented by aromatic ratio value of 0.3 . Our analysis revealed that sPPIs meet the criteria of the Lipinski rule of five (RO5) (10), thus, they have in fact a closer resemblance to the regular drug profile than iPPIs (chapter 4). Block et al (11) presented a comparison between sPPIs and enzyme binding 
pockets. In agreement with our study, the analysis revealed similarities between the main descriptors such as distribution of hydrophobicity, burial of atoms that form pockets, and volume of the binding pockets (11). Our results might facilitate future design of this type of modulators in drug discovery projects. Lessons learned from iPPIs studies showed that the first rationalization of chemical space might boost the design of new compounds (3), which might result in more specific, target-based, chemical space analysis. Thus, future detailed analysis of sPPIs targets is strongly suggested. Additionally, the cross-analysis between compounds and binding pockets as classified in our previous study (chapter 3) is recommended. Moreover, prospect analysis might assist in the design of sPPIs according to the binding place of a compound and the architecture of PPI-target protein complexes.

\section{Design of CD40-TRAF6 inhibitors}

TRAF6 is a member of the TNF receptor associated factor protein family. It mediates signal transduction from members of the TNF receptor superfamily and the Toll/IL-1 family (12). Moreover, it elicits a signal from diverse receptors such as CD40, RANK, TNFSF/RANCE, and IL-1. TRAF6 also interacts with various proteins from the IRAK family such as IRAK1, 2, M and 4 that link distinct signalling pathways (13-16). TRAF6 interacts with the transforming growth factor (TGF) beta receptor complex that is required for the Smadindependent activation of c-Jun N-terminal kinases (JNKs) and p38 mitogen-activated protein kinases (17). Additionally, TRAF6 influence ubiquitin activity by their interaction with ubiquitin conjugating enzymes. These enzymes catalyse the formation of polyubiquitin chains that are required in the activation process of IKK in the NF-kB signalling pathway (7). TRAF6 is unique amongst other TRAF family members. It shares the least sequence similarity in the conserved domain of TRAF members, the so-called C-domain (8). Subsequently, TRAF6 recognizes the X-X-P-X-E-X-Ar/Ac (the last residue stands for aromatic or acidic) peptide binding motive (18) whereas TRAF2, 3, 5 recognize the P/S/A/T-X-Q/E-E peptide binding motive (9-13). These structural differences are reflected in the functions of the TRAF protein family members; with only TRAF6 being a signal transducer for the TLR/IL-1R superfamily (1). Thus, TRAF6 is a hub protein and constitutes an important target for a variety of diseases. The aforementioned structural differences provide the basis for the design of TRAF6 specific inhibitors. However, the only TRAF6 inhibitor present to date is a peptide that is specific for the C-domain. It was shown to inhibit the TRAF6-RANK interaction by binding to the TRAF6 C-domain, resulting in inhibition of the NF-kB signalling pathway (14). Nevertheless, this peptide does not have drug-like properties, thus, it cannot be used as therapeutical agent. To date, there was no small molecule inhibitors of TRAF6 reported.

We used a drug discovery pipeline to discover inhibitors of the TRAF6-CD40 interaction. It resulted in seven compounds that were tested in an in vitro assay; their corresponding $\mathrm{IC}_{50}$ was in the range of 0.1-16 $\mu \mathrm{M}$. Subsequently, these compounds were tested in in vivo models 
of (chronic) inflammatory diseases, such as sepsis, atherosclerosis and diet-induced obesity. Due to limitations in time and costs, we choose only two compounds for long term in vivo testing. Typically, $\mathrm{IC}_{50}$ values can be used to guide the selection of compounds that proceed to the next step in a drug discovery pipeline. However, we used a peritonitis experiment, which is a short-term model of acute inflammation. The read out of this model allowed us to prioritize compounds according to the whole organism screening assay. The advantage of this assay is that it allows for testing both drug toxicity and the in vivo effect at the same time, while a first and crude insight on the in vivo side effects and toxicological profile of a compound is obtained. At this stage of our research, we omitted chemical optimization of the compounds, which could further increase their potency. Thus, currently, our compounds serve rather as a chemical probe (15) and the compounds were used to explore their effects in other (chronic) inflammatory diseases, such as diet-induced obesity, atherosclerosis, and multiple sclerosis. However, in order to further proceed with these compounds in the drug discovery pipeline, chemical optimization is inevitable.

We started chemical optimization by changing the linker that connects the substitution group in the compounds and that may have undesired properties. We sampled the activity landscape by designing new compounds with different substitution groups and by analysing their structure-activity relationship. However, further optimization that would search for activity cliffs and would guide the discovery of compounds with improved potency still requires additional attention. One of the strategies to optimise compounds might be by structural analysis of the TRAF6 C-domain in complex with the compound by NMR or X-ray crystallography. Such experimental technique could verify our predicted binding mode, and subsequently guide further optimization. The bottleneck of this method is the availability of a high yield of pure protein. We proceeded with the production and purification of the TRAF6 C-domain; however problems with protein solubility stopped us from obtaining a sufficient yield. Currently, we use alternative protein expression of the TRAF6 C-domain to produce sufficient material for experimental structural studies.

\section{Protective role of CD40-TRAF2 interaction in diet-induced obesity}

Obesity is defined as a body mass index $>30 \mathrm{~kg} / \mathrm{m}^{2}$. For a long time, it was considered to be a passive accumulation of fat. However, in recently, it became clear that obesity is not only an accumulation of fat tissue, but at the same time is a chronic, low-grade inflammatory disease of adipose tissue (16). Recent studies showed that CD40 is expressed on human adipose tissue, thus it is associated with inflammation of this tissue and with diet-induced obesity (17, 18). It was revealed that CD40-CD40L plays an important role in the inflammation of adipose tissue (19). However, further studies showed a contradictory role for CD40L-CD40L interaction in a diet-induced obesity model (20). To unravel these contradicting results, we investigated pathways further downstream of the CD40 signalling. CD40 lacks intrinsic 
activity and in order to become active it needs to recruit adaptor proteins from the TRAF family, TRAF2, 3, 5 and 6. TRAF2, 3, 5 and TRAF6 bind to different binding sites of the intracellular part of CD40 and are further involved in several different signalling pathways. We used a diet-induced obesity model of mice with a CD40-TRAF2, 3, 5 or CD40-TRAF6 interaction deficiency. Mice with a CD40-TRAF2, 3, 5 deficiencies showed aggravation of adipose tissue inflammation, insulin resistance, and hepatosteatosis, whereas the CD40TRAF6 interaction deficiency seemed to protect the mice against obesity induced aberrations (21). Thus, activation of CD40-TRAF2, 3, 5 or inhibition of CD40-TRAF6 interaction might play a therapeutical role. One of the therapeutical strategies is inhibition of the CD40-TRAF6 interaction. A second strategy is activation of the CD40-TRAF2, 3, 5 interactions. The first strategy was investigated in our study and is not within the scope of this part of the discussion. Here, we would like to focus on the second strategy. There are several different ways of activating signalling pathways. One of the ways to activate signal transduction is by stabilizing its protein-protein interactions (PPIs). Stabilization of PPIs can lead to inhibition or activation of biological processes (4). TRAF2, present as a trimer, activates CD40 signalling, thus we hypothesized that stabilization of TRAF2 trimer will increase the interaction with CD40, and activate this signalling pathway. Therefore, it will induce a protective role in the diet-induced obesity. For this reason, we analysed this complex according to the decision tree presented in chapter 3. We found a druggable pocket located at the interface of the two monomers and we performed a virtual ligand screening campaign. Currently, we are evaluating in vitro data which will identify hit compounds. However, this investigation is still being performed, and is out of the scope of this thesis.

\section{Small molecule CD40-TRAF6 inhibitors as a new therapy for (chronic) inflammatory diseases}

Our CD40-TRAF6 inhibitors served as a chemical probe to evaluate their therapeutical potential in several (chronic) inflammatory diseases. In a polymicrobial sepsis model, CD40TRAF6 inhibitors increased the survival rate by $150 \%$ and $200 \%$, respectively, thus protected against death from sepsis (chapter 5). In atherosclerosis, our inhibitors reduced initial atherosclerotic plaque area per aortic arch by $47 \%$ and $67 \%$ compared to vehicle-treated mice. Treatment with either of the two compounds, thus, prevents the progression of atherosclerosis in mice. Additionally, it induces a favourable atherosclerotic plaque phenotype that is low in inflammation. Our inhibitors reduced initial atherosclerotic plaque by hampering chemokine-mediated leukocyte recruitment to the arterial wall, and inhibiting cytokine production (chapter 6). The influence of our compounds on advanced atherosclerosis remains undetermined; however, currently it is under investigation. In the diet-induced obesity model, our inhibitors improved metabolic complications by reduction of insulin sensitivity, hepatosteatosis, and adipose tissue inflammation, as compared to vehicle treated mice 


\section{(chapter 7).}

The challenge in treatment of chronic inflammatory diseases is to combine long-lasting effective treatment in the absence of side effects. Chronic inflammatory diseases demand long-lasting treatment. Even the most specific therapies might influence the entire host defence system that is crucial for survival. Thus, special caution has to be taken in the design of this type of drugs with respect to their safety. One of the strategies to address this issue is to use long-lasting treatment only to a selected group of patients, such as patients without an already compromised immune system by e.g. tumour surveillance. Another strategy is a celltype specific targeting. Currently, we investigate nanoparticle delivery systems; our inhibitors are encapsulated in reconstituted high-density lipoprotein nanoparticles (rHDL) and used for the treatment of atherosclerosis in in vivo model.

We designed compounds that would selectively inhibit the CD40-TRAF6 interaction. Their functional specificity was confirmed in diet-induced obesity mice model. Additionally, a six weeks compound treatment did not show signs of toxic, immunosuppressive, or any other side-effects (chapter 7). However, our compounds showed very high efficacy with relatively low $\mathrm{IC}_{50}$ values obtained in in vitro cell-based assays. At this stage of the research we cannot exclude a polypharmacological effect of our inhibitors. Importantly, use of compounds interacting with multiple targets instead of one target, has several advantages as long as this use does not cause side-effects (19). Thus, possible a polypharmacology effect of our inhibitors does not exclude them from further steps in the drug discovery pipeline.

Our inhibitors have already been tested in several (chronic) inflammatory diseases; Multiple sclerosis (MS) is an inflammatory disease of the central nervous system (20). It is known that CD40-CD40L plays a role in promoting MS development (21). However, the role of CD40TRAF6 interaction is not yet established. We tested our inhibitors in a human brain endothelial cell line. CD40-TRAF6 inhibitors reduced both monocyte migration in a brain endothelium cell line and migration across the brain endothelium cell line. Further in vivo analysis is under investigation. Thus, our inhibitors might serve as a research tool to investigate therapeutical potential of CD40-TRAF6 interaction in other (chronic) inflammatory diseases. Considering that TRAF6 is overexpressed in lung (22) and pancreatic cancer (23), and plays important roles in other inflammatory diseases such as rheumatoid arthritis (24), psoriasis (25), and inflammatory bowel disease (26), and other diseases such as osteoporosis (27), we conclude that the therapeutical potential of our inhibitors is immense.

\section{Overall conclusions}

This thesis demonstrates modulation of PPIs through either stabilization or inhibition. We focus on CD40-TRAF6 interaction in (chronic) inflammatory diseases.

The first part of this thesis evaluates stabilization of PPIs that might facilitate rational design of sPPIs. We present a classification scheme for sPPIs and a decision tree that may help 
rationalize the design of new stabilizers. Our research revealed significant differences with respect to physico-chemical properties (e.g. modest size and hydrophobicity) between sPPIs and iPPIs. We established that small molecule sPPIs tend to be more similar to conventional drugs than iPPIs.

The second part of this thesis assesses inhibition of PPIs. We show a drug discovery pipeline of anti-inflammatory inhibitors. We designed small molecule inhibitors that bind to the TRAF6 C-domain and are able to disrupt the CD40-TRAF6 interaction. Our inhibitors can reduce inflammation in (chronic) inflammatory diseases such as sepsis, atherosclerosis, and diet-induced obesity. Additionally, our inhibitors revealed that blockade of the CD40-TRAF6 interaction improves insulin resistance and hepatic steatosis in diet-induced obesity, whereas CD40-TRAF2, 3, 5 interactions impair metabolic complications of diet-induced obesity. CD40-TRAF6 inhibitors thus show good therapeutical potential; however, before entering any pre-clinical study, further optimization is likely desirable. 


\section{References}

1. Milroy L-G, Grossmann TN, Hennig S, Brunsveld L, Ottmann C. Modulators of protein-protein interactions. Chem Rev. 2014 May 14;114(9):4695-748.

2. Giordanetto F, Schäfer A, Ottmann C. Stabilization of protein-protein interactions by small molecules. Drug Discov Today. 2014 Nov;19(11):1812-21.

3. Arkin MR, Tang Y, Wells JA. Small-molecule inhibitors of protein-protein interactions: progressing toward the reality. Chem Biol. 2014 Sep 18;21(9):1102-14.

4. Bartel M, Schäfer A, Stevers LM, Ottmann C. Small molecules, peptides and natural products: getting a grip on 14-3-3 protein-protein modulation. Future Med Chem. 2014 May;6(8):903-21.

5. Labbé CM, Laconde G, Kuenemann MA, Villoutreix BO, Sperandio O. iPPI-DB: a manually curated and interactive database of small non-peptide inhibitors of protein-protein interactions. Drug Discov Today. 2013 Oct;18(19-20):958-68.

6. Higueruelo AP, Jubb H, Blundell TL. TIMBAL v2: update of a database holding small molecules modulating protein-protein interactions. Database J Biol Databases Curation. 2013;2013:bat039.

7. Sperandio O, Reynès $\mathrm{CH}$, Camproux A-C, Villoutreix BO. Rationalizing the chemical space of protein-protein interaction inhibitors. Drug Discov Today. 2010 Mar;15(5-6):220-9.

8. Chène P. Drugs targeting protein-protein interactions. ChemMedChem. 2006 Apr;1(4):400-11.

9. Reynès C, Host H, Camproux A-C, Laconde G, Leroux F, Mazars A, et al. Designing focused chemical libraries enriched in protein-protein interaction inhibitors using machine-learning methods. PLoS Comput Biol. 2010 Mar;6(3):e1000695.

10. Lipinski CA, Lombardo F, Dominy BW, Feeney PJ. Experimental and computational approaches to estimate solubility and permeability in drug discovery and development settings. Adv Drug Deliv Rev. 2001 Mar 1;46(13):3-26.

11. Block P, Weskamp N, Wolf A, Klebe G. Strategies to search and design stabilizers of protein-protein interactions: a feasibility study. Proteins. 2007 Jul 1;68(1):170-86.

12. Wu H, Arron JR. TRAF6, a molecular bridge spanning adaptive immunity, innate immunity and osteoimmunology. BioEssays News Rev Mol Cell Dev Biol. 2003 Nov;25(11):1096-105.

13. Cao Z, Henzel WJ, Gao X. IRAK: a kinase associated with the interleukin-1 receptor. Science. 1996 Feb 23;271(5252):1128-31.

14. Muzio M, Ni J, Feng P, Dixit VM. IRAK (Pelle) family member IRAK-2 and MyD88 as proximal mediators of IL-1 signaling. Science. 1997 Nov 28;278(5343):1612-5.

15. Suzuki N, Suzuki S, Duncan GS, Millar DG, Wada T, Mirtsos C, et al. Severe impairment of interleukin-1 and Toll-like receptor signalling in mice lacking IRAK-4. Nature. 2002 Apr 18;416(6882):750-6.

16. Wesche H, Gao X, Li X, Kirschning CJ, Stark GR, Cao Z. IRAK-M is a novel member of the Pelle/interleukin-1 receptor-associated kinase (IRAK) family. J Biol Chem. 1999 Jul 2;274(27):19403-10.

17. Yamashita M, Fatyol K, Jin C, Wang X, Liu Z, Zhang YE. TRAF6 mediates Smad-independent activation of JNK and p38 by TGF-beta. Mol Cell. 2008 Sep 26;31(6):918-24.

18. Ye H, Arron JR, Lamothe B, Cirilli M, Kobayashi T, Shevde NK, et al. Distinct molecular mechanism for initiating TRAF6 signalling. Nature. 2002 Jul 25;418(6896):443-7.

19. Anighoro A, Bajorath J, Rastelli G. Polypharmacology: Challenges and Opportunities in Drug Discovery. J Med Chem. 2014 Oct 9;57(19):7874-87.

20. Compston A, Coles A. Multiple sclerosis. Lancet. 2008 Oct 25;372(9648):1502-17.

21. Drescher KM, Zoecklein LJ, Pavelko KD, Rivera-Quinones C, Hollenbaugh D, Rodriguez M. CD40L is critical for protection from demyelinating disease and development of spontaneous remyelination in a mouse model of multiple sclerosis. Brain Pathol Zurich Switz. 2000 Jan;10(1):1-15.

22. Starczynowski DT, Lockwood WW, Deléhouzée S, Chari R, Wegrzyn J, Fuller M, et al. TRAF6 is an amplified oncogene bridging the RAS and NF- $\kappa B$ pathways in human lung cancer. J Clin Invest. 2011 Oct 3;121(10):4095105.

23. Rong Y, Wang D, Wu W, Jin D, Kuang T, Ni X, et al. TRAF6 is over-expressed in pancreatic cancer and promotes the tumorigenicity of pancreatic cancer cells. Med Oncol Northwood Lond Engl. 2014 Nov;31(11):260.

24. Alaaeddine N, Hassan GS, Yacoub D, Mourad W. CD154: an immunoinflammatory mediator in systemic lupus erythematosus and rheumatoid arthritis. Clin Dev Immunol. 2012;2012:490148.

25. Ohta Y, Hamada Y. In situ Expression of CD40 and CD40 ligand in psoriasis. Dermatol Basel Switz. 2004;209(1):21-8.

26. Danese S, Sans M, Fiocchi C. The CD40/CD40L costimulatory pathway in inflammatory bowel disease. Gut. 2004 Jul;53(7):1035-43.

27. Lomaga MA, Yeh WC, Sarosi I, Duncan GS, Furlonger C, Ho A, et al. TRAF6 deficiency results in osteopetrosis and defective interleukin-1, CD40, and LPS signaling. Genes Dev. 1999 Apr 15;13(8):1015-24. 